\title{
Evaluating the Effects of the Blennerhassett Island Bridge Crossing (Ohio River) on Soil, Vegetation, and Wildlife
}

\author{
Joshua Allen Vance \\ West Virginia University
}

Follow this and additional works at: https://researchrepository.wvu.edu/etd

\section{Recommended Citation}

Vance, Joshua Allen, "Evaluating the Effects of the Blennerhassett Island Bridge Crossing (Ohio River) on Soil, Vegetation, and Wildlife" (2010). Graduate Theses, Dissertations, and Problem Reports. 3070. https://researchrepository.wvu.edu/etd/3070

This Thesis is protected by copyright and/or related rights. It has been brought to you by the The Research Repository @ WVU with permission from the rights-holder(s). You are free to use this Thesis in any way that is permitted by the copyright and related rights legislation that applies to your use. For other uses you must obtain permission from the rights-holder(s) directly, unless additional rights are indicated by a Creative Commons license in the record and/ or on the work itself. This Thesis has been accepted for inclusion in WVU Graduate Theses, Dissertations, and Problem Reports collection by an authorized administrator of The Research Repository @ WVU. For more information, please contact researchrepository@mail.wvu.edu. 

Evaluating the Effects of the Blennerhassett Island Bridge Crossing (Ohio River) on Soil, Vegetation, and Wildlife

\author{
Joshua Allen Vance \\ Thesis submitted to the \\ Davis College of Agriculture, Natural Resources and Design \\ at West Virginia University \\ in partial fulfillment of the requirements \\ for the degree of \\ Master of Science \\ in \\ Wildlife and Fisheries Resources
}

James T. Anderson, Ph.D., Chair

Petra Bohall Wood, Ph.D., Committee Member

Norse B. Angus, Committee Member

\title{
Morgantown, West Virginia
}

2010

Key Words: anurans, Blennerhassett Island, bridge, island, mammals,

Ohio River, songbirds, turtles, waterbirds

Copyright 2010 Joshua Allen Vance 


\section{ABSTRACT \\ Evaluating the Effects of the Blennerhassett Island Bridge \\ Crossing (Ohio River) on \\ Soil, Vegetation, and Wildlife}

\section{Joshua Allen Vance}

Corridor D was one of the original 23 highway corridors selected by the Appalachian Highway Development System in 1965 and stretches from Bridgeport, West Virginia to Cincinnati, Ohio. The last piece of Corridor D to be completed was the Blennerhassett Island Bridge which crosses over the Ohio River and Blennerhassett Island near Parkersburg, West Virginia and Belpre, Ohio. The Blennerhassett Island Bridge is a tied-arch style bridge about $1,220 \mathrm{~m}$ in length and $24 \mathrm{~m}$ above the ground and water surface. Construction of the bridge began in March 2005 and the bridge was opened to the public in June 2008. This study examined environmental impacts of the Blennerhassett Island Bridge to comply with mitigation requirements for the West Virginia Department of Transportation, Division of Highways in accordinance with the Blennerhassett Island Bridge Final Environmental Impact Statement. From October 2007 through July 2009, I researched the impacts of the Blennerhassett Island Bridge upon vegetation, soil, and the following wildlife groups: waterbirds, songbirds, anurans, turtles, small mammals, and furbearers. Comparisons were made to two other islands (Buckley Island [bridge crossing present for about 45 years] and Muskingum Island [no bridge crossing]), to three distances from the bridge (0 [under], 100, and $300 \mathrm{~m}$ ), and to pre-construction data collected during the 1985-1987 and 1998-2000 time periods.

Over the course of this study, 170 plant, 19 waterbird, 60 songbird, 7 anuran, 5 turtle, 9 small mammal, and 4 furbearer species were detected among the three islands. Also, 19 soil variables were analyzed. Vegetative communities were different under the bridge compared to other sampling distances and pre-construction data. Vegetative communities were composed of species from the seed mixture used for reclamation, exotic and invasive species, and disturbance tolerant species with low herbaceous cover and minimal woody plants. Thirteen soil variables (phosphorus, bray II phosphorus, potassium, sodium, calcium, manganese, soluble sulfur, zinc, aluminum, copper, total exchange capacity, organic matter, and estimated nitrogen released) had altered levels under the Blennerhassett Island Bridge and/or Buckley Island Bridge. Great blue heron (Ardea herodias) abundances were lower at islands with bridges. Songbird abundances were lower under the bridge and species composition differed compared to other distances with generalist species present under the bridge. Carolina chickadee (Poecile carolinensis), Carolina wren (Thryothorus ludovicianus), and common yellowthroat (Geothlypis trichas) abundances were lower under the bridge and rock pigeon (Columba livia), cliff swallow (Petrochelidon pyrrhonota), and European starling (Sturnus vulgaris) abundances were highest under bridges. Overall small mammal abundance, richness, and diversity were lower under the new bridge compared to other distances and abundances of Peromyscus spp. were lower under the new bridge. Raccoon (Procyon lotor) occurrences were lower under the new bridge compared to other sites and distances. Anurans and turtles showed no differences among islands and distances. 
The Blennerhassett Island Bridge was found to have some impacts to vegetation, soil, and wildlife. These impacts, however, are minor in scale and are mostly limited to the area directly under the bridge and did not impact large portions of Blennerhassett Island or the adjacent mainlands. Some of these impacts under the bridge include: altered soil chemistry, altered amount and type of vegetation, attraction of exotic and non-native vegetation, lower abundances and different composition of songbirds, attraction of urbanized songbird species, lower abundance, richness, and diversity of small mammals, and changes and alteration in habitat. I recommend that all possible care should be taken during future bridge construction to minimize environmental impacts to vegetation, soil, and wildlife and to restore the impacted land back to previous conditions. I also suggest that vegetation, soil, songbirds, and small mammals should continually be monitored at the Blennerhassett Island site to determine if these impacts found in this study are temporary or permanent. 


\section{ACKNOWLEDGEMENTS}

First and foremost I thank my Lord and Savior Jesus Christ who died for my sins and changed my heart. I would not be the person I am today without His work in me. I thank my major advisor Dr. James T. Anderson for his advice, patience, and willingness to work with me through difficult times. I thank my other committee members Dr. Petra Wood and Norse B. Angus for their support and advice. I thank the West Virginia Department of Transportation, Division of Highways for providing funding for this project. Special thanks go to the U.S. Fish and Wildlife Service and West Virginia Division of Natural Resources Wildlife Resources and Parks and Recreation sections specifically Patty Morrison, Scott Morrison, Gary Batton, Jeff McCrady, and Matt Baker for their cooperation with this project including use of boats and 5 star living arrangements at the world renowned "Bass Shack".

I am endebted to Dr. Phil Turk and Dr. George Merovich for their assistance with statistical analyses with this project. I thank Dr. Jim Rentch and the late Bill Grafton for their assistance and unprecedented knowledge displayed during vegetation sampling. I thank my fellow graduate students for their support, encouragement, advice, and friendship during my time at WVU. I thank my friend and mentor Bill Tolin for his work on the Ohio River islands and the advice he provided for me throughout this project. I thank the biologists from the WVDNR Wildlife Diversity unit in Elkins, WV for support and encouragement during this study. Many thanks go to the multiple technicians, volunteers, and graduate students who are too many to name who assisted with this project. Much appreciation is extended to my Uncle Dan and Aunt Rhonda for opening their house to me and the hospitality they provided. Lastly, I thank my parents, David Vance and Rachael Vance, for instilling the love of the outdoors into my heart and encouraging me to always chase and never give up on my dreams. I love you both. 


\title{
Table of Contents
}

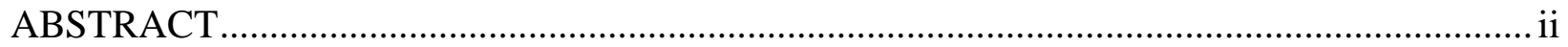

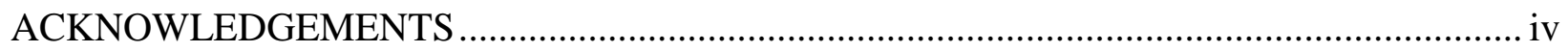

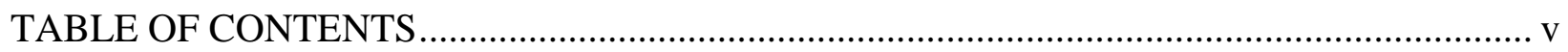

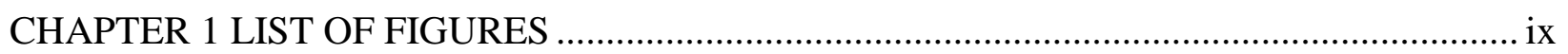

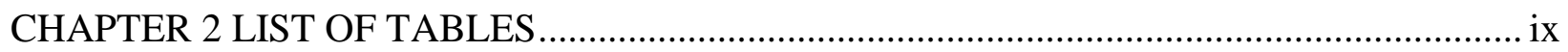

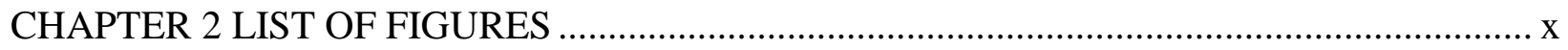

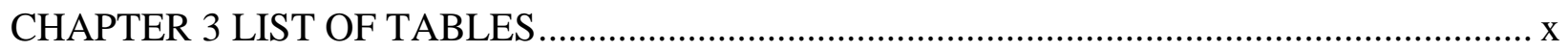

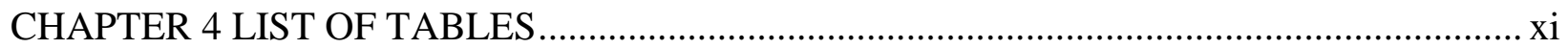

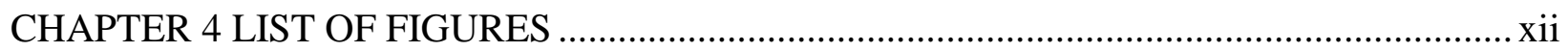

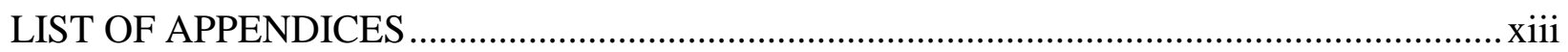

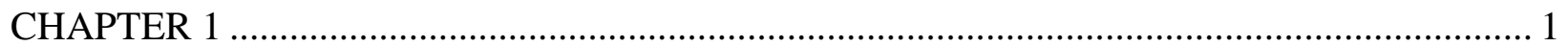

\begin{abstract}
AN INTRODUCTION AND LITERATURE REVIEW OF THE BLENNERHASSETT
ISLAND BRIDGE CROSSING, OHIO RIVER ISLANDS, AND POTENTIAL IMPACTS AND

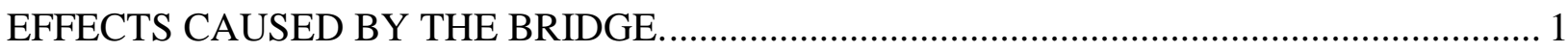

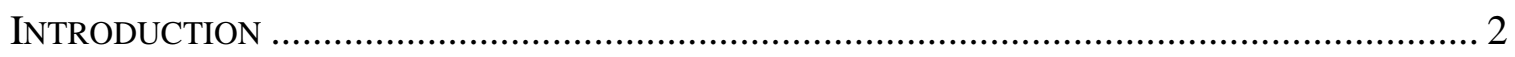

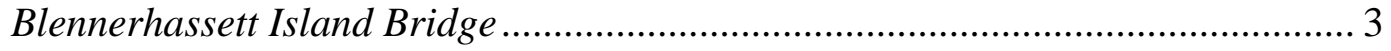

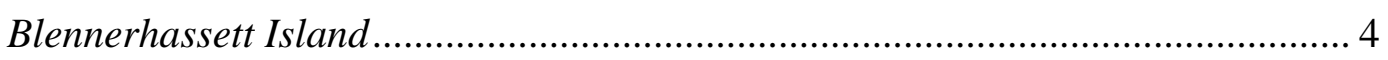

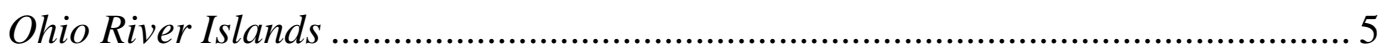

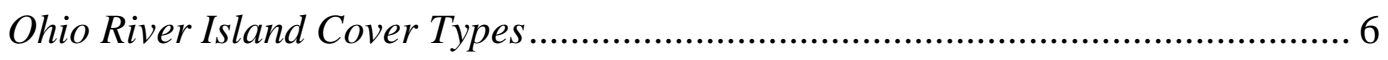

Ohio River Island Wildlife Assemblages........................................................... 7

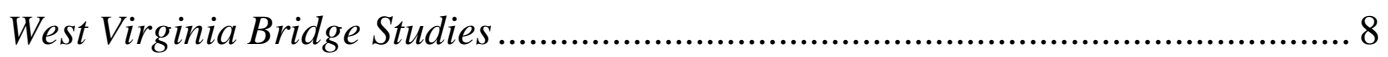

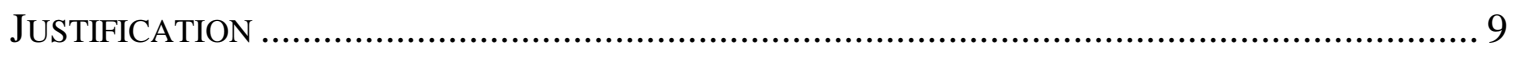

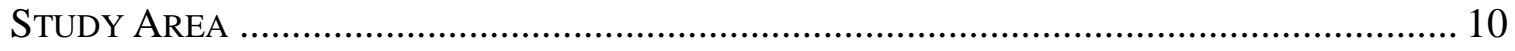

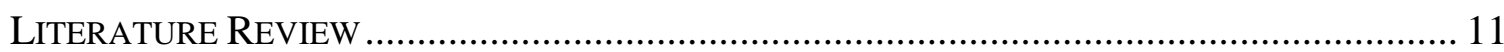

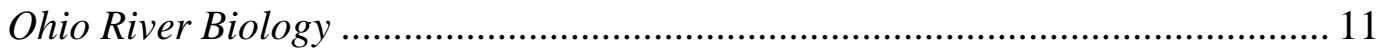

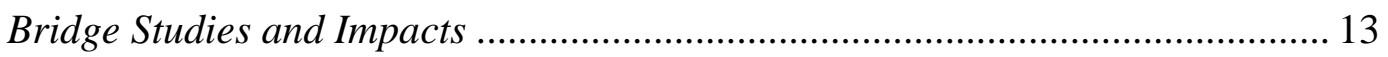

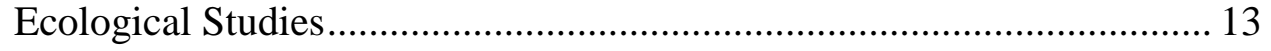

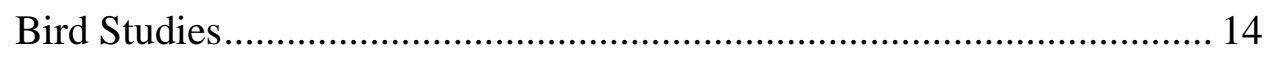

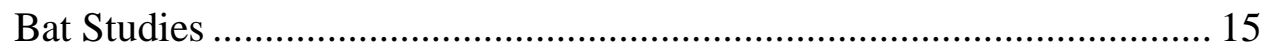



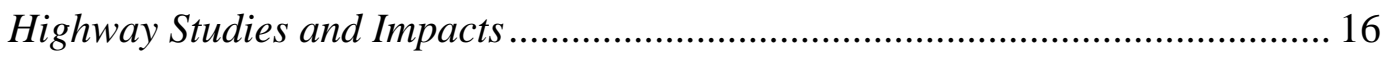

Wildlife-vehicle Mortality ..................................................................... 16

Mitigations for Movement ……………….......................................... 17

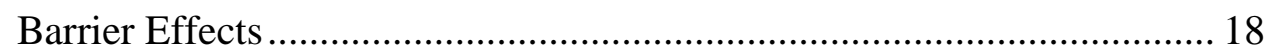






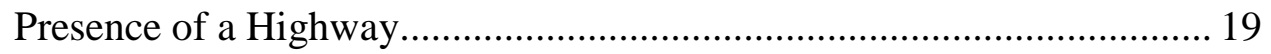

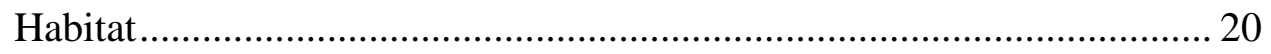

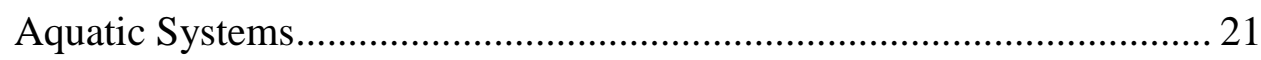

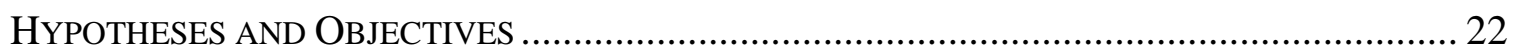

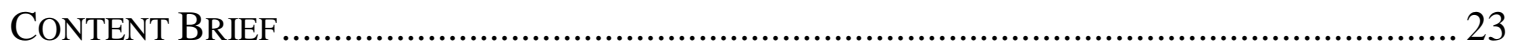

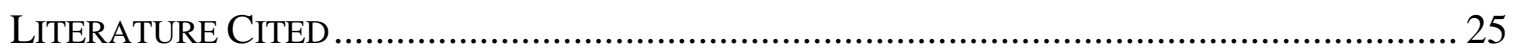

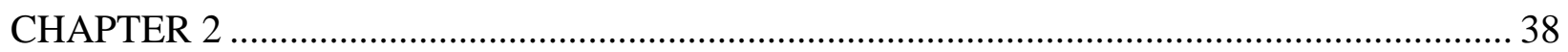

VEGETATION AND SOIL PARAMETERS AT AN ISLAND BRIDGE CROSSING............. 38

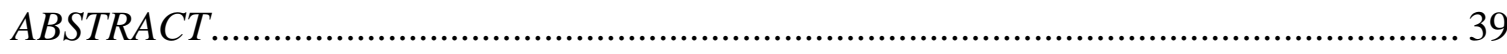

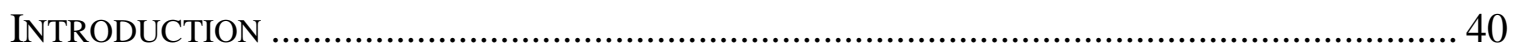

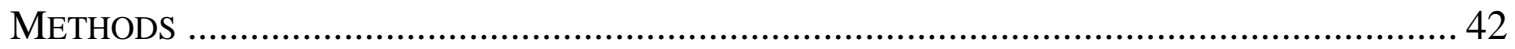

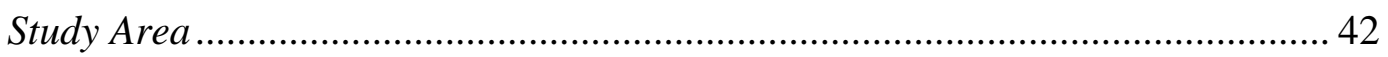

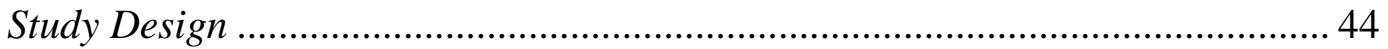

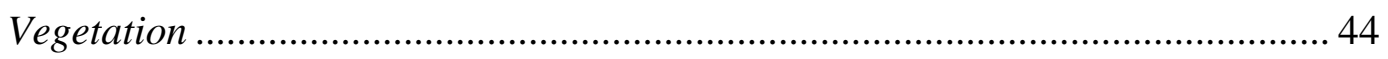



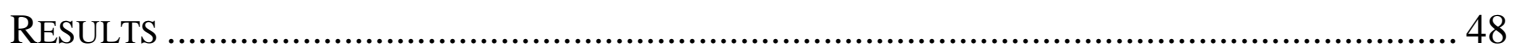

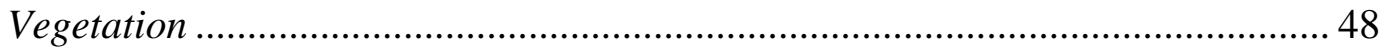



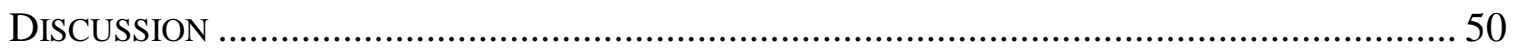

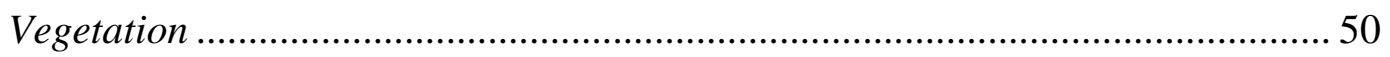

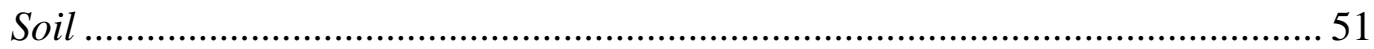

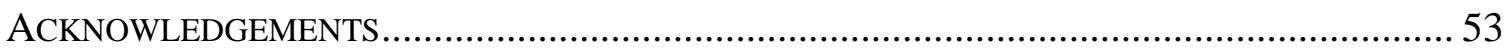

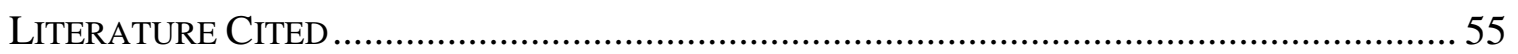

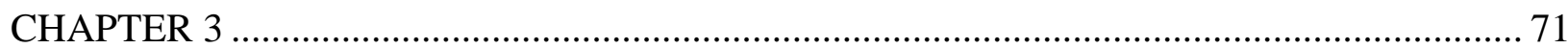

RIPARIAN AND RIVERINE WILDLIFE RESPONSE TO AN OHIO RIVER ISLAND

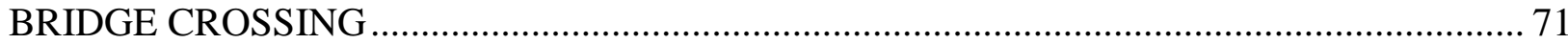

ABSTRACT

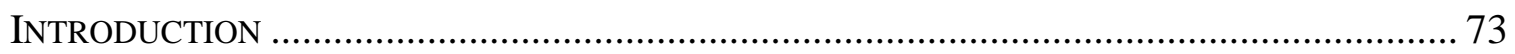

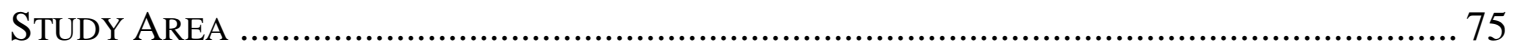

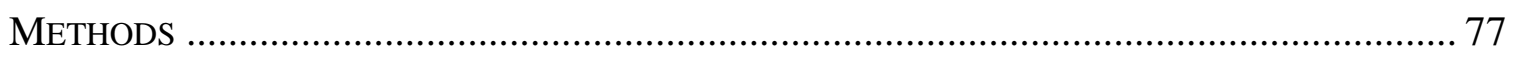

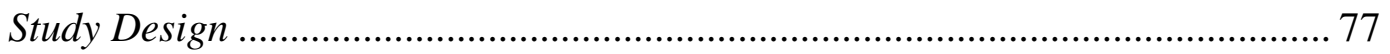

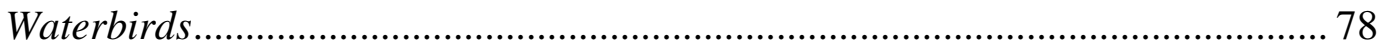

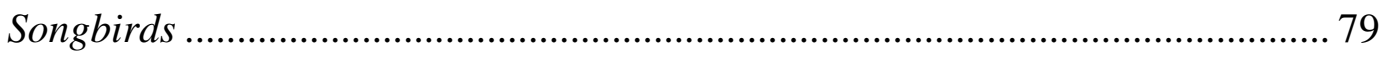

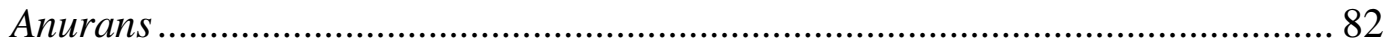






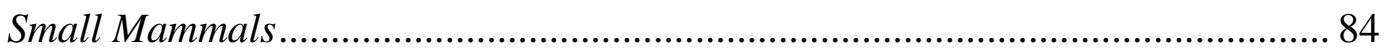

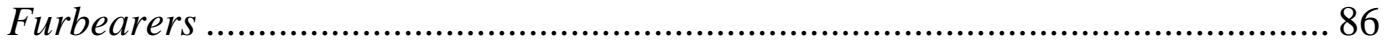

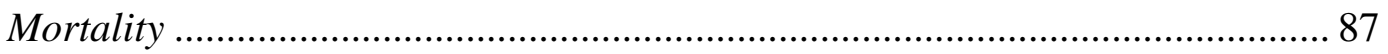

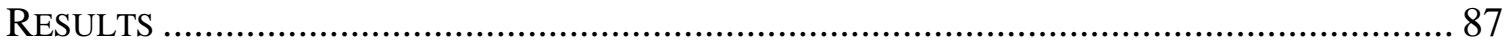

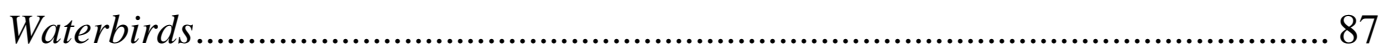

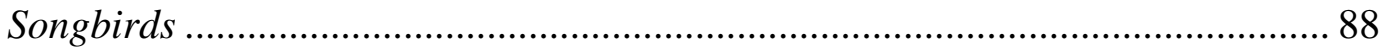

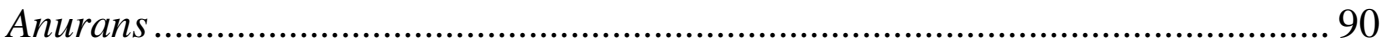

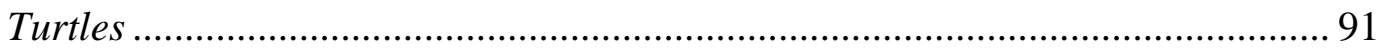

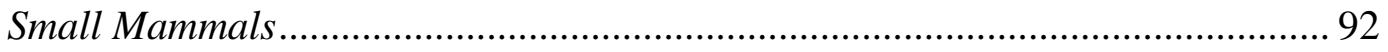



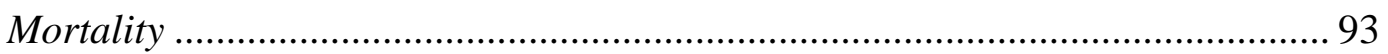

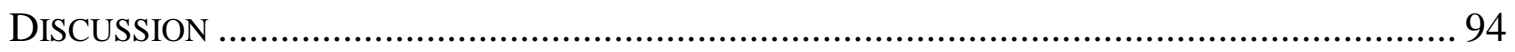

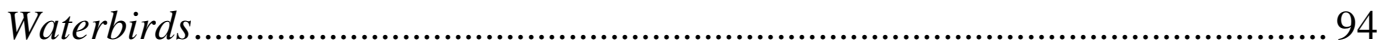

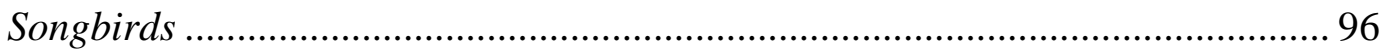



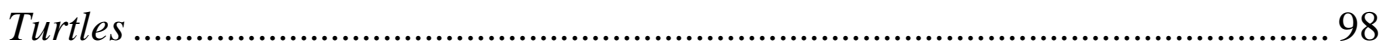

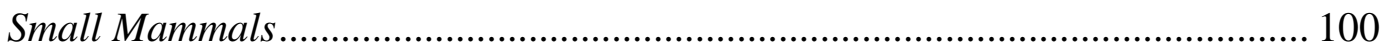

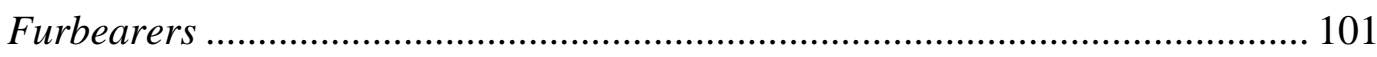

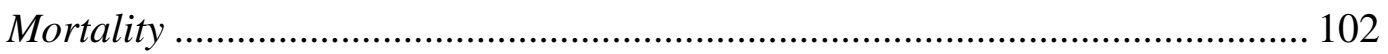

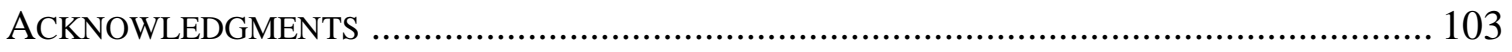

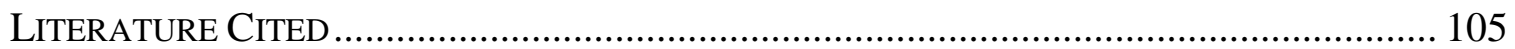

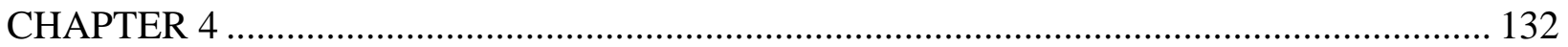

\section{PRE-CONSTRUCTION AND POST-CONSTRUCTION COMPARISONS OF THE} BLENNERHASSETT ISLAND BRIDGE CROSSING, OHIO RIVER, USA .......................... 132

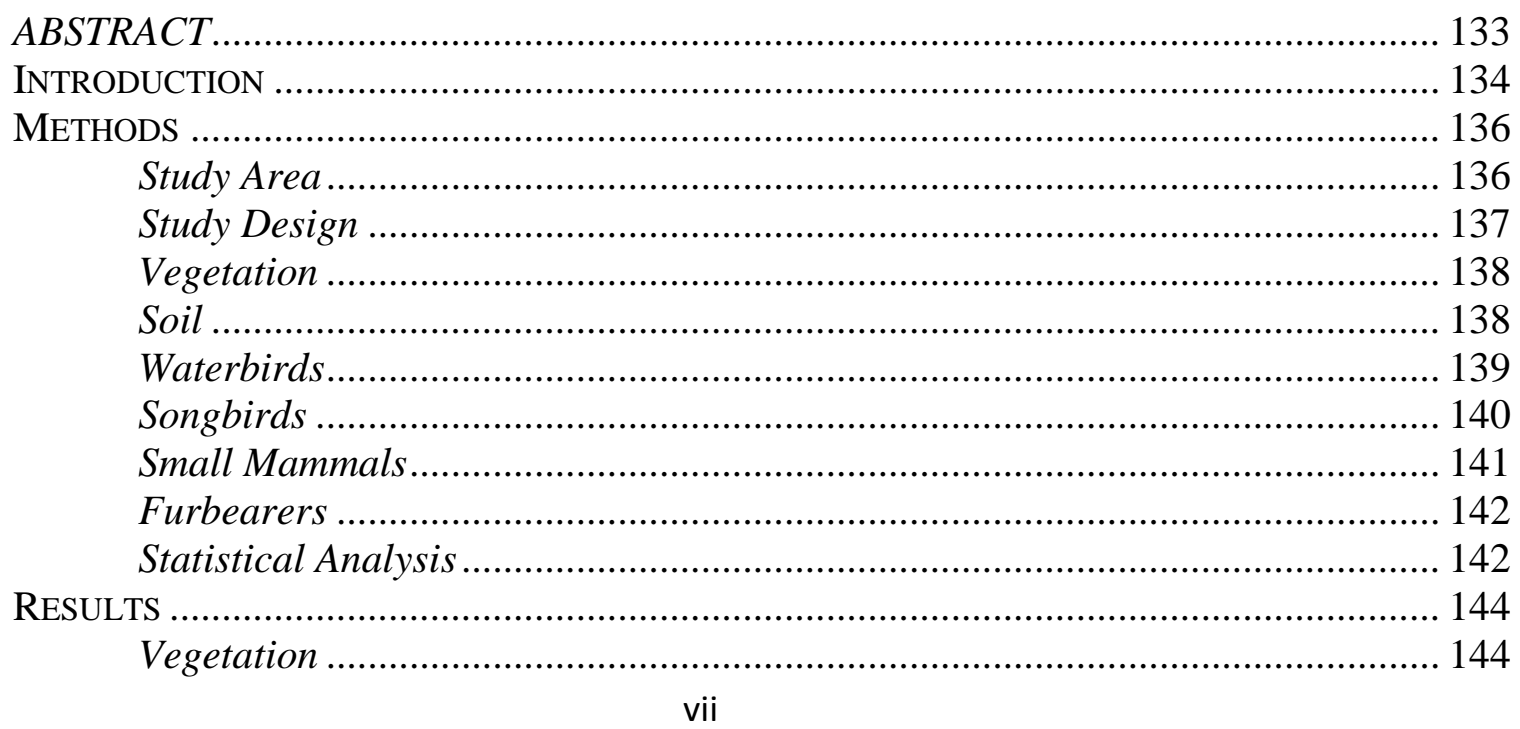




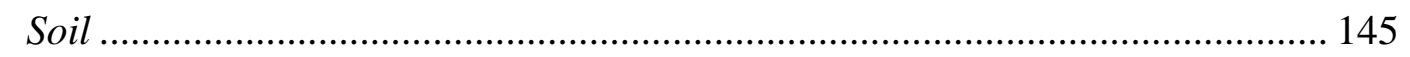

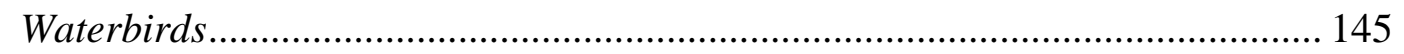

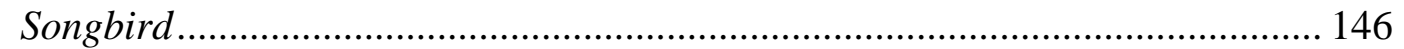

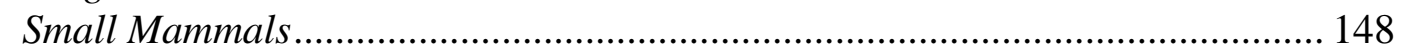

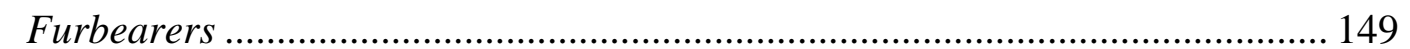

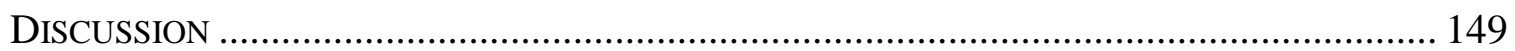



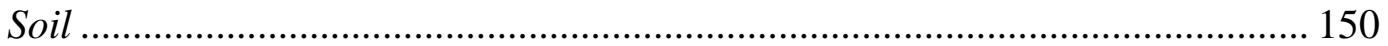



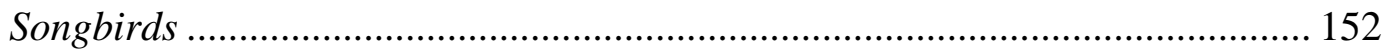

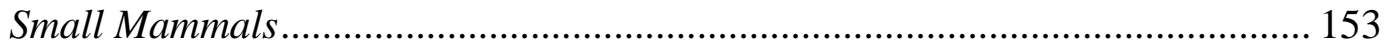

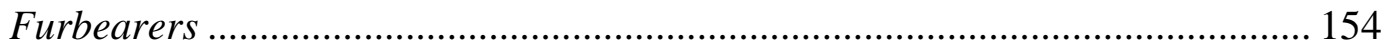

IMPLICATIONS FOR FUTURE MANAGEMENT PROJECTS .............................................. 155



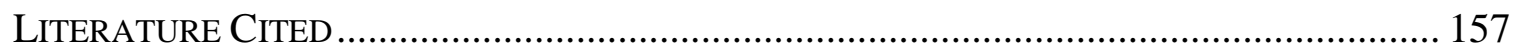

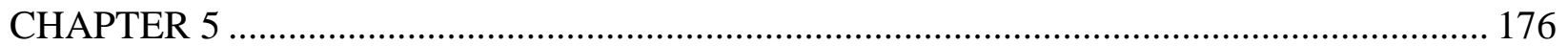

CONCLUSIONS, MANAGEMENT IMPLICATIONS, AND FUTURE RESEARCH NEEDS FOR THE BLENNERHASSETT ISLAND BRIDGE CROSSING IN RELATION TO SOIL,

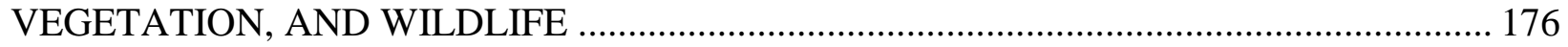

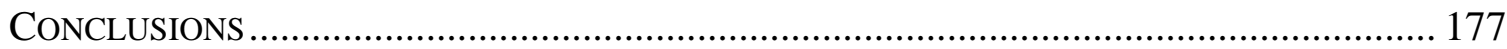

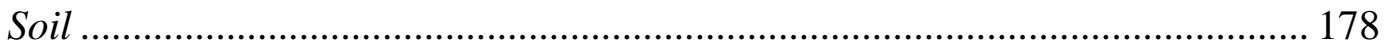

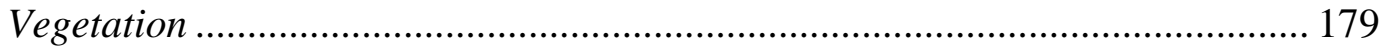

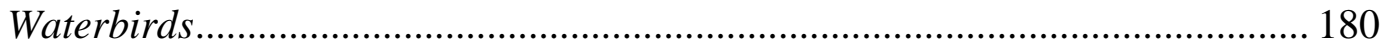

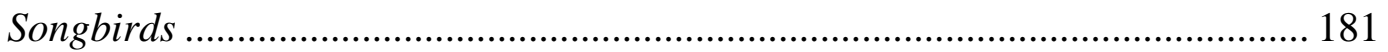

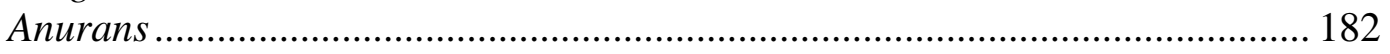

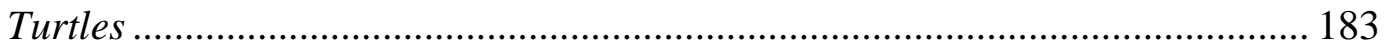

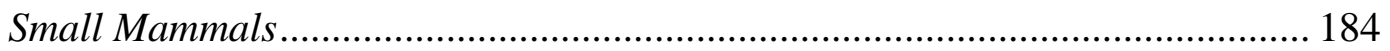

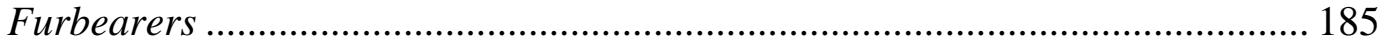

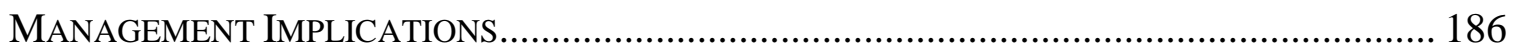

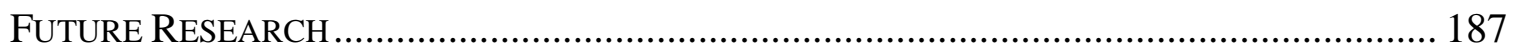

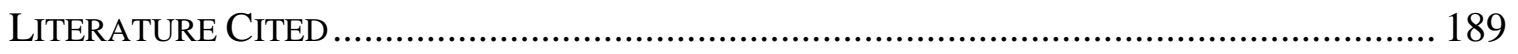

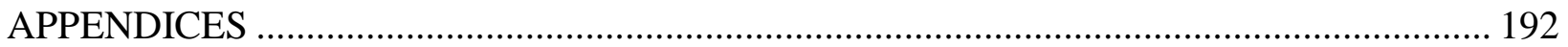




\section{List of Tables and Figures}

\section{Chapter 1 List of Figures}

Figure 1: Aerial photo of Blennerhassett Island and U.S. Rt. 50 (Corridor D) in 2007 showing the Blennerhassett Island Bridge near completion and as the last section of Corridor D to be complete.

Figure 2: Photo of the Blennerhassett Island Bridge taken from Dupont Road near Blennerhassett Heights, WV, USA on 25 January 2008.

Figure 3: Photo of the Blennerhassett Island Bridge taken along the Ohio River on the West Virginia mainland on 25 January 2008.

\section{Chapter 2 List of Tables}

Table 1: Summary statistics for vegetation metrics with means and standard errors (SE) analyzed by sites (Blennerhassett, Buckley, and Muskingum islands, West Virginia, USA), distances from bridge $(0,100$, and $300 \mathrm{~m})$, and interaction during the July 2008 sampling period with same letters indicating no significant difference for an individual vegetation stratum (bolded vegetation stratum are significant at $\alpha=0.05$ ).

Table 2: Summary statistics for all species with means (\% cover for herbs and shrubs and basal area $\left[\mathrm{m}^{2} / \mathrm{ha}\right.$ ] for trees) and standard errors (SE) that occurred 3 or more times during vegetation surveys and used in the PERMANOVA and multi-response permutations procedure composition matrix (all 64 species for the site analysis and 53 species (bolded) for the distance analysis) for Blennerhassett, Buckley, and Muskingum islands, West Virginia, USA during the July 2008 field season.

Table 3: Summary statistics for multi-response permutation procedures for herbaceous, shrub, and tree strata for sites (Blennerhassett, Buckley, and Muskingum islands, West Virginia, USA) and distances from bridge (0, 100, and $300 \mathrm{~m})$ during the July 2008 field season. Strata were grouped by site and distance. The $T$ statistic is the weighted mean withingroup distance, the $A$ statistic is the chance-corrected within group agreement, and $P$ is the $\mathrm{p}$-value $(\alpha=0.05)$

Table 4: Species indicator values (IV) for site (Blennerhassett, Buckley, and Muskingum islands, West Virginia, USA) and distance from bridge $(0,100$, and $300 \mathrm{~m}) . P$-values $(P)$ based on the proportion of randomized trials with expected $I V>$ observed $I V$. Only species whose observed $I V$ exceeds $I V \exp$ at $P$-values < 0.05 are shown; 4,999 permutations were used in a Monte Carlo test. $I V=100 \times$ (relative abundance $\times$ relative frequency).

Table 5: Summary statistics for soil with means and standard errors (SE) analyzed by sites (Blennerhassett, Buckley, and Muskingum islands, West Virginia, USA), distances from bridge $(0,100$, and $300 \mathrm{~m})$, and interaction during the July 2008 sampling period with same letters indicating no significant difference for an individual soil variable (bolded soil variables are significant at $\alpha=0.05$ ). 


\section{Chapter 2 List of Figures}

Figure 1: Location of 3 island study areas between kilometer markers 271.8 and 305.6 (mile markers 168.9 and 189.9) on the Ohio River, West Virginia, USA.

Figure 2: A schematic of vegetation sampling effort within the 0.1 ha plots used for each transect at each of the study areas. 70

\section{Chapter 3 List of Tables}

Table 1: Summary of waterbird variables (abundances in the form of individuals/39.25 ha plot) with their means and standard errors for Blennerhassett, Buckley, and Muskingum islands, West Virginia, USA for the 2007-2009 field seasons with same letters indicating no significance among sites (bolded means are significant at $\alpha=0.05$ ). 116

Table 2: Summary of songbird variables (abundances in the form of individuals/ha) with their means and standard errors for Blennerhassett, Buckley, and Muskingum islands, West Virginia, USA and at 0, 100, and $300 \mathrm{~m}$ from the bridge for the 2008-2009 field seasons with same letters indicating no significance among sites or distances (bolded means are significant at $\alpha=0.05$ ).

Table 3: Summary statistics for multi-response permutation procedures for songbird strata for sites (Blennerhassett, Buckley, and Muskingum islands, West Virginia, USA) and distance from bridge $(0,100$, and $300 \mathrm{~m})$ during the 2008 and 2009 field seasons. Strata were grouped by site and distance. The $T$ statistic is the weighted mean within-group distance, the $A$ statistic is the chance-corrected within group agreement, and the $P$ statistic is the P-value $(\alpha=0.05)$.

Table 4: Species indicator values (IV) for each site (Blennerhassett, Buckley, and Muskingum islands, West Virginia, USA), distance $(0,100$, and $300 \mathrm{~m})$, and location (under or away from bridge (100 and $300 \mathrm{~m}$ transects combined)). $P$-values based on the proportion of randomized trials with expected $I V>$ observed $I V$. Only species whose observed $I V$ exceeds $I V$ exp at $P<0.05$ are shown; 4,999 permutations were used in a Monte Carlo test. $I V=100 \times($ relative abundance $\times$ relative frequency $)$.

Table 5: Summary of anuran variables for Blennerhassett and Grape islands, West Virginia, USA and for 0,100 , and $300 \mathrm{~m}$ from the bridge at Blennerhassett including relative abundances (individuals/transect) and call index codes (Wisconsin Index 0-3) of anurans used in analyses as well as species richness and diversity for the 2008-2009 field seasons (none of the means differed significantly by sites or distances at $\alpha=0.05$ ).

Table 6: Summary of turtle and small mammal trapping data for Blennerhassett, Buckley, Muskingum, and Grape islands, West Virginia, USA (averages in the form of captures/100 trap nights) for the 2008 and 2009 field seasons.

Table 7: Summary of turtle variables (abundances in the form of captures/100 trap nights) with their means and standard errors for Blennerhassett, Buckley, Muskingum, and Grape islands, West Virginia, USA and 0, 100, and $300 \mathrm{~m}$ from the bridge for the 2008 and 
2009 field seasons with same letters indicating no significance among sites or distances (bolded means are significant at $\alpha=0.05$ ).

Table 8: Summary of small mammal variables (abundances in the form of captures/100 trap nights) for Blennerhassett, Buckley, and Muskingum islands, West Virginia, USA and 0, 100 , and $300 \mathrm{~m}$ from the bridge for the 2008 and 2009 field seasons with same letters indicating no significance among sites or distances (bolded means are significant at $\alpha=$ $0.05)$.

Table 9: Average mass (g) and proportion of males, adults, and reproductive females for Peromyscus spp. captured at Blennerhassett, Buckley, and Muskingum islands, West Virginia, USA and at 0,100,300 m from the bridge during the 2008-2009 field seasons (none of the means differed significantly by sites or distances at $\alpha=0.05$ ).

Table 10: Summary of scent station data for furbearers with their presence (P) and absence (A) percentages for Blennerhassett, Buckley, and Muskingum islands, West Virginia, USA and 0,100 , and $300 \mathrm{~m}$ from the bridge for the 2008 and 2009 field seasons with same letters indicating no significance among sites or distances (bolded species are significant at $\alpha=0.05)$

\section{Chapter 4 List of Tables}

Table 1: Summary of most common vegetation sampled (> $2 \%$ cover or importance values (IV) for any site or survey period) with means and standard errors (SE) (percent cover for herbaceous vegetation and IV for woody vegetation) at the $0 \mathrm{~m}$ transects only at Blennerhassett and Buckley islands, West Virginia, USA during Phases II (Pre: 19982000) and III (Post: 2007-2009). SE could not be calculated for pre-construction at Blennerhassett.

Table 2: Summary of soil variables with means and standard errors (SE) taken at the $0 \mathrm{~m}$ transects at Blennerhassett and Buckley islands, West Virginia, USA during Phases II (Pre: 1998-2000) and III (Post: 2007-2009). SE could not be calculated for preconstruction at Blennerhassett. 166

Table 3: List of waterbirds with means (individuals/39.25 ha plot) and standard errors that were observed during Phase III (Post: 2008-2009) along with their Phase I (Pre: 1985-1987) mean for Blennnerhassett and Buckley islands. SE could not be calculated for preconstruction during Phase I.

Table 4: Summary of all songbirds used in the site, distance, and phase analyses with their means (individuals/ha), standard errors (SE), F-statistics, and P-values along with species richness and Shannon Diversity Index for Blennerhassett and Buckley islands, West Virginia, USA, and 0, 100, and $300 \mathrm{~m}$ from the bridge, and Phases I (1985-1987), II (1998-2000), and III (2007-2009) with same letters indicating no difference (bolded means indicate significant difference at $\alpha=0.05$ ).

Table 5: Summary of small mammal trapping data for Blennerhassett and Buckley islands, West Virginia, USA (averages in the form of captures per 100 trap nights) for 14 transects $(\mathrm{n}=$ 
6 at Blennerhassett and $n=8$ at Buckley) during Phases I (1985-1987), II (1998-2000),

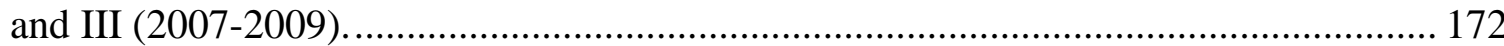

Table 6: Summary of all small mammals used in the site, distance, and phase analyses with their means (captures/100 trap nights), standard errors (SE), F-statistics, and P-values along with species richness and Shannon Diversity Index for Blennerhassett and Buckley Islands, West Virginia, USA, and 0, 100, and $300 \mathrm{~m}$ from the bridge, and Phases I (19851987), II (1998-2000), and III (2007-2009) with same letters indicating no difference (bolded means indicate significant difference at $\alpha=0.05$ ).

\section{Chapter 4 List of Figures}

Figure 1: Location of two island study areas between kilometer markers 271.8 and 305.6 (mile markers 168.9 and 189.9) on the Ohio River, West Virginia, USA. 


\section{List of Appendices}

Appendix 1: Location of 4 island study areas between kilometer markers 244.0 and 305.6 (mile markers 151.6 and 189.9) on the Ohio River, West Virginia, USA.

Appendix 2: Cover type map of Blennerhassett Island, West Virginia, USA using the 2009 National Agriculture Imagery Program (NAIP) aerial, $1 \mathrm{~m}$ accuracy, orthophotos with the 2001 National Land Cover Database (NLCD) classifications for each cover type with PUB3 = Palustrine Unconsolidated Bottom (Mud) Wetland from the National Wetlands Inventory (NWI).

Appendix 3: Cover type map of Buckley Island, West Virginia, USA using the 2009 National Agriculture Imagery Program (NAIP) aerial, $1 \mathrm{~m}$ accuracy, orthophotos with the 2001 National Land Cover Database (NLCD) classifications for each cover type with PUB3 = Palustrine Unconsolidated Bottom (Mud) Wetland from the National Wetlands Inventory (NWI).

Appendix 4: Cover type map of Muskingum Island, West Virginia, USA using the 2009 National Agriculture Imagery Program (NAIP) aerial, $1 \mathrm{~m}$ accuracy, orthophotos with the 2001 National Land Cover Database (NLCD) classifications for each cover type with PUB3 = Palustrine Unconsolidated Bottom (Mud) Wetland from the National Wetlands Inventory (NWI). 196

Appendix 5: Cover type map of Grape Island, West Virginia, USA using the 2009 National Agriculture Imagery Program (NAIP) aerial, $1 \mathrm{~m}$ accuracy, orthophotos with the 2001 National Land Cover Database (NLCD) classifications for each cover type with PUB3 = Palustrine Unconsolidated Bottom (Mud) Wetland from the National Wetlands Inventory (NWI).

Appendix 6: List of all plant species sampled and their means (\% cover for herbs and shrubs and basal area $\left[\mathrm{m}^{2} / \mathrm{ha}\right]$ for trees) and standard errors (SE) from Blennerhassett, Buckley, and Muskingum islands, West Virginia, USA during the July 2008 field season. 198

Appendix 7: List of all non-native and exotic plant species to the Ohio River islands study area (Blennerhassett, Buckley, and Muskingum islands, West Virginia, USA) and their means (\% cover for herbs and shrubs and basal area $\left[\mathrm{m}^{2} / \mathrm{ha}\right]$ for trees) and standard errors (SE) that were sampled during the July 2008 field season. 206

Appendix 8: Summary of simple effects analysis for six soil variables (ppm of soluble sulfur, phosphorus, bray II phosphorus, potassium, sodium, and zinc) that had a significant site by distance interaction for Blennerhassett, Buckley, and Muskingum islands, West Virginia, USA and at 0, 100, and $300 \mathrm{~m}$ from the bridge (bolded values indicate significant contrasts of simple effects at $\alpha=0.05$ ) with the estimate, standard error (SE), degrees of freedom (df), t-value, and P-value $(P)$.

Appendix 9: Cumulative list of waterbirds (individuals/39.25 ha plot) with their means and standard errors (SE) for Blennerhassett, Buckley, and Muskingum islands, West Virginia, USA for the 2007-2009 field seasons. 
Appendix 10: List of additional waterbirds and the amount detected within the study area but not during survey hours for Blennerhassett, Buckley, and Muskingum islands, West Virginia, USA during the 2007-2009 field seasons. 215

Appendix 11: Cumulative list of songbirds (individuals/ha) with their means and standard errors (SE) for Blennerhassett, Buckley, and Muskingum islands, West Virginia, USA for the 2008-2009 field seasons (46 species (bolded) for sites and 44 species (represented by asterics) for distance occurred 3 or more times and were used in the PERMANOVA and multi response permutations procedures analyses)............................................. 216

Appendix 12: Summary of simple effects analysis for four songbird variables (all songbirds, Carolina Chickadee, House Wren, and Rock Pigeon) that had a significant site by distance interaction for Blennerhassett, Buckley, and Muskingum islands, West Virginia, USA and at 0,100 , and $300 \mathrm{~m}$ from the bridge (bolded values indicate significant contrasts of simple effects at $\alpha=0.05$ ) with the estimate, standard error (SE), degrees of freedom (df), t-value, and P-value $(P)$.

Appendix 13: Summary of total turtle individuals (TI) and total captures (TC) for Blennerhassett, Buckley, Muskingum, and Grape islands, West Virginia, USA for the 2008 and 2009 field seasons.

Appendix 14: Summary of total small mammal individuals (TI) and total captures (TC) for Blennerhassett, Buckley, and Muskingum islands, West Virginia, USA for the 2008 and 2009 field seasons.

Appendix 15: Summary of simple effects analysis for three small mammal variables (Peromyscus spp., species richness, Shannon Diversity Index) that had a significant site by distance interaction for Blennerhassett, Buckley, and Muskingum islands, West Virginia, USA and at 0,100 , and $300 \mathrm{~m}$ from the bridge (bolded values indicate significant contrasts of simple effects at $\alpha=0.05$ ) with the estimate, standard error (SE), degrees of freedom (df), t-value, and P-value $(P)$.

Appendix 16: Summary of $G$-tests for Raccoon presence and absence for site and distance with $G$ as the $G$-statistic, Williams as the William's correction factor, $G_{\text {adj }}$ as the adjusted $G$ statistic with the William's correction factor, $\mathrm{df}$ as the degrees of freedom, and $P$ as the P-value $(\alpha=0.05)$ for Blennerhassett, Buckley, and Muskingum islands, West Virginia, USA for the 2008 and 2009 field seasons.

Appendix 17: Summary of $G$-tests for Red Fox presence and absence for site with $G$ as the $G$ statistic, Williams as the William's correction factor, $G_{\text {adj }}$ as the adjusted $G$-statistic with the William's correction factor, $\mathrm{df}$ as the degrees of freedom, and $P$ as the P-value $(\alpha=$ 0.05) for Blennerhassett, Buckley, and Muskingum islands, West Virginia, USA for the 2008 and 2009 field seasons.

Appendix 18: List of all plant species sampled and their means (\% cover for herbs and shrubs and importance values for trees) and standard errors (SE) for Blennerhassett and Buckley islands, West Virginia, USA during Phases II (Pre: 1998-2000) and III (Post: 2007-2009). 
Appendix 19: Cumulative waterbirds and their means (individuals/39.25 ha plot) and standard errors (SE) observed during waterbird observations at Blennerhassett and Buckley islands, West Virginia, USA during Phases I (Pre: 1985-1987) and II (Post: 2007-2009). SE could not be calculated for pre-construction at Blennerhassett. 236

Appendix 20: Cumulative list of songbirds with their means (individuals/ha) and standard errors (SE) for Blennerhassett Island, West Virginia, USA during Phases I (1985-1987), II (1998-2000), and III (2007-2009).

Appendix 21: Cumulative list of songbirds with their means (individuals/ha) and standard errors (SE) for Buckley Island, West Virginia, USA during Phases I (1985-1987), II (19982000), and III (2007-2009). 240

Appendix 22: Summary of all songbirds along with species richness and Shannon Diversity Index used in the site by phase, distance by phase, and site, distance, phase interactions at $\alpha=0.05$ for Blennerhassett and Buckley islands, West Virginia, USA during Phases I, II, and III with $F$ as the F-statistic and $P$ as the $\mathrm{P}$-value 243

Appendix 23: Summary of small mammal individuals captured for Blennerhassett and Buckley islands, West Virginia, USA during Phases I (1985-1987), II (1998-2000), and III (20072009).

Appendix 24: Summary of all small mammals along with species richness and Shannon Diversity Index used in the site by phase, distance by phase, and site, distance, phase interactions at $\alpha=0.05$ for Blennerhassett and Buckley islands, West Virginia, USA during Phases I, II, and III with $F$ as the F-statistic and $P$ as the P-value.

Appendix 25: Cumulative list of songbirds (individuals/ha) and small mammals (captures/100 trap nights) sampled at 0,100 , and $300 \mathrm{~m}$ from the bridge at Blennerhassett Island, WV, USA during the 2008 and 2009 field seasons separated by island and mainland transects 


\title{
Chapter 1
}

AN INTRODUCTION AND LITERATURE REVIEW OF THE BLENNERHASSETT ISLAND BRIDGE CROSSING, OHIO RIVER ISLANDS, AND POTENTIAL IMPACTS AND EFFECTS CAUSED BY THE BRIDGE.

\author{
Joshua A. Vance \\ josh_vance10@yahoo.com \\ West Virginia University \\ Division of Forestry and Natural Resources \\ PO Box 6125 \\ Morgantown, WV 26506-6125
}




\section{$\underline{\text { Introduction }}$}

Construction of man-made objects such as roads and bridges may have temporary or permanent effects on wildlife and vegetation. Civilization has become increasingly urban, and all forecasts are for the process to continue, along with its impacts on ecosystems (Picket et al. 2001). Urbanization and the construction of roads and bridges can alter wildlife habitat, and is cited as the second most frequent cause of species endangerment, behind agriculture, in the United States in 1995 (Czech and Krausman 1997). In the past 25 years, however, more attention has been directed toward the effects of bridges and roads upon wildlife and vegetation (e.g., Forman et al. 2003).

Bridges can potentially affect mammals, birds, amphibians, reptiles, invertebrates, plants, and the soil either positively, negatively, or have no effect depending on species or location. Bridges can have positive effects on wildlife by providing habitat for nesting, roosting, and resting as well as providing corridors for movement. Cliff swallows (Petrochelidon pyrrhonota) and barn swallows (Hirundo rustica) are species that use bridges for nesting and perching (Redmond and Murphy 2007, Tumlison 2009). Additionally, peregrine falcons (Falco peregrinus) have been well documented as using bridges and skyscrapers for nesting sites and hunting perches (Tordoff and Redig 1988, Cade and Bird 1990, Bell et al. 1996). Other research shows that bridges provide roosting and resting habitat for bats (Bennett et al. 2008). Edge created by roads and bridges may provide habitat for songbirds and increase their population (Clark and Karr 1979). Also, creation of bridges can serve as movement corridors for coyotes (Canis latrans) (Sacks et al. 2006).

There is a lack of published literature on the direct effects of bridges on wildlife. However, the presence of a bridge may have direct negative impacts on wildlife similar to those 
of highway impacts which have been studied in much greater detail. Some of these negative impacts include: increased mortality from vehicle collisions (Haxton 2000, Hubbard et al. 2000), noise (Breeden et al. 2008), barrier effects (Noss et al. 1996), and attraction of undesirable or non-native species (Vankat and Roy 2002). Bridges and highways also can impact the landscape causing habitat fragmentation (Trombulak and Frissell 2000), habitat loss (Forman 2000), and habitat alteration (Rowland et al. 2000) which in turn could be negative to wildlife. This can lead to species declines and disruption of continuous population distributions (Vos and Chardon 1998), limit movements (Andrews et al. 2005), and cause potential genetic problems (Lesbarreres et al. 2006).

The purpose of this study was to investigate the impacts of the Blennerhassett Island Bridge (Corridor D) as it crosses over the Ohio River and Blennerhassett Island near Parkersburg, West Virginia, USA upon soil, vegetation, and wildlife. Mammals, birds, amphibians, and reptile populations were examined as well as vegetation and soil characteristics to determine any potential positive and negative effects of the Blennerhassett Island Bridge. This study also may serve to fill a void in published literature on the direct impacts of a bridge upon different wildlife classes and habitats. This introduction will introduce the Blennerhassett Island Bridge, Blennerhassett Island, Ohio River islands, Ohio River island cover types and wildlife assemblages, and the West Virginia Bridge Studies during the 1980s and 1990s.

\section{Blennerhassett Island Bridge}

Corridor D was one of the original 23 Appalachian corridors selected in 1965 by the Appalachian Development Highway System (K. Hall, West Virginia Division of Highways, personal communication). Corridor D was designed to connect Interstate 275 near Cincinnati, Ohio to Interstate 79 near Bridgeport, West Virginia, and carries the routes of US Rt. 50 and $\mathrm{OH}$ 
Rt. 32 (K. Hall, West Virginia Division of Highways, personal communication). The Blennerhassett Island Bridge crossing the Ohio River at Blennerhassett Island was the final piece of Corridor D to be completed (W. Kump, West Virginia Division of Highways, personal communication) (Figure 1). The bridge crosses the Ohio River near the western end of Blennerhassett Island (Figures 2 and 3). The Blennerhassett Island Bridge is the longest single span bridge in the state of West Virginia at about 1,220 $\mathrm{m}$ in total length, and also the most expensive single contract project ever taken by the West Virginia Division of Highways (WVDOH) at about \$120 million (K. Hall, West Virginia Division of Highways, personal communication). The design of the bridge is a tied-arch style. This was chosen from four other designs because it was the "most economic and least intrusive on the environment of Blennerhassett Island” (K. Hall, West Virginia Division of Highways, personal communication). Construction of the bridge began in March 2005 and was opened 13 June 2008 (W. Kump, West Virginia Division of Highways, personal communication). Upon completion of the bridge, wetland dependent vegetation was planted under the bridge on both the island and on the West Virginia and Ohio mainland. The temporary culverts placed within the wetland complex on the island were removed allowing the interior slough to return to normal flow.

\section{Blennerhassett Island}

Blennerhassett Island is one of about 88 islands on the Ohio River. It is a 206 ha hourglass shaped island located in the Ohio River about $1.61 \mathrm{~km}$ west of Parkersburg, West Virginia, USA between river mileposts 186.1 and 189.9 (Appalachian Corridor D Environmental Reevaluation and Final Section 4 Evaluation, unpublished report). The island has been uninhabited since about 1968 and has a vegetative cover of bottomland plants and trees normally 
found along the Ohio River (Appalachian Corridor D Environmental Reevaluation and Final Section 4 Evaluation, unpublished report).

Blennerhassett Island is well known for its history. There is evidence of Native American Indian use as early as 12,000 years ago and the island was home to Native American legend Nemocolin (Blennerhassett Island State Historical Park 2009). The island was documented by George Washington in 1770 during his exploration of the Ohio Valley. Throughout the last 200 years, the island was frequently visited by many presidents, vice presidents, and famous frontiersmen (Blennerhassett Island State Historical Park 2009). However, the island's most noted historical feature is the setting where former Vice President Aaron Burr, in conjunction with island owners Harmon and Margaret Blennerhassett, allegedly plotted treason against the United States (Gibbens 1914). Other notable events on the island included its use for aviation training during the pre-World War II era and a baseball diamond in which many major league baseball games were played involving teams such as the Pittsburgh Pirates, Cincinnati Reds, and the Brooklyn Dodgers (R. Swick, West Virginia Division of Natural Resources, personal communication).

Blennerhassett Island is currently owned by E.I DuPont de Nemours \& Company (DuPont). DuPont leases the island to the state of West Virginia for use as a recreational area and a historical interpretations site associated with the Blennerhassett Island Historical State Park. The West Virginia Division of Natural Resources (WVDNR) is the lead state agency with administrative responsibility over the park (Blennerhassett Island State Historical Park 2009).

\section{Ohio River Islands}

The Ohio River begins in Pittsburgh, Pennsylvania, at the merging of the Allegheny and Monongahela Rivers, and ends in Cairo, Illinois where it empties into the Mississippi River 
(Sacilotto 2003, Zadnik et al. 2009). Along this 1,582 km track, about 88 islands exist. The islands were formed by an accumulation of flood deposits on gravel and rock bars that reached the height of the floodplain (United States Fish and Wildlife Service 2000). The initial accumulation of sand and gravel, followed by subsequent actions of the river have led to the islands being generally tear drop or crescent shaped, with round, shallow heads, and narrow, pointed toes (Zadnik et al. 2009). However, due to the lack of glacial transport of soils that created the islands, and due to the current navigation system, new islands cannot be formed (United States Fish and Wildlife Service 2000, Sacilotto 2003). Many islands have been lost due to dredging of the river and increased pool levels caused by the current lock and dam system for navigation. Additionally, current islands along the Ohio River have decreased in number and size by 43\% since 1900 (United States Army Corp. of Engineers 2000).

The islands of the Ohio River range in size from less than 1 ha to over 200 ha. Islands support a great variety of cover types and wildlife assemblages. Historically, many of the islands were used for agriculture and natural gas drilling, and currently 2 islands are fully developed. However, many of the islands are now protected by the foundation of the Ohio River Islands National Wildlife Refuge which owns all or part of 22 of the islands in the Upper Ohio River. Additionally, Blennerhassett Island is protected by the state of West Virginia, who rents the island and maintains it as a state historical park.

\section{Ohio River Island Cover Types}

Aquatic and terrestrial cover types associated with the Ohio River islands provide some of the area's highest quality riverine, wetland, and bottomland hardwood cover types, and are used by a diverse community of birds, mammals, and freshwater mussels (United States Fish and Wildlife Service 1989). Nine terrestrial cover types and 10 wetland cover types have been 
classified for the islands (United States Fish and Wildlife Service 2000). Bottomland hardwood forest is the most abundant cover type on the islands (Tolin and Schettig 1983). Bottomland hardwood forests are known for high species richness in part because they serve as transitional areas between uplands and bodies of water for many wildlife species (Wigley and Lancia 1998). These forests serve as bird habitat for breeding, wintering, and migration stop-overs (Kellison et al. 1998). Bottomland hardwoods are especially important for passerines (perching birds) as they support about 70 species, including about 30 neotropical migrant species (Pashley and Barrow 1992). Late and early old-fields are the second most common cover type on the islands (Tolin and Schettig 1983). Old-field habitats are the transitional areas between bare ground and forest. They are usually comprised of vegetation such as forbs, grasses, and small shrubs (Bleich et al. 2005). This cover type serves as important habitat for animals such as small mammals (Foster and Gaines 1991) and early successional bird species (Hunter et al. 2001), and also play a pivotal role in succession of a habitat (Kie et al. 1994). The most prominent wetland type on the islands is palustrine (Cowardin et al. 1979) which, in association with the Ohio River islands, provide habitat for waterbirds, aquatic mammals, turtles, frogs, fishes, and freshwater mussels (Zadnik et al. 2009).

\section{Ohio River Island Wildlife Assemblages}

Blennerhassett Island and the Ohio River Islands National Wildlife Refuge support a variety of mammals, birds, amphibians, and reptiles. There are 193 bird, 25 mammalian, and 15 species of amphibians and reptiles documented on the islands (United States Fish and Wildlife Service 2000). Of the 193 bird species, 143 are passerines (Sacilotto 2003). Fifteen species of birds listed on the refuge are on the West Virginia Partners in Flight list of 20 species of concern (Sacilotto 2003). Other bird groups common to the islands include waterfowl, wading birds, 
shorebirds, and raptors. Mammalian groups common to the islands include white-tailed deer (Odocoileus virginianus), aquatic furbearing mammals, carnivores, and small mammals (United States Fish and Wildlife Service 2000). Amphibian and reptile species are constricted to more aquatic groups such as frogs and turtles (United States Fish and Wildlife Service 2002). Thirtyeight mussel species and over 100 species of warm water fishes have been identified around the islands in the upper Ohio River. Additionally, 3 federally listed species occur in the area: Indiana bat (Myotis sodalis), pink mucket pearly mussel (Lampsilis orbiculata), and fanshell mussel (Cyprogenia stegaria), and 2 species: bald eagle (Haliaeetus leucocephalus) and peregrine falcon have recently been delisted.

\section{West Virginia Bridge Studies}

In West Virginia, the WVDOH initiated a research project in 1985 to determine the effects of major bridges on wildlife and vegetation communities. The purposes of these studies were to: investigate the impacts and severity of bridges on wildlife (barrier effect, loss of habitat, attraction of undesirable species), determine any wildlife benefits provided by bridges, and provide specific information on island wildlife concerning possible impacts of a proposed Corridor D bridge crossing. These studies were conducted at bridges throughout the state including: Interstate 77 over Ohio River at Buckley Island, Corridor H US Rt. 33 over Middle Fork River, Corridor H US Rt. 33 over Tygart Valley River, Interstate 64 over Greenbrier River, and US Rt. 19 over Meadow River. Studies also were conducted at the proposed site of Corridor D US Rt. 50 over Ohio River at Blennerhassett Island before construction of the bridge began.

The initial studies of Corridor D were conducted from 1985-1987 and were titled Phase I. These studies were conducted by WVDOH personnel. Follow up studies were conducted from 1998-2000, and were titled Phase II. Phase II studies were conducted by biologists with West 
Virginia University and Salem International University. The Phase I and Phase II studies

sampled mammals, birds, vegetation, and soils in association with existing bridge crossings and the proposed crossing (Blennerhassett). Sampling methods conducted were: wildlife observations, breeding bird surveys for songbirds, small mammal snap trapping, furbearer scent station surveys, and vegetation and soil sampling. Sampling was conducted along $100 \mathrm{~m}$ parallel line transects located directly under the bridges $(0 \mathrm{~m})$ or at the proposed location of the bridge (Blennerhassett), and at 100 and $300 \mathrm{~m}$ distances.

\section{$\underline{\text { Justification }}$}

In accordance with the Appalachian Corridor D Final Environmental Impact Statement (FEIS), a post-construction study would be undertaken to review the effects of the completed Corridor D Bridge and appurtenances on island vegetation and wildlife including avian populations and bird strikes (Appalachian Corridor D Environmental Reevaluation and Final Section 4 Evaluation, unpublished report). This study would need to focus efforts on the impacts of the bridge on vegetation and wildlife on both the mainland and the island including the wetland complex on the island.

Aquatic cover types associated with the Ohio River provide some of the area's highest quality riverine, wetland, and bottomland hardwood cover types, and are used by a diverse community of birds, mammals, fish, turtles, and freshwater mussels (United States Fish and Wildlife Service 1989). Additionally, islands associated with the Ohio River provide essential habitat for many species of birds, mammals, amphibians, and reptiles (United States Fish and Wildlife Service 2000). It is important to determine the ecological impacts of this large bridge crossing upon wildlife and plant communities. Bridge crossings can either impact wildlife positively, negatively, or have no impact. It is important to conduct surveys to determine the 
effects of this bridge by looking at many classes of wildlife and plants, and not focusing on a particular species or class. Man-made structures such as bridges can affect: mammals, birds, amphibians, reptiles, invertebrates, plants, and the soil. It is also important to note that the disturbances made by man-made structures not only impact these classes of organisms, but could also impact their ecological interactions such as food webs, food chains, predator and prey interactions, niches, and habitat preferences (DeLucas et al. 2004).

\section{$\underline{\text { Study Area }}$}

This study was conducted along the Ohio River in Wood and Pleasants County, West Virginia, and Washington County, Ohio, USA. Four sites were studied (Blennerhassett Island, Buckley Island, Muskingum Island, and Grape Island) (Appendix 1) and surveys were conducted on both the islands and the adjacent mainland. Blennerhassett and Buckley both have bridge crossings, while Muskingum and Grape do not and one or the other or both were used as control sites. Construction of the Blennerhassett Island Bridge began in March 2005 and was completed in June 2008. The Buckley Island Bridge is of similar size and design to the bridge crossing Blennerhassett Island and was constructed in the mid-1960s. These islands occur between mile markers 151.6 and 189.9 with 3 sites (Blennerhassett, Buckley, and Muskingum) located in the Belleville Navigational Pool and 1 (Grape) in the Willow Island Navigational Pool (Tolin and Schettig 1983).

Blennerhassett Island is owned by DuPont Corporation and is leased to the state of West Virginia as a state historical park. Buckley, Muskingum, and Grape islands are owned by the U.S. Fish and Wildlife Service and are part of the Ohio River Islands National Wildlife Refuge (United States Fish and Wildlife Service 2000). Precipitation occurs throughout the year, totaling about 106 cm/year (IDcide West Virginia Weather 2010). Study areas ranged from 184-198 m in 
elevation (IDcide West Virginia City Data 2010). The primary cover types for these islands are: bottomland hardwood forest, late old-field, and early old-field (Tolin and Schettig 1983). Blennerhassett (Appendix 2) and Buckley (Appendix 3) have large portions of both bottomland hardwood forest and old-field cover types, while Muskingum (Appendix 4) and Grape (Appendix 5) are mostly bottomland hardwood forest (Tolin and Schettig 1983). Additionally, Blennerhassett Island and Grape Island contain a palustrine unconsolidated bottom wetland. All islands in this study area have been historically used for agriculture and the river channels around them may have been historically dredged (Tolin and Schettig 1983). The adjacent mainland has been shaped by disturbance from urbanization, agriculture, commercial development, and industrial expansion.

\section{$\underline{\text { Literature Review }}$}

\section{Ohio River Biology}

Relatively few studies have been conducted on Blennerhassett Island or other Ohio River islands. According to Zadnik et al. (2009), the first qualitative data set for the islands of the Ohio River in West Virginia was provided by Tolin and Schettig (1983). They sampled passerine birds, waterbirds, aquatic furbearing mammals, fish, and freshwater mussels in association with the islands of the river. Their study found a high diversity of passerine birds and waterbirds using the island for both nesting and resting areas during migration. They also found that aquatic furbearing mammals rely heavily on the islands. A high diversity of fish assemblages and freshwater mussel concentrations also were found around the heads of many of the islands. Their study indicated that the islands of the Ohio River provide habitat to many assemblages of wildlife and thus it laid the groundwork for the foundation of the Ohio River Islands National Wildlife Refuge which was founded in 1990. 
Additional waterbirds and shorebirds in the lower Ohio River Valley of West Virginia, dependent on islands, were found during the mid 1980s (Slack 1986). Floodplain forests associated with the Ohio River islands were found to provide the highest diversity of birds while the differences in bird species diversity along the river was attributed to differences observed in the habitat (Todt 1989). In the late 1980s, a cumulative checklist for birds of Wood County, West Virginia, USA was created which included birds dependent on the Ohio River and its islands (Rollefson 1989). About 193 bird species, including both migrants and breeders, have been documented on the Ohio River islands (United States Fish and Wildlife Service 2000). Occasionally, species not normally found along the Ohio River are sighted in the area. In the mid 1990s, a Sabine's gull (Xema sabini) was observed at Buckley Island (Morrison 1995). The Sabine's gull is an inhabitant of the arctic and uses coastlines as migration corridors. This sighting was the first in West Virginia and its occurrence was believed to be incidental. Further down the river, other bird studies were conducted which sampled bird diversity on 3 islands in Lewis County, Kentucky, USA (Gelis 1996). During the 1990s, biologist from the U.S. Fish and Wildlife Service conducted baseline biological surveys for information specific to management of the Ohio River Islands National Wildlife Refuge (U.S. Fish and Wildlife Service 2000).

Quality of habitat for cavity nesting birds on Ohio River islands was better on back channel sides than on navigational channel sides with more cavity nesting birds present on back channel sides (Sacilotto 2003). However, overall bird abundances tend to be higher on navigational channel sides than on back channel sides (Sacilotto 2003). Cavity nesting bird use of nest boxes on Ohio River islands was directly linked to visibility of the nest box, with no relation to channel side (Sacilotto and Anderson 2005). Waterbird, anuran, turtle, and aquatic furbearing mammal abundance and richness were higher on back channel sides compared to 
navigational channel sides (Zadnik et al. 2009). Habitat characteristics for belted kingfisher (Megaceryle alcyon), great blue heron (Ardea herodias), American mink (Mustela vison), common muskrat (Ondatra zibethicus), common snapping turtle (Chelydra serpentina), and wood duck (Aix sponsa) are more prevalent on back channel sides than on navigational sides (Zadnik et al. 2009).

Though fish were not investigated in this study, the Ohio River supports a large diversity of fishes and there has been many studies investigating fish biology in the Ohio River. A possible negative trend in the biological integrity of fish in the area was attributed to a power plant located along the Ohio River (Lorentz et al. 2006). Thirty years of fish population data along the Ohio River were analyzed and increases in populations of many species was found once water quality regulations were in place (Pearson and Pearson 1989). Other studies have concluded improvements of fish populations in the Ohio River since the passing of the Clean Water Act in 1972 (Cavanaugh and Mitsch 1989, Emery et al. 1998, Thomas et al. 2005). It has been suggested that more research on human disturbances on fish in the Ohio River should be conducted (Lorentz et al. 2006).

\section{Bridge Studies and Impacts}

\section{Ecological Studies}

Studies on the impacts of bridges on ecological communities are quite limited. More attention has been directed towards the use of bridges by birds and bats for nesting and roosting sites. However, there are some published studies of bridges and their impacts. The influence of high-flow events on a stream channel altered by a highway bridge was studied in West Virginia along Corridor H. High-flow events changed the streambed downstream of construction and bank erosion upstream (Hedrick et al. 2009). An investigation in Kansas evaluated the effects of 
logging and bridge construction on habitat of 2 intermittent streams and found logging and bridge construction can have adverse effects on stream habitat characteristics and localize disturbances due to lack of flow (Tiemann 2004). A series of unpublished reports from the West Virginia Department of Transportation (1998-2003) showed that highway bridges can have negative effects causing a decrease in small mammal abundances under bridges, a change in breeding bird species composition under bridges, attraction of undesirable species including exotics, and fragmentation of habitat.

\section{Bird Studies}

Bridges can be beneficial to many species of birds as they provide nesting and perching sites. Cliff swallows were studied in Arkansas where it was concluded that the construction of concrete bridges have lead to an expansion of this species outside of its original range (Tumlison 2009). Barn swallows are increasing use of bridges as nest sites due to competition for natural nesting sites (Redmond and Murphy 2007). There also have been documentations of peregrine falcons using bridges and human structures as nesting and perching sites. The Bay Bridge and Golden Gate Bridge provide pivotal habitat for nesting and hunting sites for peregrine falcons in the San Francisco Bay area (Bell et al. 1996). Earlier studies on peregrine falcon use of bridges showed that peregrine falcons are inhabiting urban environments and using man-made structures for nesting (Tordoff and Redig 1988, Cade and Bird 1990). In an update on peregrine falcon nesting throughout the United States in 1993, 88 territorial pairs of peregrine falcons were found in 60 urban areas in North America. Of these, $30 \%$ of the nests were located on bridges and overpasses (Cade et al. 1996). 


\section{$\underline{\text { Bat Studies }}$}

Much research has been directed towards the use of bridges as roosting sites for bats. Rafinesque's big-eared bat (Corynorhinus rafinesquii) is a species that use bridges as day roosts (Bennett et al. 2008). This species now occurs throughout more of its range than originally thought and bridges may provide pivotal habitat where natural roosting sites are lacking (Bennett et al. 2008). The structural characteristics and surrounding habitat of bridges used as day roosts for Rafinesque's big-eared bats are important (Lance et al. 2001). The type of support structure under bridges, material with which bridges were built, proportion of surrounding habitat composed of mature deciduous forest, and road surface of bridges were significantly associated with selection of roost sites (Lance et al. 2001). Eight species of bats used bridges in Oregon (Adams and Hayes 2000). These species roosted more frequently in end chambers than in center chambers of concrete, and differences in size and thermal characteristics of bridges influenced bat use (Adams and Hayes 2000). In Louisiana, bats roosted under bridges in areas that minimize their visibility and accessibility to predators, and areas with specific temporal variations (Ferrera and Leburg 2005a, Ferrera and Leburg 2005b). In one study, $87 \%$ of boxes placed under flatbottomed bridges were used by bats for roosting sites (Arnett and Hayes 2000). The authors recommended that future bridge designs should incorporate opportunities for roosting bats without the aid of supplemental structures.

\section{Movements}

Other research has shown that bridges may act as links to aid in movement of wildlife and reconnect disconnected populations. Coyotes have moved across the Golden Gate Bridge in San Francisco possibly linking historically distinct populations (Sacks et al. 2006). 


\section{Highway Studies and Impacts}

\section{$\underline{\text { Wildlife-vehicle Mortality }}$}

Although little work has been directed towards the impacts of bridges on ecological communities, much more work has been conducted on the impacts of highways. Much of this literature has focused on mortality caused by vehicle-animal collisions. Romin and Bissonette (1996) estimated 500,000 wild animals are killed every year by vehicle mortality while Schwabe and Schuhmann (2002) estimated 700,000. American badger (Taxidea taxus) mortality was lower in areas where there were abundant culverts leading to the conclusion that badgers are using culverts as passages instead of crossing roads (Kinley and Newhouse 2009). Deaths of black bears (Ursus americanus) due to vehicle mortality in Florida suggest the need for wildlife passages (McCown et al. 2009). Methodologies to find hotspots of amphibian and reptile mortality on rural highway have been developed and show it is possible to pinpoint hotspots for mortality and recommended priority areas for mitigation (Langen et al. 2007), and it is possible to identify meaningful predictors of hot spots of amphibian and reptile road mortality for use when planning roads or when conducting surveys on existing roads to locate priority areas for mitigation (Langen et al. 2009).

There were 205 painted turtles killed (Chrysemys picta) during a 4 month summer period along a $7.2 \mathrm{~km}$ road in Montana that fragmented a series of rounded marshy wetlands that provide habitat for the turtles (Fowle 1990). A $49 \%$ mortality rate for the endangered Florida panther (Puma concolor coryi) was accounted for by motor vehicles which suggest mitigation in the form of underpasses and fencing needs to be done to greatly reduce this percentage (Maehr et al. 1991). A long-term data set for road killed raccoons (Procyon lotor) in Indiana found that vehicle speed was the major cause of mortality (Rolley and Lehuman 1992). Additionally, a 
study on road-killed armadillos (Dasypus novemcinctus) in Florida found that traffic volume was the major cause of mortality (Inbar and Mayer 1999).

The number of colonial shorebirds killed by vehicle strikes along a bridge in Florida dropped after fences were installed along sides of bridge (Bard et al. 2002). The fences forced the birds to fly higher over the bridge and out of the way of motorists (Bard et al. 2002). There are many other studies on wildlife and vehicle mortality including: road-mortality of snapping turtles in Ontario during breeding season (Haxton 2000), the factors influencing deer and vehicle accidents in Iowa (Hubbard et al. 2000), highway and habitat characteristics of deer-vehicle collisions in Pennsylvania (Bashore et al. 1985), the effects of road kills on amphibian populations (Hels and Buchwald 2001), the demographic consequences of road mortality in Florida scrub jays (Aphelocoma coerulescens) (Mumme et al. 2000), and the rates and causes of mortality in a fragmented population of Iberian lynx (Felis pardini) (Ferreras et al. 1992).

\section{Mitigations for Movement}

With so much wildlife and vehicle mortality reported yearly, much attention has been directed towards mitigations for wildlife movements. Highway fencing in Sweden decreased moose (Alces alces) mortality substantially and improved automobile safety, but may restrict moose movements and accessibility to resources (Olsson and Widen 2008). Electric fences reduced moose from crossing highways by $78 \%$ (Leblond et al. 2007). Video surveillance show underpasses limit vehicular mortality of elk (Cervus canandesnsis) when crossing freeways (Dodd et al. 2007). Similar results were observed for white-tailed deer using underpasses in North Carolina including high use of underpasses, limited mortality, and reconnection of habitat (Kliest et al. 2007). Underpasses are also successful in limiting mortality for Florida panthers (Foster and Humphrey 1995) and for wildlife in southern California (Ng et al. 2004). A drift 
fence system and a culvert in Florida prevented mortality of many amphibians and reptiles including a $98 \%$ prevention rate for turtles (Aresco 2005). A population of meadow voles (Microtus pennsylvanicus) was able to extend its range after continuous avenues of dense vegetation were planted along an interstate highway (Getz et al. 1978).

\section{$\underline{\text { Barrier Effects }}$}

Other highway and roadway research have looked at the impacts of roads as barriers to wildlife. Roads are a barrier on grizzly bear (Ursus arctos) movements with bears crossing more often at night and in shorter reaches of the road when traffic was less and chance of collision was lower (Waller and Servheen 2005). Eastern chipmunks (Tamias striatus) avoid both roadside vegetation and road surfaces (Ford and Fahrig 2008). Moose avoid areas near highways and there is a positive relation between home-range size and the proportion of roads they contained (Laurian et al. 2008). Elk avoid roads during times of high traffic volume and use the habitat only when traffic volume was low (Gagnon et al. 2007). Grizzly bear cross roads hesitantly and usually did so rapidly and acutely (Graves et al. 2006). Rodents in the Mojave Dessert travel long distances, but hesitated to cross roads (Garland and Bradley 1984). Two species of forest dwelling mice in Germany rarely or never crossed two-lane highways (Mader 1984). Studies on carnivore populations in the Rocky Mountains indicate that roads could be barriers for crossing (Noss et al. 1996). Both Gibbs (1998) and Carr and Fahrig (2001) indicated that highways can be significant barriers to amphibian breeding migrations, seasonal migrations, and normal foraging dispersals. Older research has provided evidence that large animals including black bears, grizzly bears, elk, mule deer (Odocoileus hemionus), and wolves (Canis lupus) also appear to avoid roads (Rost and Bailey 1979, Grover and Thompson 1986, McLellan and Shackleton 1988, Brody and Pelton 1989, Thurber et al. 1994). 
$\underline{\text { Noise }}$

Some studies have found impacts of noise from traffic upon wildlife. In a series of 3 papers, Foppen and Reijnen (1994), Reijnen and Foppen (1994), and Reijnen et al. (1995) found that of 43 species of woodland breeding birds, 26 species showed reduced densities near highways. There was evidence that the presence of a highway reduced willow warbler (Phylloscopus trochilus) populations significantly. A regression model showed that road noise best explained the lower bird density near the road. Research from Texas indicates that whitewinged doves (Zenaida asiatica) near roads call less during high traffic periods and ability to detect breeding birds aurally decreased (Breeden et al. 2008). Other reports have shown that noise disturbance from roads is one of the most important factors negatively impacting terrestrial wildlife (Forman and Alexander 1998, Spellerburg 1998).

Presence of a Highway

The general presence of a road or highway could impact certain taxa of wildlife. Roads can dictate the overall species richness and abundance of salamanders with disturbance tolerant species benefiting while others decrease (Ward et al. 2008). Road mortality on snakes can be the direct result of snakes using roads as basking sites (Rosen and Lowe 1994). Presence of salt and other deicing agents used for snow removal can attract animals to roads and thus cause mortality (Fraser and Thomas 1982). Other research shows mortality in birds as a result of salt on roads (Mineau and Brownlee 2005). Additionally, vehicle mortality could also be a threat to species of scavengers such as vultures (Family Cathartidae) who feed on road kills (Coleman and Fraser 1989). 
$\underline{\text { Habitat }}$

The presence of highways can act as barriers to wildlife causing habitat fragmentation. Habitat fragmentation is generally defined as the process of subdividing a continuous habitat type into smaller patches, which results in the loss of original habitat patch size, and increasing isolation of patches (Andren 1994). Highways also can be the cause of other detriments to habitat including alteration and loss. Habitat for moose was fragmented by roads limiting home range (Laurian et al. 2008). Elk are shy and wary of roads causing habitat fragmentation and limited movement (Dodd et al. 2007). Both McGregor et al. (2003) and Conrey and Mills (2001) showed that roads and highways cause habitat fragmentation to small mammal populations. Genetic diversity was limited in an anuran population due to fragmentation from highways (Lesbarreres et al. 2006). Habitat fragmentation can cause a reduction in genetic diversity of voles (Family Cricetidea) (Gerlach and Musolf 2000). Likewise, highways can cause a decrease in genetic diversity in bighorn sheep (Ovis canadensis) (Epps et al. 2005). Roads also may cause fragmentation of habitat and limit snake movements (Andrews et al. 2005). Roads act as barriers causing habitat fragmentation and disrupting otherwise continuous population distributions (Vos and Chardon 1998) and highways may block animal movements leading to fragmentation of wildlife habitats and populations (Trombulak and Frissell 2000).

Elk distribution and modeling in relation to roads indicate that roads cause alteration of habitat which negatively affected elk movements and distribution (Rowland et al. 2000). Thousands of kilometers of roads are constructed through wetlands causing the loss, fragmentation, and degradation of habitat by filling, dredging, and alteration of hydrologic regimes (Mitsch and Gosselink 2000). Forman (2000) reported that roads and highways cause a 
direct habitat loss for certain species, while other literature suggests roads can result in direct habitat destruction for amphibians (Blaustein and Kiesecker 2002).

In certain instances, highways can create habitat and positively affect wildlife. Redwinged blackbird (Agelaius phoeniceus) and horned lark (Eremophila alpestris) abundances were greater near roads due to increase in edge and early successional habitat (Clark and Karr 1979). Roads also may create additional ecotone habitat and favor the growth of deciduous shrubs preferred by ungulates (Child 1998).

\section{$\underline{\text { Aquatic Systems }}$}

Many researchers have investigated the impacts of highways on aquatic systems (e.g., Eaglin and Hubert 1993, King et al. 2000, Wellman et al. 2000). Many of these studies have focused on sedimentation or siltation. Road construction along stream corridors can alter structure, function, and stability of stream channels (Albanese and Matlack 1998). A review by Henley et al. (2000) found inconsistent patterns of environmental impacts among sites. An increase in inorganic sediments may be due to highway construction (King and Ball 1965). Urbana and Rhoades (2003) found the same and attributed this to erosion of exposed and unvegetated river banks. Erosion increases on the disturbed land surface due to recontouring and leveling during construction (Wohl 2006). Alteration of natural stream channels by channel realignment, placement of culverts, and construction of bridges also can occur (Johnson 2006).

Suspended solids and sediment increase in streams with highway construction (Cline et al. 1982). Densities of benthic macroinvertebrates were impacted during and immediately following construction (Cline et al. 1982). Benthic macroinvertebrates in Halon Creek in Ontario had different species composition in heavily constructed and impacted areas with disturbance tolerant species found in high numbers (Barton 1977). Benthic macroinvertebrates were studied 
at 4 sites on Turtle Creek, a stream impacted by the construction of Appalachian Corridor G, and diversity and abundance was found to decrease during the construction of the highway (Chrisholm and Downs 1978). Repopulation and diversification occurred quickly within disturbed and newly created reaches of Turtle Creek, and within about 1 year, the benthic macroinvertebrate population of the disturbed stream was similar to that of a control stream (Chrisholm and Downs 1978).

In recent years, Hedrick (2008) studied the effects of highway construction and sediment on benthic macroinvertebrates, water quality, and stream functions in connection with the Appalachian Corridor $\mathrm{H}$ project. Little difference in the amount of sediment collected at upstream and downstream sites were found (Hedrick et al. 2009). Likewise, benthic macroinvertebrate communities did not differ significantly seasonally or annually by stream or by site. This lead to the conclusion that on-site controls effectively collected new sediment and macroinvertebrates were not significantly impacted (Hedrick 2008).

\section{$\underline{\text { Hypotheses and Objectives }}$}

The main goal of this study was to evaluate the impacts of the Blennerhassett Island Bridge crossing (Ohio River) by sampling vegetation, soil, waterbirds, songbirds, anurans, turtles, small mammals, and furbearers.

The specific objectives of this study were:

1.) To compare vegetation, soil, waterbirds, songbirds, anurans, turtles, small mammals, and furbearers at the Blennerhassett Island site (new bridge) to the Buckley Island site (old bridge), Muskingum Island site (no bridge), and the Grape Island site (no bridge, for anurans and turtles only). 
2.) To compare vegetation, soil, songbirds, anurans, turtles, small mammals, and furbearers at different distances from the bridge (under (0 m), away (100 and $300 \mathrm{~m})$ ).

3.) To compare pre-construction data collected during the Phase I and Phase II Studies for vegetation, soil, waterbirds, songbirds, small mammals, and furbearers to postconstruction data collected in this project.

Based on the above objectives, the following hypotheses were made:

1.) $\mathrm{H}_{0}$ : The Blennerhassett Island Bridge does not affect wildlife taxa mentioned above in comparison to other islands.

$\mathrm{H}_{\mathrm{a}}$ : The Blennerhassett Island Bridge does affect wildlife taxa mentioned above in comparison to other islands.

2.) $\mathrm{H}_{0}$ : The Blennerhassett Island Bridge does not affect wildlife taxa mentioned above in comparison to other distances from the bridge.

$\mathrm{H}_{\mathrm{a}}$ : The Blennerhassett Island Bridge does affect wildlife taxa mentioned above in comparison to other distances from the bridge.

3.) $\mathrm{H}_{0}$ : The Blennerhassett Island Bridge does not affect wildlife taxa mentioned above in comparison to pre-construction data.

$\mathrm{H}_{\mathrm{a}}$ : The Blennerhassett Island Bridge does affect wildlife taxa mentioned above in comparison to pre-construction data.

\section{Content Brief}

The research findings presented here are divided into 5 chapters with the first chapter serving as an introduction and literature review. Chapter 2 will investigate the impacts of the Blennerhassett Island Bridge on vegetation and soil for post-construction data only and investigate island and distance comparisons. Chapter 3 will investigate the impacts of the 
Blennerhassett Island Bridge on waterbirds, songbirds, anurans, turtles, small mammals, and furbearers for post-construction data only and investigate island and distance comparisons. Chapter 4 will investigate the impacts of the Blennerhassett Island Bridge over time by comparing pre-construction vegetation, soil, and wildlife data to post-construction data. Finally, Chapter 5 will give overall conclusions on the impacts the Blennerhassett Island Bridge has on soil, vegetation, and wildlife and to what degree they are affected, as well as provide management implications and outline needs and recommendations for future research. 


\section{$\underline{\text { Literature Cited }}$}

Adams, M. D. and J. P. Hayes. 2000. Use of bridges as night roosts by bats in the Oregon coast range. Journal of Mammalogy 81:402-407.

Andren, H. 1994. Effects of habitat fragmentation on birds and mammals in landscapes with different proportions of suitable habitat: a review. Oikos 71:355-366.

Albanese, B. and G. Matlack. 1998. Environmental auditing: utilization of parking lots in Hattiesburg, Mississippi, USA, and impacts on local streams. Environmental Management 24:265-271.

Andrews, K. M., J. W. Gibbons, and T. W. Reeder. 2005. How do highways influence snake movements? Behavior responses to roads and vehicles. Copeia 2005:772-782.

Aresco, M. J. 2005. Mitigation measures to reduce highway mortality of turtles and other herpetofauna at a north Florida lake. Journal of Wildlife Management 69:549-560.

Arnett, E. B. and J. P. Hayes. 2000. Bat use of roosting boxes installed under flat-bottomed bridges in western Oregon. Wildlife Society Bulletin 28:890-894.

Bard, A. M., H. T. Smith, E. D. Egensteiner, R. Mulholland, T. V. Harber, G. W. Heath, W. J. B. Miller, and J. S. Weske. 2002. A simple structure method to reduce road kills of royal terns at bridge sites. Wildlife Society Bulletin 30:603-605.

Barton, B. A. 1977. Short-term effects of highway construction on the limnology of a small stream in southern Ontario. Freshwater Biology 7:99-108.

Bashore, T. L., W. M. Tzilkowski, and E. D. Bellis. 1985. Analysis of deer-vehicle collision sites in Pennsylvania. Journal of Wildlife Management 49:769-774.

Bell, D. A., D. P. Gregoire, and B. J. Walton. 1996. Bridge use by peregrine falcons in the San Francisco Bay Area. Pages 15-24 in Bird, D. M., D. Varland, and J. Negro, editors. Raptors in human landscapes: adaptations to built and cultivated environments. Academic Publishers, San Diego, CA, USA.

Bennett, F. B., S. C. Loeb, M. S. Bunch, and W. W. Bowerman. 2008. Use and selection of bridges as daily roosts by Rafinesque's big-eared bats. American Midland Naturalist 160:386-399.

Blaustein, A. R. and J. M. Kiesecker. 2002. Complexity in conservation: lessons from the global decline of amphibian populations. Ecology Letters 5:597-608.

Bleich, V. C., J. G. Kie, E. R. Loft, T. R. Stephenson, M. W. Oehler, and A. L. Medina. 2005. Managing rangelands for wildlife. Pages 873-897 in C. E. Braun, editor. Techniques for wildlife investigations and management. Sixth edition. The Wildlife Society, Bethesda, Maryland, USA. 
Blennerhassett Island State Historical Park. 2009. http://www.blennerhassettislandstatepark.com/history.html. Accessed 10 October 2009.

Breeden, J. B., F. Hernandez, R. L. Bingham, N. J. Silvy, and G. L. Waggerman. 2008. Effects of traffic noise on auditory surveys of urban white-winged doves. Wilson Journal of Ornithology 120:384-389.

Brody, A. J. and M. R. Pelton. 1989. Effects of roads on black bear movements in western North Carolina. Wildlife Society Bulletin 17:5-10.

Cade, T. J. and D. M. Bird. 1990. Peregrine falcons (Falco peregrinus) nesting in an urban environment: a review. Canadian Field Naturalist 104:209-218.

Cade, T. J., M. Martell, P. Redig, G. Septon, and H. Tordoff. 1996. Peregrine falcons in urban North America. Pages 3-12 in Bird, D. M., D. Varland, and J. Negro, editors. Raptors in human landscapes: adaptations to built and cultivated environments. Academic Publishers, San Diego, CA, USA.

Carr, L. W. and L. Fahrig. 2001. Effect of road traffic on two amphibian species of differing vagility. Conservation Biology 15:1071-1078.

Cavanaugh, T. M., and W. J. Mitsch. 1989. Water quality trends of the Ohio River from 1977 to 1987. Ohio Journal of Science 89:73-91.

Child, K. N. 1998. Incidental mortality. Pages 275-301. in Franzmann, A. W. and C. C. Schwartz, editors. Ecology and management of the North American moose. Smithsonian Institution Press. Washington, D.C., USA.

Chrisholm, J. L. and S. C. Downs. 1978. Stress and recovery of aquatic organisms as related to highway construction along Turtle Creek, Boone County, West Virginia. U.S. Geological Survey Water Supply Paper 2055, Washington, D.C., USA.

Clark, W. D. and J. R. Karr. 1979. Effect of highways on red-winged blackbird and horned lark populations. Wilson Bulletin 91:143-145.

Cline, L. D., R. A. Short, and J. V. Ward. 1982. The influence of highway construction on the macroinvertebrate and epilithic algae of a high mountain stream. Hydrobiologia 96:149159.

Coleman, J. S. and J. D. Fraser. 1989. Habitat use and home ranges of black and turkey vultures. Journal of Wildlife Management 53:782-792.

Conrey, R. C. Y. and L. S. Mills. 2001. Do highways fragment small mammal populations? Pages 448-457. in Evnik, G. and K. P. McDermott, editors. 2001 Proceedings of the International Conference on Ecology and Transportation. Center for Transportation and the Environment, North Carolina State University. Raleigh, USA. 
Cowardin, L. M., V. Carter, F. C. Golet, and E. T. LaRoe. 1979. Classification of wetlands and deepwater habitats of the United States. U. S. Fish and Wildlife Service. FWS/OBS$79 / 31$.

Czech, B. and P. R. Krausman. 1997. Distribution and causation of species endangerment in the United States. Science 277:1116-1117.

DeLucas, M. E., G. F. Janss, and M. Ferrer. 2004. The effects of a wind farm on birds in a migration point: the Strait of Gibraltar. Biodiversity and Conservation 13:395-407.

Dodd, N. L., J. W. Gagnon, A. L. Manzo, and R. E. Schweinsburg. 2007. Video surveillance to assess highway underpass use by elk in Arizona. Journal of Wildlife Management 71:637-645.

Eaglin, G. S. and W. A. Hubert. 1993. Effects of logging and roads on substrate and trout in streams of the Medicine Bow National Forest, Wyoming. North American Journal of Fisheries Management 13:844-846.

Emery, E. B., R. Ovies, and T. P. Simon. 1998. Influence of the family Catostomidae on the metrics developed for a great river index of biological integrity. Pages 203-224. in Simon, T. P., editor. Assessing the sustainability and biological integrity of water resources using fish communities. CRC Press. Boca Raton, Florida, USA.

Epps, C. W., P. J. Palsboll, J. D. Wehausen, G. K. Roderick, R. R. Ramey II, and D. R. McCullough. 2005. Highways block gene flow and cause rapid decline in genetic diversity of desert bighorn sheep. Ecology Letters 8:1029-1038.

Ferrara, F. J. and P. L. Leburg. 2005a. Characteristics of positions selected by day-roosting bats under bridges in Louisiana. Journal of Wildlife Management 86:729-735.

Ferrara, F. J. and P. L. Leburg. 2005b. Influence of investigator disturbance and temporal variation on surveys of bats roosting under bridges. Wildlife Society Bulletin 33:11131122.

Ferreras, P., J. J. Aldama, J. F. Beltran, and M. Delibes. 1992. Rates and causes of mortality in a fragmented population of Iberian lynx Felis pardini Temminck, 1824. Biological Conservation 61:197-202.

Foppen, R. and R. Reijnen. 1994. The effect of car traffic on breeding bird populations in woodland II. Breeding dispersal of male willow warblers (Phylloscopus trochilus) in relation to the proximity of a highway. Journal of Applied Ecology 31:95-101.

Ford, A. T. and L. Fahrig. 2008. Movement patterns of eastern chipmunks (Tamias striatus) near roads. Journal of Mammalogy 89:895-903.

Foster, J. and M. S. Gaines. 1991. The effects of a successional habitat mosaic on a small mammal community. Ecology 72:1358-1373. 
Forman, R.T. and L. E. Alexander. 1998. Roads and their major ecological effects. Annual Review of Ecology and Systematics 29:207-231.

Forman, R. T. 2000. Estimate of the area affected ecologically by the road system in the United States. Conservation Biology 14:31-35.

Forman, R. T., D. Sperling, J. A. Bissonette, A. P. Clevenger, C. D. Cutshall, V. H. Dale, L. Fahrig, R. France, C. R. Goldman, K. Heanue, J. A. Jones, F. J. Swanson, T. Turrentine, and T. C. Winter. 2003. Road ecology: science and solutions. Island Press, Washington, D. C., USA.

Foster, M. L. and S. R. Humphrey. 1995. Use of highway underpasses by Florida panthers and other wildlife. Wildlife Society Bulletin 23:95-100.

Fowle, S. C. 1990. The painted turtle in the Mission Valley of western Montana. Thesis, University of Montana, Missoula, Montana, USA.

Fraser, D. and E. R. Thomas. 1982. Moose-vehicle accidents in Ontario: Relation to highway salt. Wildlife Society Bulletin 10:261-265.

Gagnon, J. W., T. C. Theimer, N. L. Dodd, S. Boe, and R. E. Schweinsburg. 2007. Traffic volume alters elk distribution and highway crossings in Arizona. Journal of Wildlife Management 71:2318-2323.

Garland, T. and W. G. Bradley. 1984. Effects of highway of Mojave Dessert rodent populations. American Midland Naturalist 111:47-56.

Gelis, R. A. 1996. Birds of Manchester 1, Manchester 2, and Brush Creek Island, Ohio River Islands National Wildlife Refuge, Lewis County, Kentucky. Kentucky Warbler 72:20-25.

Gerlach, G. and K. Musolf. 2000. Fragmentation of landscapes as a cause of genetic subdivision in bank voles. Conservation Biology 14:1066-1074.

Getz, L., F. R. Cole, and D. L. Gates. 1978. Interstate roadsides as dispersal routes for Microtus pennsylvanicus. Journal of Mammalogy 59:208-213.

Gibbens, A. F. 1914. Historic Blennerhassett Island Home. Global Printing and Binding Company, Parkersburg, WV, USA.

Gibbs, J. P. 1998. Amphibian movements in response to forest edges, roads, and streambeds in southern New England. Journal of Wildlife Management 62:584-589.

Graves, T. A., S. Farley, and C. Servheen. 2006. Frequency and distribution of highway crossings by Kenai Peninsula brown bears. Wildlife Society Bulletin 34:800-808.

Grover, K. E. and M. J. Thompson. 1986. Factors influencing spring feeding site selection by elk in the Elkhorn Mountains, Montana. Journal of Wildlife Management 50:466-470.

Haxton, T. 2000. Road mortality of snapping turtles, Chelydra serpentina, in central Ontario during their nesting period. Canadian Field Naturalist 114:106-110. 
Hedrick, L. B. 2008. Effects of the impacts of highway construction on sediment and benthic macroinvertebrates in Appalachian streams. Dissertation, West Virginia University, Morgantown, West Virginia, USA.

Hedrick, L. B., S. A. Welsh, and J. T. Anderson. 2009. Influences of high-flow events on a stream channel altered by construction of a highway bridge: a case study. Northeastern Naturalist 16:375-394.

Hels, T. and E. Buchwald. 2001. The effect of road kills on amphibian populations. Biological Conservation 99:331-340.

Henley, W. F., M. A. Patterson, R. J. Neves, and A. D. Lemley. 2000. Effects of sedimentation and turbidity on lotic food webs: A concise review for natural resource managers. Reviews in Fisheries Science 8:125-139.

Hubbard, M. W., B. J. Danielson, and R. A. Schmitz. 2000. Factors influencing the location of deer-vehicle accidents in Iowa. Journal of Wildlife Management 64:707-712.

Hunter, W. C., D. A. Buehler, R. A. Canterbury, J. L. Confer, and P. B. Hamel. 2001. Conservation of density-dependent birds in eastern North America. Wildlife Society Bulletin: 29:440-455.

IDcide West Virginia City Data. 2010. http://www.idcide.com/citydata/wv/. Accessed 16 July 2010.

IDcide West Virginia Weather. 2010. http://www.idcide.com/weather/wv/. Accessed 16 July 2010.

Inbar, M. and R. T. Mayer. 1999. Spatio-temporal trends in armadillo diurnal activity and roadkills in Florida. Wildlife Society Bulletin 27:865-872.

Johnson, P. A. 2006. Physiographic characteristics of bridge-stream interactions. River Research and Applications 22:617-630.

Kellison, R. C., M. J. Young, R. R. Braham, and E. J. Jones. 1998. Major alluvial floodplains. Pages 291-323 in Messina, M. G., and W. H. Conner, editors, Southern forested wetlands. Lewis Publishers, New York, New York, USA.

Kie, J. G., V. C. Bleich, A. L. Medina, J. D. Yoakum, and J. W. Thomas. 1994. Managing rangelands for wildlife. Pages 663-688 in T. A. Bookhout, editor. Research and management techniques for wildlife and habitats. Fifth edition. The Wildlife Society, Bethesda, Maryland, USA.

King, D. L. and R. C. Ball. 1965. The influence of highway construction on a stream. Michigan State University, Agriculture Experiment Station, East Lansing. Research Report No. 19.

King, R. R., K. T. Nunnery, and C. J. Richardson. 2000. Macroinvertebrate assemblage response to highway crossings in forested wetlands: implications for biological assessment. Wetlands Ecology and Management 8:243-256. 
Kinley, T. A. and N. J. Newhouse. 2009. Badger roadkill risks in relation to the presence of culverts and jersey barriers. Northwest Science 83:148-153.

Kliest, A. M., R. A. Lancia, and P. D. Doerr. 2007. Using video surveillance to estimate wildlife use of a highway underpass. Journal of Wildlife Management 71:2729-2800.

Lance, R. F., B. T. Hardcastle, A. Talley, and P. L. Leburg. 2001. Day-roost selection by Rafinesque's big-eared bats (Corynorhinus rafinesquii) in Louisiana forests. Journal of Mammalogy 82:166-172.

Langen, T. A., A. Machniak, E. K. Crowe, C. Mangan, D. F. Marker, N. Liddle, and B. Roden. 2007. Methodologies for surveying herpetofauna mortality on rural highways. Journal of Wildlife Management 71:1361-1368.

Langen, T. A., K. M. Ogden, and L. L. Schwarting. 2009. Predicting hot spots of herpetofauna road mortality along highway networks. Journal of Wildlife Management 73:104-114.

Laurian, C., C. Dussault, J. P. Ouellet, R. Courtois, M. Poulin, and L. Breton. 2008. Behavior of moose relative to a road network. Journal of Wildlife Management 72:1550-1557.

Leblond, M., C. Dussault, J. P. Ouellet, M. Poulin, R. Courtois, and J. Fortin. 2007. Electric fencing as a measure to reduce moose-vehicle collisions. Journal of Wildlife Management 71:1695-1703.

Lesbarreres, D., C. R. Primmer, T. Lode, and J. Merila. 2006. The effects of 20 years of highway presence on the genetic structure of Rana dalmatina populations. Ecoscience 13:531-538.

Lorentz, C. N., D. T. Saalfeld, and S. T. Saalfeld. 2006. Status and changes of Ohio River fish assemblages around William H. Zimmer Power Plant, Moscow, Ohio. Journal of the Kentucky Academy of Science 67:39-46.

Mader, H. J. 1984. Animal habitat isolation by roads and agricultural fields. Biological Conservation 29:81-96.

Maehr, D. S., E. D. Land, and M. E. Roelke. 1991. Mortality patterns of panthers in southwest Florida. Proceedings of the Annual Conference of Southeastern Association Fish and Wildlife Agencies 45:201-207.

McCown, J. W., P. Kubilis, T. H. Eason, and B. K. Scheick. 2009. Effect of traffic volume on American black bears in central Florida, USA. Ursus 20:39-46.

McGregor, R., S. Derrane, D. Bender, and L. Fahrig. 2003. The effect of traffic volume on translocated small mammal movement. Pages 294-396. in Irwin, C. L., P. Garrett, and K. P. McDermott, editors. 2003 Proceedings of the International Conference on Ecology and Transportation. Center for Transportation and the Environment, North Carolina State University. Raleigh, USA. 
McLellan, B. N. and D. M. Shackleton. 1988. Grizzly bears and resource extraction industries: Effects of roads on behavior, habitat use and demography. Journal of Applied Ecology 25:451-460.

Mineau, P. and L. J. Brownlee. 2005. Road salts and birds: an assessment of the risk with particular emphasis on winter finch mortality. Wildlife Society Bulletin 33:835-841.

Mitsch, W. J. and J. G. Gosselink. 2000. Wetlands. Third edition. J. C. Wiley and Sons, New York, USA.

Morrison, P. A. 1995. Sabine's gull visits the Ohio River: a new West Virginia record. Redstart 62:120-121.

Mumme, R. L., S. J. Schoech, G. E. Woolfenden, and J. W. Fitzpatrick. 2000. Life and death in the fast lane: demographic consequences of road mortality in the Florida scrub-jay. Conservation Biology 14:501-512.

Ng, S. J., J. W. Dole, R. M. Sauvajot, S. P. D. Riley, and T. J. Valone. 2004. Use of highway undercrossings by wildlife in southern California. Biological Conservation 115:499-507.

Noss, R. F., H. B. Quigley, M. G. Hornocker, T. Merrill, and P. C. Paquet. 1996. Conservation biology and carnivore conservation in the Rocky Mountains. Conservation Biology 10:949-963.

Olsson, M. P. O. and P. Widen. 2008. Effects of highway fencing and wildlife crossing on moose Alces alces movements and space use in southwestern Sweden. Wildlife Biology 14:111117.

Pashley, D. N. and W. C. Barrow. 1992. Pages 315-320 in Finch, D. M., and P. W. Stangel, editors. Status and management of neotropical migratory birds. United States Department of Agriculture Forest Service, General Technical Report RM-229.

Pearson, W. D. and B. J. Pearson. 1989. Fishes of the Ohio River. Ohio Journal of Science 89:181-187.

Pickett, S. T., M. L. Cadenasso, J. M. Grove, C. H. Nilon, R. V. Pouyat, W. C. Zipperer, and R. Costanza. 2001. Urban ecological systems: linking terrestrial, ecological, physical, and socioeconomic components of metropolitan areas. Annual Review of Ecology and Systematics 32:127-157.

Redmond, L. J. and M. T. Murphy. 2007. Unusual barn swallow nest placement in southeastern Oregon. Wilson Journal of Ornithology 119:307-309.

Reijnen, M. J. S. M., G. Veenbaas, and R. P. B. Foppen. 1995. Predicting the effects of motorway traffic on breeding bird populations. Delft, Netherlands: Ministry of Transport, Public Works and Water Management. 
Reijnen, R. and R. Foppen. 1994. The effects of car traffic on breeding bird populations in woodland I. Evidence of reduced habitat quality for willow warblers (Phylloscopus trochilus) breeding close to a highway. Journal of Applied Ecology 31:85-94.

Rollefson, L. 1989. Annotated check-list of birds for Wood County and the Ohio River north to Belmont, West Virginia. Redstart 56:87-95.

Rolley, R. E. and L. E. Lehman. 1992. Relationship among raccoon road-kill surveys, harvests, and traffic. Wildlife Society Bulletin 20:313-318.

Romin, L. A. and J. A. Bissonette. 1996. Deer-vehicle collisions: status of state monitoring activities and mitigation efforts. Wildlife Society Bulletin 24:276-283.

Rosen, P. C. and C. H. Lowe. 1994. Highway mortality of snakes in the Sonoran Desert of southern Arizona. Biological Conservation 68:143-148.

Rost, G. R. and J. A. Bailey. 1979. Distribution of mule deer and elk in relation to roads. Journal of Wildlife Management 43:634-641.

Rowland, M. M., M. J. Wisdom, B. K. Johnson, and J. G. Kie. 2000. Elk distribution and modeling in relation to roads. Journal of Wildlife Management 64:672-684.

Sacilotto, K. A. 2003. An assessment of natural cavity abundance, nest box use, and management recommendations for birds on the Ohio River Islands National Wildlife Refuge, West Virginia. Thesis, West Virginia University, Morgantown, West Virginia, USA.

Sacilotto, K. A. and J. T. Anderson. 2005. Avian nest box use on islands in the Ohio River. Northeastern Naturalist 12:403-410.

Sacks, B. N., H. B. Ernest, and E. E. Boydston. 2006. San Francisco's Golden Gate: A bridge between historically distinct coyote (Canis latrans) populations. Western North American Naturalist 66:263-264.

Schwabe, K. A. and P. W. Schuhmann. 2002. Deer-vehicle collisions and deer value: an analysis of competing literatures. Wildlife Society Bulletin 30:609-615.

Slack, H. E. 1986. Additional records of waterbirds and shorebirds of the lower Ohio River Valley in West Virginia. Redstart 53:110-112.

Spellerburg, I. F. 1998. Ecological effects of roads and traffic: a literature review. Global Ecology and Biogeography Letters 7:317-333.

Thomas, J. A., E. B. Emery, and F. H. McCormick. 2005. Detection of temporal trends in Ohio River fish assemblages based on lockchamber surveys (1957-2001). American Fisheries Society Symposium 45:431-449.

Thurber, J. M., R. O. Peterson, T. D. Drummer, and S. A. Thomasma. 1994. Gray wolf response to refuge boundaries and roads in Alaska. Wildlife Society Bulletin 22:61-68. 
Tiemann, J. S. 2004. Short-term effects of logging and bridge construction on habitat of two Kansas intermittent streams. Transactions of the Kansas Academy of Science 107:136142.

Todt, D. 1989. Birds in the Ohio River Valley: possible indicators of environmental quality. Ohio Journal of Science 89:192-195.

Tolin, W. A. and P. A. Schettig. 1983. A physical and biological survey of the Ohio River islands (Huntington District). U. S. Fish and Wildlife Service. Elkins, WV, USA.

Tordoff, H. B. and P. T. Redig. 1988. Dispersal, nest site selection, and age of first breeding in peregrine falcons released in the upper midwest 1982-1988. Loon 60:148-151.

Trombulak, S. C. and C. A. Frissell. 2000. Review of ecological effects of roads on terrestrial and aquatic communities. Conservation Biology 14:18-30.

Tumlison, R. 2009. Breeding by cliff swallows (Petrochelidon pyrrhonota) in southern Arkansas. Southwestern Naturalist 54:208-210.

United States Army Corps of Engineers. 2000. Ohio River ecosystem restoration program, integrated decision document and environmental assessment. U. S. Army Corps of Engineers, Great Lakes and Ohio River Division, Cincinnati, Ohio, USA.

United States Fish and Wildlife Service. 1989. Final environmental assessment of the Ohio River Islands National Wildlife Refuge proposal. U. S. Fish and Wildlife Service, Newton Corner, Massachusetts, USA.

United States Fish and Wildlife Service. 2000. Ohio River Islands National Wildlife Refuge draft comprehensive conservation plan and environmental assessment. U. S. Fish and Wildlife Service. Hadley, Massachusetts, USA.

United States Fish and Wildlife Service. 2002. Ohio River Islands National Wildlife Refuge comprehensive conservation plan. U.S. Fish and Wildlife Service, Parkersburg, West Virginia, USA.

Urbana, M. A. and B. L. Rhoads. 2003. Catastrophic human-induced change in stream-channel planform and geometry in an agricultural watershed, Illinois, USA. Annals of the Association of American Geographers 93:783-796.

Vankat, J. L. and D. G. Roy. 2002. Landscape invisibility by exotic species. Pages 170-192 in Gutzwiller, K. J., editor. Applying landscape ecology in biological conservation. Springer, New York, New York, USA.

Vos, C. C. and J. P. Chardon. 1998. Effects of habitat fragmentation and road density on the distribution pattern of the moor frog, Rana arvilis. Journal of Applied Ecology 35:44-56.

Waller, J. S. and C. Servheen. 2005. Effects of transportation infrastructure on grizzly bears in northwestern Montana. Journal of Wildlife Management 69:985-1000. 
Ward, R. L., J. T. Anderson, and J. T. Petty. 2008. Effects of road crossings on stream and streamside salamanders. Journal of Wildlife Management 72:760-771.

Wellman, J. C., D. L. Combs, and S. B. Cook. 2000. Long-term impacts of bridge and culvert construction or replacement on fish communities and sediment characteristics of streams. Journal of Freshwater Ecology 15:317-328.

Wigley, T. B., and R. A. Lancia. 1998. Wildlife communities. Pages 205-236 in Messina, M. G. and W. H. Conner, editors. Southern forested wetlands. Lewis Publishers, New York, New York, USA

Wohl, E. E. 2006. Human impacts to mountain streams. Geomorphology 79:217-248.

Zadnik, A. K., J. T. Anderson, P. B. Wood, and K. Bledsoe. 2009. Wildlife use of back channels associated with islands on the Ohio River. Wetlands 29:543-551. 
Figure 1: Aerial photo of Blennerhassett Island and U.S. Rt. 50 (Corridor D) in 2007 showing the Blennerhassett Island Bridge near completion and as the last section of Corridor D to be complete.

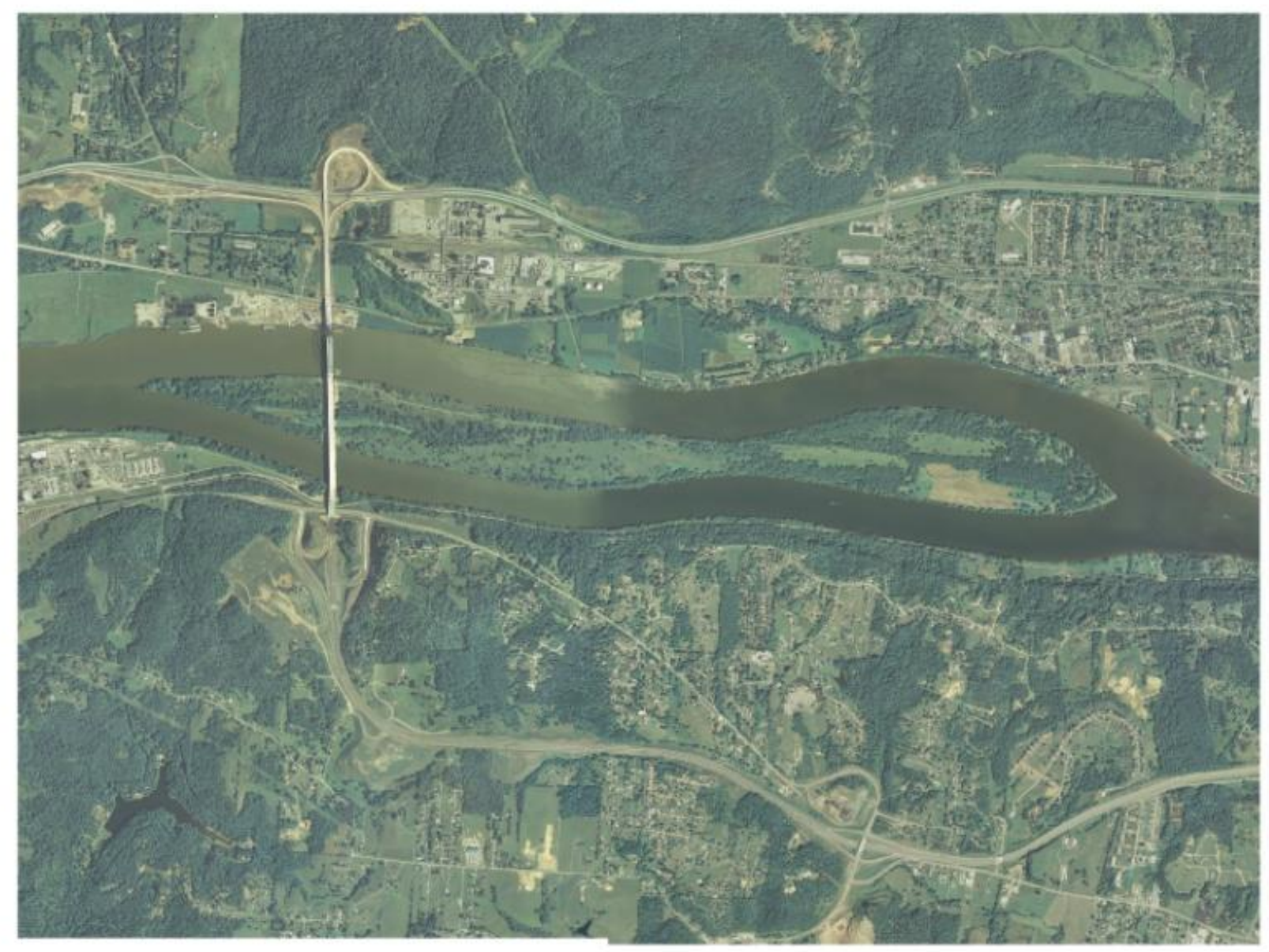


Figure 2: Photo of the Blennerhassett Island Bridge taken from Dupont Road near Blennerhassett Heights, WV, USA on 25 January 2008.

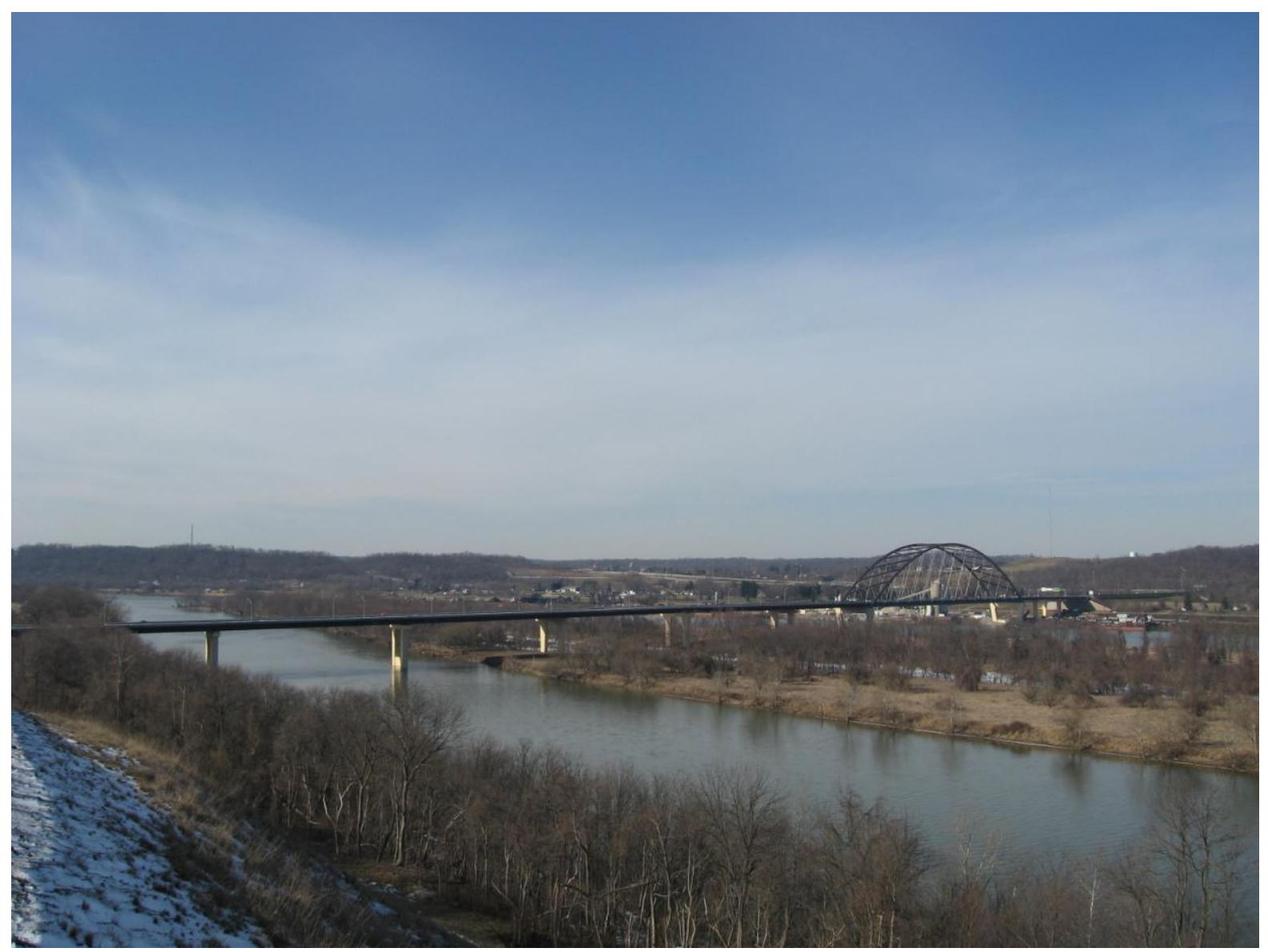


Figure 3: Photo of the Blennerhassett Island Bridge taken along the Ohio River on the West Virginia mainland on 25 January 2008.

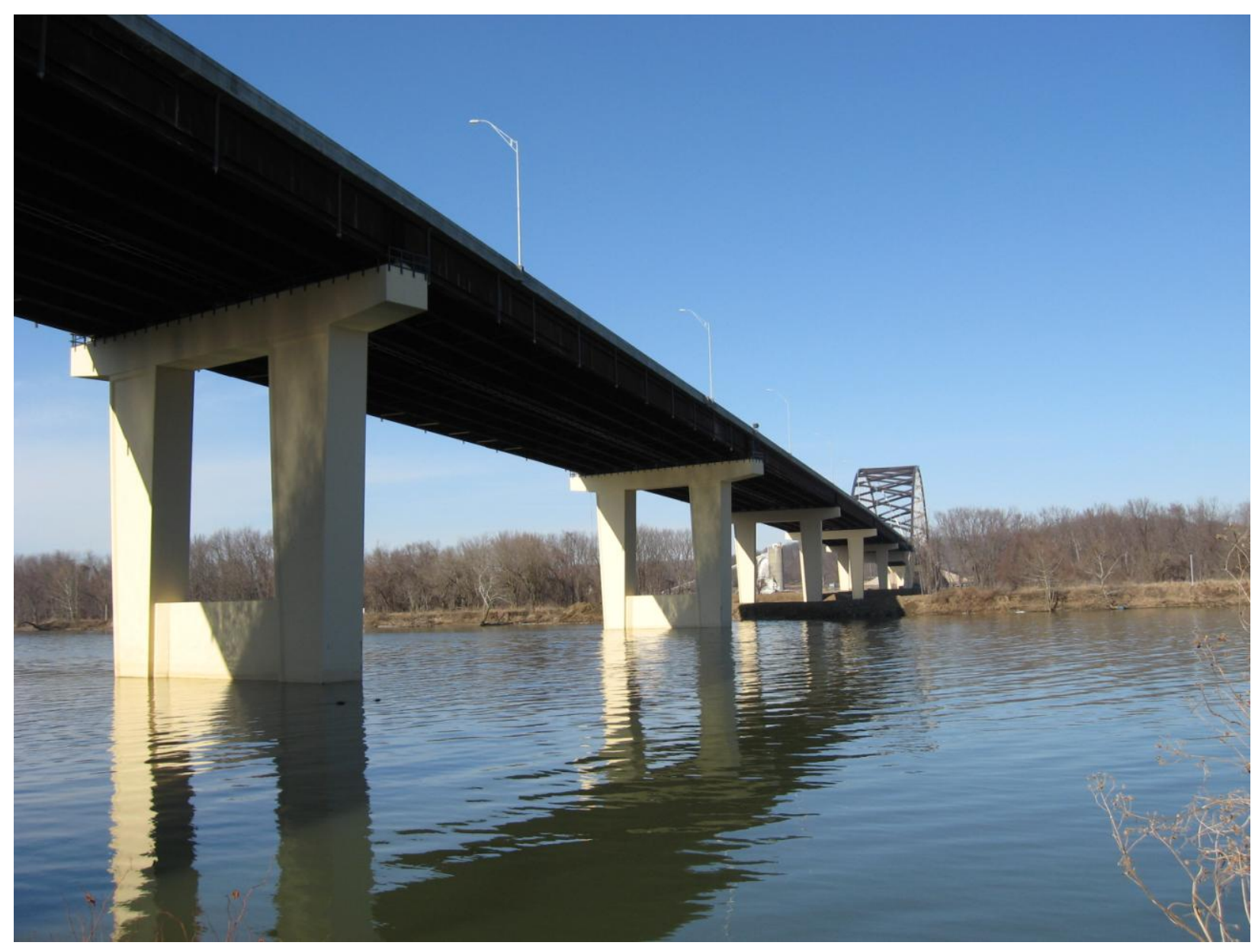


Chapter 2

VEGETATION AND SOIL PARAMETERS AT AN ISLAND BRIDGE CROSSING

JOSHUA A. VANCE*, West Virginia University, Division of Forestry and Natural Resources, PO Box 6125, Morgantown, WV 26506-6125, USA.

JAMES T. ANDERSON, West Virginia University, Division of Forestry and Natural Resources, PO Box 6125, Morgantown, WV 26506-6125, USA.

JAMES S. RENTCH, West Virginia University, Division of Forestry and Natural Resources, PO Box 6125, Morgantown, WV 26506-6125, USA.

PHILIP J. TURK, West Virginia University, Department of Statistics, PO Box 6330, Morgantown, WV 26506-6330, USA.

*josh_vance10@yahoo.com

This chapter written in the style of: Castanea 


\begin{abstract}
Roadsides are often planted with non-native, disturbance tolerant, herbaceous vegetation to enhance plant survival under highly disturbed soil conditions. We investigated vegetation and soils along the Ohio River, WV, USA at a new bridge crossing (Blennerhassett Island), a bridge crossing 45 years old (Buckley Island), and an island with no bridge crossing (Muskingum Island) and at 3 distances from the bridge or center point at each site $(0 \mathrm{~m}, 100 \mathrm{~m}, 300 \mathrm{~m})$. Overall, 170 species (131 herbaceous, 10 shrubs, and 29 trees) were observed. Percent cover of shrubs was higher at Muskingum than the other 2 sites $(P<0.05)$, and herbaceous cover and basal area of trees were lower at transects under the bridges $(P<0.05)$. Species composition differed at Muskingum Island compared to the other 2 sites $(P<0.05)$. Species composition also differed at transects under the bridges in comparison to distant transects $(P<0.05)$ with exotics such as Japanese millet and Italian perennial rye grass prevalent under the new bridge. Phosphorus, bray II phosphorus, soluble sulfur, sodium, potassium, zinc, calcium, magnesium, aluminum, total exchange capacity, organic matter, and estimated nitrogen released all had highly altered levels at transects under bridges $(P<0.05)$. Copper had lower levels at Blennerhassett compared to the other 2 sites $(P<0.05)$. The bridges influence vegetation directly beneath them by creating an environment with non-native, disturbance tolerant, herbaceous vegetation with low percent cover and basal area. Differences between sites were due to natural vegetative communities, while the presence of a bridge was responsible for differences between distances. The bridge was also found to alter soil chemistry, physical properties, and ecological processes in the soil likely due to fertilizer, road salts, and disturbance during construction.
\end{abstract}




\section{INTRODUCTION}

Roads can affect both vegetation and soil. Due to their vast presence across the landscape, there is a growing concern about the effects of highways and other roads on local and regional ecosystems (Forman 2000, Parendes and Jones 2000). Highway impacts are complex and can cause numerous potential problems including: disturbance during construction (Hedrick et al. 2009), alteration of normal hydrological flows (Forman and Alexander 1998), the introduction of salts and deicing agents into the soil (Davison 1971, Rutter and Thompson 1986), the fragmentation of natural communities (Lesbarreres et al. 2006, Dodd et al. 2007, Laurian et al. 2008, Ward et al. 2008, Poplar-Jeffers et al. 2009), and the threatening and endangerment of rare species (Stanton Fleming et al. 2007). Other concerns include vehicle exhaust emissions introducing particles and gases into the atmosphere which could affect plant photosynthesis, composition, competition, and growth (Mooney et al. 1988, Hunt et al. 1991, Ferris and Taylor 1995, Angold 1997) and potential problems from wind gusts, artificial light, noise, and dust (Fluckiger et al. 1978, Thompson et al. 1984, Spellerberg 1998). Lastly, roads serve as vectors for the introduction and spread of non-native and invasive species (Brothers and Spingar 1992, Parendes and Jones 2000, Gelbard and Belnap 2003, Rentch et al. 2005a). Once invasive plants are established, they can be detrimental to the environment by outcompeting native vegetation for resources and decreasing species richness by forming monocultures (Forman et al. 2003). Bridges may share many impacts of roads. Different impacts include increased shade and lower precipitation and soil moisture due to the overhang of the bridge. There are a lack of published data on the impacts of bridges on vegetation and soil. However, it can be hypothesized that bridges impact vegetation, soils, and their ecological roles similar to roads. 
Roadsides are often planted with disturbance-tolerant, non-native, generalist species of flowering, herbaceous plants and grasses that form discontinuous vegetation patterns and differ from contiguous native plant communities (Baker 1965, Townsend et al. 2000, Forman et al. 2003). Most species found along roadsides are pioneer, shade-intolerant, species that grow poorly or get out-competed in areas with dense shade (Forman et al. 2003, Diamond and Boyd 2004). However, some roadsides may contain natural plant communities or native plant species (Ullman et al. 1998). In West Virginia, highway corridors are usually re-vegetated with tall fescue (Kentucky 31 fescue) (Lolium arundinaceum (Scop.) Holub), red fescue (Festuca rubra L.), love grass (Eragrostis cuneata Schradu. Nees), bird's foot trefoil (Lotus corniculatus L.), and crown vetch (Coronilla varia L.) (Rentch et al. 2005a). These plants are usually chosen for seed mixtures due to their ability to take root quickly, stabilize soil, and reduce erosion (Forman et al. 2003). Once a disturbed site has been re-vegetated, the process of plant succession over time begins (Smith 1996, Townsend et al. 2000).

Construction and maintenance of roads has caused profound disturbance to the natural soil. Roadside disturbance and deicing agents change the physical properties of the soil (e.g., structure, stability, erodibility, porosity, and permeability) (Johnston and Johnston 2004) and also indirectly influence biological and chemical properties of the soil including: organic content, soil biota, chemistry, and microclimate conditions (Kuss et al. 1990). Deicing salts impact local water quality, vegetation, and soils by directly increasing concentrations of sodium, chloride, magnesium, and calcium (Liem et al. 1985, Simini and Leone 1986, Wilcox 1986). Continued infiltration of road salt into the soil may lead to potential long-term changes in soil chemistry and vegetation composition (Wilcox and Andrus 1987, Pugh et al. 1996, Panno et al. 1999, Richburg et al. 2001). Many of these impacts have the potential to compromise primary ecosystem 
function, hydrological cycles, nutrient movement and availability, and surface stability (Wilcox and Andrus 1987, Johnston and Johnston 2004). These changes in soil characteristics may affect plant growth, species diversity and composition, and create an environment conducive to colonization by exotic species (Tyser et al. 1998, Forman and Alexander 1998, Jones et al. 2000, Rentch et al. 2005a).

The purpose of this study was to evaluate the short-term impacts and effects of the Blennerhassett Island Bridge as it crosses over the Ohio River and Blennerhassett Island near Parkersburg, West Virginia, USA. The Blennerhassett Island Bridge is a large tied-arch style single-span bridge (GoBridges 2009) 1,220 $\mathrm{m}$ in length and $24 \mathrm{~m}$ above the island and water with 3 piers on the island. Construction of the bridge began in May 2005 and it was opened to the public 13 June 2008. This study investigates herbaceous and woody vegetation and soil characteristics associated with bridges. We compared vegetation and soil at Blennerhassett Island and 2 other islands ( 1 with an existing bridge crossing and 1 with no bridge crossing). We also compared vegetation and soil metrics under the bridge and at 100 and $300 \mathrm{~m}$ from the bridges.

\section{METHODS}

Study Area

This study was conducted along the Ohio River in Wood County, West Virginia and Washington County, Ohio, USA. We studied 3 sites (Blennerhassett Island, Buckley Island, and Muskingum Island) (Figure 1) and conducted surveys on both the islands and the adjacent mainlands. Blennerhassett and Buckley both have bridge crossings, but Muskingum does not and was therefore used as a control site. The bridge crossing Blennerhassett Island is a single-span tied-arch style bridge about 1,220 $\mathrm{m}$ in length and $24 \mathrm{~m}$ in height. This 4-lane bridge carries U.S. 
Route 50. The bridge crossing Buckley Island is also a single-span tied-arch style bridge similar in size to the bridge crossing Blennerhassett Island. It was constructed in the mid-1960s and is part of Interstate 77. These islands occur between km markers 271.8 and 305.6 (mi markers 168.9 and 189.9) with all 3 sites located in the Belleville Navigational Pool (Tolin and Schettig 1983).

Precipitation totals about $106 \mathrm{~cm} /$ year (IDcide West Virginia Weather 2010) and is fairly consistent from month to month. Elevation ranges from 184-198 m (IDcide West Virginia City Data 2010). All islands in this study area have been historically used for agriculture and the river channels around them may have been historically dredged (Tolin and Schettig 1983). The adjacent mainland has been shaped by disturbance from urbanization, agriculture, commercial development, and industrial development.

Bottomland hardwood forest is the most abundant cover type on the islands (Tolin and Schettig 1983) dominated by silver maple (Acer saccharinium L.), box elder (Acer negundo L.), and American sycamore (Platanus occidentalis L.) (Strausbaugh and Core 1977). Old-field cover types are the second most common cover types on the islands (Tolin and Schettig 1983). These cover types were created by past agricultural practices, oil and gas activities, recreational development, logging, and industrial activities (Zadnik et al. 2009). Old-field habitats are the transitional areas between bare ground and forest. They are usually comprised of vegetation such as forbs, grasses, and small shrubs (Bleich et al. 2005), but some of the islands may have woody plants becoming dominant (United States Fish and Wildlife Service 2002).

Soils on the Ohio River islands and their adjacent floodplains are primarily fine sandy or silt loams of the Huntington, Chagrin, and Linside series (United States Department of Agriculture 1970). These soils range from very well drained to somewhat poorly drained and 
contain normal levels of soil nutrients (United States Department of Agriculture 1970). The substrates of aquatic areas consist of muck, detritus, silt, clay, sand, gravel, cobble, riprap, emergent and submergent stumps and logs, and emergent and submergent aquatic beds (Tolin and Schettig 1983).

Following completion of the Blennerhassett Island Bridge in 2008, the soil directly under the bridge was fertilized using a nitrogen, potassium, and phosphorus mixture, mulched, and seeded. The seed mixture contained switchgrass (Panicum virgatum L.), redtop (Agrostis alba Roth), Japanese millet (Echinochloa crus-galli var frumentacea P. Beauv.), Italian perennial rye grass (Lolium perenne L.), and Kentucky 31 fescue.

Study Design

Vegetation and soils were sampled at Blennerhassett Island (new Rt. 50 bridge), Buckley Island (existing I-77 bridge), and Muskingum Island (no bridge). Vegetation and soils were sampled along 100 meter transects placed under and parallel with the bridge or for Muskingum Island at the island center, and at 100 and 300 meters from the central transect. Transects started at the shorelines and were placed on both sides of the bridge on both the mainlands and on the island. Because of site constraints (e.g., size of island, industry, agriculture, rock quarry, commercial and residential development) not every proposed transect ( $\mathrm{n}=20$ at each site) could be sampled: Blennerhassett Island $(\mathrm{n}=15)$, Buckley Island $(\mathrm{n}=9)$, and Muskingum Island $(\mathrm{n}=$ 7). This provided a total of 31 transects among the 3 sites.

\section{Vegetation}

The composition and structure of vegetation associated with each 100 meter transect was sampled using a $20 \mathrm{~m} \times 50 \mathrm{~m}$ (0.1 ha) nested quadrat (Figure 2) (Rentch et al. 2005b). In instances where this was not possible, a $20 \mathrm{~m} \times 25 \mathrm{~m}$ (0.05 ha) quadrat sample area was used. 
This was done for 4 total transects ( $\mathrm{n}=2$ at Blennerhassett and $\mathrm{n}=2$ at Buckley) due to space constraints, roads, and railroad crossings. Quadrats were positioned so that the center of the quadrat corresponded to the center of the transect. Diameter at breast height $(1.37 \mathrm{~m}$ above the ground level on uphill side and hereafter referred to as DBH) of all live stems of trees ( $\geq 10 \mathrm{~cm}$ $\mathrm{DBH})$ and small trees (2.5 to $9.9 \mathrm{~cm}$ DBH) was recorded by species in the quadrats. Saplings (individual trees $\leq 2.5 \mathrm{~cm}$ DBH but $\geq 1.0 \mathrm{~m}$ tall) were tallied by species in the same quadrat area. Numbers of seedlings (individual trees $<1.0 \mathrm{~m}$ tall) and shrubs (including woody vines) were recorded by species in $45.0 \times 5.0 \mathrm{~m}$ plots placed at regular intervals along a $50 \mathrm{~m}$ tape used to establish the centerline of the principal quadrat (Figure 2). Estimates of percent cover of herbaceous plants, exposed rock, woody debris, and bryophytes were recorded from $101.0 \times 1.0$ $\mathrm{m}$ plots placed at $5.0 \mathrm{~m}$ intervals along the same tape (Figure 2). All cover values were estimated using a cover class rating scale described by Daubenmire (1968): $1=<5 \%$ cover, $2=5-25,3=$ $26-50,4=51-75,5=76-95$, and $6=>95$, and the midpoint of cover class was used to estimate average percent cover. Vegetation sampling was conducted during July 2008.

We calculated percent cover for herbs and shrubs, basal area for trees, species richness, and Shannon diversity index (SDI) for each of the sample plots for all plants and for native plants only. Vegetation parameters were compared by site, distance, and interaction using a 2way analysis of variance (ANOVA) with an alpha level of 0.05. Non-normal data (i.e., percent cover for shrubs and basal area for trees) were rank transformed (Conover and Iman 1981). Because the levels of distance had no physical meaning for Muskingum, a partial analysis was done to examine distance only for Blennerhassett and Buckley islands. In the case where there was no significant interaction, a contrast for the effect of distance pooled across both islands was estimated and, if necessary, follow up pairwise comparisons between levels of distance were 
estimated. If there was a significant interaction, then the effect of distance was examined for the 2 islands on an individual basis (i.e., a simple effects analysis). Residual diagnostics were used to verify the assumptions of the model. The test of interaction for shrubs and basal area was done using untransformed data to obtain a more approximate analysis (Conover 1999). When subsequently testing main effects or contrasts, rank transformed data were used.

We initially evaluated the uniqueness of species composition by site and distance from bridge via PERMANOVA (Anderson 2001) using the Vegan package in Program R. A subsequent one at a time analysis was done using multi-response permutations procedures (MRPP) in PC-ORD version 5.10 software (McCune and Mefford 1999). MRPP is a nonparametric multivariate procedure for testing the hypothesis of no difference between species composition of 2 or more a priori groups of plots (McCune et al. 2002). For these analyses, all species that occurred less than 3 times were deleted. Percent cover for herbs and shrubs and basal area for trees were calculated for abundance data along with percent cover of bryophytes, bare ground or rock, and woody debris for each transect. These data were then relativized using a general column relativization. A Sorensen (Bray-Curtis) distance measure was used with a rank transformed distance matrix and an alpha level of 0.05 . A Sorensen community similarity index was used to evaluate vegetation overlap among sites and distances. The transects at Muskingum Island were not used in the distance analysis. Dependent variables were precent cover for herbaceous vegetation and shrubs and basal area for trees. Independent variables consisted of site and distance from bridge. The sample unit was the quadrat.

Lastly, the affinity of species occurrence by site and distance were calculated using indicator species analysis (Dufrene and Legendre 1997). This method combines information on the species abundance at a particular treatment and the faithfulness of occurrence (frequency) of 
a species at a particular location (Rentch et al. 2005a). First, an indicator value for each species was calculated with a value between 0 and 100. A value of 0 showed no indication of the species and a value of 100 showed perfect indication of the species. Second, the statistical significance of the highest indicator value $\left(I V_{\max }\right)$ for each species was tested using a Monte Carlo test using 4,999 permutations with an alpha level of 0.05 .

Soil

Soil samples were collected within each of the 0.1 ha quadrats established for the vegetation sampling using a $1.27 \mathrm{~cm}$ diameter soil probe. Composite samples were created from 4 sub-samples collected from the upper $10 \mathrm{~cm}$ of soil. Each quadrat was divided into 4 equal 0.025 sub-sections, and 1 subsample of soil was randomly taken from each sub-section, and all 4 samples were mixed together. Each sample was air dried, passed through a $2 \mathrm{~mm}$ sieve, and then sent to the Brookside Laboratories in New Knoxville, Ohio, USA, for analysis. The soil parameters analyzed were percent organic matter, $\mathrm{pH}$, total exchange capacity, estimated nitrogen released, parts per million for aluminum, ammonium, boron, phosphorus, bray II phosphorus, copper, calcium, iron, magnesium, potassium, zinc, nitrate, sodium, manganese, and soluble sulfur (Stephenson et al. 2007). Soil samples were collected at these sites during the vegetation sampling in July 2008.

Soil data were compared by site, distance, and interaction using a 2-way ANOVA with an alpha level of 0.05. Non-normal data or data displaying non-constant variance (i.e., parts per million of soluble sulfur, phosphorus, potassium, sodium, ammonium) were log transformed. For several variables displaying nonconstant variance that could not be remediated via a log transformation (bray II phosphorous, iron, nitrate), a model allowing for heterogeneous variance was fitted. The analysis then proceeded in the same fashion as the one with vegetation. 


\section{RESULTS}

\section{Vegetation}

A total of 170 species $(n=121$ at Blennerhassett, $n=81$ at Buckley, and $n=56$ at Muskingum) were identified among the 31 sample quadrats (Appendix 6). Of the 170 species, 131 herbaceous plants, 10 shrubs, and 29 trees were identified. A total of 52 non-native and exotic species ( $\mathrm{n}=39$ at Blennerhassett, $\mathrm{n}=30$ at Buckley, $\mathrm{n}=13$ at Muskingum) were sampled representing $30.5 \%$ of all species (Appendix 7) and $61.6 \%$ of total cover. A few of the most common exotic species sampled included: ground ivy (Glechoma hederacea L.), Japanese knotweed (Polygonum cuspidatum Siebold \& Zucc.), mile-a-minute weed (Polygonum perfoliata (L.) H. Gross), and wild stinging nettle (Urtica dioica L.). Herbaceous cover for all plants and native plants only, basal area, and SDI for native plants were lower at transects under the bridge compared to other distances (Table 1). Species richness was higher at the $100 \mathrm{~m}$ transects than the $0 \mathrm{~m}$ transects, but neither differed from the $300 \mathrm{~m}$ transects (Table 1). Additionally, percent cover for all shrubs and native shrubs were higher at Muskingum compared to the other 2 islands and SDI for native plants was higher at Muskingum than at the other 2 islands (Table 1).

All species that occurred less than 3 times were removed from the total species composition matrix reducing the 170 species to 64 species for the site analysis and 53 for the distances analysis (Table 2) plus percent cover of bryophytes, bare ground, and woody debris for the PERMANOVA and MRPP analysis. Of the 64 species, 24 (37.5\%) were non-native and exotic to the study area while 22 of the $53(41.5 \%)$ were non-native and exotic to the study area (Appendix 7). Results of the PERMANOVA showed no evidence of an island by distance interaction $\left(F_{4,23}=0.80, P=0.97\right)$. Results of the MRPP suggest that different islands and distances from bridges are characterized by somewhat different vegetation assemblages with 
higher percent shrub cover at Muskingum and lower percent herbaceous cover and basal area at the $0 \mathrm{~m}$ transects (Table 1). Vegetation composition was significantly different at Muskingum Island in comparison to the other sites and at the $0 \mathrm{~m}$ transect in comparison to other distances (Table 3). The Sorensen community similarity index comparing vegetative composition between sites and distances further indicated different communities (Table 3).

Results from indicator species analysis suggest certain species were more likely to occur on particular sites and at particular distances from the bridge. Two species (Italian perennial rye grass and yellow wood sorrel (Oxalis stricta L.)) were indicative of Blennerhassett, 4 species (broadleaf dock (Rumex obtusifolius L.), common burdock (Arctium minus (Hill) Bernh.), jewelweed (Impatiens capensis Meerb.), and Kentucky bluegrass (Poa pratensis L.)) were indicative of Buckley, and 8 species (American sycamore, black elderberry (Sambucus canadensis L.), black walnut (Juglans nigra L.), box elder, ground ivy, nodding fescue (Festuca subverticillata (Pers.) Alexee), spicebush (Lindera benzoin L. Blume), and violet (Viola sp. L.)) and woody debris were indicative of Muskingum (Table 4). One species (Japanese millet) was indicative of $0 \mathrm{~m}$ transects (Table 4).

Soil

Six soil variables had a significant site by distance interaction (Table 5). Soluble sulfur and sodium had altered levels due to the $0 \mathrm{~m}$ transects at Blennerhassett and Buckley showing an overall bridge effect, while phosphorus, bray II phosphorus, and potassium had altered levels due to the $0 \mathrm{~m}$ transect at Blennerhassett, and zinc had altered levels due to the $0 \mathrm{~m}$ transect at Buckley showing site specific alterations (Appendix 8). Copper was lower at Blennerhassett and aluminum was higher at Muskingum (Table 5). Total exchange capacity, calcium, and manganese were all significantly higher at the $0 \mathrm{~m}$ transects but organic matter, estimated 
nitrogen released, and aluminum were significantly lower at the $0 \mathrm{~m}$ transects (Table 5). No other response variables showed difference among sites or distances (Table 5).

\section{DISCUSSION}

\section{Vegetation}

Our study indicates that vegetative communities directly under both bridges are highly altered and dominated by species tolerant of disturbance. This may result from disturbance from construction, compacted soil, altered soil chemistry, lack of direct sunlight and rainfall, destruction of seed bank, and poor site conditions (Mortensen et al. 2009). We found that vegetation did not provide complete coverage of all the area disturbed under the bridge and overall flora was depauperate. The vegetation that was present under the bridge was herbaceous and comprised mostly of vegetation from seed mixtures such as redtop, Japanese millet, Italian perennial rye grass, and Kentucky 31 fescue. These vegetation communities and types are consistent with roadside vegetation communities in West Virginia (Rentch et al. 2005a).

Species composition and percent shrub cover differed significantly by site primarily due to differences in Muskingum Island and was not attributed to the Blennerhassett Island Bridge affecting large amounts of the island. Muskingum Island is mostly bottomland hardwood forest cover type (Appendix 4) as opposed to Blennerhassett (Appendix 2) and Buckley (Appendix 3) islands which have large areas of old-field cover types. The difference between distances is attributed to the $0 \mathrm{~m}$ transects being different than the $100 \mathrm{~m}$ and $300 \mathrm{~m}$ transects and overall historical land use. The construction of the Blennerhassett Island Bridge has impacts on vegetation directly under the bridge, but does not impact vegetative communities at other sampling distances from the bridge. 
Anthropogenic habitats, such as roadsides, may alter the demographic behavior of species (Quintana-Ascencio et al. 2007, Weekley et al. 2008). Our study indicates that several species of exotic and invasive species (e.g., Canada thistle (Cirsium arvense (L.) Scop.), common burdock, Japanese knotweed, Japanese hop (Humulus japonicus Siebold \& Zucc.), lady's thumb (Polygonum persicaria L.), mile-a-minute weed) are promoted by the presence of the bridge. The area directly under and adjacent to the bridge is of similar condition to roadside environments which frequently provide vectors for the spread of invasive species (Forman and Alexander 1998, Rentch et al. 2005a, Christen and Matlock 2006, Mortensen et al. 2009). Many exotic species found in this study may be present due to the study area being in a floodplain; however, we believe that the poor site conditions under the bridge have created an environment favorable for a limited suite of exotic species.

The natural progression of plant succession following a disturbance has been well documented and is well understood (Oliver and Larson 1996). Ideally, this is the process that will occur under the Blennerhassett Island Bridge over time. However, many potential problems including compacted soils, altered soil chemistry, lack of direct sunlight, emissions from vehicles, particles coming from the bridge, and presence of invasive and exotic species may hinder this process. We hypothesize that the area under the Blennerhassett Island Bridge will not follow the natural series of plant succession and will be characterized by low coverage and vegetation dominated by herbaceous, disturbance tolerant, and exotic species as similarly shown under the Buckley Island Bridge.

Soil

Our study indicates that soil chemistry under both bridges is altered and that the presence of highway bridges causes high levels of certain elements and soil properties. Both bridges 
appear to impact the soil. Most of the impacts occur directly under the bridge and not at distant transects. Both bridges impact the soil due to materials leaching from the bridge, disturbances during construction, and altered levels of certain elements from fertilization. Another issue is disturbance to natural soil properties (structure, stability, erodibility, porosity, and permeability) as described by Johnston and Johnston (2004). Of the 19 variables measured, 6 had a significant interaction all caused by differences under bridges; 6 showed differences by distance all attributed to the $0 \mathrm{~m}$ transects; and 2 differed by sites attributed to islands with bridges.

We do not know the exact causes for the observed differences but we can make the following suppositions. Altered levels of phosphorus, bray II phosphorus, and potassium could be due to the fertilizer used during the reseeding of vegetation under the bridge (Bennett et al. 2001). Altered levels of sodium, calcium, and manganese are most likely due to the leaching of deicing agents placed on the bridges for snow removal (Wilcox 1986). Abnormal soluble sulfur levels could be due to emissions from vehicles using the bridge (Mooney et al. 1988). The altered levels of zinc under the bridge could be due to materials coming from the structure of the bridge or the highway surface of the bridge, while lower aluminum levels may be due to disturbance during construction. Copper levels were lower at Blennerhassett indicating that the bridge is potentially causing temporary low copper levels, but not over time, as copper levels were normal at Buckley Island. Total exchange capacity, organic matter, and estimated nitrogen released all differed under the bridge possibly due to compaction of soil and changes in the physical properties of the soil (Johnston and Johnston 2004).

The bridges may indirectly influence biological and chemical properties of the soil including: organic content, soil biota, chemical conditions, and soil microclimate (Kuss et al. 1990). Furthermore, many of these impacts may be compromising primary ecosystem function, 
hydrological cycles, nutrient movement and availability, and surface stability (Johnston and Johnston 2004). These changes in soil characteristics may be responsible for changes in plant growth, species diversity and composition, and may be creating an environment conducive to colonization by exotic species (Tyser et al. 1998, Forman and Alexander 1998, Jones et al. 2000, Rentch et al. 2005a). However, high levels of certain elements (e.g., nitrogen, potassium, phosphorus) may be beneficial to some native species as they provide nutrients into the soil and increase plant growth and uptake (Bennett et al. 2001).

We believe that the altered soil chemistry under the Blennerhassett Island Bridge will continue through the near future. This is due to the continuation of exhaust and emissions from vehicles as well as the application of deicing agents onto the bridge. We suggest that high levels of certain elements and altered properties of the soil will continue through time as shown at the Buckley Island Bridge. We also suggest that the present impacts and effects to the soil will continue to be confined to the area under the bridge and not affect distant areas.

\section{ACKNOWLEDGEMENTS}

This paper is dedicated to the late William N. Grafton who assisted with these vegetation surveys, showed his unprecedented knowledge of botany, and spent his lifetime dedicated to the study of plants and the education of young people. We thank the West Virginia Department of Transportation, Division of Highways for providing the funding for this project with a special thanks to Norse B. Angus for his overseeing of the project and willingness to assist at any time. A special thanks is extended to the U.S. Fish and Wildlife Service and the West Virginia Division of Natural Resources Parks and Recreation and Wildlife Resources sections for their cooperation throughout this project and field technicians Graham Nesselrodt and Craig Leibfreid 
who assisted with data collection. This is scientific article number xxxx of the West Virginia University Agriculture and Forestry Experimental Station. 


\section{LITERATURE CITED}

ANDERSON, M.J. 2001. A new method for non-parametric multivariate analysis of variance. Austral Ecology 26:32-46.

ANGOLD, P.G. 1997. The impact of a road upon adjacent heathland vegetation: effects on species composition. Journal of Applied Ecology 34:409-417.

BAKER, H.G. 1965.Characteristics and modes of origins of weeds. p. 141-172 In: BAKER, H.G. and G. L. STEBBINS (eds). The genetics of colonizing species. Academic Press, London.

BenNETT, E.M., S.R. CARPENTER, and N.F. CARACO. 2001. Human impact on erodable phosphorus eutrophication: a global perspective. BioScience 51:227-234.

Bleich, V.C., J.G. Kie, E.R. Loft, T.R. Stephenson, M.W. OehleR, and A.L. MedinA. 2005. Managing rangelands for wildlife. p. 873-897 In: BRAUN, C.E (ed). Techniques for wildlife investigations and management. Sixth edition. The Wildlife Society, Bethesda, Maryland.

Brothers, T.S. and A. SPINGAR. 1992. Forest fragmentation and alien plant invasion of central Indiana old-growth forest. Conservation Biology 6:91-100.

Christen, D. and G. MATLOCK. 2006. The role of roadsides in plant invasions: a demographic approach. Conservation Biology 20:285-391.

CONOVER, W.J. and R.L. IMAN. 1981. Rank transformations as a bridge between parametric and non-parametric statistics. American Statistician 35:124-129.

CONOVER, W.J. 1999. Practical nonparametric statistics. John Wiley and Sons, New York, New York.

DAubenmiRe, R. 1968. Plant communities. Harper and Row, New York, New York.

DAVISON, A.W. 1971. The effects of de-icing salt on roadside verges. I. Soil and plant analysis. Journal of Applied Ecology 8:555-561.

DiAmOND, A.R. and R.S. BoYD. 2004. Distribution, habitat characteristics, and population trends of the rare southeastern endemic Rudbeckia auriculata (Perdue) Kral (Asteraceae).

Castanea 69:249-264.

DodD, N.L., J.W. GAGnON, A.L. MAnZO, and R.E. SchweInsbuRG. 2007. Video surveillance to access highway underpass use by elk in Arizona. Journal of Wildlife Management 71:637645.

DuFrene, M. and P. LEGENDRE. 1997. Species assemblages and indicator species: the need for a flexible asymmetrical approach. Ecological Monographs 67:345-366.

FERRIS, R. and G. TAYLOR. 1995. Contrasting effects of elevated carbon dioxide and water deficit on two native herbs. New Phytologist 131:491-501. 
FluCKIGER, W., J.J. OERTLI, and H. FluCKIGER-KELlER. 1978. The effect of wind gusts on leaf growth and foliar water relations of aspen. Oecologia 34:101-106.

FORMAN, R.T. and L.E. ALEXANDER. 1998. Roads and their major ecological effects. Annual Review of Ecology and Systematics 29:207-231.

FORMAN, R.T. 2000. Estimate of the area affected ecologically by the road system in the United States. Conservation Biology 14:31-35.

Forman, R.T., D. Sperling, J.A. Bissonette, A.P. Clevenger, C.D. Cutshall, V.H. Dale, L. Fahrig, R. France, C.R. Goldman, K. Heanue, J.A. Jones, F.J. Swanson, T. TURRENTINE, and T.C. WINTER. 2003. Road ecology: science and solutions. Island Press, Washington, D.C.

GELBARD, J.L. and J. BELnAP. 2003. Roads as conduits for exotic plant invasions in a semiarid landscape. Conservation Biology 17:420-432.

GoBRIDGES. 2009. Rebuilding America's Infrastructure (http://www.rebuildingamericasinfrastructure.com/tag-bridges-1.html?id=323, 13 Dec 2009).

HeDRICK, L B., S.A. WELSH, and J.T. ANDERSON. 2009. Influences of high-flow events on a stream channel altered by construction of a highway bridge: a case study. Northeastern Naturalist 16:375-394.

Hunt, R., D.W. Hand, M.A. Hannah, and A.M. NEAL. 1991. Response to carbon dioxide enrichment in 27 herbaceous species. Functional Ecology 5:410-421.

IDCIDE West ViRginia City DATA. 2010. West Virginia City Data (http://www.idcide.com/citydata/wv/, 16 July 2010).

IDCIDE WEST VIRGINIA WEATHER 2010. West Virginia Weather database (http://www.idcide.com/weather/wv/, 16 July 2010).

JOHNSTON, F.M. and S.W. JOHNSTON. 2004. Impacts of road disturbance on soil properties and on exotic plant occurrence in subalpine areas of the Austrian Alps. Arctic, Antarctic, and Alpine Research 36:201-207.

JoneS, J.A., F.J. SwANSON, B.C. WEMPLE, and K.U. SNYDER. 2000. Effects of roads on hydrology, geomorphology, and disturbance patches in stream networks. Conservation Biology 14:76-85.

KuSS, F.R., A.R. GRAEFE, and J.J. VASKE. 1990. Visitor impact management: a review of research. National Parks and Conservation Service, Washington, D.C.

Laurian, C., C. Dussault, J.P. Ouellet, R. Courtois, M. Poulin, and L. Breton. 2008. Behavior of moose relative to a road network. Journal of Wildlife Management 72:15501557. 
Lesbarreres, D., C.R. Primmer, T. Lode, and J. Merila. 2006. The effects of 20 years of highway presence on the genetic structure of Rana dalmatina populations. Ecoscience 13:531-538.

LiEM, A.S.N., A. HENDRIKS, H. KRAAL, and M. LoENEN. 1985. Effects of de-icing salt on roadside grasses and herbs. Plant and Soil 84:299-310.

MCCune, B. and M.J. MefFord. 1999. PC-ORD for windows: multivariate analysis of ecological daa, Version 4.0 MjM Software, Glenedon Beach, Oregon.

McCune, B., J.B. GraCE, and D.L. Urban. 2002. Analysis of ecological communities. MjM Software Design, Glenedon Beach, Oregon.

MoOney, H.A., M. KupPers, G.W. Koch, J. Gorman, and C.C. ChU. 1988. Compensating effects to growth of carbon partitioning changes in response to sulfur dioxide induced photosynthetic reduction in radish. Oecologia 75:502-506.

Mortensen, D.A., E.S.J. RAuschert, A.N. NoRD, and B.P. JonES. 2009. Forest roads facilitate the spread of invasive plants. Invasive Plant Science and Management 2:191-199.

Oliver, C.D. and B.C. LARSON. 1996. Forest stand dynamics. John Wiley and Sons Inc., New York, New York.

Panno, S.V., V.A. Nuzzo, K. CARTwright, B.R. Hensel, and I.G. KrapaC. 1999. Impact of urban development on the chemical composition of ground water in a fen-wetland complex. Wetlands 19:236-245.

PARENDES, L.A. and J.A. JonES. 2000. Role of light availability and dispersal in exotic plant invasion along roads and streams in the H.J. Andrews Experimental Forest, Oregon. Conservation Biology 14:64-75.

Poplar-Jeffers, I.O., J.T. Petty, J.T. Anderson, S.J. Kite, M.P. Strager, R.H. Fortney. 2009. Culvert replacement and stream habitat restoration: implications from brook trout management in an Appalachian watershed, USA. Restoration Ecology 17:404-413.

Pugh IV, A.L., S.A. Norton, M. Schauffler, G.L. Jacobson Jr., J.S. KahL, W.F. BRUTSAERT, and C.F. MASON. 1996. Interactions between peat and salt contaminated runoff in Alton Bog, Maine, USA. Journal of Hydrology 182:83-104.

Quintana-Ascencio, P.F., C.W. Weekley, and E.S. Menges. 2007. Comparative demography of a rare species in Florida scrub and road habitats. Biological Conservation 137:263-270.

Rentch, J.S., R.H. Fortney, S.L. Stephenson, H.S. Adams, W.N. Grafton, and J.T. ANDERSON. 2005a. Vegetation-site relationships of roadside plant communities in West Virginia, USA. Journal of Applied Ecology 42:129-138.

Rentch, J.S., R.H. Fortney, S.L. Stephenson, H.S. AdAms, W.N. Grafton, R.B. Coxe, and H.H. MILLS. 2005b. Vegetation patterns within the lower Bluestone River Gorge in southern West Virginia. Castanea 70:184-203. 
Richburg, J.A., W.A. PATTERson, and F. LOWENSTEIN. 2001. Effects of road salt and Phragmites australis invasion on the vegetation of a western Massachusetts calcareous lake-basin fen. Wetlands 21:247-255.

RUTTER, A.J. and N.E. ThOMPSON. 1986. The salinity of motorway soils. III. Simulation of the effects of salt usage and rainfall on sodium and chloride concentrations in the soil of central reserves. Journal of Applied Ecology 23:271-289.

SPELLERBERG, I.F. 1998. Ecological effects or roads and traffic: a literature review. Global Ecology and Biogeography 7:317-333.

SIMINI, M. and I.A. LEONE. 1986. Studies on the effects of de-icing salts on roadside trees. Arboricultural Journal 10:221-231.

SMITH, R.L. 1996. Ecology and field biology. Harper Collins, New York, New York.

Stanton Fleming, M.M., J.M. StuCKy, and C. BrowniE. 2007. Effects and importance of soil wetness and neighbor vegetation on Solidago verna M. A. Curtis ex Torrey \& A. Gray (spring-flowering goldenrod) [Asteraceae] transplant survivorship and growth. Castanea 72:205-213.

Strausbaugh, P.D. and E. Core. 1977. Flora of West Virginia. Seneca Books Inc., Grantsville, West Virginia.

StePhenson, S.L., H.S. AdAMS, and C.D. HuEBnER. 2007. Upland forest vegetation of the Ozark Mountains in northwestern Arkansas. Rhodora 109:197-221.

Thompson, J.R., P.W. Mueller, W. Fluckiger, and A.J. RutTER. 1984. The effect of dust on photosynthesis and its significance for roadside plants. Environmental Pollution 34:171190.

Tolin, W.A. and P.A. SchetTig. 1983. A physical and biological survey of the Ohio River islands (Huntington District). U.S. Fish and Wildlife Service. Elkins, West Virginia.

Townsend, C.R., J.L. HARPER, and M. BEGON. 2000. Essentials of ecology. Blackwell Science, Malden, Massachusetts.

Tyser, R.W., J.M. AsebrooK, R.W. PotTER, and L.L. KURTH. 1998. Roadside revegetation in Glacier National Park: effects of herbicide and seeding treatments. Restoration Ecology 6:197-206.

Ullman, I., P. BANNISTER, and J.B. WiLSON. 1998. Lateral differentiation and the role of exotic species in roadside vegetation in southern New Zealand. Flora 193:149-164.

United States Department of Agriculture. 1970. Wood and Wirt Counties, West Virginia. United States Government Printing Office, Washington, D.C. 
United States Fish AND WiLdLIFE SERVICE. 2002. Ohio River Islands National Wildlife Refuge Comprehensive Conservation Plan. United States Fish and Wildlife Service, Parkersburg, West Virginia.

WARD, R.L., J.T. ANDERSON, and J.T. PETTY. 2008. Effects of road crossings on stream and streamside salamanders. Journal of Wildlife Management 72:760-771.

Weekley, C.W., J. TuCKer, S. VAlligny, and E.S. Menges. 2008. Germination ecology of Liatris ohlingerae (S.F. Blake) B.L. Rob. (Asteraceae), an endangered herb endemic to Florida scrub. Castanea 73:235-250.

WILCOX, D.A. 1986. The effects of de-icing salts on water chemistry in Pinhook Bog, Indiana. Water Resources Bulletin 22:57-65.

WILCOX, D.A. and R.E. ANDRUS. 1987. The role of Sphagnum fimbriatum in secondary succession in a road salt impacted bog. Canadian Journal of Botany 65:2270-2275.

ZAdniK, A.K., J.T. Anderson, P.B. Wood, and K. Bledsoe. 2009. Wildlife use of back channels associated with islands on the Ohio River. Wetlands 29:543-551. 
Table 1: Summary statistics for vegetation metrics with means and standard errors (SE) analyzed by sites (Blennerhassett, Buckley, and Muskingum islands, West Virginia, USA), distances from bridge $(0,100$, and $300 \mathrm{~m})$, and interaction during the July 2008 sampling period with same letters indicating no significant difference for an individual vegetation stratum (bolded vegetation stratum are significant at $\alpha=0.05)$.

\begin{tabular}{|c|c|c|c|c|c|c|c|c|}
\hline \multirow{2}{*}{ Metric } & \multicolumn{2}{|c|}{ Blennerhassett } & \multicolumn{2}{|c|}{ Buckley } & \multicolumn{2}{|c|}{ Muskingum } & \multirow[b]{2}{*}{$F_{2,23}$} & \multirow[b]{2}{*}{$P$} \\
\hline & $\bar{x}$ & SE & $\bar{x}$ & SE & $\bar{x}$ & SE & & \\
\hline Percent Herbaceous Cover (All Species) & $110.80 a$ & 6.56 & $129.47 a$ & 39.69 & $127.71 a$ & 8.03 & 2.42 & 0.112 \\
\hline Percent Shrub Cover (All Species) & $2.09 b$ & 1.39 & $1.72 b$ & 3.21 & $12.64 a$ & 2.82 & 7.87 & 0.002 \\
\hline Basal Area (All Species) & $32.92 a$ & 15.22 & $58.02 a$ & 89.39 & $34.63 a$ & 4.43 & 2.74 & 0.085 \\
\hline Species Richness (All Species) & $18.00 \mathrm{a}$ & 1.91 & $16.67 a$ & 6.65 & $23.00 a$ & 1.94 & 1.89 & 0.174 \\
\hline Shannon Diversity Index (All Species) & $2.24 a$ & 0.11 & $2.01 \mathrm{a}$ & 0.33 & $2.46 a$ & 0.12 & 2.26 & 0.127 \\
\hline Percent Herbaceous Cover (Natives Only) & $35.63 a$ & 6.70 & $56.08 a$ & 14.00 & $46.75 a$ & 7.43 & 1.82 & 0.185 \\
\hline Percent Shrub Cover (Natives Only) & $2.06 b$ & 1.37 & $0.64 b$ & 0.46 & $11.79 a$ & 2.81 & 10.06 & 0.001 \\
\hline Species Richness (Natives Only) & $8.56 a$ & 1.23 & $8.33 a$ & 1.60 & $13.00 \mathrm{a}$ & 1.48 & 2.88 & 0.077 \\
\hline Shannon Diversity Index (Natives Only) & $1.24 b$ & 0.04 & $1.16 b$ & 0.16 & $1.92 \mathrm{a}$ & 0.09 & 8.62 & 0.002 \\
\hline
\end{tabular}


Table 1 Extended

\begin{tabular}{|c|c|c|c|c|c|c|c|c|c|}
\hline \multicolumn{2}{|c|}{$0 \mathrm{~m}$} & \multicolumn{2}{|c|}{$100 \mathrm{~m}$} & \multicolumn{2}{|c|}{$300 \mathrm{~m}$} & \multirow[b]{2}{*}{$F_{2,23}$} & \multirow[b]{2}{*}{$P$} & \multicolumn{2}{|c|}{ Interaction } \\
\hline $\bar{x}$ & SE & $\bar{x}$ & SE & $\bar{x}$ & SE & & & $F_{4,23}$ & $P$ \\
\hline $91.75 b$ & 10.64 & $127.55 a$ & 9.07 & $123.56 a$ & 11.43 & 4.49 & 0.023 & 0.82 & 0.525 \\
\hline $0.00 \mathrm{a}$ & 0.00 & $2.30 \mathrm{a}$ & 1.60 & $2.89 a$ & 1.73 & 1.35 & 0.280 & 0.96 & 0.450 \\
\hline $0.01 b$ & 0.01 & $49.23 a$ & 24.58 & $61.84 a$ & 27.43 & 7.23 & 0.004 & 0.79 & 0.543 \\
\hline $12.5 a$ & 2.11 & $21.50 \mathrm{~b}$ & 1.79 & $16.44 a b$ & 2.71 & 3.65 & 0.042 & 0.52 & 0.725 \\
\hline $1.94 a$ & 0.12 & $2.38 a$ & 0.07 & $2.06 a$ & 0.18 & 3.31 & 0.054 & 0.92 & 0.467 \\
\hline $18.50 \mathrm{~b}$ & 6.24 & $46.48 a$ & 10.88 & $61.25 a$ & 11.91 & 4.20 & 0.028 & 0.80 & 0.538 \\
\hline $0.00 \mathrm{a}$ & 0.00 & $2.08 a$ & 1.61 & $2.22 \mathrm{a}$ & 1.78 & 0.23 & 0.798 & 0.56 & 0.693 \\
\hline $5.33 a$ & 1.12 & 11.10a & 1.64 & 7.67 & 1.35 & 3.26 & 0.057 & 0.84 & 0.514 \\
\hline $0.76 b$ & 0.10 & $1.42 a$ & 0.09 & $1.28 \mathrm{a}$ & 0.18 & 5.39 & 0.012 & 1.07 & 0.396 \\
\hline
\end{tabular}


Table 2: Summary statistics for all species with means (\% cover for herbs and shrubs and basal area [ $\mathrm{m}^{2} / \mathrm{ha}$ ] for trees) and standard errors (SE) that occurred 3 or more times during vegetation surveys and were used in the PERMANOVA and multi-response permutations procedure composition matrix (all 64 species for the site analysis and 53 species (bolded) for the distance analysis) for Blennerhassett, Buckley, and Muskingum islands, West Virginia, USA during the July 2008 field season.

\begin{tabular}{|c|c|c|c|c|c|c|c|}
\hline \multirow{2}{*}{ Common Name } & \multirow{2}{*}{ Scientific Name } & \multicolumn{2}{|c|}{ Blennerhassett } & \multicolumn{2}{|c|}{ Buckley } & \multicolumn{2}{|c|}{ Muskingum } \\
\hline & & $\bar{x}$ & SE & $\bar{x}$ & SE & $\bar{x}$ & SE \\
\hline American Elm & Ulmus americana $\mathrm{L}$. & 0.55 & 0.36 & 0.00 & 0.00 & 0.05 & 0.05 \\
\hline American Germander & Teuchrium canadense L. & 0.00 & 0.00 & 0.19 & 0.19 & 0.36 & 0.28 \\
\hline American Sycamore & Platanus occidentalis L. & 0.00 & 0.00 & 0.02 & 0.02 & 1.85 & 0.62 \\
\hline Aster & Aster sp. L. & 0.25 & 0.22 & 0.00 & 0.00 & 0.04 & 0.04 \\
\hline Beggar-Ticks & Bidens sp. L. & 0.20 & 0.13 & 0.00 & 0.00 & 0.00 & 0.00 \\
\hline Bird's Foot Trefoil & Lotus corniculatus L. & 2.66 & 1.60 & 0.00 & 0.00 & 0.00 & 0.00 \\
\hline Black Elderberry & Sambucus canadensis L. & 0.00 & 0.00 & 0.00 & 0.00 & 1.36 & 1.05 \\
\hline Black Locust & Robinia pseudoacacia L. & 3.89 & 3.47 & 0.00 & 0.00 & 0.00 & 0.00 \\
\hline Black Walnut & Juglans nigra $\mathrm{L}$. & 0.11 & 0.08 & 0.35 & 0.31 & 1.26 & 0.70 \\
\hline Box Elder & Acer negundo L. & 9.04 & 5.61 & 5.36 & 5.01 & 2.25 & 0.90 \\
\hline Broadleaf Dock & Rumex obtusifolius L. & 0.03 & 0.03 & 0.33 & 0.21 & 0.00 & 0.00 \\
\hline Canada Thistle & Cirsium arvense (L.) Scop. & 5.98 & 2.75 & 1.25 & 0.73 & 0.00 & 0.00 \\
\hline Canada Wild Rye & Elymus canadensis $\mathrm{L}$. & 1.84 & 1.47 & 0.03 & 0.03 & 4.11 & 1.80 \\
\hline Clearweed & Pilea pumila (L.) & 0.86 & 0.48 & 0.14 & 0.11 & 0.79 & 0.47 \\
\hline Common Burdock & Arctium minus (Hill) Bernh. & 0.00 & 0.00 & 2.78 & 2.00 & 0.00 & 0.00 \\
\hline Common Hackberry & Celtis occidentalis L. & 0.51 & 0.40 & 0.04 & 0.03 & 2.23 & 2.21 \\
\hline Common Mugwort & Artemisia vulgaris $\mathrm{L}$. & 0.28 & 0.15 & 0.06 & 0.06 & 0.00 & 0.00 \\
\hline Deertongue Grass & Dichanthelium clandestinum (L.) Gould & 0.23 & 0.20 & 0.00 & 0.00 & 0.04 & 0.04 \\
\hline
\end{tabular}


Table 2 Continued

\begin{tabular}{|c|c|c|c|c|c|c|c|}
\hline False Nettle & Boehmeria cylindrica (L.) Sw. & 1.88 & 1.43 & 0.58 & 0.58 & 0.25 & 0.21 \\
\hline Garlic Mustard & Alliaria petiolata (M. Bieb.) Cavara \& Grande & 2.67 & 0.90 & 3.69 & 1.60 & 3.43 & 1.24 \\
\hline Ground-Ivy & Glechoma hederacea $\mathrm{L}$. & 5.84 & 2.42 & 14.64 & 7.51 & 40.57 & 11.70 \\
\hline Hedge Bindweed & Calystegia sepium (L.) R. Br. & 0.11 & 0.11 & 0.06 & 0.04 & 0.00 & 0.00 \\
\hline \multicolumn{2}{|c|}{ Italian Perennial Rye Grass Lolium perenne L. } & 2.19 & 1.01 & 0.00 & 0.00 & 0.00 & 0.00 \\
\hline Japanese Honeysuckle & Lonicera japonica (Thonb.) & 1.53 & 1.04 & 11.50 & 7.22 & 0.36 & 0.24 \\
\hline Japanese Hop & Humulus japonicus Siebold \& Zucc. & 1.41 & 0.71 & 0.89 & 0.69 & 0.00 & 0.00 \\
\hline Japanese Knotweed & Polygonum cuspidatum Houtt. (Ronse Decr.) & 1.55 & 1.02 & 4.36 & 4.33 & 2.96 & 2.96 \\
\hline Japanese Millet & Echinochloa crus-galli var. frumentacea P. Beauv. & 3.08 & 2.11 & 0.00 & 0.00 & 0.00 & 0.00 \\
\hline Japanese Stilt Grass & Microstegium vimineum (Trin.) A. Camus & 1.30 & 0.63 & 0.28 & 0.19 & 1.71 & 1.67 \\
\hline Jewelweed & Impatiens capensis L. & 0.00 & 0.00 & 0.72 & 0.45 & 0.00 & 0.00 \\
\hline Johnson Grass & Sorghum halepense Pers. & 1.27 & 1.01 & 0.00 & 0.00 & 0.00 & 0.00 \\
\hline Kentucky 31 Fescue & Lolium arundinaceum $\mathrm{L}$. & 5.36 & 3.21 & 3.19 & 3.16 & 0.00 & 0.00 \\
\hline Kentucky Bluegrass & Poa pratensis $\mathrm{L}$. & 0.45 & 0.31 & 15.92 & 10.32 & 3.04 & 2.09 \\
\hline Lady's Thumb & Polygonum persicaria L. & 1.34 & 0.57 & 2.72 & 1.39 & 3.00 & 1.54 \\
\hline Late Goldenrod & Solidago gigantean Aiton & 0.02 & 0.02 & 0.08 & 0.06 & 0.00 & 0.00 \\
\hline Mile-A-Minute Weed & Polygonum perfoliata (L.) H. Gross & 1.34 & 0.57 & 2.72 & 1.39 & 3.00 & 1.54 \\
\hline Multiflora Rose & Rosa multiflora Thunb. & 0.02 & 0.02 & 0.61 & 0.61 & 0.89 & 0.53 \\
\hline Nodding Fescue & Festuca subverticillata (Pers.) & 0.00 & 0.00 & 0.00 & 0.00 & 3.25 & 2.24 \\
\hline Northern Red Oak & Quercus rubra L. & 1.12 & 0.74 & 0.00 & 0.00 & 0.00 & 0.00 \\
\hline Orchard Grass & Dactylis glomerata L. & 0.64 & 0.43 & 0.00 & 0.00 & 0.21 & 0.21 \\
\hline Pawpaw & Asimina triloba Adans. & 0.06 & 0.04 & 7.18 & 7.06 & 0.96 & 0.42 \\
\hline Poison Ivy & Toxicodendron radicans (L.) Kuntze & 0.27 & 0.23 & 3.17 & 2.05 & 1.18 & 0.57 \\
\hline
\end{tabular}


Table 2 Continued

\begin{tabular}{|c|c|c|c|c|c|c|c|}
\hline Red Maple & Acer rubrum $\mathrm{L}$. & 0.04 & 0.03 & 2.36 & 2.36 & 0.00 & 0.00 \\
\hline Redtop & Agrostis alba L. & 1.19 & 0.75 & 0.03 & 0.03 & 0.00 & 0.00 \\
\hline Reed Canary Grass & Phalaris arundinacea $\mathrm{L}$. & 10.88 & 6.07 & 7.83 & 3.49 & 1.79 & 1.25 \\
\hline Sericea & Lespedeza cuneata Lindl. & 0.86 & 0.50 & 0.00 & 0.00 & 0.00 & 0.00 \\
\hline Silver Maple & Acer saccharinum L. & 11.16 & 5.97 & 36.99 & 22.76 & 25.59 & 6.43 \\
\hline Spicebush & Lindera benzoin L. & 1.28 & 1.02 & 0.00 & 0.00 & 7.96 & 2.69 \\
\hline Sugar Maple & Acer saccharum Marshall & 0.87 & 0.58 & 0.00 & 0.00 & 0.00 & 0.00 \\
\hline Summer Grape & Vitis aestivalis Michx. & 0.30 & 0.26 & 0.09 & 0.09 & 0.19 & 0.05 \\
\hline Tall Coneflower & Rudbeckia laciniata L. & 0.00 & 0.00 & 0.83 & 0.83 & 0.32 & 0.21 \\
\hline Touch-Me-Not & Impatiens sp. L. & 0.23 & 0.15 & 0.06 & 0.06 & 0.93 & 0.89 \\
\hline Tree of Heaven & Ailanthus altissima (Mill.) Swingle & 0.17 & 0.17 & 0.01 & 0.01 & 0.10 & 0.07 \\
\hline Violet & Viola sp. L. & 0.33 & 0.20 & 0.08 & 0.06 & 4.07 & 1.17 \\
\hline Virginia Creeper & Parthenocissus quinquefolia (L.) Planch. & 0.25 & 0.15 & 0.81 & 0.55 & 0.86 & 0.33 \\
\hline Virginia Knotweed & Polygonum virginianum (L.) Gaertn. & 0.09 & 0.09 & 0.03 & 0.03 & 0.93 & 0.85 \\
\hline White Clover & Trifolium repens $\mathrm{L}$. & 0.38 & 0.25 & 0.00 & 0.00 & 0.00 & 0.00 \\
\hline White Grass & Leersia virginica Willd. & 0.91 & 0.58 & 0.11 & 0.07 & 2.64 & 1.44 \\
\hline White Snakeroot & Ageratina altissima (L.) King \& H.E. Robins. & 0.73 & 0.41 & 1.33 & 1.21 & 1.29 & 0.81 \\
\hline White Wood Aster & Eurybia divaricata (L.) G.L. Nesom & 0.97 & 0.74 & 0.00 & 0.00 & 0.00 & 0.00 \\
\hline Wild Stinging Nettle & Urtica dioica $\mathrm{L}$. & 4.91 & 2.66 & 1.19 & 0.88 & 0.04 & 0.04 \\
\hline Wing-stem & Verbesina alternifolia (L.) Britt. & 6.06 & 2.16 & 16.31 & 5.16 & 15.57 & 4.32 \\
\hline Winter Grape & Vitis vulpina $\mathrm{L}$. & 0.11 & 0.11 & 0.47 & 0.41 & 0.00 & 0.00 \\
\hline Yellow Buckeye & Aesculus flava Aiton & 0.30 & 0.22 & 0.03 & 0.02 & 0.10 & 0.09 \\
\hline Yellow Wood Sorrel & Oxalis stricta $\mathrm{L}$. & 0.31 & 0.13 & 0.00 & 0.00 & 0.00 & 0.00 \\
\hline
\end{tabular}


Table 3: Summary statistics for multi-response permutation procedures for herbaceous, shrub, and tree strata for sites (Blennerhassett, Buckley, and Muskingum islands, West Virginia, USA) and distances from bridge (0, 100, and $300 \mathrm{~m})$ during the July 2008 field season. Strata were grouped by site and distance. The $T$ statistic is the weighted mean within-group distance, the $A$ statistic is the chance-corrected within group agreement, and $P$ is the p-value $(\alpha=0.05)$.

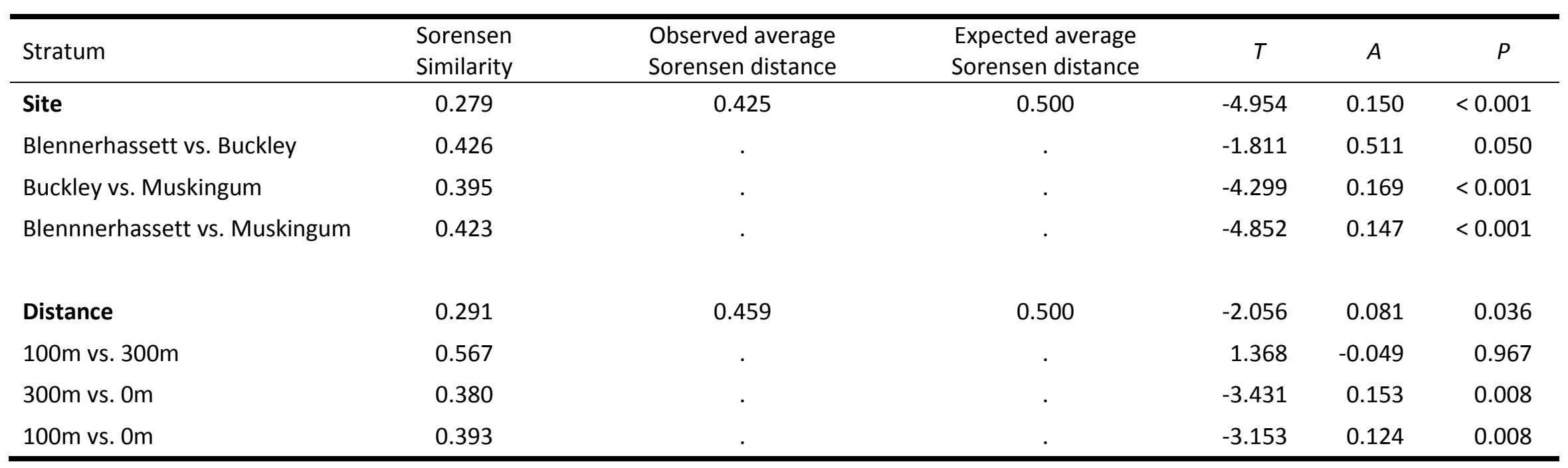


Table 4: Species indicator values (IV) for site (Blennerhassett, Buckley, and Muskingum islands, West Virginia, USA) and distance from bridge $(0,100$, and $300 \mathrm{~m})$. $P$-values $(P)$ based on the proportion of randomized trials with expected $I V>$ observed $I V$. Only species whose observed $I V$ exceeds $I v$ exp at $P$-values $<0.05$ are shown; 4,999 permutations were used in a Monte Carlo test. $I V=100$ $\times$ (relative abundance $\times$ relative frequency).

\begin{tabular}{|c|c|c|c|c|c|c|}
\hline Common Name & Scientific Name & Site or Distance & $I \mathrm{~V}_{\max }$ & $\bar{x}$ & SD & $P$ \\
\hline American Sycamore & Platanus occidentalis L. & Muskingum & 70.7 & 17.6 & 8.05 & 0.0002 \\
\hline Black Elderberry & Sambucus canadensis L. & Muskingum & 42.9 & 13.8 & 6.96 & 0.0086 \\
\hline Black Walnut & Juglans nigra L. & Muskingum & 41.7 & 20.6 & 8.80 & 0.0290 \\
\hline Box Elder & Acer negundo L. & Muskingum & 57.1 & 14.2 & 7.55 & 0.0012 \\
\hline Broadleaf Dock & Rumex obtusifolius L. & Buckley & 30.5 & 14.5 & 7.35 & 0.0356 \\
\hline Common Burdock & Arctium minus (Hill) Bernh. & Buckley & 33.3 & 13.4 & 6.85 & 0.0228 \\
\hline Ground Ivy & Glechoma hederacea $\mathrm{L}$. & Muskingum & 57.0 & 34.2 & 8.50 & 0.0194 \\
\hline Italian Perennial Rye Grass & Lolium perenne L. & Blennerhassett & 37.5 & 17.8 & 8.29 & 0.0330 \\
\hline Japanese Millet & $\begin{array}{l}\text { Echinochloa crus-galli var } \\
\text { frumentacea P. Beauv. }\end{array}$ & $0 \mathrm{~m}$ & 50.0 & 16.1 & 8.60 & 0.0092 \\
\hline Jewelweed & Impatiens capensis Meerb. & Buckley & 33.3 & 12.9 & 6.83 & 0.0224 \\
\hline Kentucky Bluegrass & Poa pratensis L. & Buckley & 54.7 & 28.2 & 10.63 & 0.0162 \\
\hline Nodding Fescue & Festuca subverticillata (Pers.) & Muskingum & 57.1 & 15.8 & 7.76 & 0.0016 \\
\hline Spicebush & Lindera benzoin L. Blume & Muskingum & 73.8 & 21.8 & 8.82 & 0.0004 \\
\hline Violet & Viola sp. L. & Muskingum & 77.8 & 28.6 & 9.60 & 0.0006 \\
\hline Woody Debris & - & Muskingum & 55.1 & 35.0 & 6.79 & 0.0078 \\
\hline Yellow Wood Sorrel & Oxalis stricta $\mathrm{L}$. & Blennerhassett & 50.0 & 20.9 & 8.88 & 0.0074 \\
\hline
\end{tabular}


Table 5: Summary statistics for soil variables with means and standard errors (SE) analyzed by sites (Blennerhassett, Buckley, and Muskingum islands, West Virginia, USA), distances from bridge $(0,100$, and $300 \mathrm{~m})$, and interaction during the July 2008 sampling period with same letters indicating no significant difference for an individual soil variable (bolded soil variables are significant at $\alpha=$ $0.05)$.

\begin{tabular}{|c|c|c|c|c|c|c|c|c|}
\hline \multirow{2}{*}{ Soil Variable } & \multicolumn{2}{|c|}{ Blennerhassett } & \multicolumn{2}{|c|}{ Buckley } & \multicolumn{2}{|c|}{ Muskingum } & \multirow[b]{2}{*}{$F_{2,26}$} & \multirow[b]{2}{*}{$P$} \\
\hline & $\bar{x}$ & SE & $\bar{x}$ & SE & $\bar{x}$ & SE & & \\
\hline Total Exchange Capacity (cmolc/kg) & $15.97 a$ & 1.16 & $15.73 a$ & 1.80 & $13.72 \mathrm{a}$ & 1.12 & 1.18 & 0.323 \\
\hline $\mathrm{pH}$ & $6.40 a$ & 0.21 & $6.63 a$ & 0.19 & $6.09 a$ & 0.37 & 1.85 & 0.178 \\
\hline Organic Matter (\%) & $3.61 a$ & 0.33 & $3.82 a$ & 0.30 & 3.93a & 0.39 & 0.88 & 0.427 \\
\hline Estimated Nitrogen Released (kg/ha) & $92.75 a$ & 4.51 & $96.97 a$ & 3.65 & $99.36 a$ & 3.59 & 2.42 & 0.109 \\
\hline Soluble Sulfur (ppm) & $31.13 a$ & 5.73 & $41.42 \mathrm{a}$ & 14.73 & $31.00 \mathrm{a}$ & 1.48 & 0.14 & 0.873 \\
\hline Phosphorus (ppm) & $38.94 a$ & 11.85 & 23.17b & 2.84 & $17.00 \mathrm{~b}$ & 2.69 & 6.97 & 0.004 \\
\hline Bray II Phosphorus (ppm) & $95.50 a$ & 21.75 & $77.25 a$ & 13.92 & $47.00 \mathrm{~b}$ & 2.18 & 16.54 & $<0.001$ \\
\hline Calcium (ppm) & $2,017.94 a$ & 164.92 & $1,935.67 a$ & 168.74 & $1,633.29 a$ & 281.68 & 2.08 & 0.146 \\
\hline Magnesium (ppm) & $265.06 a$ & 22.43 & $220.75 a$ & 14.38 & $228.86 a$ & 39.27 & 2.35 & 0.116 \\
\hline Potassium (ppm) & $145.31 a$ & 16.83 & $133.00 \mathrm{a}$ & 10.27 & $105.86 \mathrm{~b}$ & 18.85 & 5.69 & 0.009 \\
\hline Sodium (ppm) & $53.69 b$ & 9.32 & $497.92 a$ & 266.48 & $49.14 b$ & 12.63 & 25.64 & $<0.001$ \\
\hline Boron (ppm) & $0.66 a$ & 0.04 & $0.67 a$ & 0.04 & $0.56 a$ & 0.05 & 1.87 & 0.174 \\
\hline Iron (ppm) & $312.19 a$ & 15.12 & $311.50 a$ & 14.06 & $348.71 a$ & 7.68 & 2.24 & 0.138 \\
\hline Manganese (ppm) & $82.38 a$ & 8.16 & $76.83 a$ & 8.05 & $60.86 a$ & 4.32 & 3.34 & 0.051 \\
\hline Copper (ppm) & $6.11 b$ & 0.54 & $8.21 a$ & 0.51 & $9.06 a$ & 0.66 & 8.86 & 0.001 \\
\hline Zinc (ppm) & $15.39 \mathrm{~b}$ & 2.67 & $27.17 a$ & 4.09 & $17.87 b$ & 3.23 & 10.11 & 0.001 \\
\hline Aluminum (ppm) & $687.47 b$ & 19.57 & $672.50 \mathrm{~b}$ & 44.36 & $824.14 a$ & 17.42 & 4.88 & 0.016 \\
\hline Nitrate (ppm) & 69.40 & 18.80 & 47.72 & 6.99 & 38.80 & 2.77 & 1.29 & 0.348 \\
\hline Ammonium (ppm) & 1.63 & 0.41 & 1.55 & 0.15 & 2.00 & 0.64 & 0.29 & 0.749 \\
\hline
\end{tabular}


Table 5 Extended

\begin{tabular}{|c|c|c|c|c|c|c|c|c|c|}
\hline \multicolumn{2}{|c|}{$0 \mathrm{~m}$} & \multicolumn{2}{|c|}{$100 \mathrm{~m}$} & \multicolumn{2}{|c|}{$300 \mathrm{~m}$} & \multirow[b]{2}{*}{$F_{2,26}$} & \multirow[b]{2}{*}{$P$} & \multicolumn{2}{|c|}{ Interaction } \\
\hline $\bar{x}$ & SE & $\bar{x}$ & SE & $\bar{x}$ & SE & & & $F_{4,26}$ & $P$ \\
\hline $21.85 a$ & 2.74 & $13.66 \mathrm{~b}$ & 0.59 & $14.92 \mathrm{~b}$ & 1.47 & 8.33 & 0.002 & 1.58 & 0.208 \\
\hline $7.15 a$ & 0.23 & $6.38 a$ & 0.19 & $6.25 a$ & 0.26 & 2.47 & 0.104 & 1.04 & 0.405 \\
\hline $2.26 \mathrm{~b}$ & 0.37 & $3.92 a$ & 0.29 & $4.31 a$ & 0.29 & 8.05 & 0.002 & 0.63 & 0.646 \\
\hline $71.68 b$ & 7.27 & $98.47 a$ & 3.16 & $103.60 \mathrm{a}$ & 2.45 & 13.27 & $<0.001$ & 1.81 & 0.156 \\
\hline $85.67 a$ & 24.14 & $20.00 \mathrm{~b}$ & 0.96 & $24.10 \mathrm{~b}$ & 2.01 & 38.90 & $<0.001$ & 2.94 & 0.040 \\
\hline $75.67 a$ & 26.30 & $19.74 b$ & 2.93 & $21.00 \mathrm{~b}$ & 2.22 & 19.70 & $<0.001$ & 4.00 & 0.012 \\
\hline $181.17 a$ & 42.25 & $59.33 b$ & 10.13 & $65.60 \mathrm{~b}$ & 9.06 & 14.27 & $<0.001$ & 7.65 & 0.001 \\
\hline $2,690.67 a$ & 334.29 & $1,805.08 b$ & 117.33 & $1,771.00 \mathrm{~b}$ & 121.52 & 5.36 & 0.011 & 1.01 & 0.419 \\
\hline $287.63 a$ & 48.58 & $221.25 a$ & 16.95 & $251.10 a$ & 19.69 & 1.42 & 0.259 & 1.20 & 0.334 \\
\hline $200.50 a$ & 28.97 & $115.92 b$ & 9.76 & $132.70 b$ & 13.22 & 5.58 & 0.010 & 2.87 & 0.043 \\
\hline $985.17 a$ & 467.25 & $44.25 b$ & 4.64 & $39.20 \mathrm{~b}$ & 3.27 & 74.52 & $<0.001$ & 21.40 & $<0.001$ \\
\hline $0.72 a$ & 0.06 & $0.63 a$ & 0.03 & $0.67 a$ & 0.05 & 0.69 & 0.513 & 0.69 & 0.606 \\
\hline $308.67 a$ & 18.29 & $305.25 a$ & 18.73 & $321.80 a$ & 16.00 & 0.36 & 0.705 & 0.57 & 0.691 \\
\hline $115.50 a$ & 8.12 & $75.58 b$ & 7.78 & $64.00 \mathrm{~b}$ & 7.01 & 9.46 & 0.001 & 1.29 & 0.299 \\
\hline $5.78 a$ & 1.12 & $6.93 a$ & 0.60 & $7.84 a$ & 0.61 & 2.91 & 0.072 & 0.93 & 0.464 \\
\hline $26.54 a$ & 9.76 & $17.79 a$ & 2.73 & $19.95 a$ & 2.83 & 1.77 & 0.190 & 5.99 & 0.002 \\
\hline $561.20 a$ & 79.44 & $676.00 \mathrm{~b}$ & 22.80 & $746.40 \mathrm{~b}$ & 18.87 & 6.01 & 0.007 & 1.60 & 0.206 \\
\hline $117.054 a$ & 44.51 & $41.58 a$ & 5.17 & $48.17 a$ & 8.51 & 1.70 & 0.299 & 0.65 & 0.644 \\
\hline $2.16 a$ & 1.14 & $1.43 a$ & 0.22 & $1.52 \mathrm{a}$ & 0.21 & 0.23 & 0.798 & 1.44 & 2.50 \\
\hline
\end{tabular}


Figure 1: Location of 3 island study areas between kilometer markers 271.8 and 305.6 (mile markers 168.9 and 189.9) on the Ohio River, West Virginia, USA.

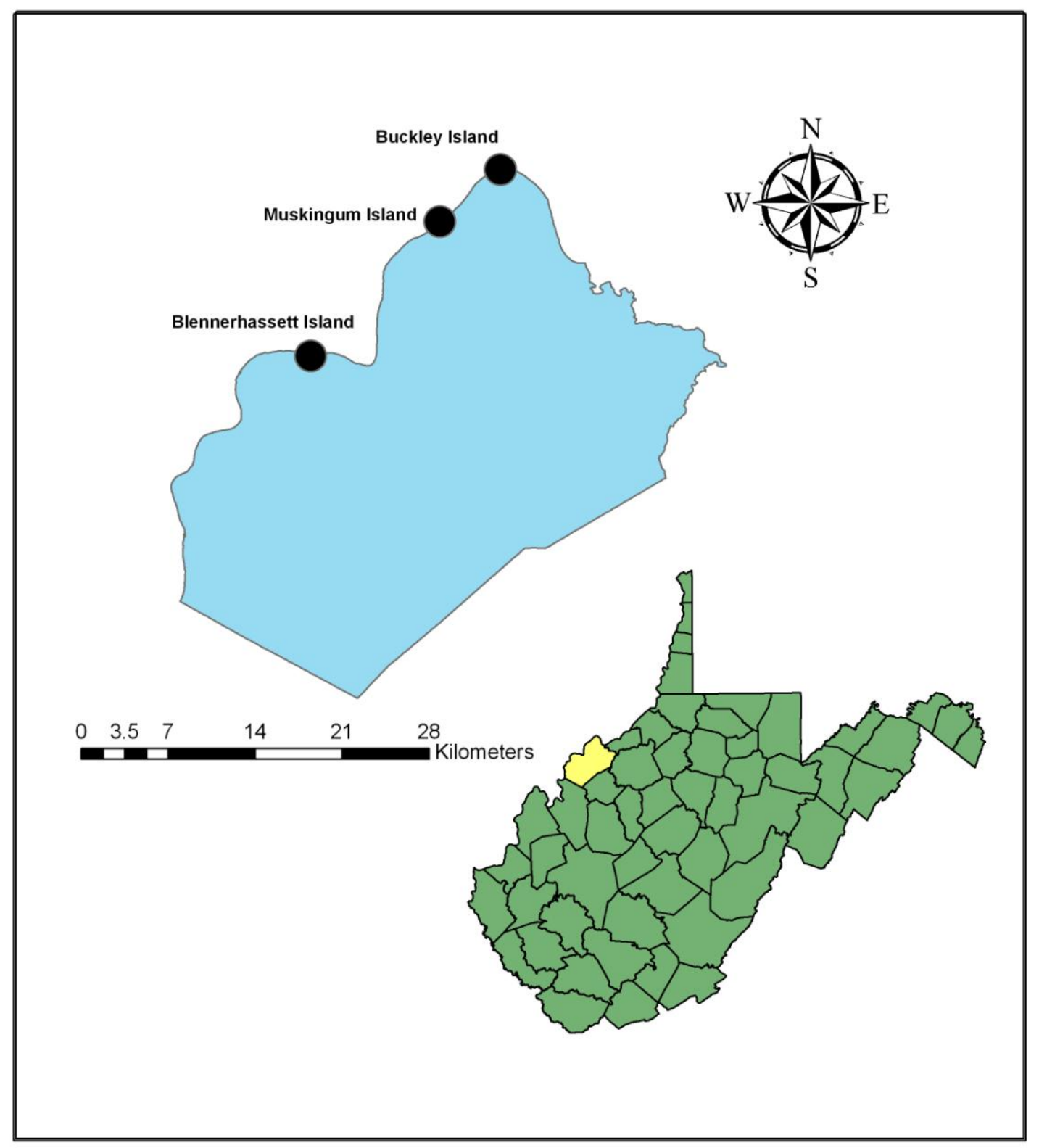


Figure 2: A schematic of vegetation sampling effort within the 0.1 ha plots used for each transect at each of the study areas.

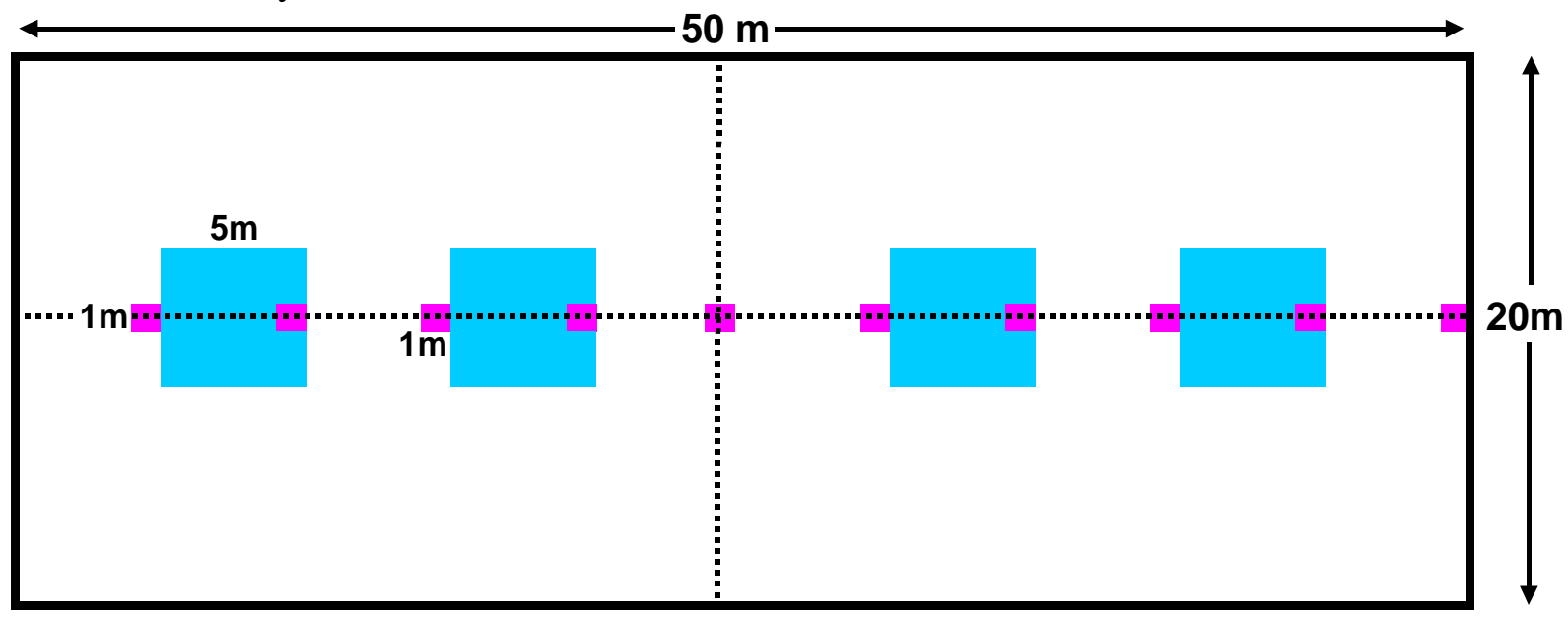




\section{Chapter 3}

Riparian and Riverine Wildlife Response to an Ohio River Island Bridge Crossing

Joshua A. Vance ${ }^{1, *}$, West Virginia University, Division of Forestry and Natural Resources, PO Box 6125, Morgantown, WV 26506-6125, USA, 304-516-3105, josh_vance10@yahoo.com.

James T. Anderson ${ }^{1}$, West Virginia University, Division of Forestry and Natural Resources, PO Box 6125, Morgantown, WV 26506-6125, USA, 304-293-3825, jim.anderson@mail.wvu.edu.

Philip J. Turk², West Virginia University, Department of Statistics, PO Box 6330, Morgantown, WV 26506-6330, USA, 304-293-2410, pturk@stat.wvu.edu

Norse B. Angus ${ }^{3}$, West Virginia Department of Transportation, Division of Highways, Building 5 Capital Complex, Charleston, WV 25305, USA, 304-558-9664, norse.b.angus@wv.gov

*Corresponding author

This chapter written in the style of: Northeastern Naturalist 


\begin{abstract}
Construction of man-made objects such as roads and bridges can influence wildlife presence and abundance. We investigated waterbirds, songbirds, anurans, turtles, small mammals, and furbearers along the Ohio River, WV, USA at a new bridge crossing (Blennerhassett Island), a 45-year old bridge (Buckley Island), and 1 or 2 islands with no bridge (Muskingum or Grape Island) and at 3 distances from the bridge or center point at each site $(0 \mathrm{~m}, 100 \mathrm{~m}$, and $300 \mathrm{~m})$. Overall, 19 waterbird, 60 songbird, 7 anuran, 5 turtle, 9 small mammal, and 4 furbearer species were sampled. Great Blue Heron abundances were greater at Muskingum Island $(P<0.05)$. Songbird composition differed among the sites $(P<0.05)$ and between the transects under and away from the bridge $(P<0.05)$ with higher abundances of Rock Pigeon, Cliff Swallow, and European Starling under the bridges and lower abundances of total songbirds, Carolina Chickadee, Carolina Wren, and Common Yellowthroat under the bridges. Small mammal abundance, richness, and diversity and abundances of Peromysucs spp. were lower under the new bridge $(P<0.05)$ compared to other sites and distances. Raccoon presence was lower under the new bridge than at other sites and distances from the bridge $(P<0.05)$. No other wildlife sampled had altered numbers correlated to bridges. Other differences between wildlife taxa studied were contributed to natural variation in abundances and cover types among islands. We conclude that the Blennerhassett Island Bridge is causing impacts to Great Blue Herons due to noise and presence of the bridge and minor short-term impacts to songbirds and small mammals directly under the bridge only in the form of habitat conversion, fragmentation, and loss due to removal of vegetation.
\end{abstract}




\section{Introduction}

Humans today are affecting natural ecosystems at extraordinary rates through conversion of land and resource consumption (Turner et al. 1991), alteration of habitat and species composition (McKinney 2002), disruption of hydrological processes (Arnold and Gibbons 1996), and modification of energy flow and nutrient cycles (Grimm et al. 2000). Since the 1940s, the human population of the United States has become increasingly urbanized (Adams 1994). Urbanization dramatically alters landscapes through habitat fragmentation and increased human presence (Prange et al. 2004). Urbanization and the construction of roads and bridges can alter wildlife habitat, and is cited as the second most frequent cause of species endangerment, behind agriculture, in the United States (Czech and Krausman 1997). Construction of these man-made objects may have temporary or permanent effects on wildlife and vegetation. Historically, relatively few published studies have evaluated these effects. Recently, more attention has been directed toward the effects of bridges and roads upon wildlife and vegetation (e.g., Forman et al. 2003).

Bridges can potentially affect mammals, birds, amphibians, and reptiles either positively, negatively, or have no effect depending on species or location. Bridges have positive effects on wildlife by providing habitat for nesting, roosting, and resting as well as providing corridors for movement. Petrochelidon pyrrhonota Vieillott (Cliff Swallows) and Hirundo rustica Linnaeus (Barn Swallows) are species that use bridges for nesting and perching (Redmond and Murphy 2007, Tumlison 2009). Additionally, Falco peregrinus Tunstall (Peregrine Falcons) have been well documented as using bridges and skyscrapers for nesting sites and hunting perches (Bell et al. 1996, Cade and Bird 1990, Tordoff and Redig 1988). Other research shows that bridges provide roosting and resting habitat for bats (Bennett et al. 2008). Edge created by roads and 
bridges may provide habitat for songbirds and increase their population (Clark and Karr 1979). Also, creation of bridges can serve as movement corridors for Canis latrans Say (Coyotes) (Sacks et al. 2006).

There is a lack of published literature on the ecological impacts of bridges on wildlife. However, the presence of a bridge may have direct negative impacts on wildlife similar to those of highway impacts which have been studied in much greater detail. Some of these negative impacts include: increased mortality from vehicle collisions (Haxton 2000, Hubbard et al. 2000), noise (Breeden et al. 2008), barrier effects (Noss et al. 1996), and attraction of undesirable or non-native species (Vankat and Roy 2002). Bridges and highways also can impact the landscape causing habitat fragmentation (Trombulak and Frissell 2000), habitat loss (Forman 2000), and habitat alteration (Rowland et al. 2000) which in turn are negative for some wildlife. This can lead to species declines and disruption of continuous population distributions (Vos and Chardon 1998), limit movements (Andrews et al. 2005), and cause potential genetic problems (Lesbarreres et al. 2006).

The purpose of this study was to evaluate the short-term impacts and effects of the Blennerhassett Island Bridge as it crosses over the Ohio River and Blennerhassett Island near Parkersburg, West Virginia, USA. The Blennerhassett Island Bridge is a tied-arch style singlespan bridge (GoBridges 2009) about 1,220 $\mathrm{m}$ in length and about $24 \mathrm{~m}$ above the island and water with 3 piers on the island. Construction of the bridge began in May 2005 and it was opened to the public 13 June 2008. This study investigated waterbird, songbird, anuran, turtle, small mammal, and furbearer relative abundance and compared results to 2 other islands ( 1 with an old bridge crossing and 1 with no bridge crossing) and also at 0,100 , and $300 \mathrm{~m}$ from the 
bridge. Comparisons for anurans and turtles also were made to an additional island with no bridge crossing.

Waterbirds, songbirds, anurans, turtles, small mammals, and furbearers were all chosen for this study as each could serve as indicators of sensitivity to the bridge. Waterbird abundances and songbird communities are highly influenced by changes in vegetative structure and land use following a disturbance (Burris and Haney 2005, Morissette et al. 2002, Rosa et al. 2003). Anurans also are commonly depicted as ecologically sensitive to anthropogenic disturbance (Price et al. 2007) and may be excellent indicators of environmental health (DeGarady and Halbrook 2006). Small mammals, furbearers, and turtles, however, are generally depicted as tolerant to urbanization and anthropogenic changes in the landscape (Kaminski et al. 2007, Plummer et al. 2008).

\section{Study Area}

This study was conducted along the Ohio River in Wood County and Pleasants County, West Virginia and Washington County, Ohio, USA. There were 4 sites (Blennerhassett Island, Buckley Island, Muskingum Island, and Grape Island) (Appendix 1) and surveys were conducted on both the islands and the adjacent mainland. Blennerhassett and Buckley both have bridge crossings, while Muskingum and Grape do not and one or the other were used as control sites for some surveys. These islands occur between km markers 244.0 and 305.6 (mi markers 151.6 and 189.9). Blennerhassett, Buckley, and Muskingum are located in the Belleville Navigational Pool, while Grape Island is located in the Willow Island Navigational Pool (Tolin and Schettig 1983).

Blennerhassett Island is owned by Dupont Corporation and is leased to the state of West Virginia as a state historical park. Buckley, Muskingum, and Grape islands are owned by the 
U.S. Fish and Wildlife Service and are part of the Ohio River Islands National Wildlife Refuge (United States Fish and Wildlife Service 2000). Precipitation occurs throughout the year, totaling about $106 \mathrm{~cm} /$ year (Idcide West Virginia Weather 2010). The elevation of the study areas ranges from 184-198 m in elevation (Idcide West Virginia City Data 2010). The primary cover types for these islands are: bottomland hardwood forest, late old-field, and early old-field (Tolin and Schettig 1983). Additionally, both Blennerhassett and Grape islands contain a palustrine unconsolidated bottom wetland. All islands in this study area have been historically used for agriculture and the river channels around them may have been historically dredged (Tolin and Schettig 1983). The adjacent mainland has been characterized by disturbance from urbanization, agriculture, commercial development, and industrial expansion.

The Ohio River islands support a variety of mammals, birds, amphibians, and reptiles. Both back and main channels of Ohio River islands provide critical riparian wildlife habitat for many species of birds, aquatic mammals, frogs, and turtles (Zadnik et al. 2009). There are 193 avian, 25 mammalian, and 15 species of amphibians and reptiles documented on the Ohio River islands (United States Fish and Wildlife Service 2000). Of the 193 bird species, 143 are passerines (Sacilotto 2003). Other bird groups common to the islands include waterfowl, wading birds, shorebirds, and raptors. Mammalian groups common to the islands include Odocoileus virginianus Zimmermann (White-tailed Deer), aquatic furbearing mammals, carnivores, and small mammals (United States Fish and Wildlife Service 2000). Amphibian and reptile species are constricted to more aquatic groups such as frogs and turtles (United States Fish and Wildlife Service 2002). Thirty-eight mussel species and over 100 species of warm water fishes have been identified around the islands in the upper Ohio River. Additionally, 3 federally listed species occur in the area, Myotis sodalis Miller and Allen (Indiana bat), Lampsilis orbiculata Hildreth 
(Pink Mucket Pearly Mussel), and Cyprogenia stegaria Rafinesque (Fanshell Mussel), and 2 species, Haliaeetus leucocephalus Linnaeus (Bald Eagle) and Peregrine Falcon, have recently been delisted.

\section{Methods}

\section{Study Design}

Waterbirds, songbirds, anurans, turtles, small mammals, and furbearers were sampled at Blennerhassett Island (new Rt. 50 bridge), Buckley Island (existing I-77 bridge), and Muskingum Island (no bridge) (Appendix 1). Anurans and turtles were sampled at Grape Island (no bridge) due to the presence of a wetland, but due to the island's small size, other taxa were not sampled. Songbirds, anurans, small mammals, and furbearers were sampled along $100 \mathrm{~m}$ transects placed under the bridge or island center (0), and at 100 and $300 \mathrm{~m}$ from the central transect with transects starting at the shorelines on both sides of the bridge on the mainland and on the island. Ideally our study would have had transects on the island as well as on the West Virginia and Ohio mainland ( $\mathrm{n}=20$ at each site). Because of site constraints (e.g., size of island, industry, agriculture, rock quarry, commercial and residential development) only 37 of the 80 proposed transects among the 4 sites could be sampled for all taxa except turtles: Blennerhassett Island $(\mathrm{n}=15)$, Buckley Island $(\mathrm{n}=12)$, Muskingum Island $(\mathrm{n}=7)$, and Grape Island $(\mathrm{n}=3)$. Because turtle trapping occurred at the terminal ends of the transects in the main river, all 20 transects could be sampled at each site. Additionally, turtle trapping was conducted in the slough on Blennerhassett Island, and was planned in the slough on Grape; however, water levels were not deep enough to trap. This provided 85 trap locations for turtles $(\mathrm{n}=25$ at Blennerhassett, $\mathrm{n}=$ 20 at Buckley, $\mathrm{n}=20$ at Muskingum, and $\mathrm{n}=20$ at Grape). Comparisons were made among sites 
(waterbirds, songbirds, anurans, small mammals, furbearers, mortality) and/or distance from bridge (songbirds, anurans, turtles, small mammals, and furbearers).

\section{Waterbirds}

Waterbird surveys were conducted by a single observer during 90 minute complete scan counts while sitting on the mainland facing the island and monitoring the river, air, riparian zones, and part of the island in a 39.25 ha area (semicircle with a 500 m radius from the observation point) using $8 \times 42$ power binoculars and a 15 to 60 power, $60 \mathrm{~mm}$ zoom, Bausch and Lomb® spotting scope. Surveys were conducted from 1 hour before sunset to 30 minutes after sunset (dusk) and then 30 minutes before sunrise to 1 hour after sunrise (dawn) at the same location the following morning (Burger 2001). The dusk survey and the dawn survey the following morning were combined into one single survey and the maximum count for each species between the two times was used. During these counts, all waterbirds observed were enumerated and recorded (Heusmann and Sauer 2000, Lougheed and Breault 1999) and flyovers were categorized by whether the individuals flew over or under bridge. Waterbirds were considered waterfowl, seabirds, shorebirds, wading birds, and Megaceryle alcyon Linnaeus (Belted Kingfishers) (Weller 1999). The distance from the observer to the bird was measured with a Nikon Laser ${ }^{\mathrm{TM}} 12007 \times 25$ power range finder to make accurate estimations on whether the birds were within the 39.25 ha area.

Dusk and dawn surveys were conducted from the West Virginia mainland once a month and then from the Ohio mainland later in the month because each side of the island had a different 39.25 ha area to be surveyed and to ensure the entire river channel around the island was

surveyed monthly. Observation points were placed at suitable locations with clear viewing of the 
river, air, riparian zones, and the bridge (where applicable), but were not correlated to transects. Counts were not recorded if the wind speeds exceeded $16 \mathrm{~km} / \mathrm{hr}$ or during high flow conditions and were made up at the next available time (Best et al. 1997). Surveys were completed by individuals trained in bird identification and distance estimation. Counts were conducted twice a month during October, November, and December 2007 and 2008, as well as March, April, and May 2008 and 2009.

Waterbird abundance (number/39.25 ha plot) of combined waterbirds and those species representing $2 \%$ or more of detections, species richness, and Shannon Diversity Index (SDI) (dependent variables) were rank transformed (Conover and Iman 1981) and compared among sites (independent variable) using a repeated measures single-factor analysis of variance (ANOVA) with an alpha level of 0.05. A Tukey's honest significance difference multiple comparison post hoc test was used for pairwise comparisons of significant variables. Flyovers were excluded from analyses. For the islands with bridges, data on whether the birds flew over or under the bridge also were summarized to investigate response to bridge.

\section{Songbirds}

Breeding bird surveys for songbirds were conducted along each of the $100 \mathrm{~m}$ transects using the dependent double observer method (Forcey et al. 2006). This method involved 2 observers recording data together on a single data sheet with 1 observer designed as the primary observer and the other designated as the secondary observer. The primary observer verbally dictated the number of each species detected while the secondary observer recorded the information. The secondary observer also recorded birds that the primary observer did not detect (Forcey et al. 
2006, Nichols et al. 2000). This technique was not used to calculate detection probabilities due to low number of observations, but to verify accuracy of species identifications and counts.

Songbirds were sampled by walking along each transect for a total of 15 minutes each, pausing to identify and record all birds observed or heard (Er et al. 2003). Only songbirds detected within a 1 ha area $(\leq 50 \mathrm{~m}$ perpendicular to the transect) were included in transect data. Those species detected outside or as flyovers were recorded but not included in any estimates. There were 3 scheduled stops of 3 minutes each at the beginning, middle, and end of each transect. The species, sex, age, and estimated distance of all birds detected by sight and sound was recorded (Smith et al. 2005). Estimated distances were recorded perpendicular to the transect using a Nikon Laser ${ }^{\mathrm{TM}} 12007 \times 25$ power range finder. Surveys were conducted from 0600 to 1000 (Rodewald and Smith 1998), but were not conducted during rainy or windy weather (Freeman et al. 2007). Surveys were completed by individuals trained in bird identification and distance estimation. Surveys were conducted during the breeding season in May and June 2008 and 2009.

Songbird abundance (individuals/ha) for all species combined and for any species representing $2 \%$ or more of observations, species richness, and SDI (dependent variables) were rank transformed (Conover and Iman 1981) and compared by site, distance, and the interaction term (independent variables) using a repeated measures 2-way ANOVA $(\alpha=0.05)$. Because the levels of distance had no physical meaning for Muskingum, a partial analysis was conducted to examine distance only for Blennerhassett and Buckley islands. In the case where there was no significant interaction, a contrast for the effect of distance pooled across both islands was estimated and, if necessary, follow up pairwise comparisons between levels of distance were estimated. If there was a significant interaction, then the effect of distance was examined for the 
2 islands on an individual basis (i.e., a simple effects analysis). A model allowing for heterogeneous variance was fitted for all variables due to nonconstant variance. Residual diagnostics were then used to verify the assumptions of the model. The test of interaction was done using untransformed data to obtain a more approximate analysis (Conover 1999). When subsequently testing main effects or contrasts, rank transformed data were used.

We initially evaluated the uniqueness of species composition was evaluated by site and distance from bridge (independent variables) by PERMANOVA (Anderson 2001) using the Vegan package in Program R. A subsequent one at a time analysis was done using multiresponse permutation procedures (MRPP) in PC-ORD version 5.10 software (McCune and Mefford 1999). MRPP is a non-parametric multivariate procedure for testing the hypothesis of no differences in species composition of 2 or more a priori groups of plots (McCune et al. 2002). For these analyses, all species that occurred less than 3 times were deleted. Individuals/ha (dependent variable) were calculated for abundance data and were relativized using a general column relativization. A Sorensen (Bray-Curtis) distance measure was used with a rank transformed distance matrix and an alpha level of 0.05 . A Sorensen community similarity index, which compares pairwise similarities, was used to evaluate songbird overlap among sites and distances.

Lastly, the affinity of species occurrence by site and by distance from bridge were calculated using indicator species analysis (Dufrene and Legendre 1997). Indicator species analysis combines information on the species abundance at a particular treatment and the faithfulness of occurrence of a species at a particular treatment (Rentch et al. 2005). First, an indicator value for each species was calculated with a value between 0 and 100. A value of 0 showed no indication (i.e., no association) of the species and a value of 100 showed perfect indication of the species. 
Second, the statistical significance of the highest indicator value $\left(I V_{\max }\right)$ for each species was tested using a Monte Carlo test using 4,999 permutations with an alpha level set at 0.05.

\section{Anurans}

Anuran communities were evaluated using nocturnal call count surveys to evaluate species and relative abundance (Balcombe et al. 2005). To account for temporal breeding differences among species, surveys were conducted over 3 periods (period 1: 25 February-25 March 2008 and 2009, period 2: 8 April-6 May 2008 and 2009, and period 3: 27 May-June 242008 and 2009) based on recommended temperature ranges for different survey periods (period 1: $\geq 5.6$ ${ }^{\circ} \mathrm{C}$, period 2: $\geq 10^{\circ} \mathrm{C}$, period 3: $\geq 12.8^{\circ} \mathrm{C}$ ) (Balcombe et al. 2005). Surveys were conducted between 30 minutes after sunset to midnight because calling activity is generally greater before midnight (Zimmerman 1991). Surveys were conducted along the $100 \mathrm{~m}$ transects by slowly walking each transect for 15 minutes with 3 scheduled stops of 3 minutes (Kimberly and Bouchard 2006) at the beginning, middle, and end of each transect. There was a 1-2 minute settling period for disturbance caused while walking to the transects before surveys began.

Anurans were identified to species and abundances were evaluated by assigning a Wisconsin Index (WI) value of intensity of each species' call (Mossman 1994). The WI ranked species from 0-3 based on overlap of calls and determination of individuals. A value of 0 indicated that no individuals of that species were heard. A value of 1 indicated that calling individuals could be counted and there were no overlapping calls. A value of 2 indicated that calls could be distinguished but there was some overlap. A value of 3 indicated a full chorus with continuous calling and overlapping calls. For values of 1 or 2 , the number of calling individuals was estimated. If a WI value of 3 was assigned to a species, a mandatory abundance estimate of 50 
was used (Balcombe et al. 2005). The date, time, temperature, and weather conditions were recorded before each survey. Surveys were not conducted if winds exceeded $20 \mathrm{~km} / \mathrm{hr}$ or if temperatures were below the minimum for each period. Estimated distance from the transect to the calling anurans also was recorded and mapped to lessen the chances of double-counting (Burnham et al. 1985). Surveys were conducted by individuals trained in anuran identification and distance estimation.

Combined anuran abundances, combined call index codes (CIC), abundances and CIC of those species representing $2 \%$ or more of all detections, species richness, and SDI (dependent variables) were rank transformed (Conover and Iman 1981) and compared among sites and distances (independent variables) using a single-factor ANOVA with an alpha level of 0.05. Due to anurans not being detected at Buckley or Muskingum, only Blennerhassett and Grape were used in analyses. Site comparisons for Blennerhassett and Grape used transects only in which anurans were detected. Because Grape did not have sufficient distances, distance comparisons were made only at Blennerhassett.

\section{Turtles}

Turtle trapping was conducted using turtle hoop nets (Rizkalla and Swihart 2006). Hoop nets were nylon, $1.5 \mathrm{~m}$ long $\times 0.9 \mathrm{~m}$ diameter with $5 \mathrm{~cm}$ mesh (Memphis Net and Twine Company, Inc., Memphis, TN). Traps were baited each day with chopped fish (either canned or frozen) contained in nylon mesh bags and suspended from the center hoop of each trap (Zadnik et al. 2009). If possible, traps were placed in areas suitable for turtles such as sand or gravel bars, areas of emergent vegetation, or areas of woody debris (Ernst et al. 1994). Traps were set for 3 consecutive nights and checked each morning. A trap night was considered as 1 trap found 
completely intact the day after being set (Zadnik et al. 2009). Traps with bait missing also were considered as 1 trap night, since the opportunity to capture a turtle by scent remained. A trap found with a hole torn in it $\leq 18 \mathrm{~cm}$ in diameter was considered 0.5 trap night, since the potential to capture larger turtles (> $18 \mathrm{~cm}$ carapace width) remained. Missing traps, those found to be collapsed, and those with holes $>18 \mathrm{~cm}$ were all considered 0 trap nights (Zadnik et al. 2009). All turtles captured were identified, measured, weighed, and released at the capture site. Hardshell turtles were marked by shell notching (Cagle 1939), and softshell turtles were marked along the edge of the carapace using a leather punch (Breckenridge 1955). Turtle trapping was conducted during July and August 2008 and June and July 2009.

Turtle relative abundance (captures/100 trap nights) for combined turtles and any species representing $2 \%$ or more of all captures, species richness, and SDI (dependent variables) were rank transformed (Conover and Iman 1981) and compared among sites, distances, and the interaction term (independent variables) using a 2-way ANOVA with an alpha level of 0.05 and proceded in the same fashion as the songbird analysis with a partial analysis for distance using only Blennerhassett and Buckley islands. Data were combined over each 3 day trapping interval and over the 3 trapping periods for each individual trap giving each trap a potential of 9 trap nights. Each trapping location was counted as a replicate. Recaptures were excluded from abundance analyses.

\section{Small Mammals}

Small mammal trapping was conducted by using Sherman live traps (small folding galvanized, $5 \times 6.4 \times 16.5 \mathrm{~cm}$; H. B. Sherman Traps, Tallahassee, FL) to capture small mammals such as mice, voles, moles, chipmunks, and shrews. Sherman traps were placed along the $100 \mathrm{~m}$ 
transects at 10 stations located $10 \mathrm{~m}$ apart (Pearson and Ruggiero 2003). Three Sherman live traps were set at each station. Each trap was baited with a peanut butter rolled oats mixture wrapped with wax paper (Edalgo and Anderson 2007). Traps were set and opened for 3 consecutive nights (Yunger and Randa 1999) and were checked each morning. We deduced 0.5 trap nights for each trap tripped without a capture (Beauvais and Buskirk 1999, Edalgo and Anderson 2007). Corresponding transects of each site were trapped simultaneously to account for temporal variation. Each mouse, vole, chipmunk, rat, or squirrel captured was ear-tagged with a \#1005-1 monel ear tag (National Band and Tag Company, Newport, Kentucky, 410720430) and shrews were toe-clipped for identification (Menzel et al. 1999, Silvy et al. 2005). Other information such as trap location, species, new or recapture, age, gender, mass, and reproductive condition also were recorded (Converse et al. 2006). Small mammal trapping was conducted during May, June, and July 2008 and 2009.

Small mammal relative abundance (captures/100 trap nights) of combined small mammal captures and individual species representing at least $2 \%$ of total captures, species richness, and SDI (dependent variables) were rank transformed (Conover and Iman 1981) and compared by site, distance, and the interaction term (independent variables) using a repeated measures 2-way ANOVA $(\alpha=0.05)$ in the same fashion as the songbird and turtle analyses. Abundance data were combined over each 3 night interval as 1 total trapping period. Peromyscus maniculatus Wagner (Deer Mouse) and Peromyscus leucopus Rafinesque (White-footed Mouse) were combined into a single species (Peromyscus spp. Gloger) to account for identification biases (Osbourne et al. 2005). Mean mass (g) and proportion of males, adults, and reproductive females were calculated for Peromyscus spp. and compared by a 2-way ANOVA $(\alpha=0.05)$ with a 
weighted least squares model. This was conducted for Peromyscus spp. but not for other species due to low captures. All recaptures were excluded from analyses.

\section{Furbearers}

Scent stations were constructed and monitored to measure medium-sized mammals, carnivores, and large rodent occurrence (Akins et al. 2004). Scent stations were established along the river banks at the terminal end of each transect. Scent stations were $1 \mathrm{~m} \times 1 \mathrm{~m}$ and made from scraped, sifted, and smoothed alluvial soil at a depth of $3-5 \mathrm{~cm}$ to make tracks more visible. Scent stations were baited with a fatty acid scent tablet placed in the center of the station (Helon et al. 2002). Stations were operated for 3 consecutive nights (Randa and Yunger 2006) and checked every morning (Sargeant et al. 1998). Identification of all animals investigating the scent station was made by the tracks left in the scent station. Scent stations were monitored in conjunction with small mammal traps during May, June, and July 2008 and 2009.

Scent station data for furbearers were analyzed based on presence or absence by $G$-tests of independence with William's correction factor. Data were combined for each scent station over the 3 consecutive nights each station was operated and over the 6 survey periods in 2 years. Data were then combined by distance for each site. Analyses were run for all furbearer species combined (whether any furbearer tracks were present) and for each individual species representing $2 \%$ or more of furbearer species identified. Analyses compared both site and distance from bridge by combining total presences and absences for each site or distance. Each adjusted $G$-statistic was tested and an alpha level of 0.05 was set. Pair wise comparisons (among sites or distances) of significant tests were analyzed similarly. Transects at Muskingum Island were not used in the distance comparison due to no bridge being present at that site. 


\section{Mortality}

Wildlife mortality surveys recorded all road-killed fauna under, on, around, and within a distance of $200 \mathrm{~m}$ from the bridge along the highway. Surveys were conducted by slowly driving ( $<48.3 \mathrm{~km} / \mathrm{hr}$ or $30.0 \mathrm{mi} / \mathrm{hr}$ ) or walking along the road or bridge and recording all road-killed species and the total number of each (Bard et al. 2002). Larger animals were marked with orange spray paint to ensure that they were not counted in future surveys. Multiple animals found together were noted. Mortality surveys began in October 2007 and were conducted once a month through September 2009.

\section{Results}

\section{Waterbirds}

A total of 19 waterbird species $(n=11$ at Blennerhassett, $n=8$ at Buckley, and $n=17$ at Muskingum) was observed during surveys (Appendix 9). Additionally, 15 other waterbird species were observed within the study area but not during survey hours (Appendix 10). Combined waterbird abundance (individuals/39.25 ha plot) was not significantly higher at Blennerhassett compared to Buckley or Muskingum although Blennerhassett had 4 times as many waterbirds as Buckley (Table 1).

Only Branta canadensis Linnaeus (Canada Goose) $(\mathrm{n}=1,007,73.6 \%)$, Phalacrocorax auritus Lesson (Double-crested Cormorant) $(\mathrm{n}=28,2.1 \%)$, Ardea herodias Linnaeaus (Great Blue Heron) ( $\mathrm{n}=36,2.6 \%)$, Anas platyrhynchos Linnaeus (Mallard) $(\mathrm{n}=124,9.1 \%)$, and Aix sponsa Linnaeaus (Wood Duck) $(\mathrm{n}=54,3.9 \%)$ had enough observations to analyze separately. Canada Goose, Double-crested Cormorant, and Wood Duck abundances did not differ significantly among sites (Table 1). Great Blue Heron abundances were greater at Muskingum 
than at Blennerhassett or Buckley, which were similar (Table 1). Mallard abundances were similar between Blennerhassett and Muskingum, but were significantly lower at Buckley (Table 1).

Overall species richness was significantly lower at Buckley than the other 2 sites (Table 1). Overall SDI differed among all 3 sites with Muskingum having the highest diversity and Buckley having the lowest (Table 1). At Blennerhassett, 185 of 239 (77.4\%) observations of waterbirds flew over the bridge and 54 of 239 (22.6\%) flew under the bridge. At Buckley, 138 of 191 (72.3\%) observations of waterbirds flew over the bridge and 54 of 191 (27.7\%) flew under the bridge.

\section{Songbirds}

Songbird surveys detected a total of 60 species $(n=48$ at Blennerhassett, $n=53$ at Buckley, and $n=42$ at Muskingum) (Appendix 11). Combined songbird abundance (individuals/ha) had a significant interaction between sites and distances due to the $0 \mathrm{~m}$ transects at Blennerhassett differing from the 100 and $300 \mathrm{~m}$ transects at Blennerhassett and the $0 \mathrm{~m}$ transects at Buckley and Muskingum (Appendix 12). A total of 17 species resulted in enough observations to analyze separately by sites and distances (Table 2). Three of these species had a significant site by distance interaction with Poecile carolinensis Audubon (Carolina Chickadee) having higher abundances at the $0 \mathrm{~m}$ transect at Muskingum than at the $0 \mathrm{~m}$ transects at Blennerhassett and Buckley, while Troglodytes aedon Vieillot (House Wren) had higher abundances at the $0 \mathrm{~m}$ transects at Blennerhassett compared to the $0 \mathrm{~m}$ transects at Buckley and Muskingum, and Columba livia Gmelin (Rock Pigeon) was only found at the $0 \mathrm{~m}$ transects at Blennerhassett and Buckley causing an interaction and indicating an overall bridge effect (Appendix 12). 
Seven species significantly differed by sites. Agelaius phoeniceus Linnaeus (Red-winged Blackbird) and Melospiza melodia Wilson (Song Sparrow) were higher at Blennerhassett, Dumetella carolinensis Linnaeus (Gray Catbird) and Vireo olivaceus Linnaeus (Red-eyed Vireo) were lower at Blennerhassett, Thryothorus ludovicianus Latham (Carolina Wren) and Baeolophus bicolor Linnaeus (Tufted Titmouse) were higher at Muskingum, and Sturnus vulgaris Linnaeus (European Starling) and Dendroica petechia Linnaeus (Yellow Warbler) were higher at Buckley (Table 2). Three species significantly differed by distances. Geothlypis trichas Linnaeus (Common Yellowthroat) and Carolina Wren were lower at $0 \mathrm{~m}$ transects and European Starling was higher at $0 \mathrm{~m}$ transects (Table 2).

No other species significantly differed among sites, distances, or interaction. This included: Spinus tristis Linnaeus (American Goldfinch), Turdus migratorius Linnaeus (American Robin), Passerina cyanea Linnaeus (Indigo Bunting), Zenaida macroura Linnaeus (Mourning Dove), and Cardinalis cardinalis Linnaeus (Northern Cardinal) (Table 2). Overall species richness and SDI were higher at Muskingum than at Blennerhassett or Buckley; however, there was no distance or interaction effect (Table 2).

All species that occurred less than 3 times were removed from the total species composition matrix reducing the 60 to 46 for the site analysis and 44 for the distance analysis for MRPP (Appendix 11). Results of the PERMANOVA showed no evidence of a site by distance interaction $\left(F_{4,25}=0.98, P=0.53\right)$. Results of the MRPP suggest that all 3 islands have different songbird communities and that the $0 \mathrm{~m}$ transects have significantly different songbird communities than $100 \mathrm{~m}$ and $300 \mathrm{~m}$ transects (Table 3). The Sorensen community similarity index comparing songbird composition among sites and distances further indicated different communities (Table 3). 
Results from indicator species analysis suggest certain species were more likely to occur on particular sites and at particular distances from bridge. One species (Song Sparrow) was indicative of Blennerhassett, 1 species (Carpodacus mexicanus Muller (House Finch)) was indicative of Buckley, and 12 species (Cyanocitta cristata Linnaeus (Blue Jay), Polioptila caerulea Linnaeus (Blue-gray Gnatcatcher), Carolina Chickadee, Picoides pubescens Linnaeus (Downy Woodpecker), Pipilo erythrophthalmus Linnaeus (Eastern Towhee), Indigo Bunting, Northern Cardinal, Melanerpes carolinus Linnaeus (Red-bellied Woodpecker), Red-eyed Vireo, Tufted Titmouse, Sitta carolinensis Latham (White-breasted Nuthatch), and Hylocichla mustelina Gmelin (Wood Thrush)) were indicative of Muskingum (Table 4). Two species (Petrochelidon pyrrhonota Vieillot (Cliff Swallow) and Rock Pigeon) were indicative of $0 \mathrm{~m}$ transects.

\section{Anurans}

A total of 7 anuran species were detected at Blennerhassett Island and 5 anuran species at Grape Island. Species detected were Pseudacris crucifer Wied-Neuwied (Spring Peeper), Anaxyrus fowleri Hinckley (Fowler's Toad), Anaxyrus americanus americanus Holbrook (Eastern American Toad), Lithobates catesbeianus Shaw (American Bullfrog), Hyla chrysoscelis Cope (Cope's Gray Tree Frog), Lithobates palustris LeConte (Pickerel Frog), and Lithobates clamitans melanota Rafinesque (Northern Green Frog). Only observations of Spring Peeper ( $\mathrm{n}=$ 674, 88.5\%), Cope's Gray Tree Frog $(n=39,5.1 \%)$, American Bullfrog $(n=19,2.5 \%)$, and Northern Green Frog $(\mathrm{n}=18,2.4 \%)$ resulted in enough detections to analyze separately.

Combined anuran abundances (individuals/transect) were similar between Blennerhassett and Grape islands and at 0,100, and $300 \mathrm{~m}$ transects (Table 5). Likewise, Spring Peeper, American 
Bullfrog, Cope's Gray Tree Frog, and Northern Green Frog abundances did not show significant difference between sites or among distances (Table 5). Call index codes for combined anurans also were similar between Blennerhassett and Grape and among 0,100, and $300 \mathrm{~m}$ transects at Blennerhassett (Table 5). Similarly, Spring Peeper, American Bullfrog, Cope's Gray Tree Frog, and Northern Green Frog call index codes did not differ between sites or among distances (Table 5). Species richness and SDI also were similar between sites and among distances (Table 5).

\section{Turtles}

A total of 728 trap nights were attempted with 651 total trap nights after deductions. We had 96 captures of 88 individuals from 5 species (Table 6). The five species of turtles captured were: Apalone spinifera spinifera Lesueur (Eastern Spiny Softshell), Chelydra serpentina Linnaeus (Common Snapping Turtle), Graptemys geographica Le Suer (Northern Map Turtle), Chrysemys picta marginata Agassiz (Midland Painted Turtle), and Sternotherus odoratus Latrielle (Stinkpot) (Appendix 13). Of these 88 individuals, a total of 11 Common Snapping Turtles and 4 Midland Painted Turtles were captured in the slough on Blennerhassett Island.

Combined abundances (captures/100 trap nights) were not different among sites, distances from the bridge, or by the interaction term (Table 7). Eastern Spiny Softshell $(n=46,52.3 \%)$, Common Snapping Turtle $(n=31,35.2 \%)$, Northern Map Turtle $(n=6,6.8 \%)$, and Midland Painted Turtle ( $n=4,4.5 \%)$ occurred in large enough numbers to analyze separately. Eastern Spiny Softshell, Common Snapping Turtle, and Northern Map Turtle abundances did not differ significantly among sites, distances, or by the interaction term (Table 7). Midland Painted Turtle abundances significantly differed among sites due to that species only being captured at Blennerhassett (Table 7). Species richness did not differ among sites, distances, or by the 
interaction term (Table 7). SDI differed significantly among sites due to Blennerhassett and Grape differing from Buckley and Muskingum, but did not differ by distance, or by the interaction term (Table 7).

\section{Small Mammals}

A total of 16,448 trap nights were attempted with 14,625 total trap nights calculated after deductions yielding a total of 1,124 captures of 733 individuals (Table 6). A total of 9 small mammal species were encountered during trapping surveys (Appendix 14). Peromyscus $\mathrm{spp} .(\mathrm{n}=$ 495, 67.5\%), Microtus pennsylvanicus Ord (Meadow Vole) $(\mathrm{n}=183,25.0 \%)$, and Tamias striatus Linnaeus (Eastern Chipmunk) $(\mathrm{n}=24,3.3 \%)$ occurred in enough observations to analyze separately. Three variables, Peromyscus spp., species richness, and SDI, had a significant interaction effect (Table 8). These 3 variables had a significant interaction effect due to the $0 \mathrm{~m}$ transects at Blennerhassett (Appendix 15) having lower abundances, richness, and diversity under the bridge compared to 100 and $300 \mathrm{~m}$ transects. Also, the 100 and $300 \mathrm{~m}$ transects at Blennerhassett differed from the 100 and 300 m transects at Buckley and Muskingum due to higher abundances, richness, and diversity at the 100 and $300 \mathrm{~m}$ transects at Blennerhassett (Appendix 15).

Combined small mammal abundances differed significantly by distances due to lower abundances at the $0 \mathrm{~m}$ transects, but did not differ among sites or by the interaction term (Table 8). Meadow Vole abundances differed by sites due to this species not being sampled at Muskingum, but did not differ among distances or by the interaction term (Table 8). Eastern Chipmunk abundances did not differ among sites, distances, or by the interaction term (Table 8). Mean mass, proportion of males, proportion of adults, and proportion of reproductive females, 
showed no significant differences among sites, distances, or the interaction term for Peromyscus spp. (Table 9).

\section{Furbearers}

A total of 4 furbearer species were encountered in scent station surveys: Procyon lotor Linnaeus (Raccoon) representing 82.8\% of all occurrences, Vulpes vulpes Linnaeus (Red Fox) representing 8.2\%, Didelphis virginiana Kerr (Virginia Opossum) representing 7.5\%, and Castor canadensis Kuhl (American Beaver) representing 1.5\%. Occurrences of all furbearer species combined did not differ by site or by distance (Table 10). Raccoon occurrences differed by site and by distance (Table 10) with transects at $0 \mathrm{~m}$ at Blennerhassett having lower occurrences (Appendix 16). Red Fox occurrences differed by site (Table 10) with Blennerhassett having the highest occurrences (Appendix 17), but not by distance (Table 10). Virginia Opossum occurrences did not differ by site or by distance (Table 10). American Beaver occurrences were not tested due to too few observations.

\section{Mortality}

A total of 24 mortality surveys detected 13 individuals from 3 species between 2 of the 3 sites. Blennerhassett Island had a total of 3 individuals (all Raccoons, $\mathrm{n}=1$ on the bridge and $\mathrm{n}=$ $2 \leq 200 \mathrm{~m}$ from the bridge along the highway). Buckley Island had a total of 10 individuals (Raccoon $n=3$, Virginia Opossum $n=2$, and White-tailed Deer $n=5 ; n=3$ on the bridge, $n=5$ under the bridge, and $\mathrm{n}=2 \leq 200 \mathrm{~m}$ from the bridge along the highway). Mortality was not detected at the Muskingum Island site. Mortality totals were standardized by individuals $/ \mathrm{km} / \mathrm{month}$. There were 3 observation of White-tailed Deer and 2 observations of 
Raccoons found under the Buckley Island Bridge. These observations were from vehicular collisions on Waverly Road, which runs underneath of the Buckley Island Bridge and had no connection to the Buckley Island Bridge, and were therefore removed from the mortality standardization. Blennerhassett had an average mortality rate of $0.07(\mathrm{SE}=0.04)$ individuals $/ \mathrm{km} / \mathrm{month}$ while Buckley had an average mortality rate of $0.15(\mathrm{SE}=0.10)$ individuals $/ \mathrm{km} / \mathrm{month}$. Because the Blennerhassett Island Bridge was not opened until June 2008, 8 surveys were conducted at that site before the bridge was officially opened to the public. We removed these surveys from the analysis and found that mortality increased to 0.10 ( $\mathrm{SE}=$ 0.05) individuals/km/month from June 2008-September 2009.

\section{Discussion}

\section{Waterbirds}

Of the 5 species analyzed, only Great Blue Heron and Mallard differed among sites. Great Blue Heron densities were 3.84 times higher at Muskingum than Blennerhassett and 13.67 times higher at Muskingum than Buckley. This could be attributed to Great Blue Herons being negatively impacted by the highway bridge crossings at the other 2 islands. Great Blue Herons prefer remoteness and lack of human disturbance (Gibbs et al. 1987, Short and Cooper 1985, Watts and Bradshaw 1994). Noise can disrupt heron breeding and nesting patterns (Grubb 1977). Additionally, Great Blue Heron nesting patterns and nest success can be altered by other human disturbances including: increased human presence, land development, and destruction of habitat (Parnell et al. 1988, Skagen et al. 2001, Vennesland and Butler 2004). Mallard abundance was lower at Buckley Island possibly indicating that over time bridges impact Mallards, but because Mallard abundances were similar at Blennerhassett and Muskingum, we believe the 
Blennerhassett Island Bridge has no current impacts to Mallards. There was no evidence that the Blennerhassett Island Bridge caused negative impacts to abundances of any other waterbird species.

We found waterbird species richness and diversity were lower at Buckley compared to the other 2 islands. This may be the result of the bridge at Buckley, but this is difficult to determine due to low abundances of the 6 species found only at Muskingum. Each of these species (Anas rubripes Brewster (American Black Duck), Chroicocephalus philadelphia Ord (Bonaparte's Gull), Bucephala albeola Linnaeus (Bufflehead), Gavia immer Brunnich (Common Loon), Podiceps auritus Linnaeus (Horned Grebe), and Actitis macularia Linnaeus (Spotted Sandpiper)) represented less than $2 \%$ of all observations and did not provide enough representation for individual abundance comparisons. All 6 species are migratory, although American Black Duck is an uncommon nester in the study area, and Spotted Sandpiper is a late migrant usually arriving in early May (P. Morrison, U.S. Fish and Wildlife Service, Williamstown, WV, personal communication). Lower species richness and diversity at Buckley are more easily explained by natural variation in observations rather than from the presence of a bridge.

Waterbirds do collide with bridges, which create barriers to movement and causes mortality and population declines (Bard et al. 2002). Our data, however, shows no indication that the bridge is a barrier or cause of mortality to waterbirds during diurnal time periods. Waterbirds more often flew over the bridge as opposed to under the bridge; however, waterbirds did not hesitate to fly under the bridge when flying low over the water. We had direct observations of many species including: Belted Kingfisher, Canada Goose, Double-crested Cormorant, Great Blue Heron, Mallard, Spotted Sandpiper, and Wood Duck flying under the bridge. The bridge does not seem to be a major barrier for waterbirds during flight, likely due to its relatively low 
height (24 $\mathrm{m}$ above the surface). There were no observations or documentations of waterbirds colliding with the bridge during diurnal flight.

\section{Songbirds}

Our study indicates that the Blennerhassett Island Bridge has some, albeit minor impacts to songbirds that resulted in a decrease in overall songbird abundance and changes in species composition most likely due to the area directly under the bridge being highly disturbed and lacking woody vegetation. This effect was mostly due to the removal of all trees, snags, and coarse woody debris (Brawn et al. 2001, Lohr et al. 2002) and may be responsible for decreases in forest interior songbirds. Rock Pigeon, Cliff Swallow, and European Starling had high affinity for transects under bridges as these are all generalist species that use bridges and other manmade structures for nesting, roosting, and perching (Peterson 2002, Tumlison 2009). House Wrens had high abundances under the Blennerhassett Island Bridge due to the placement of songbird nest boxes under the bridge after construction.

Songbird species composition is closely related to habitat structure (Burris and Haney 2005, Karr and Roth 1971, Niemi and Hanowski 1984, Pearman 2002). Our study echoes this as songbirds observed were closely related to known habitat preferences with habitat generalist species using the areas directly under the bridges (Peterson 2002). Muskingum Island had higher species richness and diversity, different composition, and higher abundances of forest interior songbirds than the other 2 sites. This is largely due to all transects at Muskingum Island being located in bottomland hardwood forest (Appendix 4) which harbor high species richness of passerines (Kellison et al. 1998, Pashly and Barrow 1992, Wigley and Lancia 1998) while 
transects at Blennerhassett (Appendix 2) and Buckley (Appendix 3) islands varied across cover types with transects in old-field habitat having lower species richness.

Changes in songbird communities found in our study follows previously documented findings on the changes in species composition following a disturbance. Songbird communities vary among successional stages and forest types, and a diversity of landscapes maintains

songbird diversity (Brawn et al. 2001, Kirk et al. 1996, Schieck et al. 1995). Community changes of songbirds similar to those under the bridge have been documented for many types of natural and anthropogenic disturbances including: fire (Morissette et al. 2002), blow downs (Burris and Haney 2005), timber harvests (Hobson and Schieck 1999, Niemi and Hanowski 1984), mowing (Zuckerberg and Vickery 2006), agriculture (Sutter and Brigham 1998), residential development (Germaine et al. 1998), and urbanization (Odell and Knight 2001).

\section{Anurans}

Anurans are commonly depicted as ecologically sensitive to anthropogenic disturbance (Kolozsvary and Swihart 1999, Price et al. 2007, Vitt et al. 1990, Willson and Dorcas 2003). However, we found anuran relative abundance and richness was not negatively impacted by the presence of a highway bridge over an island wetland complex. Anuran abundances, richness, and diversity were no different between a site with a large bridge crossing and a site without a bridge. Also, anuran abundances, richness, and diversity were no different at the different distances at Blennerhassett Island. Species were found calling throughout the wetland complex on the island and also in the wetland vegetation under the bridge on the West Virginia mainland. This indicates that the bridge had no negative effect on anuran relative abundance. CIC did not differ 
between sites or among distances further indicating the Blennerhassett Island Bridge has no negative effect on abundance or richness.

All anuran species encountered in this study had been previously documented on the Ohio River Islands National Wildlife Refuge (United States Fish and Wildlife Service 2002) and are common along the Ohio River (Green and Pauley 1987). Habitat was the determining factor of anuran presence (Dayton et al. 2004), and anuran abundance and richness in relation to the bridge indicated the bridge had no negative effect. Other research has indicated that anurans respond positively or neutrally to disturbance. Two endangered anuran species responded favorably or neutrally to ground disturbance on a military training area in Germany (Warren and Buttner 2008). Populations of anurans in floodplain wetlands were similar in abundance and richness compared to less dynamic wetlands not in floodplains (Henning and Schirato 2006). Also, anuran abundance and richness was stable at a suburban wildlife refuge despite large amounts of development in close proximity to wetlands (Brander et al. 2007).

\section{Turtles}

Turtles are tolerant of urbanization and anthropogenic changes in the landscape (Conner et al. 2005, Marchand and Litvaitis 2004, Mitchell 1988, Plummer et al. 2008, Souza and Abe 2000). Our study indicated that turtle abundance and richness were no different among sites or at the different distances from the bridges indicating that the new bridge has no negative effect on these metrics. Additionally, the difference in diversity among sites had no attribution to the new bridge. Eastern Spiny Softshell and Common Snapping Turtle represented the majority of captures which compares to other studies on the Ohio River (Zadnik et al. 2009). Eastern Spiny Softshells were encountered only in the main river which coincides with habitat preferences for 
this species (DonnerWright et al. 1999, Ernst et al. 1994, Zadnik et al. 2009). Common Snapping Turtles were found readily in the main river at each of the study islands and more frequently in back channels as opposed to main channels as previously indicated by Zadnik et al. (2009). We believe the Ohio River supports a large population of these 2 species around the study areas due to quality and quantity of habitat in the form of sand and gravel bars, emergent vegetation, and woody debris (Zadnik et al. 2009).

The other 3 species (Northern Map Turtle, Midland Painted Turtle, and Stinkpot) were all encountered in low numbers. Each species is associated with slow bodies of water with soft bottoms and abundant basking sites (Green and Pauley 1987) which are plentiful around Ohio River islands and in the slough on Blennerhassett, and we do not believe the bridge is affecting their abundances. Aquatic turtles are disturbance tolerant animals unlike many other taxa of wildlife. Spiny Softshell turtle survival in Arkansas was not negatively affected when creek beds were bulldozed and woody debris was removed which decreased habitat quality and quantity (Plummer et al. 2008). Painted Turtle nesting ecology showed no changes with increases of human recreation at a major nesting beach (Bowen and Janzen 2008). Species of freshwater turtles, including those found in this study, persist following disturbances in the form of urbanization (Conner et al. 2005, Marchand and Litvaitis 2004, Mitchell 1988, Souza and Abe 2000) and in some cases may even be more abundant in urban habitats than they are in more undisturbed natural areas (Gasith and Sidis 1984, Germano and Bury 2001, Lindeman 1996, Moll 1980). 


\section{Small Mammals}

Small mammals are typically depicted as disturbance tolerant (Elliot and Root 2006, Kaminski et al. 2007, Kirkland 1990, Root 1990). However, we found that combined small mammal abundance and abundances of Peromyscus spp. were lower under the new bridge indicating that it has negative impacts. Species richness and diversity also were lower under the new bridge compared to other distances indicating that the disturbance from construction of the bridge may result in a decrease in small mammal richness and diversity. We believe these impacts are due to the amount and type of vegetative cover (Silva and Prince 2008), and preferences of microhabitat by certain species (Castleberry et al. 2002, Dalmagro and Vieira 2005, Lozanda and Guthman 1998). We suggest these impacts are temporary and that abundance, richness, and diversity under the bridge will increase to levels similar to other distances as shown at the older Buckley Island Bridge making it consistent with other studies following a disturbance (Campbell and Clark 1980, Hansson 1992, Martell 1983, Pagels et al. 1992, Sullivan et al. 1999).

Total abundances of small mammals were highest at Blennerhassett, which is most likely due to more quality, quantity, and diversity of habitat. Lack of grasslands, old fields, and brushy areas at Muskingum Island (Appendix 4) may be causing lower abundances (Barko et al. 2003), while possible reasons for lower abundance at Buckley Island include high numbers of Raccoons preying on small mammals (Okabe and Agetsuma 2007) or high intensity disturbance from agriculture, residential development, and urbanization. Also, all 3 sites may be experiencing variation due to cyclical fluctuations of small mammal populations (Elias et al. 2004, Getz et al. 2006, Oli and Dobson 2001). 
The vegetation under the new bridge was of low coverage and consisted of herbaceous, disturbance tolerant plants typically used for reclamation making it similar to roadsides (Rentch et al. 2005) and may be the reason why abundances, richness, and diversity was low. However, capture rates and diversity increased under the bridge as vegetative cover increased during the study. We hypothesize that the low abundances, richness, and diversity under the bridge is temporary and will increase as vegetative coverage increases. Also, there was only one detection of a small mammal moving from transect to transect at all of the sites (one Peromyscus spp. moved from a $100 \mathrm{~m}$ transect to a $0 \mathrm{~m}$ transect at Blennerhassett) possibly indicating that small mammal populations were impacted under the bridge during construction and are slowly increasing as habitat is restored.

\section{Furbearers}

We found that combined furbearer detections did not differ among sites or distances. However, 2 species, Raccoon and Red Fox, did vary. Raccoon detections were much lower at 0 $\mathrm{m}$ transects at Blennerhasset. These impacts could possibly be from habitat fragmentation and loss, most notably disturbance of natural shorelines caused by construction of the bridge. However, increased urbanization and habitat modification and fragmentation result in higher Raccoon densities (Hoffman and Gottschang 1977, Owen et al. 2004, Riley et al. 1998). Raccoons respond well and use wildlife passages and underpasses (Foster and Humphrey 1995, $\mathrm{Ng}$ et al. 2004) and we assume they use the area under the bridge similarly. We hypothesize that Raccoons commonly frequent the area beneath the bridge, but may be patrolling around the wetland instead of the shorelines, thus avoiding our scent stations. Raccoon populations within the study area appear to be high due to high presence shown in scent station surveys, large 
amounts of tampering of small mammal traps during small mammal trapping periods, abundant quality and quantity of habitat (proximity to water, proximity to urban areas, and multiple cover types), lack of hunting and minimal trapping on the islands, and abundant food sources (Beasley et al. 2007, Gehrt 2003, Oehler and Litvaitis 1996, Okabe and Agetsuma 2007).

Red Fox occurrences were highest at Blennerhassett and this species did not occur at Muskingum which is the reason for variation among sites and indicates the new bridge has no negative impacts. Personal observations suggest Red Fox populations are high on Blennerhassett as this island has preferred habitats including: forest, open areas, and grasslands and mixed vegetation communities such as edge habitats and mixed scrub and woodland (Van Etten et al. 2007, Weber and Meia 1996).

\section{Mortality}

Wildlife is threatened by highways and bridges due to the possibility of wildlife-vehicle collisions. Estimates range between 500,000 and 700,000 individuals are killed every year due to vehicle mortality (Romin and Bissonette 1996, Schwabe and Schuhmann 2002). For our study, mortality was documented at the 2 sites with bridges (Blennerhassett and Buckley), but not at the site that didn't (Muskingum). All mortality was assumed to be from vehicles. There was no mortality found linked to collision with the bridge, though there was no way of detecting animals that may have fallen into the river. There was more mortality observed at Buckley as opposed to Blennerhassett, but mortality was still low. This may be due to the bridge at Buckley being open from the start of the surveys (October 2007), while the bridge at Blennerhassett wasn't opened until June 2008. Therefore, there were 8 surveys conducted at Blennerhassett before the bridge was officially opened to the public, with no mortality found during these surveys. However, 
mortality for Blennerhassett during the months it was open was only slightly higher. Mortality at both Blennerhassett and Buckley were distributed well between on the bridge and at distances less than $200 \mathrm{~m}$ from bridge along the highway.

The presence of this highway bridge has the potential to lead to more wildlife mortality. We hypothesize that mortality rates at the Blennerhassett Island Bridge will increase to numbers similar to the Buckley Island Bridge as time passes. Wildlife use bridges to reconnect fragmented habitat and populations (Sacks et al. 2006), and it is believed that Raccoons, Virginia Opossums, and White-tailed Deer are using both bridges in this study to cross the river. This will increase the likelihood of vehicular mortality. It is estimated that more than 1.5 million deervehicle collisions occur annually in the United States injuring 29,000 people and killing 200 humans per year (Conover et al. 1995). Similarly, Raccoons and Virginia Opossums are vulnerable to vehicular mortality (Kamler and Gipson 2004) and can lead to localized population declines in these species.

\section{Acknowledgments}

We thank the West Virginia Department of Transportation, Division of Highways for the funding of this project. We thank the U.S. Fish and Wildlife Service, the West Virginia Division of Natural Resources Wildlife Resources Section and Recreation and Parks Section for their cooperation throughout this project. We thank Dr. George Merovich and Dr. Jim Rentch for their additional assistance with statistical analysis for this project. A special thanks is also extended to the many biologists, field technicians, graduate students, and volunteers including: Patty Morrison, Gary Batton, Jeff McCrady, Matt Baker, Craig Leibfreid, Graham Nesselrodt, Matt Coen, Brandon Miller, Tristan Gingerich, Walter Veselka, Gabe Strain, Kyle Aldinger, Mandy 
Weston, Curtis DeLong, Brian Reed, and David Vance who assisted with this project. This is scientific article number xxxx of the West Virginia University Agriculture and Forestry Experiment Station. 


\section{Literature Cited}

Adams, L.W. 1994. Urban Wildlife Habitats: A Landscape Perspective. University of Minnesota Press, Minneapolis, Minnesota.

Akins, J.B., B.D. Carver, and M.L. Kennedy. 2004. An assessment of species richness in mammals using scent-station procedures in three habitats. Tennessee Academy of Science 79:56-56.

Anderson, M.J. 2001. A new method for non-parametric multivariate analysis of variance. Austral Ecology 26:32-46.

Andrews, K.M., J.W. Gibbons, and T.W. Reeder. 2005. How do highways influence snake movements? Behavior responses to roads and vehicles. Copeia 2005:772-782.

Arnold, C.L., and C. Gibbons. 1996. Impervious surface coverage. The emergence of a key environmental indicator. Journal of the American Planning Association 62:243-258.

Balcombe, C.K., J.T. Anderson, R.H. Fortney, and W.S. Kordek. 2005. Wildlife use of mitigation and reference wetlands in West Virginia. Ecological Engineering 25:85-99.

Bard, A.M., H.T. Smith, E.D. Egensteiner, R. Mulholland, T.V. Harber, G.W. Heath, W.J.B. Miller, and J.S. Weske. 2002. A simple structure method to reduce road kills of Royal Terns at bridge sites. Wildlife Society Bulletin 30:603-605.

Barko, V.A., G.A. Feldhamer, M.C. Nicholson, and D.K. Davie. 2003. Urban habitat: A determinant of White-footed Mouse (Peromyscus leucopus) abundances in southern Illinois. Southeastern Naturalist 2:369-376.

Beasley, J.C., T.L. Devault, M.I. Retamosa, and O.E. Rhodes, Jr. 2007. A hierarchical analysis of habitat selection by Raccoons in northern Illinois. Journal of Wildlife Management 71:1125-1133.

Beauvais, G.P., and S.W. Buskirk. 1999. Modifying estimates of sampling effort to account for sprung traps. Wildlife Society Bulletin 27: 39-43.

Bell, D.A., D.P. Gregoire, and B.J. Walton 1996. Bridge Use by Peregrine Falcons in the San Francisco Bay Area. Pages 15-24 In Bird, D. M., D. Varland, and J. Negro, Editors. Raptors in Human Landscapes: Adaptations to Built and Cultivated Environments. Academic Publishers, San Diego, CA.

Bennett, F.B., S.C. Loeb, M.S. Bunch, and W.W. Bowerman. 2008. Use and selection of bridges as daily roosts by Rafinesque's Big-eared Bats. American Midland Naturalist 160:386-399.

Best, L.B., I.H. Campa, K.E. Kemp, R.J. Robel, M.R. Ryan, J.A. Savidge, J.H.P. Weeks, and S.R. Winterstein. 1997. Bird abundance and nesting in CRP fields and cropland in the Midwest: A regional approach. Wildlife Society Bulletin 25:864-877. 
Bowen, K.D., and F.J. Janzen. 2008. Human recreation and the nesting ecology of a freshwater turtle (Chrysemys picta). Chelonian Conservation and Biology 7:95-100.

Brander, S.M., J.A. Royle, and M. Eames. 2007. Evaluation of the status of anurans on a refuge in suburban Maryland. Journal of Herpetology 41:52-60.

Brawn, J.D., S.K. Robinson, and F.R. Thompson III. 2001. The role of disturbance in the ecology and conservation of birds. Annual Review of Ecology and Systematics 32:251-276.

Breckenridge, W.J. 1955. Observations on the life history of the Soft-shelled Turtle Trionyx. Copeia 1955:5-9.

Breeden, J.B., F. Hernandez, R.L. Bingham, N.J. Silvy, and G.L. Waggerman. 2008. Effects of traffic noise on auditory surveys of urban White-winged Doves. Wilson Journal of Ornithology 120:384-389.

Burger, A.E. 2001. Using radar to estimate populations and assess habitat associations of Marbled Murrelets. Journal of Wildlife Management 65:696-715.

Burnham, K.P., D.R. Anderson, and J.L. Laake. 1985. Efficiency and bias in strip and line transect sampling. Journal of Wildlife Management 49:1012-1018.

Burris, J.M., and A.W. Haney. 2005. Bird communities after blowdown in late successional Great Lakes spruce-fir forest. Wilson Bulletin 117:341-352.

Cade, T.J., and D.M. Bird. 1990. Peregrine Falcons (Falco peregrinus) nesting in an urban environment: A review. Canadian Field Naturalist 104:209-218.

Cagle, F.R. 1939. A system of marking turtles for future identification. Copeia 1939:170-173.

Campbell, T.M., and T.W. Clark. 1980. Short term effects of logging on Red-backed Voles and Deer Mice. Great Basin Naturalist 40:183-189.

Castleberry, S.B., P.B. Wood, W.M. Ford, N.L. Castleberry, and M.T. Mengak. 2002. Summer microhabitat selection by foraging Allegheny Woodrats (Neotoma magister) in a managed forest. American Midland Naturalist 147:93-101.

Clark, W.D., and J.R. Karr. 1979. Effect of highways on Red-winged Blackbird and Horned Lark populations. Wilson Bulletin 91:143-145.

Conner, C.A., B.A. Douthitt, and T.J. Ryan. 2005. Descriptive ecology of a turtle assemblage in an urban landscape. American Midland Naturalist 153:428-435.

Conover, M.R., W.C. Pitt, K.K. Kessler, T.J. Dubow, and W.A. Sanborn. 1995. Review of human injuries, illness and economic losses caused by wildlife in the U.S. Wildlife Society Bulletin 23:407-414.

Conover, W.J., and R.L. Iman. 1981. Rank transformations as a bridge between parametric and non-parametric statistics. The American Statistician 35:124-129. 
Conover, W.J. 1999. Practical Nonparametric Statistics. John Wiley and Sons, New York, New York.

Converse, S.J., G.C. White, and W.M. Block. 2006. Small mammal responses to thinning and wildfire in ponderosa pine dominated forests of the southwestern United States. Journal of Wildlife Management 70:1711-1722.

Czech, B., and P.R. Krausman. 1997. Distribution and causation of species endangerment in the United States. Science 277:1116-1117.

Dalmagro, A.D., and E.M. Vieira. 2005. Patterns of habitat utilization of small rodents in an area of Araucaria forest in southern Brazil. Austral Ecology 30:353-362.

Dayton, G.H., R.E. Jung, and S. Droege. 2004. Large scale habitat association of four desert anurans in Big Bend National Park, Texas, Journal of Herpetology 38:619-627.

DeGarady, C.J., and R.S. Holbrook. 2006. Using anurans as bioindicators of PCB contaminated streams. Journal of Herpetology 40:127-130.

DonnerWright, D.M., M.A. Bozek, J.R. Probst, and E.M. Anderson. 1999. Response of turtle assemblage to environmental gradients in the St., Croix River in Minnesota and Wisconsin, U.S.A. Canadian Journal of Zoology 77:989-1000.

Dufrene, M. and P. Legendre. 1997. Species assemblages and indicator species: the need for a flexible assmmetrical approach. Ecological Monographs 67:345-366.

Edalgo, J.A., and J.T. Anderson. 2007. Effects of prebaiting on small mammal trapping success in a Morrow's Honeysuckle-dominated area. Journal of Wildlife Management 71:246-250.

Elias, S.P., J.W. Witham, and M.L. Hunter Jr. 2004. Peromyscus leucopus abundance and acorn mast: Population fluctuations over 20 years. Journal of Mammalogy 85:743-747.

Elliott, A.G., and B.G. Root. 2006. Small mammal responses to silvicultural and precipitationrelated disturbance in northeastern Missouri riparian forests. Wildlife Society Bulletin 34:485-501.

Er, K.B., J.L. Innes, and A. Kozak. 2003. Effects of census duration on estimates of winter bird abundance and species richness along line transects in coastal coniferous forest fragments. Journal of Field Ornithology 74:119-124.

Ernst, C.H., R.W. Barbour, and J.E. Lovich. 1994. Turtles of the United States and Canada. Smithsonian Institution Press, Washington, D. C.

Forcey, G.M., J.T. Anderson, F.K. Ammer, and R.C. Whitmore. 2006. Comparison of two double-observer point-count approaches for estimating breeding bird abundance. Journal of Wildlife Management 70:1674-1681.

Forman, R.T. 2000. Estimate of the area affected ecologically by the road system in the United States. Conservation Biology 14:31-35. 
Forman, R.T., D. Sperling, J.A. Bissonette, A.P. Clevenger, C.D. Cutshall, V.H. Dale, L. Fahrig, R. France, C.R. Goldman, K. Heanue, J.A. Jones, F.J. Swanson, T. Turrentine, and T.C. Winter. 2003. Road Ecology: Science and Solutions. Island Press, Washington, D. C., USA.

Foster, M.L., and S.R. Humphrey. 1995. Use of highway underpasses by Florida Panthers and other wildlife. Wildlife Society Bulletin 23:95-100.

Freeman, S.N., D.G. Noble, S.E. Newson, and S.R. Baillie. 2007. Modeling population changes using data from different surveys: The common birds census and the breeding bird survey. Bird Study 54:61-72.

Gasith, A. and I. Sidis. 1984. Polluted water bodies, the main habitat of the Caspian Terrapin (Mauremys caspica rivulata) in Israel. Copeia 1984:216-219.

Gehrt, S.D. 2003. Raccoons. Pages 611-634. In Feldhamer, G.A., B.C. Thompson, and J.A. Chapman, editors. Wild Mammals of North America: Biology, Management, and Conservation. Johns Hopkins University Press. Baltimore, Maryland.

Germaine, S.S., S.S. Rosenstock, R.E. Schweinsburg, and W.S. Richardson. 1998. Relationships among breeding birds, habitat, and residential development in greater Tuscon, Arizona. Ecological Applications 8:680-691.

Germano, D.J., and R.B. Bury. 2001. Western Pond Turtles (Clemmys marmorata) in the Central Valley of California: Status and population structure. Transactions of the Western Section of the Wildlife Society 37:22-36.

Getz, L.L., M.K. Oli, J.E. Hoffman, and B. McGuire. 2006. Vole population fluctuations: Factors that initiate and determine intervals between them in Microtus ochrogaster. Journal of Mammalogy 87:387-393.

Gibbs, J.P., S. Woodward, M.L. Hunter, and A.E. Hutchinson. 1987. Determinants of Great Blue Heron colony distribution in coastal Maine. Auk 104:38-47.

GoBridges. 2009. Rebuilding America's Infrastructure. Available at http://www.rebuildingamericasinfrastructure.com/tag-bridges-1.html?id=323. Accessed 13 December 2009.

Green, N.B., and T.K. Pauley. 1987. Amphibians and Reptiles in West Virginia. University of Pittsburgh Press, Pittsburgh, Pennsylvania.

Grimm, N.B., J.M. Grove, S.T. A. Pickett, C.L. Redman. 2000. Integrated approaches to longterm studies of urban ecological systems. Bioscience 50:571-584.

Grubb, M.M. 1979. Effects of increased noise on nesting herons and egrets. Proceedings of the Colonial Waterbird Group 2:49-54.

Hansson, L. 1992. Small mammal communities on clearcuts in a latitudinal gradient. Acta Ecology 13:687-699. 
Haxton, T. 2000. Road mortality of Snapping Turtles, Chelydra serpentina, in central Ontario during their nesting period. Canadian Field Naturalist 114:106-110.

Helon, D.A., J.T. Anderson, and J.D. Osbourne. 2002. Comparison of interior versus roadside scent stations. Game and Wildlife Science 19:303-312.

Henning, J.A., and G. Schirato. 2006. Amphibian use of Chehalis River floodplain wetlands. Northwestern Naturalist 87:209-214.

Heusmann, H.W., and J.R. Sauer. 2000. The northeastern states' waterfowl breeding population survey. Wildlife Society Bulletin 28:355-364.

Hobson, K.A., and J. Schieck. 1999. Changes in bird communities in boreal mixedwood forest: Harvest and wildfire effects over 30 years. Ecological Applications 9:849-863.

Hoffman, C.O., and J.L. Gottschang. 1977. Numbers, distribution, and movements of a Raccoon population in a suburban residential community. Journal of Mammalogy 58:623-636.

Hubbard, M.W., B.J. Danielson, and R.A. Schmitz. 2000. Factors influencing the location of deer-vehicle accidents in Iowa. Journal of Wildlife Management 64:707-712.

Idcide West Virginia City Data. 2010. West Virginia Profile. Available online at http://www.idcide.com/citydata/wv/. Accessed 16 July 2010.

Idcide West Virginia Weather 2010. West Virginia Profile. Available online at http://www.idcide.com/weather/wv/. Accessed 16 July 2010.

Kaminski, J.A, M.L. Davis, M. Kelly, and P.D. Keyser. 2007. Disturbance effects of small mammal species in a managed Appalachian forest. American Midland Naturalist 157:385397.

Kamler, J.F., and P.S. Gipson. 2004. Survival and cause-specific mortality among furbearers in a protected area. American Midland Naturalist 151:27-34.

Karr, J.R., and R.R. Roth. 1971. Vegetation structure and avian diversity in several New World areas. American Naturalist 105:423-435.

Kellison, R. C., M. J. Young, R. R. Braham, and E. J. Jones. 1998. Major alluvial floodplains. Pages 291-323 In Messina, M. G., and W. H. Conner, Editors, Southern Forested Wetlands. Lewis Publishers, New York, New York.

Kimberly, D.A., and S.S. Bouchard. 2006. Relationship between anuran species richness and abundance and pond water quality. Ohio Journal of Science 106:55-55.

Kirk, D.A., A.W. Diamond, K.A. Hobson, and A.R. Smith. 1996. Breeding bird communities of the western and northern Canadian boreal forest: A relationship to forest type. Canadian Journal of Zoology 74:1749-1770.

Kirkland, G.L. 1990. Patterns of initial small mammal community change after clearcutting of temperate North American forests. Oikos 59:313-320. 
Kolozsvary, M.B., and R.K. Swihart. 1999. Habitat fragmentation and the distribution of amphibians: Patch and landscape correlates in farmland. Canadian Journal of Zoology 77:1288-1299.

Lesbarreres, D., C.R. Primmer, T. Lode, and J. Merila. 2006. The effects of 20 years of highway presence on the genetic structure of Rana dalmatina populations. Ecoscience 13:531-538.

Lindeman, P.V. 1996. Comparative life history of Painted Turtle (Chrysemys picta) in two habitats in the inland Pacific Northwest. Copeia 1996:114-130.

Lohr, S.M., S.A. Gauthreaux, and J.C. Kilgo. 2002. Importance of coarse woody debris to avian communities in loblolly pine forests. Conservation Biology 16:767-778.

Lougheed, L.W., and A. Breault. 1999. Estimating statistical power to evaluate ongoing waterfowl population monitoring. Journal of Wildlife Management 63:1359-1369.

Lozada, M., and N. Guthmann. 1998. Microhabitat selection under experimental conditions of three sigmodontine rodents. Ecoscience 5:51-55.

Marchand, M.N., and J.A. Litvaitis. 2004. Effects of habitat features and landscape composition on the population structure of a common aquatic turtle in a region undergoing rapid development. Conservation Biology 18:758-767.

Martell, A.M. 1983. Changes in small mammal communities after logging in north-central Ontario. Canadian Journal of Zoology 61:970-980.

McCune, B., and M.J. Mefford. 1999. PCORD for windows: multivariate analysis of ecological data, Version 4.0 MjM Software, Glenedon Beach, Oregon.

McCune, B., J.B. Grace, and D.L. Urban. 2002. Analysis of Ecological Communities. MjM Software Design, Glenedon Beach, Oregon.

McKinney, M.L. 2002. Urbanization, biodiversity, and conservation. BioScience 52:883-890.

Menzel, M.A., W.M. Ford, J. Laerm, and D. Krishon. 1999. Forest to wildlife openings: Habitat gradient analysis among small mammals in the southern Appalachians. Forest Ecology and Management 114:227-232.

Mitchell, J.C. 1988. Population ecology and life histories of the freshwater turtles Chrysemys picta and Sternotherus odoratus in an urban lake. Herpetological Monographs 2:40-61.

Moll, D. 1980. Dirty river turtle. Natural History 89:42-49.

Morissette, J.L., T.P. Cobb, R.M. Brigham, and P.C. James. 2002. The response of boreal forest songbird communities to fire and post-fire harvesting. Canadian Journal of Forest Research $32: 2169-2183$.

Mossman, M. 1994. Wisconsin Frogs and Toads Survey Instructions. Endangered Species Branch, Department of Natural Resources, Madison, Wisconsin. 
Ng, S.J., J.W. Dole, R.M. Sauvajot, S.P.D. Riley, and T.J. Valone. 2004. Use of highway undercrossings by wildlife in southern California. Biological Conservation 115:499-507.

Nichols, J.D., J.E. Hines, J.R. Sauer, F.W. Fallon, J.E. Fallon, and P.J. Heglund. 2000. A doubleobserver approach for estimating detection probability and abundance from point counts. Auk 117:393-408.

Niemi, G.J., and J.M. Hanowski. 1984. Relationships of breeding birds to habitat characteristics in logged areas. Journal of Wildlife Management 48:438-443.

Noss, R.F., H.B. Quigley, M.G. Hornocker, T. Merrill, and P.C. Paquet. 1996. Conservation biology and carnivore conservation in the Rocky Mountains. Conservation Biology 10:949963.

Odell, E.A., and R.L. Knight. 2001. Songbird and medium-sized mammal communities associated with exurban development in Pitkin, County, Colorado. Conservation Biology 15:1143-1150.

Oehler, J.D., and J.A. Litvaitis. 1996. The role of spatial scale in understanding responses of medium-sized carnivores to forest fragmentation. Canadian Journal of Zoology 74:20702079.

Okabe, F., and N. Agetsume. 2007. Habitat use by introduced Raccoons and native Raccoon Dogs in a deciduous forest in Japan. Journal of Mammalogy 88:1090-1097.

Oli, M.K., and F.S. Dobson. 2001. Population cycles in small mammals: The alpha hypothesis. Journal of Mammalogy 82:572-581.

Osbourne, J.D., J.T. Anderson, and A.B. Spurgeon. 2005. Effects of habitat on small mammal abundance in West Virginia. Wildlife Society Bulletin 33:814-822.

Owen, S.F., J.W. Edwards, W.M. Ford, J.M. Crum, and P.B. Wood. 2004. Raccoon roundworm in Raccoons in central West Virginia. Northeastern Naturalist 11:137-142.

Pagels, J.F., S.Y. Erdle, K.L. Uthus, and J.C. Mitchell. 1992. Small mammal diversity in forested and clearcut habitats in the Virginia piedmont. Virginia Journal of Science 43:171-176.

Parnell, J.F., D.G. Ainley, H. Blokpoel, B. Gain, T.W. Custer, J.L. Duri, S. Kress, J.A. Kushlan, W.E. Southern, L.E. Stenzel, and B.C. Thompson. 1988. Colonial waterbird management in North America. Colonial Waterbirds 11:129-345.

Pashley, D. N., and W. C. Barrow. 1992. Pages 315-320 in Finch, D. M., and P. W. Stangel, Editors. Status and management of neotropical migratory birds. United States Department of Agriculture Forest Service, General Technical Report RM-229.

Pearman, P.B. 2002. The scale of community structure: habitat variation and avian guilds in tropical forest understory. Ecological Monographs 72:19-39. 
Pearson, D.F., and L.F. Ruggiero. 2003. Transects versus grid trapping arrangements for sampling mammal communities. Wildlife Society Bulletin 31:454-459.

Peterson, R.T. 2002. Birds of Eastern and Central North America: Fifth Edition. Houghton Mifflin Harcourt Company, New York, New York.

Plummer, M.V., D.G. Krementz, L.A. Powell, and N.E. Mills. 2008. Effects of habitat disturbance on survival rates of Softshell Turtles (Apalone spinifera) in an urban stream. Journal of Herpetology 42:555-563.

Prange, S., S.D. Gehrt, and E.P. Wiggers. 2004. Influences of anthropogenic resources on Raccoon (Procyon lotor) movements and spatial distribution. Journal of Mammalogy 85:483-490.

Price, S.J., R.W. Howe, J.M. Hanowski, R.R. Regal, G.J. Niemi, and C.R. Smith. 2007. Are anurans of Great Lake coastal wetlands reliable indicators of ecological condition. Journal of Great Lakes Research 33:211-223.

Randa, L.A., and J.A. Yunger. 2006. Carnivore occurrence along an urban-rural gradient: A landscape-level analysis. Journal of Mammalogy 87:1154-1164.

Redmond, L.J., and M.T. Murphy. 2007. Unusual Barn Swallow nest placement in southeastern Oregon. Wilson Journal of Ornithology 119:307-309.

Rentch, J.S., R.H. Fortney, S.L. Stephenson, H.S. Adams, W.N. Grafton, and J.T. Anderson. 2005. Vegetation-site relationships of roadside plant communities in West Virginia, USA. Journal of Applied Ecology 42:129-138.

Riley, S.P., D.J. Hadidian, and D.A. Manski. 1998. Population density, survival, and rabies in Raccoon in an urban national park. Canadian Journal of Zoology 76:1153-1164.

Rizkalla, C.E., and R.K. Swihart. 2006. Community structure and differential response of aquatic turtles to agriculturally induced habitat fragmentation. Landscape Ecology 21:1361-1375.

Rodewald, P.G., and K.G. Smith. 1998. Short-term effects of understory and overstory management on breeding birds in Arkansas oak-hickory forests. Journal of Wildlife Management 62:1411-1417.

Romin, L.A., and J.A. Bissonette. 1996. Deer-vehicle collisions: Status of state monitoring activities and mitigation efforts. Wildlife Society Bulletin 24:276-283.

Root, B.G., F.R. Thompson, D.E. Figert, and E.K. Kritzell. 1990. Peromyscus leucopus response to clearcutting in a Missouri oak-hickory forest. Transactions of the Missouri Academy of Science 24:43-48.

Rosa, S., J.M. Palmeirim, and F. Morcira. 2003. Factors affecting waterbird abundance and species richness in an increasingly urbanized area of the Tagus Estuary in Portugal. Waterbirds 26:226-232. 
Rowland, M.M., M.J. Wisdom, B.K. Johnson, and J.G. Kie. 2000. Elk distribution and modeling in relation to roads. Journal of Wildlife Management 64:672-684.

Sacilotto, K.A. 2003. An assessment of natural cavity abundance, nest box use, and management recommendations for birds on the Ohio River Islands National Wildlife Refuge, West Virginia. Thesis, West Virginia University, Morgantown, West Virginia.

Sacks, B.N., H.B. Ernest, and E.E. Boydston. 2006. San Francisco's Golden Gate: A bridge between historically distinct Coyote (Canis latrans) populations. Western North American Naturalist 66:263-264.

Sargeant, G.A., D.H. Johnson, and W.E. Berg. 1998. Interpreting carnivore scent-station surveys. Journal of Wildlife Management 62:1235-1245.

Schieck, J., M. Nietfeld, B. Stelfox. 1995. Differences in bird species richness and abundance among three successional stages of aspen-dominated boreal forests. Canadian Journal of Zoology 73:1417-1431.

Schwabe, K.A., and P.W. Schuhmann. 2002. Deer-vehicle collisions and deer value: An analysis of competing literatures. Wildlife Society Bulletin 30:609-615.

Short, H.L., and R.J. Cooper. 1985. Habitat suitability index models: Great Blue Heron. U.S. Fish and Wildlife Service Biological Report 82 (10.99), Washington, D.C.

Silva, M., and M.E. Prince. 2008. The conservation value of hedgerows for small mammals in Prince Edward Island, Canada. American Midland Naturalist 159:110-124.

Silvy, N.J., R.R. Lopez, and M.J. Peterson. 2005. Wildlife Marking Techniques. Sixth edition. Pages 339-376 In Braun, C.E., editor. Techniques for wildlife investigation and management. The Wildlife Society, Bethesda, Maryland.

Skagen, S.K., C.P. Melchor, E. Muths. 2001. The interplay of habitat change, human disturbance, and species interactions in a waterbird colony. American Midland Naturalist 145:18-28.

Smith, M.D., P.J. Barbour, W. L. Burger, and S. J. Dinsmore. 2005. Density and diversity of overwintering birds in managed field borders in Mississippi. Wilson Bulletin 117:258-269.

Souza, F.L., and A.S. Abe. 2000. Feeding ecology, density and biomass of the Freshwater Turtle, Phrynops geoffroanus, inhabiting a polluted urban river in south-eastern Brazil. Journal of Zoology London 252:437-446.

Sullivan, T.P., R.A. Lautenschlager, and R.G. Wagner. 1999. Clearcutting and burning of northern spruce-fir forests: implications for small mammal communities. Journal of Applied Ecology 36:327-344.

Sutter, G.G., and R.M. Brigham. 1998. Avifaunal and habitat changes resulting from conversion of native prairie to crested wheat grass: Patterns at songbird community and species levels. Canadian Journal of Zoology 76:869-975. 
Tolin, W.A., and P.A. Schettig. 1983. A physical and biological survey of the Ohio River islands (Huntington District). U. S. Fish and Wildlife Service. Elkins, West Virginia.

Tordoff, H.B., and P.T. Redig. 1988. Dispersal, nest site selection, and age of first breeding in Peregrine Falcons released in the upper Midwest 1982-1988. Loon 60:148-151.

Trombulak, S.C., and C.A. Frissell. 2000. Review of ecological effects of roads on terrestrial and aquatic communities. Conservation Biology 14:18-30.

Tumlison, R. 2009. Breeding by Cliff Swallows (Petrochelidon pyrrhonota) in southern Arkansas. Southwestern Naturalist 54:208-210.

Turner, II, B.L., W.C. Clark, R.W. Kates, J.F. Richards, J.T. Matthews, and W.B. Meyer. 1991. The Earth as Transformed by Human Actions: Global and Regional Changes in the Biosphere Over the Past 300 Years. Cambridge University Press, Cambridge, England, UK.

United States Fish and Wildlife Service. 2000. Ohio River Islands National Wildlife Refuge Draft Comprehensive Conservation Plan and Environmental Assessment. United States of the Interior. Hadley, Massachusetts.

United States Fish and Wildlife Service. 2002. Ohio River Islands National Wildlife Refuge Comprehensive Conservation Plan. U.S. Fish and Wildlife Service, Parkersburg, West Virginia.

Van Etten, K.W., K.R. Wilson, and R.L. Crabtree. 2007. Habitat use of Red Foxes in Yellowstone National Park based on snow tracking and telemetry. Journal of Mammalogy 88:1498-1507.

Vankat, J.L., and D.G. Roy. 2002. Landscape invisibility by exotic species. Pages 170-192 In Gutzwiller, K.J., Editor. Applying Landscape Ecology in Biological Conservation. Springer, New York, New York.

Vennesland, R.G., and R.W. Butler. 2004. Factors influencing Great Blue Heron nesting productivity on the Pacific Coast of Canada from 1998 to 1999. Waterbirds 27:289-296.

Vitt, L.J., J.P. Caldwell, H.M. Wilbur, and D.C. Smith. 1990. Amphibians as harbingers of decay. BioScience 40:418.

Vos, C.C., and J.P. Chardon. 1998. Effects of habitat fragmentation and road density on the distribution pattern of the Moor Frog, Rana arvilis. Journal of Applied Ecology 35:44-56.

Warren, S.D., and R. Buttner. 2008. Relationship of endangered amphibians to landscape disturbance. Journal of Wildlife Management 72:738-744.

Watts, B.D., and D.S. Bradshaw. 1994. The influence of human disturbance on the location of Great Blue Heron colonies in the lower Chesapeake Bay. Colonial Waterbirds 17:184-186.

Weber, J.M., and J.S. Meia. 1996. Habitat use by the Red Fox Vulpes vulpes in a mountainous region. Ethology Ecology and Evolution 8:223-232. 
Weller, M.W. 1999. Wetland Birds, Habitat Resources and Conservation. Cambridge University Press, New York, New York.

Wigley, T.B., and R.A. Lancia. 1998. Wildlife Communities. Pages 205-236 In Messina, M.G. and W.H. Conner, Editors. Southern Forested Wetlands. Lewis Publishers, New York, New York.

Willson, J.D., and M.E. Dorcas. 2003. Effects of habitat disturbance on stream salamanders: Implications for buffer zone and watershed management. Conservation Biology 17:763-761.

Yunger, J.A., and L.A. Randa. 1999. Trap decontamination using hypochlorite: Effects on trappability of small mammals. Journal of Mammalogy 80:1336-1340.

Zadnik, A.K., J.T. Anderson, P.B. Wood, and K. Bledsoe. 2009. Wildlife use of back channels associated with islands on the Ohio River. Wetlands 29:543-551.

Zimmerman, B.L. 1991. Distribution and abundance of frogs in a central Amazonian forest. Dissertation, Florida State University, Tallahassee, Florida.

Zuckerberg, B., and P.D. Vickery. 2006. Effects of mowing and burning on shrubland and grassland birds on Nantucket Island, Massachusetts. Wilson Journal of Ornithology 118:353363. 
Table 1: Summary of waterbird variables (abundances in the form of individuals/39.25 ha plot) with their means and standard errors for Blennerhassett, Buckley, and Muskingum islands, West Virginia, USA for the 2007-2009 field seasons with same letters indicating no significance among sites (bolded means are significant at $\alpha=0.05$ ).

\begin{tabular}{|c|c|c|c|c|c|c|c|c|c|}
\hline \multirow{2}{*}{ Common Name } & \multirow{2}{*}{ Scientific Name } & \multicolumn{2}{|c|}{ Blennerhassett } & \multicolumn{2}{|c|}{ Buckley } & \multicolumn{2}{|c|}{ Muskingum } & \multirow[b]{2}{*}{$F_{2,9}$} & \multirow[b]{2}{*}{$P$} \\
\hline & & $\bar{x}$ & SE & $\bar{x}$ & SE & $\bar{x}$ & SE & & \\
\hline Canada Goose & Branta canadensis Linnaeus & $28.59 a$ & 8.12 & $6.86 a$ & 2.46 & $10.32 a$ & 2.52 & 1.51 & 0.272 \\
\hline Double-crested Cormorant & Phalacrocorax auritus Lesson & $0.09 a$ & 0.09 & $0.00 a$ & 0.00 & $1.18 a$ & 1.00 & 1.44 & 0.286 \\
\hline Great Blue Heron & Ardea herodias Linnaeus & $0.32 b$ & 0.12 & $0.09 b$ & 0.06 & $1.23 a$ & 0.39 & 5.33 & 0.030 \\
\hline Mallard & Anas platyrhynchos Linnaeus & $2.50 a$ & 0.81 & $0.64 b$ & 0.29 & $2.50 a$ & 0.57 & 5.24 & 0.031 \\
\hline Wood Duck & Aix sponsa Linnaeus & $0.91 a$ & 0.35 & $0.91 a$ & 0.35 & $0.64 a$ & 0.30 & 0.58 & 0.579 \\
\hline All Waterbirds & & $33.77 a$ & 7.99 & $8.82 a$ & 2.53 & $19.59 a$ & 4.20 & 3.38 & 0.080 \\
\hline Species Richness & & $2.50 a$ & 0.31 & $1.31 b$ & 0.20 & $3.50 a$ & 0.35 & 5.54 & 0.027 \\
\hline Shannon Diversity Index & & $0.49 b$ & 0.10 & $0.19 c$ & 0.06 & $0.85 a$ & 0.09 & 8.64 & 0.008 \\
\hline
\end{tabular}


Table 2: Summary of songbird variables (abundances in the form of individuals/ha) with their means and standard errors for Blennerhassett, Buckley, and Muskingum islands, West Virginia, USA and at 0, 100, and $300 \mathrm{~m}$ from the bridge for the 2008-2009 field seasons with same letters indicating no significance among sites or distances (bolded means are significant at $\alpha=0.05$ ).

\begin{tabular}{|c|c|c|c|c|c|c|c|c|c|c|}
\hline \multirow{3}{*}{ Common Name } & \multirow{3}{*}{ Scientific Name } & \multicolumn{6}{|c|}{ Island } & \multirow[b]{3}{*}{$\mathrm{df}$} & \multirow[b]{3}{*}{$F$} & \multirow[b]{3}{*}{$P$} \\
\hline & & \multicolumn{2}{|c|}{ Blennerhassett } & \multicolumn{2}{|c|}{ Buckley } & \multicolumn{2}{|c|}{ Muskingum } & & & \\
\hline & & $\bar{x}$ & SE & $\overline{\bar{x}}$ & SE & $\bar{x}$ & SE & & & \\
\hline American Goldfinch & Spinus tristis Linnaeus & $0.38 a$ & 0.08 & $0.60 a$ & 0.12 & $0.42 a$ & 0.16 & $2,54.6$ & 1.41 & 0.254 \\
\hline American Robin & Turdus migratorius Linnaeus & $0.82 a$ & 0.14 & $0.94 a$ & 0.16 & $0.67 a$ & 0.20 & $2,54.7$ & 1.11 & 0.337 \\
\hline Carolina Chickadee & Poecile carolinensis Audubon & $0.33 b$ & 0.10 & $0.21 b$ & 0.07 & $1.13 a$ & 0.28 & $2,56.0$ & 17.36 & $<0.001$ \\
\hline Carolina Wren & Thryothorus ludovicianus Latham & $0.84 a$ & 0.13 & $0.73 a$ & 0.15 & $1.33 b$ & 0.14 & $2,55.0$ & 7.10 & 0.002 \\
\hline Common Yellowthroat & Geothlypis trichas Linnaeus & $0.58 a$ & 0.10 & $0.23 a$ & 0.07 & $0.33 a$ & 0.13 & $2,53.6$ & 2.27 & 0.114 \\
\hline European Starling & Sturnus vulgaris Linnaeus & $0.25 a$ & 0.14 & $1.15 b$ & 0.49 & $0.04 a$ & 0.04 & $2,117.0$ & 17.76 & $<0.001$ \\
\hline Gray Catbird & Dumetella carolinensis Linnaeus & $0.78 b$ & 0.11 & $1.38 \mathrm{a}$ & 0.17 & $1.50 \mathrm{a}$ & 0.21 & $2,117.0$ & 8.32 & $<0.001$ \\
\hline House Wren & Troglodytes aedon Vieillot & $0.82 a$ & 0.15 & $0.31 b$ & 0.09 & $0.29 b$ & 0.13 & $2,52.7$ & 5.71 & 0.006 \\
\hline Indigo Bunting & Passerina cyanea Linnaeus & $0.55 a$ & 0.10 & $0.60 \mathrm{a}$ & 0.10 & $0.96 a$ & 0.15 & $2,117.0$ & 2.82 & 0.063 \\
\hline Mourning Dove & Zenaida macroura Linnaeus & $0.15 a$ & 0.05 & $1.25 a$ & 0.85 & $0.08 a$ & 0.06 & $2,54.4$ & 0.54 & 0.586 \\
\hline Northern Cardinal & Cardinalis cardinalis Linnaeus & $0.62 a$ & 0.10 & $0.90 \mathrm{a}$ & 0.16 & $1.21 \mathrm{a}$ & 0.19 & $2,55.3$ & 2.91 & 0.063 \\
\hline Red-eyed Vireo & Vireo olivaceus Linnaeus & $0.16 \mathrm{~b}$ & 0.06 & $0.54 a$ & 0.09 & $0.79 a$ & 0.13 & $2,56.4$ & 10.86 & $<0.001$ \\
\hline Red-winged Blackbird & Agelaius phoeniceus Linnaeus & $1.35 a$ & 0.31 & $0.15 a$ & 0.05 & $0.21 a$ & 0.10 & $2,50.7$ & 4.56 & 0.015 \\
\hline Rock Pigeon & Columba livia Gmelin & $0.29 b$ & 0.12 & $0.90 \mathrm{a}$ & 0.29 & $0.00 c$ & 0.00 & $2,55.4$ & 11.45 & $<0.001$ \\
\hline Song Sparrow & Melospiza melodia Wilson & $2.91 a$ & 0.21 & $1.79 b$ & 0.20 & $1.83 b$ & 0.26 & $2,54.5$ & 6.32 & 0.003 \\
\hline Tufted Titmouse & Baeolophus bicolor Linnaeus & $0.20 \mathrm{~b}$ & 0.05 & $0.29 b$ & 0.07 & $1.13 a$ & 0.23 & $2,117.0$ & 16.34 & $<0.001$ \\
\hline Yellow Warbler & Dendroica petechia Linnaeus & $0.25 b$ & 0.07 & $0.65 a$ & 0.13 & $0.17 b$ & 0.08 & $2,56.5$ & 3.70 & 0.039 \\
\hline All Songbirds & & $14.60 \mathrm{~b}$ & 0.61 & $16.83 a$ & 1.22 & $18.13 a$ & 1.01 & $2,58.4$ & 5.89 & 0.005 \\
\hline Species Richness & & $9.04 b$ & 0.38 & $9.77 b$ & 0.63 & $12.58 \mathrm{a}$ & 0.67 & $2,55.6$ & 11.83 & $<0.001$ \\
\hline Shannon Diversity Index & & $2.01 b$ & 0.04 & $1.98 \mathrm{~b}$ & 0.08 & $2.40 a$ & 0.06 & $2,54.7$ & 7.29 & 0.002 \\
\hline
\end{tabular}


Table 2 Extended

\begin{tabular}{|c|c|c|c|c|c|c|c|c|c|c|c|}
\hline \multicolumn{6}{|c|}{ Distance } & \multirow[b]{3}{*}{$d f$} & \multirow[b]{3}{*}{$F$} & \multirow[b]{3}{*}{$P$} & \multirow{2}{*}{\multicolumn{3}{|c|}{ Interaction }} \\
\hline \multicolumn{2}{|c|}{$0 \mathrm{~m}$} & \multicolumn{2}{|c|}{$100 \mathrm{~m}$} & \multicolumn{2}{|c|}{$300 \mathrm{~m}$} & & & & & & \\
\hline $\bar{x}$ & SE & $\bar{x}$ & SE & $\bar{x}$ & SE & & & & $\mathrm{df}$ & $F$ & $P$ \\
\hline $0.35 a$ & 0.13 & $0.52 a$ & 0.11 & $0.53 a$ & 0.12 & $2,55.4$ & 0.66 & 0.520 & $4,50.7$ & 1.22 & 0.314 \\
\hline $0.83 a$ & 0.17 & $1.00 \mathrm{a}$ & 0.20 & $0.76 a$ & 0.16 & $2,55.6$ & 0.41 & 0.665 & $4,55.7$ & 1.19 & 0.325 \\
\hline $0.17 a$ & 0.08 & $0.36 a$ & 0.12 & $0.24 a$ & 0.08 & $2,55.6$ & 3.33 & 0.053 & $4,55.9$ & 4.04 & 0.006 \\
\hline $0.35 b$ & 0.16 & $1.05 a$ & 0.17 & $0.76 a$ & 0.14 & $2,55.9$ & 4.28 & 0.019 & $4,55.4$ & 1.65 & 0.176 \\
\hline $0.13 a$ & 0.07 & $0.36 a b$ & 0.10 & $0.66 a$ & 0.12 & $2,54.4$ & 4.19 & 0.020 & $4,52.0$ & 1.52 & 0.210 \\
\hline $1.48 a$ & 0.57 & $0.14 a$ & 0.08 & $0.76 a$ & 0.55 & $2,117.0$ & 22.14 & $<0.001$ & $4,117.0$ & 1.96 & 0.105 \\
\hline $0.87 a$ & 0.21 & $1.24 a$ & 0.19 & $0.97 a$ & 0.12 & $2,117.0$ & 1.16 & 0.316 & $4,117.0$ & 1.61 & 0.176 \\
\hline $0.74 a$ & 0.26 & $0.67 a$ & 0.15 & $0.39 a$ & 0.10 & $2,52.5$ & 0.21 & 0.811 & $4,52.7$ & 2.73 & 0.039 \\
\hline $0.52 a$ & 0.16 & $0.74 a$ & 0.12 & $0.42 a$ & 0.09 & $2,117.0$ & 2.02 & 0.138 & 4, 117.0 & 0.59 & 0.671 \\
\hline 0.30a & 0.15 & $0.40 a$ & 0.20 & $1.16 a$ & 1.05 & $2,55.2$ & 0.14 & 0.872 & $4,56.4$ & 0.56 & 0.692 \\
\hline $0.52 a$ & 0.15 & $0.67 a$ & 0.11 & $0.97 a$ & 0.19 & $2,56.1$ & 1.55 & 0.222 & $4,55.8$ & 0.88 & 0.480 \\
\hline $0.26 a$ & 0.11 & $0.31 a$ & 0.09 & $0.42 a$ & 0.10 & $2,57.3$ & 1.28 & 0.286 & $4,56.4$ & 0.54 & 0.707 \\
\hline $0.17 a$ & 0.08 & $0.64 a$ & 0.29 & $1.32 \mathrm{a}$ & 0.33 & $2,51.5$ & 2.60 & 0.080 & $4,26.4$ & 0.38 & 0.824 \\
\hline $2.57 a$ & 0.51 & $0.00 \mathrm{~b}$ & 0.00 & $0.00 \mathrm{~b}$ & 0.00 & $2,55.1$ & 23.48 & $<0.001$ & $4,55.4$ & 9.35 & $<0.001$ \\
\hline $2.26 a$ & 0.33 & $2.33 a$ & 0.26 & $2.53 a$ & 0.24 & $2,55.4$ & 0.27 & 0.762 & $4,54.3$ & 0.57 & 0.685 \\
\hline 0.09a & 0.06 & $0.29 a$ & 0.07 & $0.29 a$ & 0.07 & 2, 117.0 & 1.84 & 0.163 & $4,117.0$ & 1.50 & 0.206 \\
\hline $0.48 a$ & 0.14 & $0.50 a$ & 0.13 & $0.34 a$ & 0.10 & $2,57.4$ & 0.28 & 0.759 & $4,56.3$ & 0.09 & 0.984 \\
\hline $15.57 a$ & 1.44 & $15.12 a$ & 0.82 & $16.26 a$ & 1.29 & $2,54.5$ & 0.48 & 0.619 & $4,54.8$ & 2.69 & 0.040 \\
\hline $8.22 a$ & 0.72 & $9.74 a$ & 0.57 & $9.68 a$ & 0.59 & $2,56.4$ & 2.04 & 0.139 & $4,55.6$ & 1.85 & 0.133 \\
\hline $1.86 a$ & 0.07 & $2.04 a$ & 0.08 & $2.02 \mathrm{a}$ & 0.07 & $2,55.4$ & 1.22 & 0.303 & $4,54.7$ & 0.72 & 0.581 \\
\hline
\end{tabular}


Table 3: Summary statistics for multi-response permutation procedures for songbird strata for sites (Blennerhassett, Buckley, and Muskingum islands, West Virginia, USA) and distance from bridge (0, 100, and $300 \mathrm{~m})$ during the 2008 and 2009 field seasons. Strata were grouped by site and distance. The $T$ statistic is the weighted mean within-group distance, the $A$ statistic is the chance-corrected within group agreement, and the $P$ statistic is the $\mathrm{P}$-value $(\alpha=0.05)$.

\begin{tabular}{|c|c|c|c|c|c|c|}
\hline Stratum & Sorensen Similarity & $\begin{array}{l}\text { Observed Average } \\
\text { Sorensen Distance }\end{array}$ & $\begin{array}{l}\text { Expected Average } \\
\text { Sorensen Distance }\end{array}$ & $T$ & $A$ & $P$ \\
\hline Site & 0.755 & 0.408 & 0.500 & -6.70 & 0.184 & $<0.001$ \\
\hline Blennerhassett vs. Buckley & 0.851 & . & . & -3.56 & 0.091 & 0.002 \\
\hline Blennerhassett vs. Muskingum & 0.844 & . & . & -5.84 & 0.194 & $<0.001$ \\
\hline Buckley vs. Muskingum & 0.842 & . & . & -4.83 & 0.157 & $<0.001$ \\
\hline Distance & 0.706 & 0.456 & 0.500 & -2.38 & 0.088 & 0.016 \\
\hline $100 \mathrm{~m}$ vs. $300 \mathrm{~m}$ & 0.875 & . & . & 1.09 & -0.035 & 0.877 \\
\hline $300 m$ vs. $0 m$ & 0.776 & . & . & -3.61 & 0.156 & $<0.001$ \\
\hline $100 \mathrm{~m}$ vs. $0 \mathrm{~m}$ & 0.747 & . & . & -2.99 & 0.130 & 0.005 \\
\hline
\end{tabular}


Table 4: Species indicator values (IV) for each site (Blennerhassett, Buckley, and Muskingum islands, West Virginia, USA), distance $(0,100$, and $300 \mathrm{~m})$, and location (under or away from bridge (100 and $300 \mathrm{~m}$ transects combined)). $P$-values based on the proportion of randomized trials with expected $I V>$ observed $I V$. Only species whose observed $I V$ exceeds $I V$ exp at $P<0.05$ are shown; 4,999 permutations were used in a Monte Carlo test. $I V=100 \times$ (relative abundance $\times$ relative frequency).

\begin{tabular}{|c|c|c|c|c|c|c|}
\hline Common Name & Scientific Name & Site or Distance & $\mathrm{IV}_{\max }$ & $\bar{x}$ & SD & $P$ \\
\hline Blue Jay & Cyanocitta cristata Linnaeus & Muskingum & 46.4 & 27.5 & 7.09 & 0.0178 \\
\hline Blue-gray Gnatcatcher & Polioptila caerulea Linnaeus & Muskingum & 53.9 & 31.4 & 6.76 & 0.0058 \\
\hline Carolina Chickadee & Poecile carolinensis Audubon & Muskingum & 66.6 & 35.1 & 7.32 & 0.0004 \\
\hline Cliff Swallow & Petrochelidon pyrrhonota Vieillot & $0 \mathrm{~m}$ & 50.0 & 14.9 & 8.02 & 0.0084 \\
\hline Downy Woodpecker & Picoides pubescens Linnaeus & Muskingum & 54.1 & 27.1 & 7.61 & 0.0066 \\
\hline Eastern Towhee & Pipilo erythrophthalmus Linnaeus & Muskingum & 83.8 & 25.6 & 8.09 & 0.0002 \\
\hline House Finch & Carpodacus mexicanus Muller & Buckley & 41.7 & 14.6 & 7.13 & 0.0042 \\
\hline Indigo Bunting & Passerina cyanea Linnaeus & Muskingum & 45.5 & 37.8 & 3.62 & 0.0322 \\
\hline Northern Cardinal & Cardinalis cardinalis Linnaeus & Muskingum & 45.9 & 37.2 & 4.45 & 0.0458 \\
\hline Red-bellied Woodpecker & Melanerpes carolinus Linnaeus & Muskingum & 56.4 & 26.2 & 7.79 & 0.0040 \\
\hline Red-eyed Vireo & Vireo olivaceus Linnaeus & Muskingum & 54.3 & 34.3 & 5.95 & 0.0028 \\
\hline Rock Pigeon & Columba livia Gmelin & $0 \mathrm{~m}$ & 100.0 & 20.1 & 9.12 & 0.0002 \\
\hline Song Sparrow & Melospiza melodia Wilson & Blennerhassett & 46.3 & 37.0 & 2.47 & 0.0004 \\
\hline Tufted Titmouse & Baeolophus bicolor Linnaeus & Muskingum & 71.0 & 35.5 & 6.66 & 0.0002 \\
\hline White-breasted Nuthatch & Sitta carolinensis Latham & Muskingum & 77.7 & 23.0 & 7.77 & 0.0002 \\
\hline Wood Thrush & Hylochichla mustelina Gmelin & Muskingum & 62.8 & 23.8 & 8.30 & 0.0014 \\
\hline
\end{tabular}


Table 5: Summary of anuran variables for Blennerhassett and Grape islands, West Virginia, USA and for 0, 100, and 300 $\mathrm{m}$ from the bridge at Blennerhassett including relative abundances (individuals/transect) and call index codes (Wisconsin Index 0-3) of anurans used in analyses as well as species richness and diversity for the 2008-2009 field seasons (none of the means differed significantly by sites or distances at $\alpha=0.05$ ).

\begin{tabular}{|c|c|c|c|c|c|c|c|}
\hline \multirow{3}{*}{ Metric } & \multirow{3}{*}{ Scientific Name } & \multicolumn{4}{|c|}{ Island } & \multirow[b]{3}{*}{$F_{1,41}$} & \multirow[b]{3}{*}{$P$} \\
\hline & & \multicolumn{2}{|c|}{ Blennerhassett } & \multicolumn{2}{|c|}{ Grape } & & \\
\hline & & $\bar{x}$ & SE & $\bar{x}$ & SE & & \\
\hline \multicolumn{8}{|l|}{ Relative Abundance } \\
\hline American Bullfrog & Lithobates catesbeianus Shaw & 0.47 & 0.19 & 0.33 & 0.17 & 0.23 & 0.634 \\
\hline Cope's Gray Tree Frog & Hyla chrysocelis Cope & 1.00 & 0.39 & 0.56 & 0.39 & 0.05 & 0.828 \\
\hline Northern Green Frog & Lithobates clamitans melanota Rafinesque & 0.47 & 0.21 & 0.22 & 0.15 & 0.01 & 0.984 \\
\hline Spring Peeper & Pseudacris crucifer Wied-Neuwied & 15.24 & 3.91 & 17.33 & 8.18 & 0.12 & 0.727 \\
\hline All Anurans & & 17.35 & 3.78 & 19.11 & 7.75 & 0.25 & 0.623 \\
\hline \multicolumn{8}{|l|}{ Call Index Codes } \\
\hline American Bullfrog & Lithobates catesbeianus Shaw & 0.24 & 0.07 & 0.33 & 0.17 & 0.35 & 0.560 \\
\hline Cope's Gray Tree Frog & Hyla chrysocelis Cope & 0.38 & 0.12 & 0.22 & 0.14 & 0.17 & 0.682 \\
\hline Northern Green Frog & Lithobates clamitans melanota Rafinesque & 0.17 & 0.07 & 0.22 & 0.14 & 0.09 & 0.761 \\
\hline Spring Peeper & Pseudacris crucifer Wied-Neuwied & 1.09 & 0.23 & 1.22 & 0.46 & 0.13 & 0.724 \\
\hline All Anurans & & 2.00 & 0.24 & 2.22 & 0.32 & 0.72 & 0.400 \\
\hline Species Richness & & 1.24 & 0.15 & 1.56 & 0.29 & 0.72 & 0.402 \\
\hline Shannon Diversity Index & & 0.20 & 0.05 & 0.14 & 0.08 & 0.17 & 0.682 \\
\hline
\end{tabular}


Table 5 Extended

\begin{tabular}{|c|c|c|c|c|c|c|c|}
\hline \multicolumn{6}{|c|}{ Distance } & \multirow[b]{3}{*}{$F_{2,31}$} & \multirow[b]{3}{*}{$P$} \\
\hline \multicolumn{2}{|c|}{$0 \mathrm{~m}$} & \multicolumn{2}{|c|}{$100 \mathrm{~m}$} & \multicolumn{2}{|c|}{$300 \mathrm{~m}$} & & \\
\hline $\bar{x}$ & SE & $\bar{x}$ & SE & $\bar{x}$ & SE & & \\
\hline 0.17 & 0.17 & 0.55 & 0.31 & 0.72 & 0.47 & 0.78 & 0.466 \\
\hline 1.83 & 0.91 & 0.45 & 0.37 & 0.64 & 0.54 & 0.67 & 0.520 \\
\hline 0.75 & 0.54 & 0.64 & 0.28 & 0.00 & 0.00 & 2.03 & 0.148 \\
\hline 9.08 & 5.54 & 18.73 & 7.48 & 18.45 & 7.55 & 0.57 & 0.570 \\
\hline 12.08 & 5.26 & 20.64 & 7.41 & 19.82 & 7.27 & 0.36 & 0.701 \\
\hline 0.08 & 0.08 & 0.36 & 0.15 & 0.27 & 0.14 & 1.30 & 0.287 \\
\hline 0.58 & 0.26 & 0.27 & 0.14 & 0.27 & 0.19 & 0.45 & 0.644 \\
\hline 0.17 & 0.11 & 0.36 & 0.11 & 0.00 & 0.00 & 2.68 & 0.084 \\
\hline 0.75 & 0.33 & 1.27 & 0.43 & 1.27 & 0.44 & 0.37 & 0.691 \\
\hline 1.83 & 0.41 & 2.36 & 0.34 & 1.82 & 0.50 & 0.36 & 0.698 \\
\hline 1.17 & 0.28 & 1.64 & 0.20 & 0.91 & 0.25 & 2.87 & 0.072 \\
\hline 0.24 & 0.10 & 0.30 & 0.09 & 0.07 & 0.07 & 1.98 & 0.155 \\
\hline
\end{tabular}


Table 6: Summary of turtle and small mammal trapping data for Blennerhassett, Buckley, Muskingum, and Grape islands, West Virginia, USA (averages in the form of captures/100 trap nights) for the 2008 and 2009 field seasons.

\begin{tabular}{|c|c|c|c|c|c|c|c|c|}
\hline Taxa & Attempts & Trap Nights & Captures & Recaptures & Individuals & Species & $\bar{x}$ & SE \\
\hline \multicolumn{9}{|l|}{$\underline{\text { Turtles }}$} \\
\hline Blennerhassett Island & 210 & 200 & 42 & 2 & 40 & 4 & 19.00 & 3.77 \\
\hline Buckley Island & 167 & 133 & 14 & 1 & 13 & 4 & 9.92 & 3.46 \\
\hline Muskingum Island & 171 & 150 & 15 & 0 & 15 & 2 & 9.55 & 3.98 \\
\hline Grape Island & 180 & 168 & 25 & 5 & 20 & 2 & 11.69 & 2.74 \\
\hline Totals & 728 & 651 & 96 & 8 & 88 & 5 & 13.95 & 1.81 \\
\hline \multicolumn{9}{|l|}{ Small Mammals } \\
\hline Blennerhassett Island & 6,748 & $6,098.5$ & 761 & 306 & 455 & 7 & 7.37 & 0.86 \\
\hline Buckley Island & 6,469 & $5,600.5$ & 213 & 34 & 179 & 7 & 2.97 & 0.36 \\
\hline Muskingum Island & 3,231 & $2,925.5$ & 150 & 51 & 99 & 4 & 3.35 & 0.49 \\
\hline Totals & 16,448 & $14,624.5$ & 1,124 & 391 & 733 & 9 & 4.85 & 0.42 \\
\hline
\end{tabular}


Table 7: Summary of turtle variables (abundances in the form of captures/100 trap nights) with their means and standard errors for Blennerhassett, Buckley, Muskingum, and Grape islands, West Virginia, USA and 0, 100, and $300 \mathrm{~m}$ from the bridge for the 2008 and 2009 field seasons with same letters indicating no significance among sites or distances (bolded means are significant at $\alpha=0.05$ ).

\begin{tabular}{|c|c|c|c|c|c|c|c|c|c|c|c|}
\hline \multirow{3}{*}{ Common Name } & \multirow{3}{*}{ Scientific Name } & \multicolumn{8}{|c|}{ Island } & \multirow[b]{3}{*}{$F_{3,72}$} & \multirow[b]{3}{*}{$P$} \\
\hline & & \multicolumn{2}{|c|}{ Blennerhassett } & \multicolumn{2}{|c|}{ Buckley } & \multicolumn{2}{|c|}{ Muskingum } & \multicolumn{2}{|c|}{ Grape } & & \\
\hline & & $\bar{x}$ & SE & $\bar{x}$ & SE & $\bar{x}$ & SE & $\bar{x}$ & SE & & \\
\hline Eastern Spiny Softshell & Apalone spinifera spinifera Lesueur & $9.00 \mathrm{a}$ & 2.60 & $7.81 a$ & 3.53 & $6.25 a$ & 3.90 & $4.67 a$ & 1.32 & 0.73 & 0.537 \\
\hline Common Snapping Turtle & Chelydra serpentina Linnaeus & $5.94 a$ & 3.05 & $0.70 a$ & 0.70 & $3.30 a$ & 1.68 & $7.01 \mathrm{a}$ & 2.27 & 2.06 & 0.114 \\
\hline Northern Map Turtle & Graptemys geographica Le Suer & $2.22 a$ & 1.57 & $0.70 a$ & 0.70 & $0.00 a$ & 0.00 & $0.00 \mathrm{a}$ & 0.00 & 0.59 & 0.624 \\
\hline Midland Painted Turtle & Chrysemys picta marginata Agassiz & $1.83 a$ & 1.07 & $0.00 a$ & 0.00 & $0.00 a$ & 0.00 & $0.00 \mathrm{a}$ & 0.00 & 2.75 & 0.049 \\
\hline All Turtles & & 19.00a & 3.77 & $9.92 a$ & 3.46 & $9.55 a$ & 3.98 & $11.69 a$ & 2.74 & 1.88 & 0.140 \\
\hline Species Richness & & $0.80 a$ & 0.14 & $0.47 a$ & 0.12 & $0.40 a$ & 0.11 & $0.80 a$ & 0.16 & 2.56 & 0.062 \\
\hline Shannon Diversity Index & & $0.10 a$ & 0.04 & $0.00 \mathrm{~b}$ & 0.00 & $0.00 \mathrm{~b}$ & 0.00 & $0.10 a$ & 0.05 & 3.13 & 0.031 \\
\hline
\end{tabular}


Table 7 Extended

\begin{tabular}{|c|c|c|c|c|c|c|c|c|c|}
\hline \multicolumn{6}{|c|}{ Distance } & \multirow[b]{3}{*}{$F_{2,72}$} & \multirow[b]{3}{*}{$P$} & \multirow{2}{*}{\multicolumn{2}{|c|}{ Interaction }} \\
\hline \multicolumn{2}{|c|}{$0 \mathrm{~m}$} & \multicolumn{2}{|c|}{$100 \mathrm{~m}$} & \multicolumn{2}{|c|}{$300 \mathrm{~m}$} & & & & \\
\hline $\bar{x}$ & SE & $\bar{x}$ & SE & $\bar{x}$ & SE & & & $F_{6,72}$ & $P$ \\
\hline $6.90 a$ & 3.87 & $12.59 a$ & 3.85 & $7.53 a$ & 2.96 & 1.47 & 0.236 & 0.70 & 0.653 \\
\hline $5.17 a$ & 4.17 & $6.06 a$ & 3.74 & $3.08 a$ & 1.52 & 0.11 & 0.900 & 0.24 & 0.963 \\
\hline $0.00 a$ & 0.00 & $1.85 a$ & 1.85 & $1.98 a$ & 1.40 & 0.98 & 0.382 & 0.27 & 0.948 \\
\hline $1.39 a$ & 1.39 & $0.00 a$ & 0.00 & $1.93 a$ & 1.38 & 1.57 & 0.215 & 0.83 & 0.554 \\
\hline $12.46 a$ & 6.04 & $20.24 a$ & 4.80 & $13.52 \mathrm{a}$ & 3.54 & 1.65 & 0.199 & 0.75 & 0.608 \\
\hline $0.50 a$ & 0.27 & $0.78 a$ & 0.13 & $0.61 a$ & 0.16 & 1.43 & 0.247 & 0.94 & 0.474 \\
\hline $0.07 a$ & 0.07 & $0.03 a$ & 0.03 & $0.07 a$ & 0.05 & 0.20 & 0.820 & 1.50 & 0.190 \\
\hline
\end{tabular}


Table 8: Summary of small mammal variables (abundances in the form of captures/100 trap nights) for Blennerhassett, Buckley, and Muskingum islands, West Virginia, USA and 0, 100, and $300 \mathrm{~m}$ from the bridge for the 2008 and 2009 field seasons with same letters indicating no significance among sites or distances (bolded means are significant at $\alpha=0.05$ ).

\begin{tabular}{|c|c|c|c|c|c|c|c|c|c|c|}
\hline \multirow{3}{*}{ Common Name } & \multirow{3}{*}{ Scientific Name } & \multicolumn{6}{|c|}{ Island } & \multirow[b]{3}{*}{$\mathrm{df}$} & \multirow[b]{3}{*}{$F$} & \multirow[b]{3}{*}{$P$} \\
\hline & & \multicolumn{2}{|c|}{ Blennerhassett } & \multicolumn{2}{|c|}{ Buckley } & \multicolumn{2}{|c|}{ Muskingum } & & & \\
\hline & & $\bar{x}$ & SE & $\bar{x}$ & SE & $\bar{x}$ & SE & & & \\
\hline Peromyscus & Peromyscus spp. Gloger & $5.67 a$ & 0.67 & $0.89 \mathrm{~b}$ & 0.15 & $3.09 b$ & 0.45 & $2,47.9$ & 6.94 & 0.002 \\
\hline Meadow Vole & Microtus pennsy/vanicus Ord & $1.56 a$ & 0.30 & $1.43 a$ & 0.32 & $0.00 \mathrm{~b}$ & 0.00 & $2,53.8$ & 4.60 & 0.014 \\
\hline Eastern Chipmunk & Tamias striatus Linnaeus & $0.06 a$ & 0.03 & $0.30 a$ & 0.10 & $0.07 a$ & 0.05 & $2,61.2$ & 1.90 & 0.159 \\
\hline All Small Mammals & & $7.37 a$ & 0.86 & $2.97 a$ & 0.36 & $3.35 a$ & 0.49 & $2,65.6$ & 2.45 & 0.094 \\
\hline Species Richness & & $1.57 a$ & 0.11 & $1.07 a$ & 0.10 & $1.28 \mathrm{a}$ & 0.12 & $2,69.9$ & 1.91 & 0.156 \\
\hline Shannon Diversity Index & & $0.36 a$ & 0.04 & $0.20 \mathrm{a}$ & 0.04 & $0.23 a$ & 0.05 & $2,67.8$ & 1.08 & 0.345 \\
\hline
\end{tabular}


Table 8 Extended

\begin{tabular}{|c|c|c|c|c|c|c|c|c|c|c|c|}
\hline \multicolumn{6}{|c|}{ Distance } & \multirow[b]{3}{*}{$d f$} & \multirow[b]{3}{*}{$F$} & \multirow[b]{3}{*}{$P$} & \multirow{2}{*}{\multicolumn{3}{|c|}{ Interaction }} \\
\hline \multicolumn{2}{|c|}{$0 \mathrm{~m}$} & \multicolumn{2}{|c|}{$100 \mathrm{~m}$} & \multicolumn{2}{|c|}{$300 \mathrm{~m}$} & & & & & & \\
\hline $\bar{x}$ & SE & $\bar{x}$ & SE & $\bar{x}$ & SE & & & & $d f$ & $F$ & $P$ \\
\hline $1.17 a$ & 1.18 & $4.10 a$ & 0.71 & $3.96 a$ & 0.69 & $2,48.1$ & 0.66 & 0.519 & $4,48.1$ & 2.96 & 0.021 \\
\hline $0.75 a$ & 1.67 & $1.50 a$ & 0.29 & $1.97 a$ & 0.45 & $2,53.9$ & 1.71 & 0.191 & $4,47.4$ & 0.41 & 0.803 \\
\hline $0.21 a$ & 0.66 & $0.19 a$ & 0.08 & $0.14 a$ & 0.10 & $2,61.3$ & 0.20 & 0.822 & $4,68.8$ & 0.11 & 0.980 \\
\hline $2.29 b$ & 2.16 & $5.99 a$ & 0.83 & $6.33 a$ & 0.93 & $2,65.5$ & 6.34 & 0.003 & $4,45.7$ & 2.40 & 0.064 \\
\hline $1.06 a$ & 0.16 & $0.93 a$ & 0.12 & $1.37 a$ & 0.13 & $2,70.3$ & 1.23 & 0.297 & $4,70.3$ & 5.88 & $<0.001$ \\
\hline $0.22 a$ & 0.06 & $0.29 a$ & 0.05 & $0.30 a$ & 0.05 & $2,68.2$ & 0.39 & 0.676 & $4,68.2$ & 3.99 & 0.005 \\
\hline
\end{tabular}


Table 9: Average mass (g) and proportion of males, adults, and reproductive females for Peromyscus spp. captured at Blennerhassett, Buckley, and Muskingum islands, West Virginia, USA and at 0, 100, $300 \mathrm{~m}$ from the bridge during the 2008-2009 field seasons (none of the means differed significantly by sites or distances at $\alpha=0.05$ ).

\begin{tabular}{|c|c|c|c|c|c|c|c|c|}
\hline \multirow{3}{*}{ Index } & \multicolumn{6}{|c|}{ Island } & \multirow[b]{3}{*}{$F_{2,21}$} & \multirow[b]{3}{*}{$P$} \\
\hline & \multicolumn{2}{|c|}{ Blennerhassett } & \multicolumn{2}{|c|}{ Buckley } & \multicolumn{2}{|c|}{ Muskingum } & & \\
\hline & $\bar{x}$ & SE & $\bar{x}$ & SE & $\bar{x}$ & SE & & \\
\hline Average mass (g) & 16.27 & 0.63 & 16.55 & 1.15 & 17.02 & 0.26 & 1.69 & 0.208 \\
\hline Proportion of males & 0.73 & 0.04 & 0.67 & 0.08 & 0.62 & 0.04 & 0.89 & 0.427 \\
\hline Proportion of adults & 0.84 & 0.07 & 0.72 & 0.13 & 0.89 & 0.04 & 0.64 & 0.539 \\
\hline Proportion of reproductive females & 0.17 & 0.04 & 0.25 & 0.06 & 0.23 & 0.05 & 0.57 & 0.572 \\
\hline
\end{tabular}


Table 9 Extended

\begin{tabular}{|c|c|c|c|c|c|c|c|c|c|}
\hline \multicolumn{6}{|c|}{ Distance } & \multirow[b]{3}{*}{$F_{2,21}$} & \multirow[b]{3}{*}{$P$} & \multirow{2}{*}{\multicolumn{2}{|c|}{ Interaction }} \\
\hline \multicolumn{2}{|c|}{$0 \mathrm{~m}$} & \multicolumn{2}{|c|}{$100 \mathrm{~m}$} & \multicolumn{2}{|c|}{$300 \mathrm{~m}$} & & & & \\
\hline $\bar{x}$ & SE & $\bar{x}$ & SE & $\bar{x}$ & SE & & & $F_{4,21}$ & $P$ \\
\hline 15.68 & 1.80 & 16.11 & 0.29 & 16.84 & 0.20 & 0.27 & 0.763 & 0.18 & 0.945 \\
\hline 0.77 & 0.10 & 0.67 & 0.05 & 0.72 & 0.06 & 0.00 & 0.999 & 0.43 & 0.787 \\
\hline 0.50 & 0.21 & 0.86 & 0.06 & 0.91 & 0.03 & 0.79 & 0.469 & 1.17 & 0.353 \\
\hline 0.18 & 0.08 & 0.20 & 0.04 & 0.22 & 0.07 & 0.40 & 0.678 & 1.47 & 0.247 \\
\hline
\end{tabular}


Table 10: Summary of scent station data for furbearers with their presence (P) and absence (A) percentages for Blennerhassett, Buckley, and Muskingum islands, West Virginia, USA and 0, 100, and $300 \mathrm{~m}$ from the bridge for the 2008 and 2009 field seasons with same letters indicating no significance among sites or distances (bolded species are significant at $\alpha=0.05$ ).

\begin{tabular}{|c|c|c|c|c|c|c|c|c|c|}
\hline \multirow{3}{*}{ Common Name } & \multirow{3}{*}{ Scientific Name } & \multicolumn{6}{|c|}{ Island } & \multirow[b]{3}{*}{$G_{2}$} & \multirow[b]{3}{*}{$P$} \\
\hline & & \multicolumn{2}{|c|}{ Blennerhassett } & \multicolumn{2}{|c|}{ Buckley } & \multicolumn{2}{|c|}{ Muskingum } & & \\
\hline & & $\mathrm{P}$ & $A$ & $\mathrm{P}$ & A & $P$ & A & & \\
\hline Raccoon & Procyon lotor Linnaeus & $50.0 \% \mathrm{~b}$ & $50.0 \%$ & $70.8 \% a$ & $29.2 \%$ & $69.4 \% a$ & $30.6 \%$ & 7.39 & 0.025 \\
\hline Red Fox & Vulpes vulpes Linnaeus & $15.7 \%$ a & $84.3 \%$ & $2.8 \% b$ & $97.2 \%$ & $0.0 \% b$ & $100.0 \%$ & 13.14 & 0.001 \\
\hline Virginia Opossum & Didelphis virginiana Kerr & $4.3 \% a$ & $95.7 \%$ & $8.3 \% a$ & $91.7 \%$ & $2.8 \% a$ & $97.2 \%$ & 1.67 & 0.433 \\
\hline American Beaver & Castor canadensis Kuhl & $0.0 \%$ & $100.0 \%$ & $2.8 \%$ & $97.2 \%$ & $0.0 \%$ & $100.0 \%$ & - & - \\
\hline All Furbearers & & $60.0 \% a$ & $40.0 \%$ & $75.0 \% a$ & $25.0 \%$ & $49.9 \% a$ & $50.1 \%$ & 3.66 & 0.161 \\
\hline
\end{tabular}


Table 10 Extended

\begin{tabular}{|c|c|c|c|c|c|c|c|}
\hline \multicolumn{6}{|c|}{ Distance } & \multirow[b]{3}{*}{$G_{2}$} & \multirow[b]{3}{*}{$P$} \\
\hline \multicolumn{2}{|c|}{$0 \mathrm{~m}$} & \multicolumn{2}{|c|}{$100 \mathrm{~m}$} & \multicolumn{2}{|c|}{$300 \mathrm{~m}$} & & \\
\hline $\mathrm{P}$ & A & $P$ & A & $\mathrm{P}$ & A & & \\
\hline $40.6 \% b$ & $59.4 \%$ & $63.8 \% a b$ & $36.2 \%$ & $69.2 \% a$ & $30.8 \%$ & 7.00 & 0.030 \\
\hline $15.6 \% \mathrm{a}$ & $84.4 \%$ & $8.6 \% a$ & $91.4 \%$ & $5.8 \% a$ & $94.2 \%$ & 2.08 & 0.354 \\
\hline $6.3 \% a$ & $93.7 \%$ & $5.2 \% a$ & $94.8 \%$ & $7.7 \% a$ & $92.3 \%$ & 0.27 & 0.873 \\
\hline $6.3 \%$ & $93.7 \%$ & $0.0 \%$ & $100.0 \%$ & $0.0 \%$ & $100.0 \%$ & - & - \\
\hline $59.4 \% a$ & $40.6 \%$ & $67.2 \% a$ & $32.8 \%$ & $73.1 \% a$ & $26.9 \%$ & 1.66 & 0.436 \\
\hline
\end{tabular}


Chapter 4

\title{
PRE-CONSTRUCTION AND POST-CONSTRUCTION COMPARISONS OF THE BLENNERHASSETT ISLAND BRIDGE CROSSING, OHIO RIVER, USA.
}

\author{
Joshua A. Vance ,* $^{*}$ \\ James T. Anderson ${ }^{2}$ \\ Norse B. Angus ${ }^{3}$
}

1 West Virginia University, Division of Forestry and Natural Resources, Wildlife and Fisheries

Resources, PO Box 6125, Percival Hall, Morgantown, WV 26506, email:

josh_vance10@yahoo.com, phone: (304) 516-3105, fax: (304) 293-2441

2 West Virginia University, Division of Forestry and Natural Resources, Wildlife and Fisheries Resources, PO Box 6125, Percival Hall, Morgantown, WV 26506

3 West Virginia Department of Transportation, Division of Highways, Building 5 Capital Complex, Charleston, WV 25305

*Corresponding Author

This chapter written in the style of: Environmental Monitoring and Assessment 


\begin{abstract}
Construction of man-made objects such as roads and bridges can have positive, negative, or neutral impacts on wildlife, vegetation, and soil depending on species or location. We investigated vegetation, soil, waterbirds, songbirds, small mammals and furbearers along the Ohio River, WV, USA at a new bridge both before and after construction and at a bridge crossing that was present throughout the study. Comparisons were made at each site over three time periods (1985-1987 and 1998-2000 [pre-construction], 2007-2009 [post-construction]) and at three distances $(0 \mathrm{~m}, 100 \mathrm{~m}, 300 \mathrm{~m})$ from the bridge or proposed bridge location. Overall, 118 plant, 16 waterbird, 70 songbird, 10 small mammal, and 6 furbearer species were detected during the study. Though not statistically tested, some vegetation and soil parameters appeared to be altered after construction of the bridge. Waterbird abundances did not show any declines that could be attributed to the bridge and combined songbird abundances did not differ after construction of the bridge $(\mathrm{P}>0.05)$. Cliff swallows and rock pigeons showed high affinity for bridges $(\mathrm{P}<0.05)$. Combined small mammal abundances increased between Phases I and II $(\mathrm{P}<$ 0.05), but did not differ between Phases II and III (P > 0.05). Species richness and diversity for songbirds and small mammals did not differ before and after bridge construction $(\mathrm{P}>0.05)$. We found that most species sampled responded neutrally to the bridge crossing, and believe that the bridge is not causing any measurable negative density impacts to the species we investigated. The bridge does provide habitat for rock pigeon and cliff swallow that are adjusted to man-made structures for nesting.
\end{abstract}

Key words: bridge, island, Ohio River, Blennerhassett Island, impacts, effects, BACI, wildlife, vegetation, soil 


\section{Introduction}

Highway bridge crossings can affect waterbirds, songbirds, small mammals, furbearers, vegetation, and the soil positively, negatively, or not at all depending on species or location. There are limited published data on the ecological impacts of bridges on wildlife, vegetation, and soil; however, more attention has been drawn to the positive effects of bridges upon wildlife. Cliff swallows (Petrochelidon pyrrhonota), barn swallows (Hirundo rustica), and peregrine falcons (Falco peregrinus) use bridges for nesting and perching (Bell et al. 1996, Cade and Bird 1990, Redmond and Murphy 2007, Tordoff and Redig 1988, Tumlison 2009). Other research shows that bridges provide roosting and resting habitat for bats (Bennett et al. 2008). Edge created by roads and bridges may provide habitat for songbirds and increase their population (Clark and Karr 1979). Also, bridges can serve as movement corridors for coyotes (Canis latrans) (Sacks et al. 2006).

The presence of a bridge may have direct negative impacts on wildlife similar to those of highway impacts which have been studied in much greater detail. Some of these negative impacts include: increased mortality from vehicle collisions (Haxton 2000, Hubbard et al. 2000), noise (Breeden et al. 2008), barrier effects (Noss et al. 1996), and attraction of undesirable or non-native species (Vankat and Roy 2002). Bridges and highways also can impact the landscape causing habitat fragmentation (Trombulak and Frissell 2000), habitat loss (Forman 2000), and habitat alteration (Rowland et al. 2000) which in turn are negative for some species. This can lead to further tribulations including species declines and disruption of continuous population distributions (Vos and Chardon 1998), limit movements (Andrews et al. 2005), and limit genetic diversity (Lesbarreres et al. 2006). 
Vegetation under bridges may be similar to roadsides with disturbance-tolerant, nonnative, generalist species of flowering, herbaceous plants and grasses that form discontinuous vegetative communities (Forman et al. 2003, Townsend et al. 2000). These disturbed areas may harbor poor site conditions and may become favorable to a suite of invasive species (Forman and Alexander 1998, Rentch et al. 2005). Similarly, soil under bridges may have altered nutrient levels due to application of deicing agents on bridges during winter months (Wilcox 1986) and other materials leaching from the bridge which could alter physical properties of the soil (Johnston and Johnston 2004). Altered soil chemistry may change plant growth and species diversity and composition (Forman and Alexander 1998, Jones et al. 2000, Rentch et al. 2005, Tyser et al. 1998).

In West Virginia, the West Virginia Division of Highways (WVDOH) initiated research on the effects of bridges on wildlife and vegetation communities with two major projects occurring (1985-1987, 1998-2000). The purposes of these studies were to investigate effects of bridges on wildlife (barrier effect, loss of habitat, attraction of undesirable/desirable species) and vegetation. Communities investigated included waterbirds, songbirds, small mammals, furbearers, and vegetation; soil parameters also were measured. Surveys were conducted during both time periods at the Buckley Island Bridge (existing bridge constructed in the mid-1960s) and at the proposed site of the Blennerhassett Island Bridge (although construction had not begun) (West Virginia Division of Highways 2010, unpublished report).

The purpose of this study was to evaluate the ecological impacts and effects of the Blennerhassett Island Bridge as it crosses over the Ohio River and Blennerhassett Island near Parkersburg, WV, USA. Construction of the bridge began in May 2005 and it was opened to the public 13 June 2008. This study investigates waterbird, songbird, small mammal, furbearer, 
vegetation, and soil parameters and makes comparisons to the data collected during the 19851987 and 1998-2000 studies.

\section{Methods}

$\underline{\text { Study Area }}$

This study was conducted along the Ohio River in Wood County, West Virginia and Washington County, Ohio, USA. We studied two sites (Blennerhassett Island and Buckley Island) (Figure 1) and conducted surveys on both the islands and the adjacent mainland. The bridge crossing Blennerhassett Island is a single-span tied-arch style bridge about 1,220 m in length and $24 \mathrm{~m}$ in height. This four-lane bridge carries U.S. Route 50. The bridge crossing Buckley Island also is a single-span tied-arch style bridge similar in size to the bridge crossing Blennerhassett Island. It was constructed in the mid-1960s and is part of Interstate 77. These islands occur between km markers 271.8 and 305.6 (mi markers 168.9 and 189.9) with both sites located in the Belleville Navigational Pool (Tolin and Schettig 1983).

Precipitation occurs throughout the year, totaling about $106 \mathrm{~cm} /$ year (Idcide West Virginia Weather 2010) and elevation ranges from 184-198 m (Idcide West Virginia City Data 2010). Both islands have been historically used for agriculture and the river channels around them may have been historically dredged (Tolin and Schettig 1983). The adjacent mainland has been shaped by disturbance from urbanization, agriculture, commercial development, and industrial expansion.

Bottomland hardwood forest, dominated by silver maple (Acer saccharinium), box elder (Acer negundo), and American sycamore (Platanus occidentalis), is the most abundant cover type on the islands (Tolin and Schettig 1983). Late and early old-fields (transitional areas between bare ground and forest) are the second most common cover type on the islands (Tolin 
and Schettig 1983). Old fields were created by past agricultural practices, oil and gas activities, recreational development, logging, and industrial activities (Zadnik et al. 2009). They are usually comprised of vegetation such as forbs, grasses, and small shrubs (Bleich et al. 2005), but some of these areas may have woody plants becoming dominant (United States Fish and Wildlife Service 2002).

$\underline{\text { Study Design }}$

This study used the before-after/control-impact (BACI) design to investigate differences at the Blennerhassett Island site. In the BACI design, experimental units are allocated to both treatment and reference areas before and after treatment is applied (Morrison et al. 2001). The Blennerhassett Island study area (new Rt. 50 bridge) was the treatment area and the Buckley Island study area (existing I-77 bridge) was the reference area. Phase I (1985-1987) and Phase II (1998-2000) studies were conducted before construction of the Blennerhassett Island Bridge, and Phase III (2007-2009) was conducted after construction of the bridge. A bridge was present at Buckley during all three studies. Vegetation, soil, waterbirds, songbirds, small mammals, and furbearers were sampled during at least two of the three phases depending on the variable (vegetation [Phases II and III], soil [Phases II and III], waterbirds [Phases I and III], songbirds [Phases I, II, and III], small mammals [Phases I, II, and III], and furbearers [Phases I and III]). Waterbirds were sampled from observation points at each site; vegetation, soil, songbirds, small mammals, and furbearers were sampled along $100 \mathrm{~m}$ transects placed under the bridge and at 100 and $300 \mathrm{~m}$ from the bridge with transects starting at the shorelines on the mainland and on the island. Blennerhassett Island had a total of 6 transects $(n=2$ under the bridge, $n=2$ at $100 \mathrm{~m}$, and $n=2$ at $300 \mathrm{~m})$, and Buckley Island had a total of 8 transects $(\mathrm{n}=3$ under the bridge, $\mathrm{n}=3$ at $100 \mathrm{~m}$, and $\mathrm{n}=2$ at $300 \mathrm{~m}$ ). However, during Phase II, vegetation and soil data were not 
collected at all of these transects (vegetation: 3 transects sampled at Blennerhassett [n $=1$ at 0 m, $\mathrm{n}=1$ at $100 \mathrm{~m}$, and $\mathrm{n}=1$ at $300 \mathrm{~m}$ ] and 5 transects sampled at Buckley [n =2 at $0 \mathrm{~m}, \mathrm{n}=2$ at $100 \mathrm{~m}, \mathrm{n}=1$ at $300 \mathrm{~m}$ ]; soil: 2 transects sampled at Blennerhassett [n=1 at $0 \mathrm{~m}, \mathrm{n}=1$ at $100 \mathrm{~m}$ ] and 3 transects sampled at Buckley [n=1 at $0 \mathrm{~m}, \mathrm{n}=1$ at $100 \mathrm{~m}$, and $\mathrm{n}=1$ at $300 \mathrm{~m}]$ ). Vegetation

The vegetation associated with each 100 meter transect was sampled using a $20 \mathrm{~m} \times 50$ m (0.1 ha) quadrat. Quadrats were positioned so that the center of the quadrat corresponded to the center of the transect. Within each quadrat, the composition and structure of the vegetation was determined using a roadside sampling method (Rentch et al. 2005). Diameter at breast height (1.37 $\mathrm{m}$ above the ground level on uphill side and hereafter referred to as DBH) of all live stems of trees $(\geq 2.5 \mathrm{~cm} \mathrm{DBH})$ was recorded by species in the quadrats. Percent cover of herbaceous plants, exposed rock, woody debris, and bryophytes was estimated for ten $1.0 \times 1.0 \mathrm{~m}$ plots placed at $5.0 \mathrm{~m}$ intervals along a $50 \mathrm{~m}$ tape used to establish the centerline of the principal quadrat. All cover values were estimated using a cover class rating scale described by Daubenmire (1968): $1<5 \%$ cover, $2=5-25,3=26-50,4=51-75,5=76-95$, and $6>95$. Vegetation sampling was conducted during the growing season during Phase II and in July 2008 for Phase III.

$\underline{\text { Soil }}$

Soil samples were collected within each of the 0.1 ha quadrats established for the vegetation sampling using a $1.27 \mathrm{~cm}$ diameter soil probe. The composite samples were composed of four sub-samples from the upper $10 \mathrm{~cm}$. Each quadrat was divided into four 0.025 ha sub-sections, one sample of soil was taken from each sub-section, and all four were mixed together for one composite sample from each quadrat. Each sample was air dried, passed through 
a $2 \mathrm{~mm}$ sieve, and then sent to the Brookside Laboratories in New Knoxville, Ohio, USA, for analysis. The soil parameters analyzed were percent organic matter, $\mathrm{pH}$, total exchange capacity, parts per million for aluminum, boron, copper, calcium, iron, magnesium, potassium, zinc, nitrate, sodium, manganese, and soluble sulfur (Stephenson et al. 2007). Soil samples were collected at these sites during the Phase II sampling period and during vegetation sampling for Phase III in July 2008.

$\underline{\text { Waterbirds }}$

Waterbird surveys were conducted by a single observer during 90 minute complete scan counts while sitting on the mainland facing the island and monitoring the river, air, riparian zones, and part of the island in a 39.25 ha area (semicircle with a 500 m radius from the observation point) using binoculars. Additionally during Phase III, a 15 to 60 power, $60 \mathrm{~mm}$ zoom, Bausch and Lomb® spotting scope was used. Surveys were conducted from 1 hour before sunset to 30 minutes after sunset (dusk) and then 30 minutes before sunrise to 1 hour after sunrise (dawn) at the same location the following morning (Burger 2001). The dusk survey and the dawn survey the following morning were combined into one single survey and the maximum count for each species between the two times was used. During these surveys, all waterbirds observed were enumerated and recorded by species (Heusmann and Sauer 2000, Lougheed and Breault 1999). Waterbirds were considered waterfowl, seabirds, shorebirds, wading birds, and belted kingfishers (Megaceryle alcyon) (Weller 1999). To make accurate estimations on distance during Phase III, the distance from the observer to the bird was measured with a Nikon Laser ${ }^{\mathrm{TM}}$ $12007 \times 25$ power range finder.

Dusk and dawn surveys were conducted from the West Virginia mainland once a month and then from the Ohio mainland later in the month because each side of the island had a 
different 39.25 ha area to be surveyed and to ensure the entire river channel around the island was surveyed monthly. Observation points were placed at suitable locations with clear viewing of the river, air, riparian zones, and the bridge but were not correlated to transects. Counts were not conducted if the wind speeds exceeded $16 \mathrm{~km} / \mathrm{hr}$ or during high flow conditions and were made up at the next available time (Best et al. 1997). Surveys were completed by individuals trained in bird identification and distance estimation. Counts were conducted twice a month during April, May, and June 1985-1987 for Phase I and April and May 2008-2009 for Phase III. $\underline{\text { Songbirds }}$

Breeding bird surveys for songbirds were conducted along each of the $100 \mathrm{~m}$ transects by a single observer during Phases I and II and the dependent double observer method (Forcey et al. 2006) for Phase III. The dependent double observer method was used in Phase III in lieu of the single observer method to increase accuracy of species identifications and counts, but not to calculate detection probabilities due to low number of observations. This technique involved two observers recording data together on a single data sheet with one observer designed as the primary observer and the other designated as the secondary observer. The primary observer verbally dictated the number of each species detected while the secondary observer recorded the information. The secondary observer also recorded birds that the primary observer did not detect (Forcey et al. 2006, Nichols et al. 2000).

Songbirds were sampled by walking along each transect for a total of 15 minutes, pausing to identify and record all birds observed or heard (Er et al. 2003). Only songbirds detected within a 1 ha area $(\leq 50 \mathrm{~m}$ perpendicular to the transect) were included in transect data. Those species detected outside or as flyovers were recorded but not included in any estimates. There were three scheduled stops of three minutes each at the beginning, middle, and end of each transect. 
Species, sex, age, and estimated distance of all birds detected by sight and sound was recorded (Smith et al. 2005). Estimated distances were recorded perpendicular to the transect and a Nikon Laser $^{\mathrm{TM}} 12007 \times 25$ power range finder was used during Phase III to increase accuracy of distance estimations. Surveys were conducted from 0600 to 1000 (Rodewald and Smith 1998), but were not conducted during rainy or windy weather (Freeman et al. 2007). Surveys were completed by individuals trained in bird identification and distance estimation. Surveys were conducted in both May and June of 1985-1987, 1998-1999, and 2008-2009 for Phases I, II, and III respectively.

$\underline{\text { Small Mammals }}$

Small mammal trapping was conducted using snap traps during Phases I and II and Sherman live traps (small folding galvanized, $5 \times 6.4 \times 16.5 \mathrm{~cm} ; \mathrm{H}$. B. Sherman Traps, Tallahassee, FL) during Phase III to capture small mammals such as mice, voles, moles, chipmunks, and shrews. Sherman traps were used in lieu of snap traps during Phase III due to their ability to keep animals alive and their similar capture success to snap traps (Pelikan et al. 1977). Traps were placed along the $100 \mathrm{~m}$ transects at ten stations located $10 \mathrm{~m}$ apart with three traps at each station (Pearson and Ruggiero 2003). Each trap was baited with a peanut butter rolled oats mixture. Traps were set for three consecutive nights (Yunger and Randa 1999) and were checked each morning. The number of traps tripped without a capture was recorded and 0.5 trap nights was deducted (Beauvais and Buskirk 1999, Edalgo and Anderson 2007). Corresponding transects for each site was trapped simultaneously to account for temporal variation. During Phase III, each rodent captured was ear-tagged with a \#1005-1 monel ear tag (National Band and Tag Company, Newport, Kentucky, 41072-0430) and shrews were toeclipped for identification (Menzel et al. 1999, Silvy et al. 2005). Other information such as trap 
location and species were recorded and age, gender, mass, reproductive condition, and whether the animal was a new or recapture were recorded during Phase III (Converse et al. 2006). Small mammal trapping was conducted during April or May and June 1985-1987 for Phase I, April and June 1998 and April 1999 for Phase II, and May and June 2008-2009 for Phase III. $\underline{\text { Furbearers }}$

Scent stations were constructed and monitored to measure medium-sized mammals, carnivores, and large rodent occurrence (Akins et al. 2004). Scent stations were established along the river banks at the terminal end of each transect. Scent stations were $1 \mathrm{~m} \times 1 \mathrm{~m}$ and made from scraped, sifted, and smoothed alluvial soil at a depth of 3-5 cm to make tracks more visible (Kalpin 1986). Scent stations were then baited with a fatty acid scent tablet placed in the center of the station (Helon et al. 2002, Nottingham et al. 1989, Warrick and Harris 2001). Stations were operated for three consecutive nights (Randa and Yunger 2006) and checked every morning (Sargeant et al. 1998). Identification of all animals investigating the scent station was made by the tracks left in the scent station. Scent stations were monitored in conjunction with small mammal traps during April, May, and June 1985-1987 for Phase I and May and June 2008-2009 for Phase III.

\section{$\underline{\text { Statistical Analysis }}$}

Electronic data from Phases I and II pre-construction studies could not be located. The only raw data available from these phases were for small mammals. However, pre-construction data for other taxa from these two time periods could be used from previous unpublished reports from the WVDOH. Unfortunately, these data limited us due to the reports only containing summaries of each time period, cumulative means for each time period without means for each 
individual observation (one datum point for each response variable for each phase), no or limited replication, and means without standard deviations or standard errors.

For vegetation and soil, data could be combined among transects by site to provide multiple replicates; however, we believe that bridge impacts onto vegetation and soil are limited to the area directly under the bridge and the areas disturbed during construction and should not affect transects at 100 or $300 \mathrm{~m}$ distance. Thus combining data would not provide any meaningful results. Because waterbird surveys were conducted by site and not correlated to transects, there was no way to combine pre-construction data to get multiple replicates. Preconstruction furbearer data summarized the total, average, and maximum number of tracks of each species left at all the scent stations combined within a site, but because the total number of tracks left in a scent station is not an accurate estimation of abundance (i.e., one animal could make multiple tracks), post-construction data recorded only the presence or absence of each species. Moreover, pre-construction data did not present presence or absence information for each scent station and thus the data were not comparable. Due to these issues, no quantitative comparisons were made for vegetation, soil, waterbirds, and furbearers. Instead, a qualitative description of vegetation and soil at the $0 \mathrm{~m}$ transects and waterbirds and furbearers at each site was made over time regarding impacts of the Blennerhassett Island Bridge.

For songbird and small mammal data, each transect distance had replication at both sites during all three phases and a quantitative statistical analysis was performed. Songbird data were standardized by individuals/ha (songbirds) or captures/100 trap nights (small mammals). Combined songbird and small mammal relative abundance, relative abundances of individual species that were sampled during all three time periods, species richness, and Shannon Diversity Index (SDI) (dependent variables) were rank transformed (Conover and Iman 1981) and 
compared by site, distance, and phase (independent variables) using a three-way analysis of variance (ANOVA) with interaction terms and an alpha level of 0.05 . The main effects of this model were compared along with the site by phase, distance by phase, and site by distance by phase interactions to determine effects from the bridge. The test of interaction was conducted using untransformed data to obtain a more approximate analysis (Conover 1999). A Tukey’s honest significance difference multiple comparison post hoc test was used for comparisons of

significant means. Deer mouse (Peromyscus maniculatus) and white-footed mouse (Peromyscus leucopus) were combined into a single genus (Peromyscus spp.) to account for identification biases (Osbourne et al. 2005) and to stay consistent with pre-construction data.

\section{Results}

Vegetation

Overall a total of 118 species of plants were detected in the two phases including 78 species ( $n=24$ during Phase II and $n=69$ during Phase III) at Blennerhassett and 79 species (n = 39 during Phase II and $n=61$ during Phase III) at Buckley (Appendix 18). Vegetative communities at the $0 \mathrm{~m}$ transect at Blennerhassett were dominated by box elder, false nettle (Boehmeria cylindrica), Japanese hop (Humulus japonicus), reed canary grass (Phalaris arundinacea), silver maple, and wing-stem (Verbesina alternifolia) before construction of the bridge and by bare ground, Japanese millet (Echinochloa crus-galli var frumentacea), Japanese stilt grass (Microstegium vimineum), and wild rye (Elymus riparius) after construction of the bridge (Table 1).

Vegetative communities at the $0 \mathrm{~m}$ transect at Buckley showed changes as well despite the bridge being present during both survey periods. The areas under the bridge had high amounts of bare ground with vegetation dominated by red fescue (Festuca rubra), silver maple, 
reed canary grass, and wild teasel (Dispacus fullonum) (Table 1). During Phase III, the areas under the bridges continued to have high amounts of bare ground along with common burdock (Arctium minus), Japanese knotweed (Polygonum cuspidatum), and Kentucky 31 fescue (Lolium arundinaceum), with lower amounts of reed canary grass, and no woody vegetation (Table 1).

There also were increases in many invasive and exotic species under both bridges over time. Some exotic species that were absent during pre-construction surveys but present during post-construction surveys included: common mugwort (Artemisia vulgaris), Japanese knotweed, Japanese millet, Japanese stilt grass, Kentucky 31 fescue, lady’s thumb (Polygonum persicaria), mile-a-minute weed (Polygonum perfoliata), and prickly lettuce (Lactuca serriola) (Table 1). $\underline{\text { Soil }}$

We found dramatic decreases in organic matter (77.4\%), magnesium (18.6\%), potassium (32.1\%), boron (43.0\%), iron (21.9\%), zinc (85.3\%), copper (54.2\%), and aluminum $(55.8 \%)$ and dramatic increases in nitrate (493.4\%), calcium (18.5\%), sodium (735.7\%), and manganese (43.5\%) at the $0 \mathrm{~m}$ transect at Blennerhassett over time (Table 2). We also found dramatic decreases in organic matter (58.3\%), magnesium (49.2\%), boron (35.0\%), iron (25.8\%), manganese (46.7\%), and aluminum (52.8\%) and dramatic increases in nitrate (692.1\%), soluble sulfur $(68.9 \%)$, and sodium $(6,317.2 \%)$ at the $0 \mathrm{~m}$ transect at Buckley over time (Table 2). $\underline{\text { Waterbirds }}$

Overall, a total of 16 species of waterbirds were detected including 14 species $(n=13$ at Blennerhassett and $n=5$ at Buckley) during the 1985-1987 period and $7(n=7$ at Blennerhassett and $n=3$ at Buckley) during the 2007-2009 period (Appendix 19). Five species were detected at Blennerhassett and 2 species were detected at Buckley during both time periods (Table 3). Canada goose (Branta canadensis) and combined waterbird abundances dramatically increased 
and belted kingfisher, great blue heron (Ardea herodias), mallard (Anas platyrhynchos), and wood duck (Aix sponsa) remained similar at Blennerhassett between the two time periods (Table 3). Canada goose and combined waterbird abundances also dramatically increased at Buckley while mallard and wood duck remained similar at that site over time (Table 3). The combined waterbird abundance was dominated by Canada geese $(85 \%)$.

\section{$\underline{\text { Songbirds }}$}

A total of 70 species were detected among both sites during the three phases including 54 species ( $\mathrm{n}=34$ during Phase I, $\mathrm{n}=36$ during Phase II, and $\mathrm{n}=42$ during Phase III) at Blennerhassett over the three periods (Appendix 20) and 58 species at Buckley ( $\mathrm{n}=41$ during Phase I, $n=39$ during Phase II, and $n=44$ during Phase III) over the three periods (Appendix 21). A total of 33 species occurred during each of the three time periods and were therefore analyzed separately in abundance estimates. Four of these 33 species had a significant interaction effect either by site and phase, distance and phase, or site by distance by phase (Appendix 22). Only significant interactions are presented in the text.

Cliff swallow abundances had a significant interaction by site, distance, and phase $\left(F_{4,24}=\right.$ 3.20, $P=0.023$ ) due to only being detected at Buckley (Phase I: $\overline{\mathrm{X}}=0.02$, SE $=0.01$; Phase II: $\overline{\mathrm{X}}$ $=0.06, \mathrm{SE}=0.06$; Phase III: $\overline{\mathrm{X}}=1.16, \mathrm{SE}=0.70$ ) and increases at the $0 \mathrm{~m}$ transects (Phase I and II: $\bar{x}=0.00, \mathrm{SE}=0.00$; Phase III: $\overline{\mathrm{X}}=1.85, \mathrm{SE}=1.02$ ). Hairy woodpecker (Picoides villosus) abundances had a significant site by phase interaction $\left(F_{2,24}=3.82, P=0.036\right)$ due to decreases over time at Blennerhassett (Phase I: $\bar{X}=0.20, \mathrm{SE}=0.14$; Phase II: $\overline{\mathrm{X}}=0.00, \mathrm{SE}=0.00$; Phase III: $\overline{\mathrm{X}}=0.04, \mathrm{SE}=0.04)$ and a significant distance by phase interaction $\left(F_{4,24}=3.63, P=0.019\right)$ due to decreases at the $0 \mathrm{~m}$ transects (Phase I: $\overline{\mathrm{x}}=0.26, \mathrm{SE}=0.15$; Phases II and III: $\overline{\mathrm{x}}=0.00$, $\mathrm{SE}=0.00$ ). Song sparrow (Melospiza melodia $)$, had a significant site by phase interaction $\left(F_{2,24}=\right.$ 
$3.98, P=0.032)$ due to increases at Blennerhassett from Phase $\mathrm{I}(\overline{\mathrm{X}}=0.50, \mathrm{SE}=0.15)$ to Phase II $(\bar{X}=1.06, \mathrm{SE}=0.53)$, to Phase III $(\overline{\mathrm{X}}=3.00, \mathrm{SE}=0.37)$. One other species, eastern towhee (Pipilo erythrophthalmus), had a significant site by phase interaction $\left(F_{2,24}=4.91, P=0.016\right)$ due to decreases at Blennerhassett over time (Phase I: $\bar{x}=0.17$, SE $=0.10$; Phases II and III: $\bar{x}=$ $0.00, \mathrm{SE}=0.00)$.

Carolina wren (Thryothorus ludovicianus), white-eyed vireo (Vireo griseus), and yellowbilled cuckoo (Coccyzus americanus) had significantly higher abundances at Blennerhassett whereas cliff swallow, European starling (Sturnus vulgaris), gray catbird (Dumetella carolinensis), mourning dove (Zenaida macroura), and rock pigeon (Columba livia) had significantly higher abundances at Buckley (Table 4). Cliff swallow and rock pigeon had significantly higher abundances at the $0 \mathrm{~m}$ transects, and American robin (Turdus migratorius), brown-headed cowbird (Molothrus ater), Carolina wren, cedar waxwing (Bombycilla cedrorum), cliff swallow, and combined songbirds had higher abundances during Phase III (Table 4). Additionally, northern flicker (Colaptes auratus) abundances decreased during Phase II, but returned to similar numbers of Phase I during Phase III (Table 4). There were no other significant variables by site, distance, or phase (Table 4).

No other species differed significantly by site, distance, or phase (Table 4) or interaction (Appendix 22) including: American goldfinch (Spinus tristis), Baltimore oriole (Icterus galbula), blue jay (Cyanocitta cristata), Carolina chickadee (Poecile carolinensis), common grackle (Quiscalus quiscula), common yellowthroat (Geothlypis trichas), downy woodpecker (Picoides pubescens), house wren (Troglodytes aedon), indigo bunting (Passerina cyanea), northern cardinal (Cardinalis cardinalis), northern parula (Parula americana), orchard oriole (Icterus spurius), pileated woodpecker (Dryocopus pileatus), red-eyed vireo (Vireo olivaceus), red- 
winged blackbird (Agelaius phoeniceus), tufted titmouse (Baeolophus bicolor), wood thrush (Hylocichla mustelina), and yellow warbler (Dendroica petechia).

$\underline{\text { Small Mammals }}$

A total of 15,150 trap night attempts with 12,830 total trap nights after deductions captured 556 individuals (Table 5) of 10 species (Appendix 23) between both sites throughout all three time periods. Only combined small mammal and Peromyscus spp. had significant interactions (Appendix 24). Combined small mammal abundances were significantly lower during Phase I $(\bar{x}=2.09, \mathrm{SE}=0.48)$ compared to Phases II $(\overline{\mathrm{X}}=6.98, \mathrm{SE}=0.72)$ and III $(\overline{\mathrm{X}}=$ 9.05, $\mathrm{SE}=4.22)$ at Blennerhassett causing a significant site by phase interaction $\left(F_{2,24}=5.33, P\right.$ $=0.012)$. Similarly, Peromyscus spp. abundances were significantly lower during Phase $\mathrm{I}(\overline{\mathrm{X}}=$ 1.67, SE $=0.47)$ compared to Phases II $(\overline{\mathrm{X}}=5.08, \mathrm{SE}=0.40)$ and III $(\overline{\mathrm{X}}=7.20, \mathrm{SE}=3.21)$ at Blennerhassett causing a significant site by phase interaction $\left(F_{2,24}=7.13, P=0.004\right)$.

Peromyscus spp. and combined small mammals significantly increased during Phases II and III compared to Phase I, but did not differ significantly by sites or distances (Table 6). Northern short-tailed shrew (Blarina brevicauda) abundances were significantly higher at Blennerhassett than at Buckley, decreased during Phase II, and did not differ among distances (Table 6). Species richness was highest in Phase I, and decreased significantly during Phases II and III, but did not differ by sites or distances (Table 6). No other species or variables significantly differed by site, distance, or phase (Table 6) or by interactions (Appendix 24) including meadow vole (Microtus pennsylvanicus), house mouse (Mus musculus), eastern chipmunk (Tamias striatus), or SDI. 


\section{$\underline{\text { Furbearers }}$}

A total of 6 species of furbearers were detected throughout this study. Five species were detected in scent stations during pre-construction surveys: American beaver (Castor canadensis), common muskrat (Ondatra zibethicus), striped skunk (Mephitis mephitis), raccoon (Procyon lotor), and Virginia opossum (Didelphis virginiana). Four species were encountered in postconstruction scent station surveys: American beaver, raccoon, red fox (Vulpes vulpes), and Virginia opossum. Both raccoon and common muskrat were detected at both sites, while American beaver and Virginia opossum were only detected at Buckley, and striped skunk was only detected at Blennerhassett. Raccoon, red fox, and Virginia opossum were found at both Blennerhassett Island and Buckley Island, but American beaver was only detected at Buckley Island.

\section{Discussion}

\section{$\underline{\text { Vegetation }}$}

We believe that both bridges impact vegetation directly under them. Our study indicated that vegetative communities directly under both bridges are highly altered and dominated by species tolerant of disturbance. This may result from disturbance from construction, compacted soils, altered soil chemistry, lack of direct sunlight and rainfall, destruction of seed bank, and poor site conditions (Mortensen et al. 2009). We found that vegetation did not provide complete coverage of all the area disturbed under the bridges and overall flora was depauperate. The vegetation that was present under the bridge at Blennerhassett after construction consisted mostly of non-natives and exotics and species found in the seed mixture used to reseed the disturbed area after construction making it similar to the vegetative communities of roadsides (Rentch et al. 2005). This is contrasted by the vegetative communities of bottomland hardwood forest and 
old-field cover types which were found at the $0 \mathrm{~m}$ transects at Blennerhassett before construction of the bridge. Many exotic species found in this study may be present due to the floodplain; however, we believe that the disturbance caused by the construction of a bridge may be promoting these species as the poor site conditions may be creating an environment favorable for a limited suite of exotic species.

The natural series of plant succession following a disturbance has been well documented and is well understood (Oliver and Larson 1996). Ideally, this is the process that will occur under the Blennerhassett Island Bridge over time. However, many potential problems include compacted soils, altered soil chemistry, lack of direct sunlight or rainfall, emissions from vehicles, particles coming from the bridge, and presence of invasive and exotic species which may inhibit the vegetation communities, growth, and ecological processes under the bridge (Forman and Alexander 1998, Rentch et al. 2005, Christen and Matlock 2006, Mortensen et al. 2009). We hypothesize that the area under the Blennerhassett Island Bridge will not follow the natural series of plant succession. Based on present conditions at the 45-year-old Buckley Island Bridge, we believe that the vegetation communities under the Blennerhassett Island Bridge will remain this way for some time with low coverage and vegetation dominated by herbaceous, disturbance tolerant, and exotic species.

$\underline{\text { Soil }}$

Altered soil parameters over time in this study were not easily explainable and may be due to errors in analyses at the lab, changes in procedures, detectability limits over time, or random chance; however, some parameters could be linked to the bridge. Disturbance to the natural soil during construction could be responsible for decreases in organic matter, magnesium, potassium, boron, iron, zinc, copper, and aluminum under the bridge at Blennerhassett (Johnston 
and Johnston 2004). Increases in calcium, sodium, and manganese at Blennerhassett could be due to materials leaching from the bridge such as deicing agents for snow removal (Wilcox 1986), while increases in nitrate may be due to the fertilizer applied during reseeding of vegetation (Ross and Van Acker 2005), and increases in soluble sulfur may be due to emissions from vehicles (Mooney et al. 1988). Altered parameters at Buckley could be due to many of the reasons mentioned above at Blennerhassett. Due to lack of replication, it was difficult to link altered soil parameters to the bridge. However, both bridges may have impacts to the natural soil due to disturbance during construction, leaching of deicing agents and other materials from the surface or structure of the bridge, limited sunlight and rainfall due to the bridge overhang, herbaceous, disturbance-tolerant vegetation communities, and changes in the physical properties of the soil (structure, stability, erodibility, porosity, and permeability) as described by Johnston and Johnston (2004).

\section{$\underline{\text { Waterbirds }}$}

We found no evidence to conclude that the Blennerhassett Island Bridge is affecting waterbird populations. Canada goose and combined waterbird abundances increased at both sites over the two time periods indicating no negative effect from the bridge. Abundances of Canada goose have increased over time due to region-wide population increases within the study area (United States Fish and Wildlife Service 2002). Belted kingfisher, great blue heron, mallard, and wood duck abundances remained similar over the two time periods further indicating no impact. Results at Buckley Island were similar with increases in Canada goose and combined waterbird abundances and similar abundances of mallard and wood duck. All other waterbird species observed over the two time periods occurred in numbers too low to determine effects from the bridge. 
Waterbirds have shown no response to human disturbances in other studies. Doublecrested cormorant (Phalacrocorax auritus) distribution of nests, nesting and fledgling success, breeding chronology, adult nest behavior, and chick behavior were not altered when a wildlife viewing area was created near a breeding colony increasing human activity and presence (Skagen et al. 2001). Waterbirds have colonized urban landscapes and shown no negative response to increased urbanization (Campbell 2008). However, in a study on the impacts of many human disturbances on ducks, ducks were less likely to fly from human disturbances caused by vehicles opposed to other human disturbances such as walking or bicycling (Pease et al. 2005). We found no trends over the two time periods to indicate that the bridge is causing impacts to waterbirds. Because the bridge is crossing over such a small portion of the river and island, we believe the bridge is not a barrier or cause of decline for Ohio River waterbird species, nor is it impacting the local waterbird populations at Blennerhassett Island.

\section{$\underline{\text { Songbirds }}$}

The Blennerhassett Island Bridge had little impact on songbird abundance, richness, and diversity. Most of the songbirds analyzed showed no significant abundance decreases over time at Blennerhassett since the bridge was built. Cliff swallows and rock pigeons had an affinity for the bridge as they were found only under the bridges. Both cliff swallows and rock pigeons are highly adaptive to man-made structures and use bridges for nesting (Peterson 2002, Tumlison 2009). Decreased abundances of other species could not be directly attributed to the presence of the new bridge. However, 9 songbird species showed non-significant declines at the $0 \mathrm{~m}$ transect at Blennerhassett after construction of the bridge. This decline could be due to removal of trees directly under the bridge during construction. This removal lead to habitat loss for tree canopy 
and forest interior songbirds (Wallendorf et al. 2007), but was limited to the area directly under and near the bridge that was altered during construction and did not cause significant declines.

Our study is comparable to other studies that have shown songbird abundances, richness, and diversity to respond neutrally to a disturbance. Aquilani (2006) found that overall songbird abundances did not significantly drop in areas with different silvicultural treatments. Harrison and Kilgo (2004) found similar species richness and diversity in forests disturbed by patchretention harvests compared to control plots. Songbird abundances, richness, and diversity were not highly affected by the bridge because of the relatively small amount of area the bridge crosses and the small amounts of disturbance to the landscape restricted to directly under and near the bridge.

$\underline{\text { Small Mammals }}$

We found no evidence that the Blennerhassett Island Bridge is negatively impacting small mammals in comparison to pre-construction data. Meadow vole, northern-short-tailed shrew, house mouse, and eastern chipmunk all showed no significant abundance changes at each site and distance over time all indicating no effect from bridge. Peromyscus spp. and combined small mammal abundances increased at Blennerhassett over time indicating that the bridge is not causing negative impacts to either species of Peromyscus and total abundances of small mammals. Possible reasons for high small mammal abundances at Blennerhassett could be due to cyclical fluctuations of small mammal populations (Elias et al. 2004, Getz et al. 2006, Oli and Dobson 2001) or lack of natural predators (Okabe and Agetsuma 2007). Additionally, small mammal abundances could have been lower during Phase I due to high numbers of predators (Okabe and Agetsume 2007), cyclical fluctuations (Elias et al. 2004, Getz et al. 2006, Oli and Dobson 2001), or from a catastrophic event such as flooding and inundation of the island 
(Williams et al. 2001). Additionally, similar species richness and diversity at each site and distance over time indicate no negative impacts from the new bridge upon small mammals.

Moreover, our findings are comparable to other literature that indicates small mammals are disturbance tolerant. In a review of 21 studies investigating the impacts of clearcuts on small mammal populations, Kirkland (1990) identified a general pattern of initial increase in small mammal abundance following a clearcut. Four species of small mammals, southern red-backed vole (Myodes gapperi), woodland jumping mouse (Napaeozapus insignis), Peromyscus spp., and eastern chipmunk responded neutrally or favorably to forest disturbance in the form of clearcutting, deferment cutting, and single-tree selection (Kaminski et al. 2007). Root et al. (1990) found no effect of timber harvests on small mammals outside normal population fluctuations and few changes in taxonomic composition or abundances were found for small mammals over many silvicultural treatments (Elliott and Root 2006).

\section{$\underline{\text { Furbearers }}$}

Both common muskrat and striped skunk were detected in pre-construction surveys but not during post-construction surveys. There are not enough data to suggest that their absence in Phase III was caused by the construction and presence of the bridge. Both species were visually detected within the study area from personal observations during post-construction surveys. The reason these species were absent could be more easily explained by these animals still being present in the study area but in small abundances, these species not being easily detected with scent station surveys due to an abundance of other resources, or declines in these species in the study areas not correlated to the bridge. Additionally, the lack of red fox detections during preconstruction surveys may be contributed to many of the reasons listed above. 
Both Blennerhassett and Buckley islands provide good habitat for many species of furbearers. Striped skunks, raccoons, Virginia opossum, and red foxes benefit by the presence of multiple cover types including bottomland hardwood forest and early and late old-field habitats as each of these species use a variety of habitat types (Beasley et al. 2007, Randa and Yunger 2006). Proximity to water, proximity to urban areas, lack of hunting and minimal trapping on the islands, and abundant food sources all benefit these furbearers (Beasley et al. 2007, Gehrt 2003, Oehler and Litvaitis 1996, Okabe and Agetsume 2007). The shorelines of each island and the slough on Blennerhassett Island provide good habitat for American beavers and common muskrats. Beavers and muskrats both benefit from the slow current and dense herbaceous vegetation along the shorelines of the back channels (Zadnik et al. 2009). Additionally, both islands have large areas of woody vegetation which is primarily used as winter food for beavers (Jenkins 1979) and an abundance of coarse woody debris and submerged woody debris which provide habitat for riverine muskrats (Brooks 1980, Zadnik et al. 2009).

\section{Implications for Future Management Projects}

Bridges can negatively impact soil and vegetation due to presence of the bridge and alteration of habitat. Though these impacts are limited in scale, all possible care should be taken during future projects to limit disturbance during construction. This starts by following best management practices (BMP) including temporary silt fencing and creation of water breaks to minimize erosion and runoff. Soil can be removed before construction, stored, and re-spread after construction to minimize destruction to the seed bank. If this is not feasible, we recommend that soil and vegetation should be impacted minimally during construction and shrubs and herbaceous vegetation should be kept under the bridge if possible. In instances where this is not possible, reseeding of disturbed areas should be done with native seed mixtures that include 
shade tolerant grasses such as Canada wild rye (Elymus canadensis), wild rye (Elymus riparis), and bearded shorthusk (Brachyletrum erectum) which provide cover and food for wildlife. Native vegetation should sufficiently cover all areas impacted by the bridge, while stream banks should be stabilized by plantings of native trees. All possible care should be taken to restore the impacted land to previous conditions.

Additionally, wildlife habitat can be created by scattering brush piles and coarse woody debris beneath the bridge to improve wildlife habitat. Nest boxes for birds and bats and nesting platforms for large raptors can be erected under the bridge to compensate for habitat lost during construction. Bridges also can be constructed to provide slots and spaces for roosting bats and platforms can be placed on the bridge for peregrine falcon nesting sites. However, these improvements should be conducted away from traffic to prevent animal-human conflicts.

\section{Acknowledgements}

We thank the West Virginia Department of Transportation, Division of Highways for funding this project. We also thank the U.S. Fish and Wildlife Service and the West Virginia Division of Natural Resources Wildlife Resources Section and Recreation and Parks Section for their cooperation throughout this project. We thank A.B. Billings and Dr. Phil Turk for statistical assistance. A special thanks is extended to Dr. Jim Rentch and the late Bill Grafton for their assistance with vegetation surveys. We also thank Dr. Edwin Michael for assistance in gathering pre-construction data. Lastly, we thank all of the biologists and field technicians including: Patty Morrison, Gary Batton, Jeff McCrady, Matt Baker, Craig Leibfreid, Graham Nesselrodt, Matt Coen, and Brandon Miller who assisted with this project. This is scientific article number xxxx of the West Virginia University Agriculture and Forestry Experiment Station. 


\section{Literature Cited}

Akins, J. B., Carver, B. D., Kennedy, M. L. (2004). An assessment of species richness in mammals using scent-station procedures in three habitats. Tennessee Academy of Science, 79, 56-56.

Andrews, K. M., Gibbons, J. W., Reeder, T. W. (2005). How do highways influence snake movements? Behavior responses to roads and vehicles. Copeia, 2005, 772-782.

Aquilani, S. M. (2006). Bird communities in silvicultural fragments of Holly Springs National Forest, Mississippi. Southeastern Naturalist, 5, 135-148.

Beasley, J. C., Devault, T. L., Retamosa, M. I., Rhodes, Jr., O. E. (2007). A hierarchical analysis of habitat selection by raccoons in northern Illinois. Journal of Wildlife Management, 71, 11251133 .

Beauvais, G. P., Buskirk, S. W. (1999). Modifying estimates of sampling effort to account for sprung traps. Wildlife Society Bulletin, 27, 39-43.

Bell, D. A., Gregoire, D. P., Walton, B. J. (1996). Bridge use by peregrine falcons in the San Francisco Bay area. In Bird, D. M., Varland, D., Negro, J. (Eds). Raptors in human landscapes: adaptations to built and cultivated environments (pp. 15-24). San Diego, CA: Academic Publishers.

Bennett, F. B., Loeb, S. C., Bunch, M. S., Bowerman, W. W. (2008). Use and selection of bridges as daily roosts by Rafinesque's big-eared bats. American Midland Naturalist, 160, 386399.

Best, L. B., Campa, I. H., Kemp, K. E., Robel, R. J., Ryan, M. R., Savidge, J. A., Weeks, J. H. P, Winterstein, S. R. (1997). Bird abundance and nesting in CRP fields and cropland in the Midwest: a regional approach. Wildlife Society Bulletin, 25, 864-877.

Bleich, V. C., Kie, J. G., Loft, E. R., Stephenson, T. R., Oehler, M. H., Medina, A. L. (2005). Managing rangelands for wildlife. In Braun, C. E. (Ed). Techniques for wildlife investigations and management. Sixth edition (pp. 873-897) Bethesda, MD: The Wildlife Society.

Breeden, J. B., Hernandez, F., Bingham, R. L., Silvy, N. J. Waggerman, G. L. (2008). Effects of traffic noise on auditory surveys of urban white-winged doves. Wilson Journal of Ornithology, 120, 384-389.

Brooks, R. P. (1980). A model of habitat selection and population estimation for muskrats (Ondatra zibethicus) in riverine environments in Massachusetts. Ph.D. Dissertation, University of Massachusetts.

Burger, A. E. (2001). Using radar to estimate populations and assess habitat associations of marbled murrelets. Journal of Wildlife Management, 65, 696-715.

Cade, T. J., Bird, D. M. (1990). Peregrine falcons (Falco peregrinus) nesting in an urban environment: a review. Canadian Field Naturalist, 104, 209-218. 
Campbell, M. O. (2008). The impact of vegetation, river, and urban features on waterbird ecology in Glosgaw, Scotland. Journal of Coastal Research, 24, 239-245.

Christen, D., Matlock, G. (2006). The role of roadsides in plant invasions: a demographic approach. Conservation Biology, 20, 295-391.

Clark, W. D., Karr, J. R. (1979). Effect of highways on red-winged blackbird and horned lark populations. Wilson Bulletin, 91, 143-145.

Conover, W. J., Iman, R. L. 1981. Rank transformations as a bridge between parametric and nonparametric statistics. American Statistician 35, 124-129.

Conover, W. J. (1999). Practical Nonparametric Statistics. New York, NY: John Wiley and Sons.

Converse, S. J., White, G. C., Block, W. M. (2006). Small mammal responses to thinning and wildfire in ponderosa pine dominated forests of the southwestern United States. Journal of Wildlife Management, 70, 1711-1722.

Daubenmire, R. F. (1968). Plant Communities: A Textbook of Plant Synecology. New York, NY: Harper and Row.

Edalgo, J. A., Anderson, J. T. (2007). Effects of prebaiting on small mammal trapping success in a Morrow's honeysuckle-dominated area. Journal of Wildlife Management, 71, 246-250.

Elias, S. P., Witham, J. W., Hunter, Jr., M. L. (2004). Peromyscus leucopus abundance and acorn mast: population fluctuations over 20 years. Journal of Mammalogy, 85, 743-747.

Elliot, A. G., Root, B. G. (2006). Small mammal responses to silvicultural and precipitationrelated disturbance in northeastern Missouri riparian forests. Wildlife Society Bulletin, 34, 485501.

Er, K. B., Innes, J. L, Kozak, A. (2003). Effects of census duration on estimates of winter bird abundance and species richness along line transects in coastal coniferous forest fragments. Journal of Field Ornithology, 74, 119-124.

Forcey, G. M., Anderson, J. T., Ammer, F. K., Whitmore, R. C. (2006). Comparison of two double-observer point-count approaches for estimating breeding bird abundance. Journal of Wildlife Management, 70, 1674-1681.

Forman, R. T., Alexander, L. E. (1998). Roads and their major ecological effects. Annual Review of Ecology and Systematics, 29, 207-231.

Forman, R. T. (2000). Estimate of the area affected ecologically by the road system in the United States. Conservation Biology, 14, 31-35.

Forman, R. T., Sperling, D., Bissonette, J. A., Clevenger, A. P., Cutshall, C. D., Dale, V. H., Fahrig, L., France, R., Goldman,, C. R., Heanue, K., Jones, J. A., Swanson, F. J., Turrentine, T., and Winter, T. C. (2003). Road Ecology: Science and Solutions. Washington, D.C: Island Press. 
Freeman, S. N., Noble, D. G., Newson, S. E., Baillie, S. R. (2007). Modeling population changes using data from different surveys: the common birds census and the breeding bird survey. Bird Study, 54, 61-72.

Gehrt, S. D. (2003). Raccoons. In Feldhamer, G. A., Thompson, B. C., Chapman, J. A. (Eds), Wild Mammals of North America: Biology, Management, and Conservation. (pp. 611-634). Baltimore, MD: Johns Hopkins University Press.

Getz, L. L., Oli, M. K., Hoffman, J. E., McGuire, B. (2006). Vole population fluctuations: Factors that initiate and determine intervals between them in Microtus ochrogaster. Journal of Mammalogy, 87, 387-393.

Harrison, C. A., Kilgo, J. C. (2004). Short-term breeding bird response to two harvest practices in a bottomland hardwood forest. Wilson Bulletin, 116, 314-323.

Haxton, T. (2000). Road mortality of Snapping Turtles, Chelydra serpentina, in central Ontario during their nesting period. Canadian Field Naturalist, 114, 106-110.

Helon, D. A., Anderson, J. T., Osbourne, J. D. (2002). Comparison of interior versus roadside scent stations. Game and Wildlife Science, 19, 303-312.

Heusmann, H. W., Sauer, J. R. (2000). The northeastern states' waterfowl breeding population survey. Wildlife Society Bulletin, 28, 355-364.

Hubbard, M. W., Danielson, B. J, Schmitz, R. A. (2000). Factors influencing the location of deer-vehicle accidents in Iowa. Journal of Wildlife Management, 64, 707-712.

Idcide West Virginia City Data. (2010). http://www.idcide.com/citydata/wv/. Accessed 16 July 2010.

Idcide West Virginia Weather. (2010). http://www.idcide.com/weather/wv/. Accessed 16 July 2010.

Jenkins, S. H. (1979). Problems, progress, and prospects in studies of food selection by beavers. In Chapman, J. A., Pursley, D. (Eds). Worldwide Furbearer Conference Proceedings, Vol. 1, Aug. 3-11, 1980, (pp. 559-579) Frostburg, MD.

Johnston, F. M., Johnston, S. W. (2004). Impacts of road disturbance on soil properties and on exotic plant occurrence in subalpine areas of the Austrian Alps. Arctic, Antarctic, and Alpine Research, 36, 201-207.

Jones, J. A., Swanson, F. J., Wemple, B. C., Snyder, K. U. (2000). Effects of roads on hydrology, geomorphology, and disturbance patches in stream networks. Conservation Biology, 14, 76-85.

Kalpin, M. C. (1986). Scent station indices as a measure of fox abundance. Master's Thesis, West Virginia University.

Kaminski, J. A., Davis, M. L., Kelly, M., Keyser, P. D. (2007). Disturbance effects of small mammal species in a managed Appalachian forest. American Midland Naturalist, 157, 385-397. 
Kirkland, G. L. (1990). Patterns of initial small mammal community change after clearcutting of temperate North American forests. Oikos, 59, 313-320.

Lesbarreres, D., Primmer, C. R., Lode, T., Merila, J. (2006). The effects of 20 years of highway presence on the genetic structure of Rana dalmatina populations. Ecoscience, 13, 531-538.

Lougheed, L. W., Breault, A. (1999). Estimating statistical power to evaluate ongoing waterfowl population monitoring. Journal of Wildlife Management, 63, 1359-1369.

Menzel, M. A., Ford, W. M., Laerm, J., Krishon, D. (1999). Forest to wildlife openings: habitat gradient analysis among small mammals in the southern Appalachians. Forest Ecology and Management, 114, 227-232.

Mooney, H. A., Kuppers, M., Koch, G. W., Gorman, J., Chu, C. C. (1988). Compensating effects to growth of carbon partitioning changes in response to sulfur dioxide induced photosynthetic reduction in radish. Oecologia, 75, 502-506.

Morrison, M. L., Block, W. M., Strickland, M. D., Kendall, W. L. (2001). Wildlife Study Design. New York, NY: Springer-Verlag.

Mortensen, D. A., Rauschert, E. S. J., Nord, A. N., Jones, B. P. (2009). Forest roads facilitate the spread of invasive plants. Invasive Plant Science and Management, 2, 191-299.

Nichols, J. D., Hines, J. E., Sauer, J. R., Fallon, F. W., Fallon, J. E., Heglund, P. J. (2000). A double-observer approach for estimating detection probability and abundance from point counts. Auk, 117, 393-408.

Noss, R.F., Quigley, H. B., Hornocker, M. G., Merrill, T., Paquet, P.C. (1996). Conservation biology and carnivore conservation in the Rocky Mountains. Conservation Biology, 10, 949-963.

Nottingham Jr., B. G., Johnson, K. G., Pelton, M. R. (1989). Evaluation of scent-station surveys to monitor raccoon density. Wildlife Society Bulletin, 17, 29-35.

Oehler, J. D., Litvaitis, J. A. (1996). The role of spatial scale in understanding responses of medium-sized carnivores to forest fragmentation. Canadian Journal of Zoology, 74, 2070-2079.

Okabe, F., Agetsume, N. (2007). Habitat use by introduced raccoons and native raccoon dogs in a deciduous forest in Japan. Journal of Mammalogy, 88, 1090-1097.

Oli, M. K., Dobson, F. S. (2001). Population cycles in small mammals: The alpha hypothesis. Journal of Mammalogy, 82, 572-581.

Oliver, C. D., Larson, B. C. (1996). Forest Stand Dynamics. New York, NY: John Wiley and Sons, Inc.

Osbourne, J. D., Anderson, J. T., Spurgeon, A. B. (2005). Effects of habitat on small mammal abundance in West Virginia. Wildlife Society Bulletin, 33, 814-822.

Pearson, D. F., Ruggiero, L. F. (2003). Transects versus grid trapping arrangements for samplemammal communities. Wildlife Society Bulletin, 31, 454-459. 
Pease, M. L., Rose, R. K., Butler, M. J. (2005). Effects of human disturbances on the behavior of wintering ducks. Wildlife Society Bulletin, 33, 103-112.

Pelikan, J., Zejda, J., Holisova, V. (1977). Efficiency of different traps in catching small mammals. Folia Zoology, 26, 1-13.

Peterson, R. T. (2002). Birds of Eastern and Central North America: Fifth Edition. New York, NY: Houghton Mifflin Harcourt Company.

Randa, L. A., Yunger, J. A. (2006). Carnivore occurrence along an urban-rural gradient: A landscape-level analysis. Journal of Mammalogy, 87, 1154-1164.

Redmond, L. J., and Murphy, M. T. (2007). Unusual barn swallow nest placement in southeastern Oregon. Wilson Journal of Ornithology, 119, 307-309.

Rentch, J. S., Fortney, R. H., Stephenson, S. L., Adams, H. S., Grafton, W. N., Anderson, J. T. (2005). Vegetation-site relationships of roadside plant communities in West Virginia, USA. Journal of Applied Ecology, 42, 129-139.

Rodewald, P. G., Smith, K. G. (1998). Short-term effects of understory and overstory management on breeding birds in Arkansas oak-hickory forests. Journal of Wildlife Management, 62, 1411-1417.

Root, B. G., Thompson, F. R., Figert, D. E., Kritzell, E. K. (1990). Peromyscus leucopus response to clearcutting in a Missouri oak-hickory forest. Transactions of the Missouri Academy of Science, 24, 43-28.

Ross, D. M., Van Acker, R. C. (2005). Effect of nitrogen fertilizer and landscape position on wild oat (Avena fatua) interference in spring wheat. Weed Science, 6, 869-876.

Rowland, M. M., Wisdom, M. J., Johnson, B. K., Kie, J. G. (2000). Elk distribution and modeling in relation to roads. Journal of Wildlife Management, 64, 672-684.

Sacks, B. N., Ernest, H. B., Boydston, E. E. (2006). San Francisco’s Golden Gate: A bridge between historically distinct coyote (Canis latrans) populations. Western North American Naturalist, 66, 263-264.

Sargeant, G. A., Johnson, D. H., Berg, W. E. (1998). Interpreting carnivore scent-station surveys. Journal of Wildlife Management, 62, 1235-1245.

Silvy, N. J., Lopez, R. R., Peterson, M. J. (2005). Wildlife marking techniques. In Braun, C. E. (Ed.) Techniques for wildlife investigation and management. Sixth Edition. (pp. 339-376).

Bethesda, MD: The Wildlife Society.

Skagen, S. K., Melcher, C. P., Muths, E. (2001). The interplay of habitat change, human disturbance, and species interactions in a waterbird colony. American Midland Naturalist, 145, 18-28. 
Smith, M. D., Barbour, P. J., Burger, W. L., Dinsmore, S. J. (2005). Density and diversity of overwintering birds in managed field borders in Mississippi. Wilson Bulletin, 117, 258-269.

Stephenson, S. L., Adams, H. S., Huebner, C. D. (2007). Upland forest vegetation of the Ozark Mountains in northwestern Arkansas. Rhodora, 109, 197-221.

Tolin, W. A., Schettig, P. A. (1983). A physical and biological survey of the Ohio River islands (Huntington District). Elkins, WV: U. S. Fish and Wildlife Service.

Tordoff, H. B., Redig, P. T. (1988). Dispersal, nest site selection, and age of first breeding in peregrine falcons released in the upper Midwest 1982-1988. Loon, 60, 148-151.

Townsend, C. R., Harper, J. L., Begon M. (2000). Essentials of Ecology. Malden, MA: Blackwell Science.

Trombulak, S.C., Frissell, C. A. (2000). Review of ecological effects of roads on terrestrial and aquatic communities. Conservation Biology, 14, 18-30.

Tumlison, R. 2009. Breeding by cliff swallows (Petrochelidon pyrrhonota) in southern Arkansas. Southwestern Naturalist, 54, 208-210.

Tyser, R. W., Asebrook, J. M., Potter, R. W., Kurth, L. L. (1998). Roadside revegetation in Glacier National Park: Effects of herbicide and seeding treatments. Restoration Ecology, 6, 197206.

United States Fish and Wildlife Service. 2002. Ohio River Islands National Wildlife Refuge Comprehensive Conservation Plan. Parkersburg, WV: U.S. Fish and Wildlife Service.

Vankat, J. L., Roy, D. G. (2002). Landscape invisibility by exotic species. In Gutzwiller, K.J., (Ed) Applying Landscape Ecology in Biological Conservation. (pp. 170-192) New York, NY:Springer.

Vos, C. C., Chardon, J. P. (1998). Effects of habitat fragmentation and road density on the distribution pattern of the Moor Frog, Rana arvilis. Journal of Applied Ecology, 35, 44-56.

Wallendorf, M. J., Porneluzi, P. A., Gram, W. K., Clawson, R. L., Faaborg, J. (2007). Bird response to clear cutting in Missouri Ozark forests. Journal of Wildlife Management, 71, 18991905.

Warrick, G. D., Harris, C. E. (2001). Evaluation of spotlight and scent-station surveys to monitor kit fox abundance. Wildlife Society Bulletin, 29, 827-832.

Weller, M. W. (1999). Wetland birds, habitat resources and conservation. New York, NY:Cambridge Press.

Wilcox, D. A. (1986). The effects of de-icing salts on water chemistry in Pinhook Bog, Indiana. Water Resources Bulletin, 22, 57-65. 
Williams, A. K., Ratnaswamy, M. J., Renken, R. B. (2001). Impacts of a flood on small mammal populations of lower Missouri River floodplain forests. American Midland Naturalist, 146, 217221.

Yunger, J. A., Randa, L. A. (1999). Trap decontamination using hypochlorite: effects on trappability of small mammals. Journal of Mammalogy, 80, 1336-1340.

Zadnik, A. K., Anderson, J. T., Wood, P. B., Bledsoe, K. (2009). Wildlife use of back channels associated with islands on the Ohio River. Wetlands, 29, 543-551. 
Table 1: Summary of most common vegetation sampled (> 2\% cover or importance values (IV) for any site or survey period) with means and standard errors (SE) (percent cover for herbaceous vegetation and IV for woody vegetation) at the $0 \mathrm{~m}$ transects only at Blennerhassett and Buckley islands, West Virginia, USA during Phases II (Pre: 1998-2000) and III (Post: 2007-2009). SE could not be calculated for pre-construction at Blennerhassett.

\begin{tabular}{|c|c|c|c|c|c|c|c|c|}
\hline \multirow{3}{*}{ Common Name } & \multirow{3}{*}{ Scientific Name } & \multicolumn{3}{|c|}{ Blennerhassett } & \multicolumn{4}{|c|}{ Buckley } \\
\hline & & \multirow{2}{*}{$\frac{\text { Pre }}{\overline{\mathrm{x}}}$} & \multicolumn{2}{|c|}{ Post } & \multicolumn{2}{|c|}{ Pre } & \multicolumn{2}{|c|}{ Post } \\
\hline & & & $\bar{x}$ & SE & $\bar{x}$ & SE & $\bar{x}$ & SE \\
\hline Bryophytes & & 0.00 & 2.25 & 0.75 & 0.00 & 0.00 & 0.08 & 0.08 \\
\hline Rocks or Bare Ground & & 0.00 & 34.00 & 3.00 & 22.38 & 9.38 & 35.42 & 18.52 \\
\hline Woody Debris & & 0.00 & 0.25 & 0.25 & 2.50 & 2.50 & 0.33 & 0.08 \\
\hline Box Elder & Acer negundo L. & 80.80 & 0.00 & 0.00 & 0.00 & 0.00 & 0.00 & 0.00 \\
\hline Canada Goldenrod & Solidago canadensis L. & 0.00 & 0.00 & 0.00 & 3.38 & 3.38 & 0.00 & 0.00 \\
\hline Canada Thistle & Cirsium arvense (L.) Scop. & 0.00 & 0.00 & 0.00 & 0.00 & 0.00 & 3.25 & 1.75 \\
\hline Common Burdock & Arctium minus (Hill) Bernh. & 0.00 & 0.00 & 0.00 & 0.00 & 0.00 & 6.00 & 6.00 \\
\hline Common Mugwort & Artemisia vulgaris $\mathrm{L}$. & 0.00 & 0.75 & 0.75 & 0.00 & 0.00 & 2.00 & 1.76 \\
\hline English Plantain & Plantago lanceolata L. & 0.00 & 2.38 & 2.38 & 0.00 & 0.00 & 0.00 & 0.00 \\
\hline False Nettle & Boehmeria cylindrica (L.) Sw. & 15.25 & 0.00 & 0.00 & 0.00 & 0.00 & 0.00 & 0.00 \\
\hline Japanese Hop & Humulus japonicus Siebold \& Zucc. & 14.50 & 1.13 & 1.13 & 0.00 & 0.00 & 0.00 & 0.00 \\
\hline Japanese Knotweed & Polygonum cuspidatum Siebold \& Zucc. & 1.50 & 0.00 & 0.00 & 0.00 & 0.00 & 13.00 & 13.00 \\
\hline Japanese Millet & Echinochloa crus-galli var frumentacea P. Beauv. & 0.00 & 15.00 & 15.00 & 0.00 & 0.00 & 0.00 & 0.00 \\
\hline Japanese Stilt Grass & Microstegium vimineum (Trin.) A. Camus & 0.00 & 5.00 & 5.00 & 0.00 & 0.00 & 0.00 & 0.00 \\
\hline Kentucky 31 Fescue & Lolium arundinaceum (Scop.) Holub & 0.00 & 0.00 & 0.00 & 0.00 & 0.00 & 9.58 & 9.46 \\
\hline Lady's Thumb & Polygonum persicaria $\mathrm{L}$. & 0.00 & 2.25 & 2.25 & 0.00 & 0.00 & 0.17 & 0.17 \\
\hline Mile-A-Minute Weed & Polygonum perfoliata (L.) H. Gross & 0.00 & 2.25 & 2.25 & 0.00 & 0.00 & 0.25 & 0.25 \\
\hline Poison Ivy & Toxicodendron radicans (L.) Kuntze & 0.00 & 0.00 & 0.00 & 0.00 & 0.00 & 2.67 & 2.67 \\
\hline
\end{tabular}


Table 1 Continued

\begin{tabular}{|c|c|c|c|c|c|c|c|c|}
\hline Prickly Lettuce & Lactuca serriola L. & 0.00 & 1.63 & 1.63 & 0.00 & 0.00 & 2.17 & 2.04 \\
\hline Red Fescue & Festuca rubra L. & 0.00 & 0.00 & 0.00 & 9.63 & 8.13 & 0.00 & 0.00 \\
\hline Reed Canary Grass & Phalaris arundinacea $\mathrm{L}$. & 60.25 & 0.00 & 0.00 & 30.00 & 30.00 & 8.92 & 8.92 \\
\hline Silver Maple & Acer saccharinum $\mathrm{L}$. & 18.70 & 0.00 & 0.00 & 47.49 & 47.49 & 0.00 & 0.00 \\
\hline Staghorn Sumac & Rhus typhina $\mathrm{L}$. & 0.00 & 50.00 & 50.00 & 0.00 & 0.00 & 0.00 & 0.00 \\
\hline Three-Square & Schoenplectus pungens (Vahl) Palla & 0.00 & 0.00 & 0.00 & 0.00 & 0.00 & 2.58 & 2.58 \\
\hline Wild Rye & Elymus riparius Wiegand & 0.00 & 8.88 & 8.88 & 0.00 & 0.00 & 0.00 & 0.00 \\
\hline Wild Teasel & Dispacus fullonum L. & 0.00 & 0.00 & 0.00 & 5.13 & 5.13 & 0.00 & 0.00 \\
\hline Wing-stem & Verbesina alternifolia (L.) Britton ex Kearney & 18.00 & 0.00 & 0.00 & 0.00 & 0.00 & 0.00 & 0.00 \\
\hline
\end{tabular}


Table 2: Summary of soil variables with means and standard errors (SE) taken at the $0 \mathrm{~m}$ transects at Blennerhassett and Buckley islands, West Virginia, USA during Phases II (Pre: 1998-2000) and III (Post: 2007-2009). SE could not be calculated for preconstruction at Blennerhassett.

\begin{tabular}{|c|c|c|c|c|c|c|}
\hline \multirow{3}{*}{ Soil Variable } & \multicolumn{3}{|c|}{ Blennerhassett } & \multicolumn{3}{|c|}{ Buckley } \\
\hline & \multirow{2}{*}{$\frac{\text { Pre }}{\bar{x}}$} & \multicolumn{2}{|c|}{ Post } & \multirow{2}{*}{$\begin{array}{c}\text { Pre } \\
\bar{x}\end{array}$} & \multicolumn{2}{|c|}{ Post } \\
\hline & & $\bar{x}$ & SE & & $\bar{x}$ & SE \\
\hline Total Exchange Capacity (cmolc/kg) & 16.59 & 19.23 & 6.01 & 18.35 & 24.08 & 4.50 \\
\hline $\mathrm{pH}$ & 7.10 & 6.85 & 0.75 & 7.10 & 7.40 & 0.12 \\
\hline Organic Matter (\%) & 5.90 & 1.33 & 0.43 & 6.81 & 2.84 & 0.42 \\
\hline Nitrate (ppm) & 28.70 & 170.30 & 130.60 & 6.70 & 53.07 & 3.55 \\
\hline Soluble Sulfur (ppm) & 42.00 & 53.00 & 9.00 & 60.00 & 101.33 & 48.50 \\
\hline Calcium (ppm) & $2,281.00$ & $2,704.00$ & $1,057.00$ & $2,670.00$ & $2,555.67$ & 391.54 \\
\hline Magnesium (ppm) & 436.00 & 355.00 & 143.00 & 436.00 & 221.67 & 25.86 \\
\hline Potassium (ppm) & 302.00 & 205.00 & 14.00 & 177.00 & 154.33 & 16.25 \\
\hline Sodium (ppm) & 14.00 & 117.00 & 59.00 & 29.00 & $1,861.00$ & 568.59 \\
\hline Boron (ppm) & 1.14 & 0.65 & 0.19 & 1.17 & 0.76 & 0.04 \\
\hline Iron (ppm) & 402.00 & 314.00 & 52.00 & 414.00 & 307.00 & 27.47 \\
\hline Manganese (ppm) & 77.00 & 110.50 & 4.50 & 202.00 & 107.67 & 9.84 \\
\hline Zinc (ppm) & 42.05 & 6.18 & 1.47 & 62.80 & 47.80 & 4.73 \\
\hline Copper (ppm) & 8.56 & 3.92 & 1.42 & 11.09 & 7.99 & 0.79 \\
\hline Aluminum (ppm) & 944.00 & 417.00 & 320.00 & $1,066.00$ & 502.67 & 119.04 \\
\hline
\end{tabular}


Table 3: List of waterbirds with means (individuals/39.25 ha plot) and standard errors that were observed during Phase III (Post: 20082009) along with their Phase I (Pre: 1985-1987) mean for Blennnerhassett and Buckley islands. SE could not be calculated for preconstruction during Phase I.

\begin{tabular}{|c|c|c|c|c|c|c|c|}
\hline \multirow{3}{*}{ Common Name } & \multirow{3}{*}{ Scientific Name } & \multicolumn{3}{|c|}{ Blennerhassett } & \multicolumn{3}{|c|}{ Buckley } \\
\hline & & \multirow{2}{*}{$\begin{array}{c}\text { Phase I } \\
\bar{x}\end{array}$} & \multicolumn{2}{|c|}{ Phase III } & \multirow{2}{*}{$\frac{\text { Phase I }}{\bar{x}}$} & \multicolumn{2}{|c|}{ Phase III } \\
\hline & & & $\bar{x}$ & SE & & $\bar{x}$ & SE \\
\hline Belted Kingfisher & Megaceryle alcyon Linnaaeus & 0.39 & 0.14 & 0.14 & 0.22 & 0.00 & 0.00 \\
\hline Canada Goose & Branta canadensis Linnaeus & 0.35 & 23.00 & 7.67 & 0.72 & 14.86 & 6.10 \\
\hline Great Blue Heron & Ardea herodias Linnaeus & 0.48 & 0.18 & 0.12 & 0.00 & 0.00 & 0.00 \\
\hline Hooded Merganser & Lophodytes cucullatus Linnaeus & 0.00 & 0.71 & 0.71 & 0.00 & 0.00 & 0.00 \\
\hline Mallard & Anas platyrhynchos Linnaeaus & 0.22 & 2.14 & 1.26 & 0.00 & 0.86 & 0.46 \\
\hline Pied-billed Grebe & Podilymbus podiceps Linnaeus & 0.00 & 0.29 & 0.29 & 0.00 & 0.00 & 0.00 \\
\hline Wood Duck & Aix sponsa Linnaeus & 0.87 & 0.71 & 0.47 & 0.06 & 1.55 & 1.07 \\
\hline Combined Waterbirds & & 3.65 & 27.14 & 7.11 & 1.22 & 17.57 & 5.76 \\
\hline
\end{tabular}


Table 4: Summary of all songbirds used in the site, distance, and phase analyses with their means (individuals/ha), standard errors (SE), F-statistics, and P-values along with species richness and Shannon Diversity Index for Blennerhassett and Buckley islands, West Virginia, USA, and 0, 100, and $300 \mathrm{~m}$ from the bridge, and Phases I (1985-1987), II (1998-2000), and III (2007-2009) with same letters indicating no difference (bolded means indicate significant difference at $\alpha=0.05$ ).

\begin{tabular}{|c|c|c|c|c|c|c|}
\hline \multirow{3}{*}{ Common Name } & \multicolumn{6}{|c|}{ Island } \\
\hline & \multicolumn{2}{|c|}{ Blennerhassett } & \multicolumn{2}{|c|}{ Buckley } & \multirow[b]{2}{*}{$F_{1,24}$} & \multirow[b]{2}{*}{$P$} \\
\hline & $\bar{x}$ & SE & $\bar{x}$ & SE & & \\
\hline American Goldfinch & $0.78 a$ & 0.17 & $0.50 \mathrm{a}$ & 0.07 & 1.18 & 0.288 \\
\hline American Robin & $0.38 a$ & 0.09 & $0.73 a$ & 0.13 & 3.49 & 0.074 \\
\hline Baltimore Oriole & $0.02 a$ & 0.02 & $0.04 a$ & 0.03 & 0.01 & 0.908 \\
\hline Blue Jay & $0.11 a$ & 0.04 & $0.07 a$ & 0.02 & 0.12 & 0.728 \\
\hline Brown-headed Cowbird & $0.11 a$ & 0.05 & $0.23 a$ & 0.08 & 0.82 & 0.376 \\
\hline Carolina Chickadee & $0.42 a$ & 0.19 & $0.25 a$ & 0.04 & 0.51 & 0.481 \\
\hline Carolina Wren & $0.66 a$ & 0.09 & $0.39 b$ & 0.13 & 12.80 & 0.002 \\
\hline Cedar Waxwing & $0.20 a$ & 0.08 & $0.24 a$ & 0.06 & 0.64 & 0.431 \\
\hline Cliff Swallow & $0.00 \mathrm{~b}$ & 0.00 & $0.41 a$ & 0.25 & 15.74 & $<0.001$ \\
\hline Common Grackle & $0.20 a$ & 0.05 & $0.19 a$ & 0.05 & 0.37 & 0.549 \\
\hline Common Yellowthroat & $0.41 a$ & 0.14 & $0.24 a$ & 0.06 & 0.11 & 0.739 \\
\hline Downy Woodpecker & $0.31 a$ & 0.08 & $0.18 a$ & 0.07 & 2.09 & 0.161 \\
\hline Eastern Towhee & $0.06 a$ & 0.04 & $0.06 a$ & 0.03 & 0.07 & 0.790 \\
\hline European Starling & $0.02 b$ & 0.02 & $0.91 a$ & 0.31 & 6.55 & 0.017 \\
\hline Gray Catbird & $0.52 b$ & 0.10 & $1.05 a$ & 0.13 & 7.70 & 0.011 \\
\hline Hairy Woodpecker & $0.08 a$ & 0.05 & $0.08 a$ & 0.04 & 0.36 & 0.555 \\
\hline House Wren & $0.55 a$ & 0.17 & $0.24 a$ & 0.06 & 1.11 & 0.303 \\
\hline Indigo Bunting & $0.46 a$ & 0.09 & $0.42 a$ & 0.08 & 0.09 & 0.768 \\
\hline
\end{tabular}


Table 4 Continued

\begin{tabular}{|c|c|c|c|c|c|c|}
\hline Mourning Dove & $0.01 b$ & 0.01 & $0.98 a$ & 0.44 & 8.72 & 0.007 \\
\hline Northern Cardinal & $1.07 a$ & 0.17 & $0.76 a$ & 0.09 & 1.07 & 0.311 \\
\hline Northern Flicker & $0.12 \mathrm{a}$ & 0.05 & $0.11 \mathrm{a}$ & 0.03 & 0.22 & 0.646 \\
\hline Northern Parula & $0.01 a$ & 0.01 & $0.02 a$ & 0.01 & 0.45 & 0.511 \\
\hline Orchard Oriole & $0.09 a$ & 0.06 & $0.01 a$ & 0.01 & 0.75 & 0.394 \\
\hline Pileated Woodpecker & $0.02 a$ & 0.01 & $0.02 a$ & 0.01 & 0.03 & 0.866 \\
\hline Red-eyed Vireo & $0.24 a$ & 0.07 & $0.32 \mathrm{a}$ & 0.06 & 0.95 & 0.338 \\
\hline Red-winged Blackbird & $0.40 a$ & 0.25 & $0.11 \mathrm{a}$ & 0.03 & 0.04 & 0.841 \\
\hline Rock Pigeon & $0.10 \mathrm{~b}$ & 0.10 & $1.66 a$ & 0.78 & 27.13 & $<0.001$ \\
\hline Song Sparrow & $1.52 \mathrm{a}$ & 0.33 & $1.52 \mathrm{a}$ & 0.19 & 0.21 & 0.649 \\
\hline Tufted Titmouse & $0.36 a$ & 0.10 & $0.21 \mathrm{a}$ & 0.04 & 0.73 & 0.400 \\
\hline White-eyed Vireo & $0.18 a$ & 0.05 & $0.04 b$ & 0.02 & 4.85 & 0.038 \\
\hline Wood Thrush & $0.12 a$ & 0.05 & $0.02 \mathrm{a}$ & 0.01 & 2.67 & 0.115 \\
\hline Yellow Warbler & $0.32 \mathrm{a}$ & 0.15 & $0.24 a$ & 0.06 & 0.38 & 0.545 \\
\hline Yellow-billed Cuckoo & $0.06 a$ & 0.03 & $0.00 \mathrm{~b}$ & 0.00 & 6.08 & 0.021 \\
\hline Combined Songbirds & $12.18 \mathrm{a}$ & 1.39 & $13.56 a$ & 1.12 & 1.36 & 0.256 \\
\hline Species Richness & $16.89 a$ & 0.86 & $18.83 a$ & 0.84 & 2.33 & 0.167 \\
\hline Shannon Diversity Index & 2.49a & 0.06 & $2.45 a$ & 0.09 & $<0.01$ & 0.961 \\
\hline
\end{tabular}


Table 4 Extended

\begin{tabular}{|c|c|c|c|c|c|c|c|c|c|c|c|c|c|c|c|}
\hline \multicolumn{8}{|c|}{ Distance } & \multicolumn{8}{|c|}{ Phase } \\
\hline \multicolumn{2}{|c|}{$0 \mathrm{~m}$} & \multicolumn{2}{|c|}{$100 \mathrm{~m}$} & \multicolumn{2}{|c|}{$300 \mathrm{~m}$} & \multirow[b]{2}{*}{$F_{2,24}$} & \multirow[b]{2}{*}{$P$} & \multicolumn{2}{|c|}{ Phase I } & \multicolumn{2}{|c|}{ Phase II } & \multicolumn{2}{|c|}{ Phase III } & \multirow[b]{2}{*}{$F_{2,24}$} & \multirow[b]{2}{*}{$P$} \\
\hline $\bar{x}$ & SE & $\bar{x}$ & SE & $\bar{x}$ & SE & & & $\bar{x}$ & SE & $\bar{x}$ & SE & $\bar{x}$ & SE & & \\
\hline $0.51 a$ & 0.11 & $0.74 a$ & 0.20 & $0.60 a$ & 0.11 & 0.31 & 0.737 & $0.62 a$ & 0.17 & $0.68 a$ & 0.18 & $0.55 a$ & 0.08 & 0.06 & 0.940 \\
\hline $0.54 a$ & 0.13 & $0.74 a$ & 0.19 & $0.42 a$ & 0.11 & 0.55 & 0.586 & $0.44 b$ & 0.12 & $0.37 b$ & 0.14 & $0.93 a$ & 0.16 & 4.60 & 0.020 \\
\hline $0.02 a$ & 0.01 & $0.06 a$ & 0.05 & $0.02 a$ & 0.02 & 0.09 & 0.918 & $0.02 a$ & 0.01 & $0.06 a$ & 0.05 & $0.02 a$ & 0.02 & 0.21 & 0.812 \\
\hline $0.10 a$ & 0.04 & $0.06 a$ & 0.03 & $0.09 a$ & 0.05 & 0.24 & 0.790 & $0.07 a$ & 0.03 & $0.06 a$ & 0.04 & $0.13 a$ & 0.04 & 1.31 & 0.289 \\
\hline $0.12 a$ & 0.05 & $0.28 a$ & 0.13 & $0.11 a$ & 0.06 & 0.39 & 0.682 & $0.03 b$ & 0.02 & $0.30 a$ & 0.08 & $0.20 a$ & 0.13 & 4.64 & 0.020 \\
\hline $0.27 a$ & 0.09 & $0.32 a$ & 0.09 & $0.39 a$ & 0.26 & 0.37 & 0.690 & $0.42 a$ & 0.22 & $0.35 a$ & 0.11 & $0.20 a$ & 0.05 & 0.20 & 0.823 \\
\hline $0.40 a$ & 0.09 & $0.68 a$ & 0.18 & $0.42 a$ & 0.14 & 1.79 & 0.189 & $0.24 b$ & 0.08 & $0.45 a b$ & 0.09 & $0.82 a$ & 0.19 & 6.30 & 0.006 \\
\hline $0.15 a$ & 0.06 & $0.28 a$ & 0.08 & $0.24 a$ & 0.12 & 0.84 & 0.442 & $0.09 b$ & 0.06 & $0.33 a$ & 0.08 & $0.25 a$ & 0.10 & 3.64 & 0.042 \\
\hline $0.62 a$ & 0.39 & $0.03 b$ & 0.03 & $0.02 b$ & 0.01 & 8.68 & $<0.001$ & $0.01 b$ & 0.01 & $0.04 b$ & 0.04 & $0.66 a$ & 0.42 & 9.76 & $<0.001$ \\
\hline $0.22 a$ & 0.06 & $0.24 a$ & 0.08 & $0.12 a$ & 0.04 & 1.06 & 0.364 & $0.30 a$ & 0.08 & $0.17 a$ & 0.05 & $0.13 a$ & 0.04 & 1.65 & 0.212 \\
\hline $0.14 a$ & 0.06 & 0.39a & 0.15 & $0.44 a$ & 0.12 & 2.29 & 0.123 & $0.25 a$ & 0.07 & $0.44 a$ & 0.17 & $0.25 a$ & 0.10 & 0.44 & 0.652 \\
\hline $0.20 \mathrm{a}$ & 0.06 & $0.28 a$ & 0.12 & $0.24 a$ & 0.10 & 0.05 & 0.955 & $0.17 a$ & 0.09 & $0.38 a$ & 0.12 & $0.16 a$ & 0.06 & 2.37 & 0.115 \\
\hline $0.07 a$ & 0.04 & $0.07 a$ & 0.04 & $0.02 a$ & 0.02 & 0.67 & 0.522 & $0.07 a$ & 0.05 & $0.02 a$ & 0.02 & $0.07 a$ & 0.04 & 0.29 & 0.753 \\
\hline $0.84 a$ & 0.38 & $0.24 a$ & 0.16 & $0.51 a$ & 0.41 & 1.04 & 0.367 & $0.07 a$ & 0.07 & $0.54 a$ & 0.26 & $0.98 a$ & 0.49 & 1.60 & 0.222 \\
\hline $0.88 a$ & 0.22 & $0.83 a$ & 0.12 & $0.74 a$ & 0.15 & 0.13 & 0.879 & $0.66 a$ & 0.11 & $0.72 \mathrm{a}$ & 0.19 & $1.09 a$ & 0.17 & 2.34 & 0.118 \\
\hline $0.09 a$ & 0.06 & $0.07 a$ & 0.05 & $0.10 a$ & 0.05 & 0.93 & 0.409 & $0.10 a$ & 0.06 & $0.02 a$ & 0.02 & $0.13 a$ & 0.06 & 1.67 & 0.210 \\
\hline $0.28 a$ & 0.17 & $0.45 a$ & 0.14 & $0.36 a$ & 0.10 & 1.38 & 0.272 & $0.20 a$ & 0.07 & $0.37 a$ & 0.14 & $0.54 a$ & 0.20 & 0.57 & 0.572 \\
\hline $0.41 a$ & 0.10 & $0.50 a$ & 0.08 & $0.40 a$ & 0.12 & 0.67 & 0.522 & $0.30 a$ & 0.05 & $0.37 a$ & 0.12 & $0.64 a$ & 0.09 & 3.37 & 0.051 \\
\hline $0.23 a$ & 0.11 & $0.47 a$ & 0.26 & $1.10 a$ & 0.85 & 0.23 & 0.793 & $0.40 a$ & 0.21 & $0.26 a$ & 0.14 & $1.04 a$ & 0.74 & 0.35 & 0.709 \\
\hline $0.84 a$ & 0.14 & $0.97 a$ & 0.17 & $0.85 a$ & 0.17 & 0.32 & 0.726 & $0.82 a$ & 0.19 & $1.02 \mathrm{a}$ & 0.15 & $0.82 a$ & 0.13 & 0.86 & 0.434 \\
\hline $0.08 a$ & 0.04 & $0.17 a$ & 0.05 & $0.09 a$ & 0.05 & 1.03 & 0.372 & $0.14 a$ & 0.05 & $0.01 b$ & 0.01 & $0.20 a$ & 0.06 & 4.31 & 0.025 \\
\hline
\end{tabular}


Table 4 Extended and Continued

\begin{tabular}{|c|c|c|c|c|c|c|c|c|c|c|c|c|c|c|c|}
\hline $0.02 a$ & 0.02 & $0.03 a$ & 0.02 & $0.00 a$ & 0.00 & 0.67 & 0.523 & $0.01 a$ & 0.01 & $0.02 a$ & 0.02 & $0.02 \mathrm{a}$ & 0.02 & 0.17 & 0.846 \\
\hline $0.01 a$ & 0.01 & $0.05 a$ & 0.04 & $0.10 a$ & 0.08 & 0.33 & 0.721 & $0.01 a$ & 0.01 & $0.01 a$ & 0.01 & $0.13 a$ & 0.08 & 1.00 & 0.384 \\
\hline $0.03 a$ & 0.02 & $0.03 a$ & 0.02 & $0.01 a$ & 0.01 & 0.13 & 0.882 & $0.02 a$ & 0.01 & $0.01 a$ & 0.01 & $0.04 a$ & 0.02 & 0.24 & 0.792 \\
\hline $0.27 a$ & 0.07 & $0.27 a$ & 0.09 & $0.33 a$ & 0.08 & 0.37 & 0.692 & $0.24 a$ & 0.06 & $0.23 a$ & 0.09 & $0.39 a$ & 0.08 & 2.04 & 0.152 \\
\hline $0.07 a$ & 0.04 & $0.19 a$ & 0.09 & $0.49 a$ & 0.37 & 1.11 & 0.345 & $0.09 a$ & 0.03 & $0.13 a$ & 0.10 & $0.48 a$ & 0.31 & 1.85 & 0.180 \\
\hline $2.66 a$ & 1.19 & $0.10 \mathrm{~b}$ & 0.10 & $0.01 b$ & 0.01 & 29.34 & $<0.001$ & $1.81 \mathrm{a}$ & 1.29 & $0.26 a$ & 0.13 & $0.89 a$ & 0.48 & 0.27 & 0.769 \\
\hline $1.48 a$ & 0.28 & $1.51 a$ & 0.33 & $1.58 a$ & 0.34 & 0.08 & 0.924 & $0.77 b$ & 0.11 & $1.49 \mathrm{~b}$ & 0.34 & $2.30 a$ & 0.28 & 7.17 & 0.004 \\
\hline $0.23 a$ & 0.10 & $0.25 a$ & 0.06 & $0.35 a$ & 0.11 & 1.09 & 0.352 & $0.30 a$ & 0.12 & $0.27 a$ & 0.09 & $0.23 a$ & 0.05 & 0.26 & 0.774 \\
\hline $0.11 a$ & 0.05 & $0.10 \mathrm{a}$ & 0.05 & $0.09 a$ & 0.05 & 0.15 & 0.864 & $0.11 a$ & 0.05 & $0.18 a$ & 0.06 & $0.02 a$ & 0.02 & 2.79 & 0.113 \\
\hline $0.09 a$ & 0.06 & $0.05 a$ & 0.04 & $0.05 a$ & 0.03 & 0.10 & 0.908 & $0.01 a$ & 0.01 & $0.08 a$ & 0.06 & $0.09 a$ & 0.04 & 1.08 & 0.356 \\
\hline $0.33 a$ & 0.10 & $0.32 a$ & 0.17 & $0.15 a$ & 0.05 & 0.66 & 0.526 & $0.14 a$ & 0.05 & $0.32 a$ & 0.19 & $0.38 a$ & 0.09 & 2.92 & 0.073 \\
\hline $0.01 a$ & 0.01 & $0.00 \mathrm{a}$ & 0.00 & $0.07 a$ & 0.04 & 2.25 & 0.127 & $0.03 a$ & 0.03 & $0.02 a$ & 0.02 & $0.02 a$ & 0.02 & 0.21 & 0.812 \\
\hline $14.00 a$ & 1.30 & $12.76 a$ & 1.66 & $11.94 a$ & 1.62 & 0.69 & 0.512 & $10.25 b$ & 1.09 & $11.44 b$ & 1.64 & $17.21 a$ & 1.09 & 8.73 & 0.001 \\
\hline $17.67 a$ & 0.88 & $18.33 a$ & 1.16 & $18.00 \mathrm{a}$ & 1.26 & 0.04 & 0.957 & $17.57 \mathrm{a}$ & 0.91 & $16.50 \mathrm{a}$ & 1.09 & $19.93 a$ & 1.06 & 2.83 & 0.079 \\
\hline $2.34 a$ & 0.12 & $2.58 \mathrm{a}$ & 0.07 & $2.48 a$ & 0.09 & 1.30 & 0.290 & $2.37 a$ & 0.13 & $2.48 a$ & 0.06 & $2.55 a$ & 0.08 & 0.56 & 0.576 \\
\hline
\end{tabular}


Table 5: Summary of small mammal trapping data for Blennerhassett and Buckley islands, West Virginia, USA (averages in the form of captures per 100 trap nights) for 14 transects ( $n=6$ at Blennerhassett and $n=8$ at Buckley) during Phases I (1985-1987), II (19982000), and III (2007-2009).

\begin{tabular}{|c|c|c|c|c|c|c|}
\hline & Attempts & Total Trap Nights & Individuals & Species & $\bar{x}$ & SE \\
\hline \multicolumn{7}{|l|}{ Phase I } \\
\hline Blennerhassett Island & 2,970 & 2,409 & 50 & 7 & 2.08 & 0.47 \\
\hline Buckley Island & 4,320 & 3,782 & 173 & 8 & 4.57 & 1.12 \\
\hline Total & 7,290 & 6,191 & 223 & 9 & 3.60 & 0.75 \\
\hline \multicolumn{7}{|l|}{ Phase II } \\
\hline Blennerhassett Island & 1,080 & 888 & 62 & 3 & 6.99 & 0.72 \\
\hline Buckley Island & 1,744 & 1,406 & 51 & 5 & 3.63 & 0.78 \\
\hline Total & 2,824 & 2,294 & 113 & 6 & 4.93 & 0.74 \\
\hline \multicolumn{7}{|l|}{ Phase III } \\
\hline Blennerhassett Island & 2,159 & 1,926 & 177 & 4 & 9.19 & 4.22 \\
\hline Buckley Island & 2,877 & 2,419 & 53 & 5 & 2.19 & 0.41 \\
\hline Total & 5,036 & 4,345 & 230 & 6 & 5.29 & 1.97 \\
\hline Cumulative Total & 15,150 & 12,830 & 566 & 10 & 4.51 & 0.71 \\
\hline
\end{tabular}


Table 6: Summary of all small mammals used in the site, distance, and phase analyses with their means (captures/100 trap nights), standard errors (SE), F-statistics, and P-values along with species richness and Shannon Diversity Index for Blennerhassett and Buckley Islands, West Virginia, USA, and 0, 100, and $300 \mathrm{~m}$ from the bridge, and Phases I (1985-1987), II (1998-2000), and III (2007-2009) with same letters indicating no difference (bolded means indicate significant difference at $\alpha=0.05$ ).

\begin{tabular}{|c|c|c|c|c|c|c|}
\hline \multirow{3}{*}{ Common Name } & \multicolumn{6}{|c|}{ Island } \\
\hline & \multicolumn{2}{|c|}{ Blennerhassett } & \multicolumn{2}{|c|}{ Buckley } & \multirow[b]{2}{*}{$F_{1,24}$} & \multirow[b]{2}{*}{$P$} \\
\hline & $\bar{x}$ & SE & $\bar{x}$ & SE & & \\
\hline Peromyscus spp. & $4.65 a$ & 1.16 & $2.39 a$ & 0.49 & 2.48 & 0.129 \\
\hline Meadow Vole & $1.24 a$ & 0.48 & $0.45 a$ & 0.16 & 0.58 & 0.453 \\
\hline Northern Short-tailed Shrew & $0.01 b$ & 0.01 & $0.22 a$ & 0.07 & 7.78 & 0.010 \\
\hline House Mouse & $0.00 a$ & 0.00 & $0.19 a$ & 0.10 & 3.35 & 0.079 \\
\hline Eastern Chipmunk & $0.11 a$ & 0.08 & $0.01 a$ & 0.01 & 1.85 & 0.186 \\
\hline Combined Small Mammals & $6.04 a$ & 1.52 & $3.36 a$ & 0.51 & 0.55 & 0.463 \\
\hline Species Richness & $1.89 a$ & 0.18 & $2.13 a$ & 0.28 & 0.01 & 0.931 \\
\hline Shannon Diversity Index & $0.42 a$ & 0.06 & $0.41 a$ & 0.10 & $<0.01$ & 0.946 \\
\hline
\end{tabular}


Table 6 Extended

\begin{tabular}{|c|c|c|c|c|c|c|c|c|c|c|c|c|c|c|c|}
\hline \multicolumn{8}{|c|}{ Distance } & \multicolumn{8}{|c|}{ Phase } \\
\hline \multicolumn{2}{|c|}{$0 \mathrm{~m}$} & \multicolumn{2}{|c|}{$100 \mathrm{~m}$} & \multicolumn{2}{|c|}{$300 \mathrm{~m}$} & \multirow[b]{2}{*}{$F_{2,24}$} & \multirow[b]{2}{*}{$P$} & \multicolumn{2}{|c|}{ Phase I } & \multicolumn{2}{|c|}{ Phase II } & \multicolumn{2}{|c|}{ Phase III } & \multirow[b]{2}{*}{$F_{2,24}$} & \multirow[b]{2}{*}{$P$} \\
\hline $\bar{x}$ & SE & $\bar{x}$ & SE & $\bar{x}$ & SE & & & $\bar{x}$ & SE & $\bar{x}$ & SE & $\bar{x}$ & SE & & \\
\hline $2.68 a$ & 0.60 & $3.50 a$ & 1.13 & $4.03 a$ & 1.36 & 0.05 & 0.951 & $2.92 b$ & 0.63 & $3.69 a$ & 0.58 & $3.47 a$ & 1.59 & 4.74 & 0.018 \\
\hline $0.46 a$ & 0.22 & $0.71 a$ & 0.34 & $1.30 \mathrm{a}$ & 0.62 & 0.45 & 0.643 & $0.27 a$ & 0.08 & $0.78 a$ & 0.41 & $1.31 \mathrm{a}$ & 0.53 & 0.92 & 0.327 \\
\hline $0.16 a$ & 0.09 & $0.16 a$ & 0.08 & $0.06 a$ & 0.04 & 0.33 & 0.723 & $0.20 a$ & 0.06 & $0.03 b$ & 0.03 & $0.15 a$ & 0.11 & 4.62 & 0.020 \\
\hline $0.23 a$ & 0.15 & $0.04 a$ & 0.04 & $0.05 a$ & 0.05 & 0.61 & 0.549 & $0.03 a$ & 0.03 & $0.15 a$ & 0.15 & $0.15 a$ & 0.08 & 0.67 & 0.522 \\
\hline $0.09 a$ & 0.09 & $0.05 a$ & 0.03 & $0.00 a$ & 0.00 & 1.66 & 0.211 & $0.03 a$ & 0.02 & $0.10 a$ & 0.10 & $0.02 a$ & 0.02 & 0.23 & 0.797 \\
\hline $3.70 a$ & 0.57 & $4.48 a$ & 1.30 & $5.56 a$ & 1.91 & 0.33 & 0.725 & $3.63 b$ & 0.75 & $4.79 a$ & 0.74 & 5.11a & 1.97 & 3.91 & 0.034 \\
\hline $2.20 \mathrm{a}$ & 0.33 & $1.93 a$ & 0.25 & $1.92 a$ & 0.38 & 0.27 & 0.763 & $2.79 a$ & 0.30 & $1.64 b$ & 0.27 & $1.64 b$ & 0.27 & 4.14 & 0.029 \\
\hline $0.50 a$ & 0.11 & $0.37 a$ & 0.10 & $0.37 a$ & 0.10 & 0.38 & 0.686 & $0.56 a$ & 0.08 & $0.32 a$ & 0.10 & $0.37 a$ & 0.12 & 1.47 & 0.250 \\
\hline
\end{tabular}


Figure 1: Location of two island study areas between kilometer markers 271.8 and 305.6 (mile markers 168.9 and 189.9) on the Ohio River, West Virginia, USA.

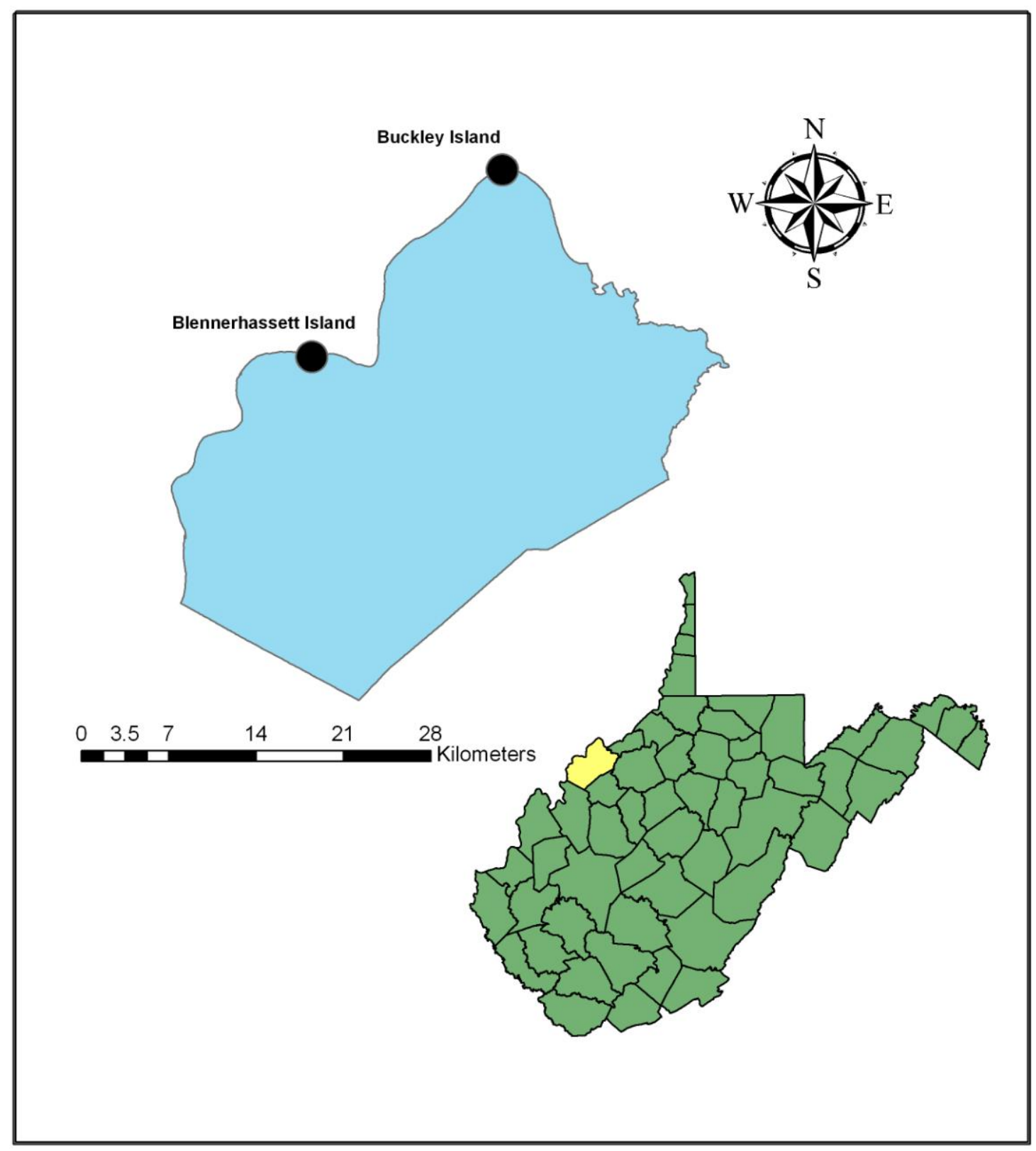




\title{
Chapter 5
}

CONCLUSIONS, MANAGEMENT IMPLICATIONS, AND FUTURE RESEARCH NEEDS FOR THE BLENNERHASSETT ISLAND BRIDGE CROSSING IN RELATION TO SOIL, VEGETATION, AND WILDLIFE

\author{
Joshua A. Vance \\ josh_vance10@yahoo.com \\ West Virginia University \\ Division of Forestry and Natural Resources \\ PO Box 6125 \\ Morgantown, WV 26506-6125
}




\section{Conclusions}

There was little evidence to suggest that the Blennerhassett Island Bridge has major impacts to soil, vegetation, and wildlife in comparison to other islands, distances from the bridge, and over time. Of 258 comparisons, only 38 (14.7\%) varied either in comparison to other islands $(8,21.1 \%)$, among different transect distances $(28,73.7 \%)$, or over time $(2,5.2 \%)$ and could be linked to the bridge. Of the $14.7 \%$ that showed variation, $47.4 \%$ was soil, $15.8 \%$ was vegetation, $2.6 \%$ was waterbirds, $23.7 \%$ was songbirds, and $10.5 \%$ was small mammals. There was no evidence to show that the Blennerhassett Island Bridge had any effect on anurans or turtles and differences with furbearers were more likely explained by difficulty sampling. This indicates that the impacts caused by the bridge were minor in scale and were confined to the area directly under and near the bridge which was altered during construction between March 2005 and June 2008. This disturbed area included about 3.36 ha on the island and 1.05 ha on the West Virginia mainland combining to about 4.41 ha total disturbed (the area under the bridge on the Ohio mainland was already disturbed due to the presence of a sand and gravel plant). At most, the disturbed area was about $103.0 \mathrm{~m}$ in width, reaching out to about $35.0 \mathrm{~m}$ on each side of the bridge, and running the entire length of the bridge over land.

Some of these minor impacts under the bridge included: altered soil chemistry, altered amount and type of vegetation, attraction of exotic and non-native vegetation and songbirds, lower abundances and different composition of songbirds, lower abundance, richness, and diversity of small mammals, and changes and alteration in habitat. The presence of bridge piers on the island caused minimal habitat fragmentation and loss, but there was no indication that the bridge piers had direct negative effects to wildlife including mortality from bird strikes. There was no indication that the bridge is impacting the environmental condition or wildlife usage of 
the slough on Blennerhassett Island as well. Each ecological parameter studied responded somewhat differently to the bridge. Below is a summary of each ecological parameter and its response to the Blennerhassett Island Bridge.

\section{Soil}

Soil chemistry at Blennerhassett Island contained normal levels of natural soil properties. Only the area directly under the bridge had altered levels of certain elements. These impacts may be due to materials leaching from the bridge, disturbances during construction, and high levels of certain elements in the fertilizer used during reseeding of vegetation after construction. Similar results were shown at the Buckley Island Bridge site indicating that both highway bridges cause altered levels of many soil properties. Of the 19 variables measured, 6 had a significant interaction all caused by differences under bridges; 6 showed differences by distance all attributed to transects under bridges; and 2 differed by sites correlated to islands with bridges.

High levels of phosphorus, bray II phosphorus, and potassium could be due to the fertilizer used during the reseeding of vegetation under the bridge (Bennett et al. 2001). High levels of sodium, calcium, and manganese were most likely due to the leaching of deicing agents placed on the bridge for snow removal (Wilcox 1986). Additionally, high levels of soluble sulfur could be due to emissions from vehicles using the bridge (Mooney et al. 1988). Low levels of aluminum and copper could be due to the disturbance caused by construction techniques and compaction of the soil. Zinc levels were not altered under the Blennerhassett Island Bridge, but may be over time as similarly shown at the Buckley Island Bridge possibly due to materials leaching from the highway surface or from the structure of the bridge. Additionally, total exchange capacity, organic matter, and estimated nitrogen released all differed as well possibly 
due to compaction of soil during construction which caused changes in physical properties of the soil (structure, stability, erodibility, porosity, permeability) (Johnston and Johnston 2004).

There were no differences in $\mathrm{pH}$, magnesium, boron, iron, nitrate, or ammonium between the islands or distances from the bridge indicating no impact to these parameters. Impacts to other soil parameters will most likely continue through the future as shown at the Buckley Island Bridge site. However, these impacts will most likely be limited to the area directly below the bridge and the areas that were disturbed during construction and not affect distant areas.

\section{Vegetation}

Vegetation found at Blennerhassett Island was consistent with species commonly found on Ohio River islands (U.S. Fish and Wildlife Service 2002). Only the area directly under the bridge showed dissimilar vegetative communities. This vegetation was highly altered and disturbed, harboring species tolerant of disturbance, and similar to roadsides. This may have resulted from disturbance during construction, compacted soils, altered soil chemistry, lack of direct sunlight and rainfall, destruction of the seed bank, and poor site conditions (Mortensen et al. 2009). This vegetation was herbaceous, comprised mostly of plants from the seed mixture such as redtop (Agrotis alba), Japanese millet (Echinochloa crus-galli var frumentacea), Italian perennial rye grass (Lolium perenne), and Kentucky 31 fescue (Lolium arundinaceum), and did not adequately cover the entire area beneath the bridge. Additionally, woody plants and shrubs were lacking.

Several species of exotic and invasive species were found to be promoted by the presence of the bridge. These species may be dominant under the bridge due to the area being in a floodplain; however, poor site conditions, disturbance during construction, limited light and rainfall, and possible dispersal by vehicles have created an environment similar to roadsides 
which frequently provide vectors for the spread of invasive species (Forman and Alexander 1998, Rentch et al. 2005, Christen and Matlock 2006, Mortensen et al. 2009) and may have created an environment suitable for these species. These invasive species may be detrimental to the environment by outcompeting native vegetation for resources, decreasing species richness, and forming monocultures (Forman et al. 2003).

The bridge was not shown to impact vegetative communities at other sampling distances. Similar results were found under the Buckley Island Bridge with highly altered vegetative communities and exotic species prevalent. It is likely the area under the Blennerhassett Island Bridge will remain in this condition as similarly shown at the much older Buckley Island Bridge site with low coverage and vegetation dominated by herbaceous, disturbance tolerant, and exotic species, but there is no evidence to suggest that these impacts will occur at further distances from the bridge.

\section{Waterbirds}

Little evidence was shown in this study to suggest the Blennerhassett Island Bridge is impacting waterbirds. Of the 5 species analyzed, only great blue heron (Ardea herodias) may be negatively impacted by the bridge crossing. Great blue heron abundances were 3.84 times higher at the control island than at Blennerhassett. Great blue herons are shy birds that prefer remoteness and lack of human disturbance (Short and Cooper 1985, Gibbs et al. 1987, Watts and Bradshaw 1994), and may be negatively impacted by the bridge due to highway noise, which can disrupt heron breeding and nesting patterns (Grubb 1977). There was no evidence that the Blennerhassett Island Bridge caused negative impacts to abundances of any other waterbird species including: Canada goose (Branta canadensis), mallard (Anas platyrhynchos), wood duck (Aix sponsa), and double-crested cormorant (Phalacrocorax auritus) which had abundances 
similar to the other study islands. Waterbird abundances were most likely not impacted due to the bridge crossing only a small portion of the river, island, and slough. Personal observations suggest the slough on Blennerhassett Island supports a thriving waterbird population regardless of the presence of the bridge.

Waterbirds have been shown to have collisions with bridges creating barriers to movement and causing mortality and population declines (Bard et al. 2002). This study, however, showed no indication that the bridge is a barrier or cause of mortality. Waterbirds more often flew over the bridge as opposed to under the bridge ( $77.4 \%$ over, $22.6 \%$ under); however, waterbirds did not hesitate to fly under the bridge when flying low over the water. There were direct observations of many species including: belted kingfisher, Canada goose, double-crested cormorant, great blue heron, mallard, spotted sandpiper (Actitis mascularia), and wood duck flying under the bridge. The bridge did not seem to be a major barrier for waterbirds during flight, mostly due to its relatively low height ( $24 \mathrm{~m}$ above the surface). There were no observations or documentations of waterbirds colliding with the bridge during diurnal flight during this study.

\section{Songbirds}

Songbird data suggests that the Blennerhassett Island Bridge had minimal impact to songbird abundances and composition directly under the bridge only and no impact to species richness or diversity. Total songbird abundance was lower under the bridge compared to other distances and species composition under the bridge differed from other distances most likely due to alteration of habitat. This was due to destruction of natural habitat during the construction of the bridge. This disturbed area was depleted of trees, shrubs, and coarse woody debris, and caused a small change in songbird communities. Songbird species that require trees and shrubs 
for nesting and foraging were impacted due to loss of habitat, while ground nesting songbirds and habitat generalists showed no effect.

Species such as Carolina chickadee (Poecile carolinensis), Carolina wren (Thryothorus ludovicianus), and common yellowthroat (Geothlypis trichas) had a high affinity for distances away from the bridge indicating a negative impact. Other songbird species showed no negative response under the bridge and songbird composition consisted of species typically depicted as habitat generalists. Additionally, the bridge attracted species such as rock pigeon (Columba livia), European starling (Sturnus vulgaris), and cliff swallows (Petrochelidon pyrrhonota) (at Buckley), which are all known to nest on man-made structures (Peterson 2002, Tumlison 2009). House wren (Troglodytes aedon) had high abundances under the bridge due to the use of songbird boxes placed under the bridge after construction.

Bird species composition is closely related to habitat structure (Pearman 2002, Burris and Haney 2005). This study echoes this as songbird species detected were closely related to their habitat preferences. Songbirds not correlated with transects under the bridge were found in suitable habitat right up to the area disturbed during the construction of the bridge which indicates a strong relation between songbird and habitat. Additionally, there was no evidence to conclude that the bridge is causing a barrier for songbirds as there were no observations or documentations of songbirds colliding with the bridge during diurnal flight, and no documentations of songbirds found dead under the bridge. Island and mainland transects responded similarly (Appendix 25).

\section{Anurans}

There was no indication from this study that the Blennerhassett Island Bridge had any effect on the 4 species of anurans compared. Anurans are commonly depicted as ecologically 
sensitive to anthropogenic disturbance (Willson and Dorcas 2003, Price et al. 2007). However, anurans were not negatively impacted by the presence of the highway bridge over the island wetland complex. Anuran abundances, call index codes, richness, and diversity were no different between Blennerhassett Island and an island without a bridge and at the different distances at Blennerhassett Island. This indicates that the bridge has no negative effect on anurans. Anurans were found calling throughout the wetland complex on the island and also in the emergent wetland under the bridge on the West Virginia mainland.

All anuran species encountered in this study had been previously documented on the Ohio River Islands National Wildlife Refuge (United States Fish and Wildlife Service 2002) and are common along the Ohio River (Green and Pauley 1987). The interior island wetland complex on Blennerhassett Island showed large availability of aquatic vegetation and coarse woody debris which provided habitat and calling sites for anurans (Green and Pauley 1987). Abundant trees on the island provided habitat for Cope's gray tree frogs (Hyla chrysoscelis), while deeper water in the wetland complex benefited American bullfrogs (Lithobates catesbeiana) and northern green frogs (Lithobates clamitans melanota) which prefer deeper water (Green and Pauley 1987). Spring peepers (Pseudacris crucifer) were also provided with abundant habitat in the wetland complex with the semi-permanent water levels and the abundance of shrubby vegetation such as alders (Alnus sp.). The fear that the Blennerhassett Island Bridge has negative impacts to anurans in the interior island wetland complex was not shown in this study.

\section{Turtles}

There was no indication from this study that the Blennerhassett Island Bridge had any effect on the 4 species of aquatic turtles found in the slough and around the island. This was expected as turtles are disturbance tolerant to urbanization and anthropogenic changes in the 
landscape (Conner et al. 2005, Plummer et al. 2008). Turtle abundances and richness did not differ between other study islands or between distances from the bridge with high capture rates at each site and distance. Captures of common snapping turtle (Cheyldra serpentina) and eastern spiny softshell (Apalone spinifera spinifera), the Ohio River's two most common turtles, were frequent at the Blennerhassett Island site in traps both under the bridge and at distances away from the bridge. Also, captures of northern map turtles (Graptemys geographica), a declining and protected species in West Virginia, was also common at Blennerhassett Island.

High capture rates in the slough on Blennerhassett Island indicate that it supports high abundances of common snapping turtles and quality habitat for other species of turtles. Common snapping turtle captures were common throughout the slough including under the bridge. Captures of midland painted turtles (Chrysemys picta marginata) also were common throughout the slough including under the bridge. There was no indication that the bridge is negatively affecting turtle abundances in the slough or around Blennerhassett Island.

\section{Small Mammals}

Small mammal abundances were highest at Blennerhassett compared to the other sites and increased over time compared to the pre-construction sampling periods. Only impacts to small mammals occurred directly under the bridge. Abundances of Peromyscus spp. (deer mouse (Peromyscus maniculatus) and white-footed mouse (Peromyscus leucopus) combined), combined small mammal abundances, species richness, and species diversity were significantly lower under the bridge compared to other distances. This is most likely due to habitat alteration and damage to the landscape from the construction of the bridge, the amount and type of vegetative coverage (Silva and Prince 2008), and the preferences of microhabitat by certain species (Castleberry et al. 2002, Dalmagro and Vieira 2005). 
These impacts are most likely temporary and abundance, richness, and diversity under the bridge will increase over time and become similar to other distances as shown at the older Buckley Island site. Small mammals in general, and specifically those found in this study, are tolerant to anthropogenic landscape disturbances (Elliot and Root 2006, Kaminski et al. 2007) and populations should increase as vegetatative coverage under the bridge increases (Silva and Prince 2008). This study found that capture rates, richness, and diversity increased throughout the study most likely due to increases in vegetative cover. Also, the only marked individual moving from transect to transect was a Peromysucs spp. that moved from a $100 \mathrm{~m}$ transect at Blennerhassett to a $0 \mathrm{~m}$ transect under the bridge possibly indicating that small mammals are coming back to the impacted area as it is reclaimed. Overall health and sex and age proportions of Peromyscus spp. were similar between other islands and distances and there were no indications that the Blennerhassett Island Bridge had any other impacts to other small mammal species. Island and mainland transects responded similarly (Appendix 25).

\section{Furbearers}

Little evidence was shown to suggest the Blennerhassett Island Bridge impacted furbearers. Of the 3 furbearers compared in this study, only raccoon (Procyon lotor) may have possibly been hindered by the Blennerhassett Island Bridge. Raccoon occurrence was significantly lower under the Blennerhassett Island Bridge only, but not at other sites or distances. Raccoons are disturbance tolerant and adaptive to urbanization and changes in landscape (Randa and Yunger 2006, Beasley et al. 2007), thus it is believed raccoons commonly frequent the area under the bridge, but may have avoided the scent stations, possibly spending more time around the edge of the wetland. Additionally, raccoon detections were not significant at the $0 \mathrm{~m}$ transects at Buckley Island indicating no impact from the Buckley Island Bridge upon 
raccoon occurrences. There was no indication that red fox (Vulpes vulpes) or Virginia opossum (Didelphis virginiana) were impacted by the bridge.

Mortality surveys indicated that furbearers such as raccoons and Virginia opossums used the bridge for movement corridors. One raccoon was found dead on the Blennerhassett Island Bridge and 2 were found dead on the highway $\leq 200 \mathrm{~m}$ from the bridge along the highway. Additionally, 2 Virginia opossums were found dead on the Buckley Island Bridge and 1 raccoon was found dead along the highway $\leq 200 \mathrm{~m}$ from the bridge. This evidence indicates these furbearers are using the bridge for movement corridors which increases the likelihood of wildlife-vehicular mortality and could cause localized population declines in these species. However, detections of furbearer mortality were quite low and only averaged $0.07(\mathrm{SE}=0.04)$ individuals $/ \mathrm{km} / \mathrm{month}$ and $0.10(\mathrm{SE}=0.05)$ for the months the bridge was opened.

\section{Management Implications}

All possible care should be taken during future bridge construction to minimize the impact to soil, vegetation, and wildlife. This starts by following best management practices (BMP) including temporary silt fencing and creation of water breaks to minimize erosion and runoff. All efforts should be taken to reduce the amount of area impacted during construction. Soil can be removed and stockpiled before construction and re-spread after construction minimizing impacts such as compaction and destruction of the seed bank. Vegetation should be impacted minimally and woody vegetation such as trees and shrubs should be left if possible. In instances where this is not possible, reseeding of disturbed areas should be done with native seed mixtures that include shade tolerant grasses such as Canada wild rye (Elymus canadensis), wild rye (Elymus riparis), and bearded shorthusk (Brachyletrum erectum). Native vegetation should sufficiently cover all areas impacted by the bridge and brush piles and coarse woody debris 
should be scattered beneath the bridge to improve wildlife habitat, while stream banks should be stabilized by plantings of native trees. All possible care should be taken to restore the impacted land to previous conditions within limits of design for safety.

Drainage from the bridge should be designed so that it does not drain directly onto the ground or into a wetland. Rather, drainage should flow into a settling or treatment basin to minimize adding adverse chemicals to the soil or river. No permanent structures, including bridge piers, should be placed in a wetland or in areas of environmental importance to minimize destruction of habitat for wildlife. To protect against bird-vehicle strikes, fences can be installed along the sides of bridges to force birds to fly higher over the bridge and out of the way of motorists (Bard et al. 2002). Additionally, wildlife habitat can be created by placing nesting boxes for birds and bats and nesting platforms for large raptors under the bridge to compensate for habitat lost during construction. Bridges can also be constructed to provide slots and spaces for roosting bats and platforms can be placed on the bridge for peregrine falcon (Falco peregrinus) nesting sites. However, these improvements should be conducted away from traffic to prevent animal-human conflicts.

\section{$\underline{\text { Future Research }}$}

Continual monitoring of soil, vegetation, songbird communities, and small mammals is recommended at the Blennerhassett Island site and should continue on a yearly basis. This will enable researchers to track changes over a long-term period to determine if the adverse effects of the bridge continue through the near future. This also will indicate if the impacts detected in this study are short-term or long-term and will provide a more reasonable understanding of the ecological effects of this bridge crossing. 
Additionally, to gain a better understanding of impacts of bridges, another study should be initiated on the impacts of bridges on soil, vegetation, songbirds, and small mammals with special emphasis on soil parameters, vegetative type and coverage, songbird nesting success under bridges and the possible impact of noise on songbird nesting success, and small mammal abundance, richness, and diversity. This research project should study at least 30 bridges across the entire state of West Virginia. Data should be collected under bridges and at 1 distance about $250 \mathrm{~m}$ away. Surveys in this study should be replicated over a 3 year period. This will provide an adequate sample size that is replicated over space and time with easy comparisons of data taken under bridges and away from bridges. In addition, transects perpendicular to the bridge can more effectively capture the area of impacts and give an better overall understanding of how far bridges impact the landscape. 


\section{$\underline{\text { Literature Cited }}$}

Bard, A. M., H. T. Smith, E. D. Egensteiner, R. Mulholland, T. V. Harber, G. W. Heath, W. J. B. Miller, and J. S. Weske. 2002. A simple structure method to reduce road kills of royal terns at bridge sites. Wildlife Society Bulletin 30:603-605.

Beasley, J. C., T. L. Devault, M. I. Retamosa, and O. E. Rhodes, Jr. 2007. A hierarchical analysis of habitat selection by raccoons in northern Illinois. Journal of Wildlife Management 71:1125-1133.

Bennett, E. M., S. R. Carpenter, and N. F. Caraco. 2001. Human impact on erodable phosphorus eutrophication: a global perspective. BioScience 51:227-234.

Burris, J. M., and A. W. Haney. 2005. Bird communities after blowdown in late successional Great Lakes spruce-fir forest. Wilson Bulletin 117:341-352.

Castleberry, S. B., P. B. Wood, W. M. Ford, N. L. Castleberry, and M. T. Mengak. 2002. Summer microhabitat selection by foraging Allegheny woodrats (Neotoma magister) in a managed forest. American Midland Naturalist 147:93-101.

Christen, D. and G. Matlock. 2006. The role of roadsides in plant invasions: a demographic approach. Conservation Biology 20:285-391.

Conner, C. A., B. A. Douthitt, and T. J. Ryan. 2005. Descriptive ecology of a turtle assemblage in an urban landscape. American Midland Naturalist 153:428-435.

Dalmagro, A. D., and E. M. Vieira. 2005. Patterns of habitat utilization of small rodents in an area of Araucaria forest in southern Brazil. Austral Ecology 30:353-362.

Elliot, A. G., and B. G. Root. 2006. Small mammal responses to silvicultural and precipitationrelated disturbance in northeastern Missouri riparian forests. Wildlife Society Bulletin 34:485-501.

Forman, R. T., and L. E. Alexander. 1998. Roads and their major ecological effects. Annual Review of Ecology and Systematics 29:207-231.

Forman, R. T., D. Sperling, J. A. Bissonette, A. P. Clevenger, C. D. Cutshall, V. H. Dale, L. Fahrig, R. France, C. R. Goldman, K. Heanue, J. A. Jones, F. J. Swanson, T. Turrentine, and T. C. Winter. 2003. Road Ecology: Science and Solutions. Island Press, Washington, D. C., USA.

Gibbs, J. P., S. Woodward, M. L. Hunter, and A. E. Hutchinson. 1987. Determinants of great blue heron colony distribution in coastal Maine. Auk 104:38-47.

Green, N. B., and T. K. Pauley. 1987. Amphibians and Reptiles in West Virginia. University of Pittsburgh Press, Pittsburgh, Pennsylvania, USA.

Grubb, M. M. 1979. Effects of increased noise on nesting herons and egrets. Proceedings of the Colonial Waterbird Group 2:49-54. 
Johnston, F. M., and S. W. Johnston. 2004. Impacts of road disturbance on soil properties and on exotic plant occurrence in subalpine areas of the Australian Alps. Arctic, Antarctic, and Alpine Research 36:201-207.

Kaminski, J. A., M. L. Davis, M. Kelly, and P. D. Keyser. 2007. Disturbance effects of small mammal species in a managed Appalachian forest. American Midland Naturalist 151:2734.

Mooney, H. A., M. Kuppers, G. W. Koch, J. Gorman, and C. C. Chu. 1988. Compensating effects to growth of carbon partitioning changes in response to sulfur dioxide induced photosynthetic reduction in radish. Oecologia 75:502-506.

Mortensen, D. A., E. S. J. Rauschert, A. N. Nord, and B. P. Jones. 2009. Forest roads facilitate the spread of invasive plants. Invasive Plant Science and Management 2:191-199.

Pearman, P. B. 2002. The scale of community structure: habitat variation and avian guilds in tropical forest understory. Ecological Monographs 72:19-39.

Peterson, R. T. 2002. Birds of Eastern and Central North America: Fifth Edition. Houghton Mifflin Harcourt Company, New York, New York, USA.

Plummer, M. V., D. G. Krementz, L. A. Powell, and N. E. Mills. 2008. Effects of habitat disturbance on survival rates of softshell turtles (Apalone spinifera) in an urban stream. Journal of Herpetology 42:555-563.

Price, S. J., R. W. Howe, J. M. Hanowski, R. R. Regal, G. J. Niemi, and C. R. Smith. 2007. Are anurans of Great Lake coastal wetlands reliable indicators of ecological condition? Journal of Great Lakes Research 33:211-223.

Randa, L. A., and J. A. Yunger. 2006. Carnivore occurrence along an urban-rural gradient: A landscape-level analysis. Journal of Mammalogy 87:1154-1164.

Rentch, J. S., R. H. Fortney, S. L. Stephenson, H. S. Adams, W. N. Grafton, and J. T. Anderson. 2005. Vegetation-site relationships of roadside plant communities in West Virginia, USA. Journal of Applied Ecology 42:129-138.

Short, H. L., and R. J. Cooper. 1985. Habitat suitability index models: Great Blue Heron. U.S. Fish and Wildlife Service Biological Report 82 (10.99), Washington, D.C, USA.

Silva, M., and M. E. Prince. 2008. The conservation of hedgerows for small mammals in Prince Edward Island, Canada. American Midland Naturalist 159:110-124.

Tumlison, R. 2009. Breeding by cliff swallows (Petrochelidon pyrrhonota) in southern Arkansas. Southwestern Naturalist 54:208-210.

United States Fish and Wildlife Service. 2002. Ohio River Islands National Wildlife Refuge Comprehensive Conservation Plan. U.S. Fish and Wildlife Service, Parkersburg, West Virginia, USA. 
Watts, B. D., and D. S. Bradshaw. 1994. The influence of human disturbance on the location of great blue heron colonies in the lower Chesapeake Bay. Colonial Waterbirds 17:184-186.

Wilcox, D. A. 1986. The effects of de-icing salts on water chemistry in Pinhook Bog, Indiana. Water Resources Bulletin 22:57-65.

Willson, J. D., and M. E. Dorcas. 2003. Effects of habitat disturbance on stream salamanders: Implications for buffer zone and watershed management. Conservation Biology 17:763761. 
APPENDICES 
Appendix 1: Location of 4 island study areas between kilometer markers 244.0 and 305.6 (mile markers 151.6 and 189.9) on the Ohio River, West Virginia, USA.

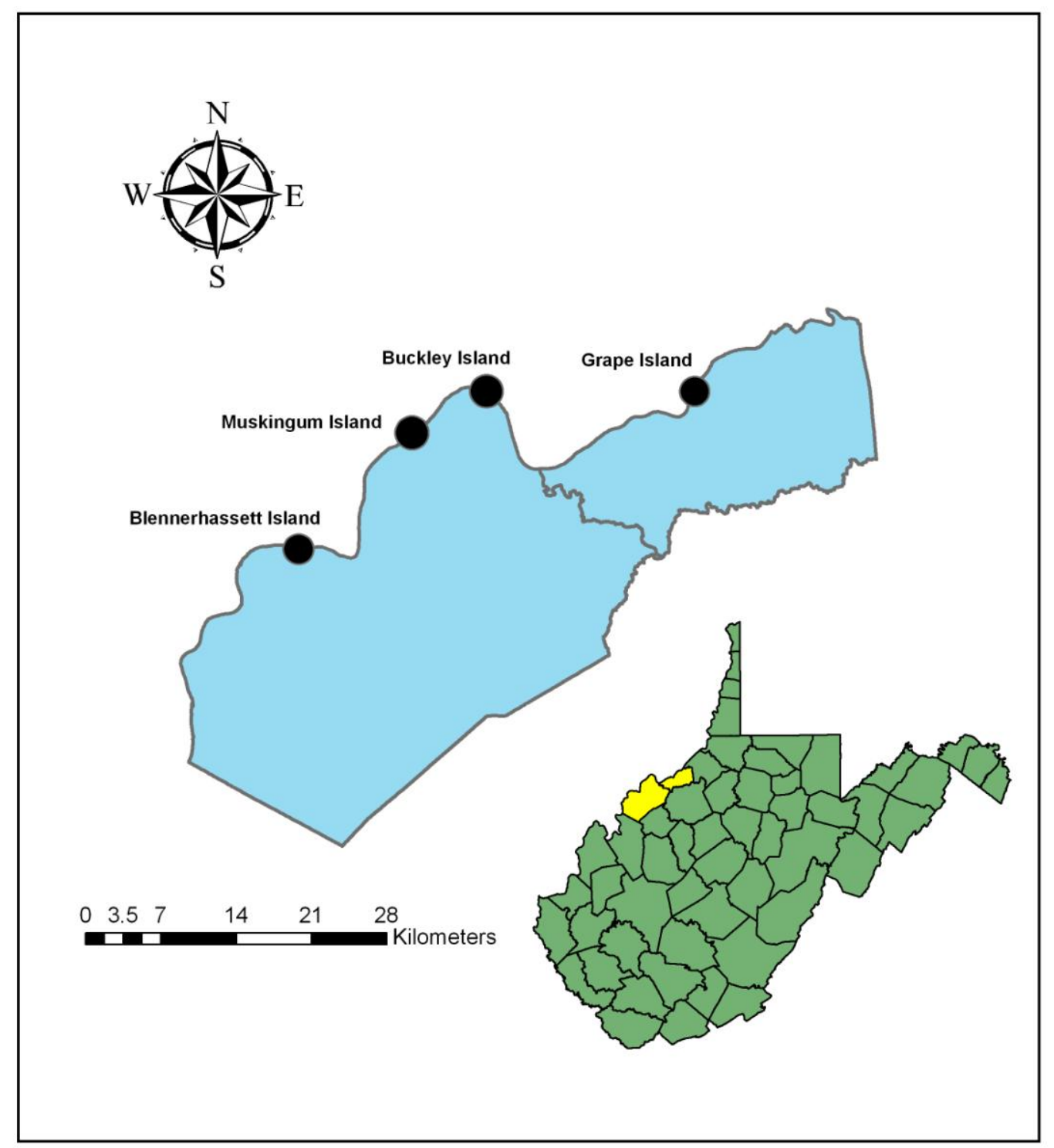


Appendix 2: Cover type map of Blennerhassett Island, West Virginia, USA using the 2009 National Agriculture Imagery Program (NAIP) aerial, $1 \mathrm{~m}$ accuracy, orthophotos with the 2001 National Land Cover Database (NLCD) classifications for each cover type with PUB3 = Palustrine Unconsolidated Bottom (Mud) Wetland from the National Wetlands Inventory (NWI).

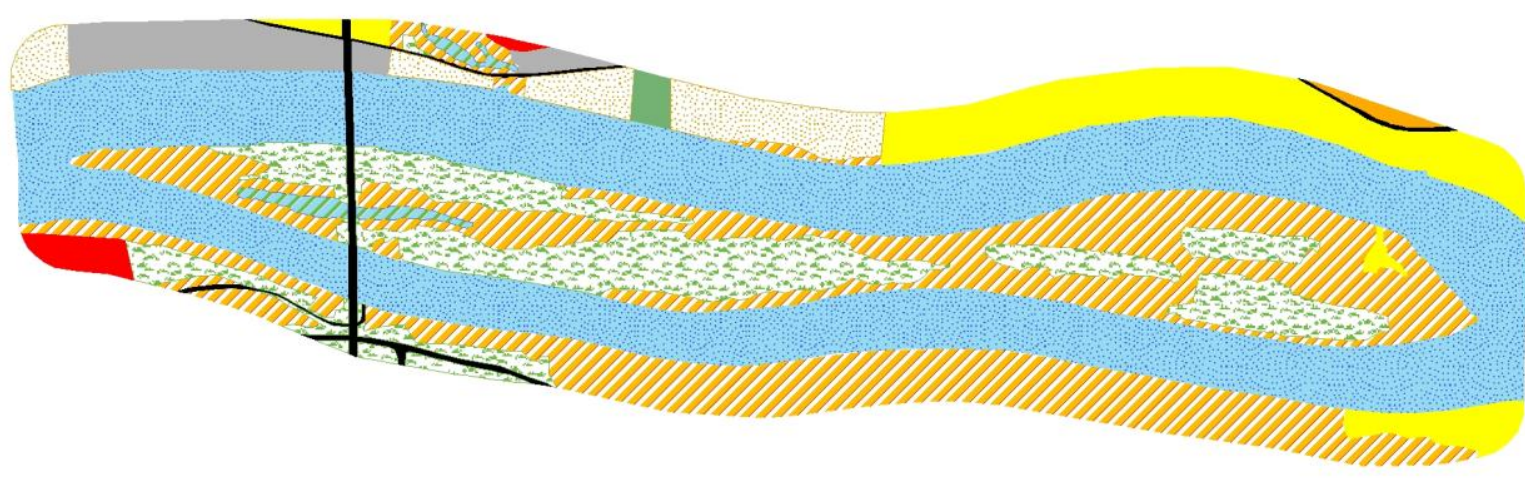

Barren Land

Unconsolidated Shore

Deciduous Forest

Developed Open Space

High Intensity Developed

Low Intensity Developed
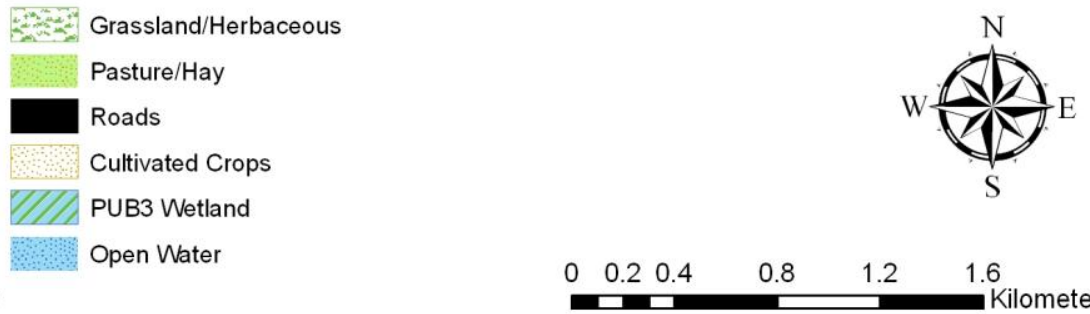

Medium Intensity Developed




Appendix 3: Cover type map of Buckley Island, West Virginia, USA using the 2009 National Agriculture Imagery Program (NAIP) aerial, $1 \mathrm{~m}$ accuracy, orthophotos with the 2001 National Land Cover Database (NLCD) classifications for each cover type with PUB3 = Palustrine Unconsolidated Bottom (Mud) Wetland from the National Wetlands Inventory (NWI).

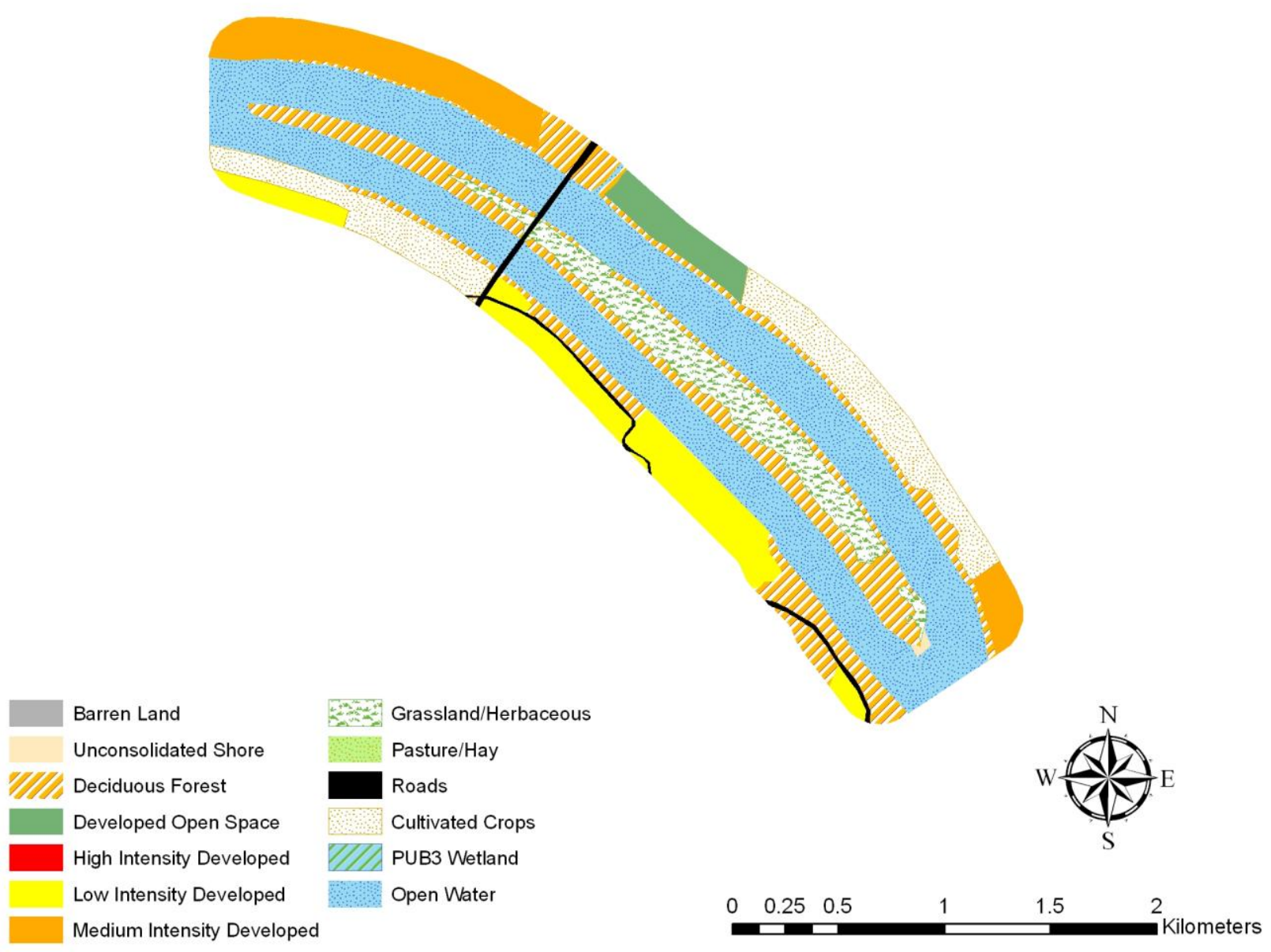


Appendix 4: Cover type map of Muskingum Island, West Virginia, USA using the 2009 National Agriculture Imagery Program (NAIP) aerial, $1 \mathrm{~m}$ accuracy, orthophotos with the 2001 National Land Cover Database (NLCD) classifications for each cover type with PUB3 = Palustrine Unconsolidated Bottom (Mud) Wetland from the National Wetlands Inventory (NWI).

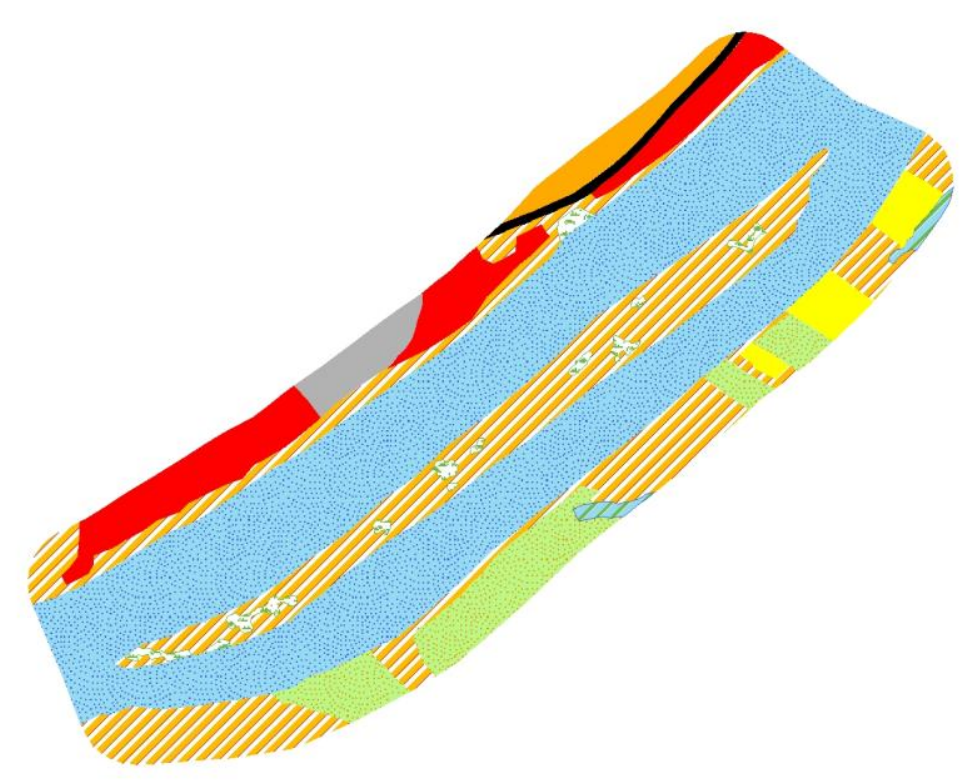

Barren Land
Unconsolidated Shore

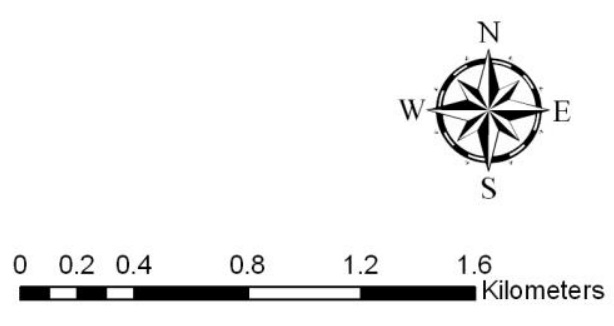


Appendix 5: Cover type map of Grape Island, West Virginia, USA using the 2009 National Agriculture Imagery Program (NAIP) aerial, $1 \mathrm{~m}$ accuracy, orthophotos with the 2001 National Land Cover Database (NLCD) classifications for each cover type with PUB3 = Palustrine Unconsolidated Bottom (Mud) Wetland from the National Wetlands Inventory (NWI).

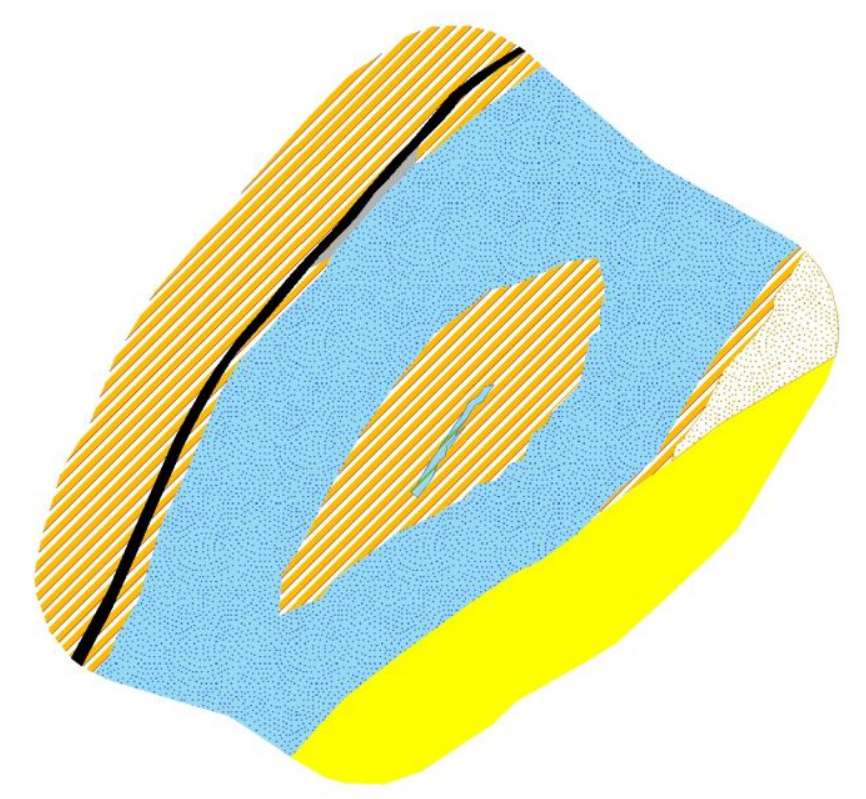

Barren Land

Unconsolidated Shore

Deciduous Forest

Developed Open Space

High Intensity Developed

Low Intensity Developed

Medium Intensity Developed

Grassland/Herbaceous
Pasture/Hay
Roads
Cultivated Crops
PUB3 Wetland
Open Water

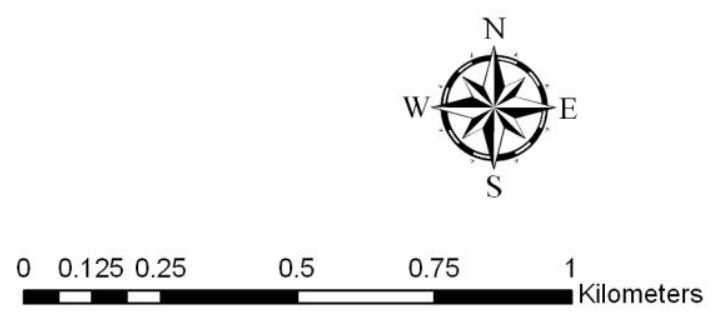


Appendix 6: List of all plant species sampled and their means (\% cover for herbs and shrubs and basal area [ $\left.\mathrm{m}^{2} / \mathrm{ha}\right]$ for trees) and standard errors (SE) from Blennerhassett, Buckley, and Muskingum islands, West Virginia, USA during the July 2008 field season.

\begin{tabular}{|c|c|c|c|c|c|c|c|}
\hline \multirow{2}{*}{ Common Name } & \multirow{2}{*}{ Scientific Name } & \multicolumn{2}{|c|}{ Blennerhassett } & \multicolumn{2}{|c|}{ Buckley } & \multicolumn{2}{|c|}{ Muskingum } \\
\hline & & $\bar{x}$ & SE & $\bar{x}$ & SE & $\bar{x}$ & SE \\
\hline American Basswood & Tilia americana $\mathrm{L}$. & 1.27 & 1.27 & 0.00 & 0.00 & 0.00 & 0.00 \\
\hline American Elm & Ulmus americana L. & 0.55 & 0.36 & 0.00 & 0.00 & 0.05 & 0.05 \\
\hline American Germander & Teuchrium canadense L. & 0.00 & 0.00 & 0.19 & 0.19 & 0.36 & 0.28 \\
\hline American Sycamore & Platanus occidentalis L. & 0.00 & 0.00 & 0.02 & 0.02 & 1.85 & 0.62 \\
\hline Apple & Malus sp. L. & 0.00 & 0.00 & 0.17 & 0.17 & 0.00 & 0.00 \\
\hline Arrowleaf Tearthumb & Polygonum sagittatum L. & 0.00 & 0.00 & 0.08 & 0.06 & 0.00 & 0.00 \\
\hline Asiatic Water Pepper & Polygonum cespitosum Blume & 0.00 & 0.00 & 0.03 & 0.03 & 0.00 & 0.00 \\
\hline Aster & Aster sp. L. & 0.25 & 0.22 & 0.00 & 0.00 & 0.04 & 0.04 \\
\hline Autumn Olive & Elaeagnus umbellata Thunb. & 0.00 & 0.00 & 0.03 & 0.03 & 0.00 & 0.00 \\
\hline Barnyard Grass & Echinocloa crus-galli L. & 0.02 & 0.02 & 0.00 & 0.00 & 0.00 & 0.00 \\
\hline Bearded Shorthusk & Brachyelytrum erectum (Schreb.) Beauv. & 0.00 & 0.00 & 0.00 & 0.00 & 0.04 & 0.04 \\
\hline Beggar-Ticks & Bidens sp. L. & 0.20 & 0.13 & 0.00 & 0.00 & 0.00 & 0.00 \\
\hline Bird's Foot Trefoil & Lotus corniculatus L. & 2.66 & 1.60 & 0.00 & 0.00 & 0.00 & 0.00 \\
\hline Bittercress & Cardamine impatiens L. & 0.02 & 0.02 & 0.03 & 0.03 & 0.00 & 0.00 \\
\hline Bitternut Hickory & Carya cordiformis (Wang.) K. Koch & 0.02 & 0.02 & 0.00 & 0.00 & 0.00 & 0.00 \\
\hline Bittersweet & Solanum dulcamara $\mathrm{L}$. & 0.02 & 0.02 & 0.00 & 0.00 & 0.00 & 0.00 \\
\hline Black Cherry & Prunus serotina Ehrh. & 0.00 & 0.00 & 0.00 & 0.00 & 1.87 & 1.79 \\
\hline Black Elderberry & Sambucus canadensis $\mathrm{L}$. & 0.00 & 0.00 & 0.00 & 0.00 & 1.36 & 1.05 \\
\hline Black Locust & Robinia pseudoacacia L. & 3.89 & 3.47 & 0.00 & 0.00 & 0.00 & 0.00 \\
\hline Black Medic & Medicago lupulina $\mathrm{L}$. & 0.02 & 0.02 & 0.00 & 0.00 & 0.00 & 0.00 \\
\hline
\end{tabular}


Appendix 6 Continued

\begin{tabular}{|c|c|c|c|c|c|c|c|}
\hline Black Raspberry & Rubus occidentalis L. & 0.00 & 0.00 & 0.44 & 0.44 & 0.04 & 0.04 \\
\hline Black Walnut & Juglans nigra $\mathrm{L}$. & 0.11 & 0.08 & 0.35 & 0.31 & 1.26 & 0.70 \\
\hline Blue Vervain & Verbena hastata $\mathrm{L}$. & 0.02 & 0.02 & 0.00 & 0.00 & 0.00 & 0.00 \\
\hline Blue Wood Aster & Symphyotrichum cordifolius L. & 0.20 & 0.20 & 0.00 & 0.00 & 0.00 & 0.00 \\
\hline Bog Yellow Crest & Rorippa palustris (L.) Besser & 0.03 & 0.03 & 0.00 & 0.00 & 0.00 & 0.00 \\
\hline Box Elder & Acer negundo L. & 9.04 & 5.61 & 5.36 & 5.01 & 2.25 & 0.90 \\
\hline Broadleaf Dock & Rumex obtusifolius L. & 0.03 & 0.03 & 0.33 & 0.21 & 0.00 & 0.00 \\
\hline Broad-leaved Cattail & Typha latifolia L. & 0.09 & 0.09 & 0.00 & 0.00 & 0.00 & 0.00 \\
\hline Broad-leaved Waterleaf & Hydrophyllum canadense L. & 0.50 & 0.50 & 0.00 & 0.00 & 0.00 & 0.00 \\
\hline Canada Goldenrod & Solidago canadensis L. & 0.00 & 0.00 & 0.22 & 0.22 & 0.00 & 0.00 \\
\hline Canada Moonseed & Menispermum canadense L. & 0.06 & 0.06 & 0.00 & 0.00 & 0.00 & 0.00 \\
\hline Canada Thistle & Cirsium arvense (L.) Scop. & 5.98 & 2.75 & 1.25 & 0.73 & 0.00 & 0.00 \\
\hline Canada Wild Rye & Elymus canadensis L. & 1.84 & 1.47 & 0.03 & 0.03 & 4.11 & 1.80 \\
\hline Canadian Horseweed & Conyza canadensis L. & 0.02 & 0.02 & 0.00 & 0.00 & 0.00 & 0.00 \\
\hline Chinquapin Oak & Quercus muehlenbergii Engelm. & 0.14 & 0.14 & 0.00 & 0.00 & 0.00 & 0.00 \\
\hline Christmas Fern & $\begin{array}{l}\text { Polystichum acrostichoides (Michx.) } \\
\text { Schott. }\end{array}$ & 0.19 & 0.19 & 0.00 & 0.00 & 0.00 & 0.00 \\
\hline Clearweed & Pilea pumila (L.) & 0.86 & 0.48 & 0.14 & 0.11 & 0.79 & 0.47 \\
\hline Clustered Snakeroot & Sanicula odorata L. & 0.11 & 0.11 & 0.00 & 0.00 & 0.00 & 0.00 \\
\hline Common Burdock & Arctium minus (Hill) Bernh. & 0.00 & 0.00 & 2.78 & 2.00 & 0.00 & 0.00 \\
\hline Common Dandelion & Taraxacum officinale Zinn & 0.00 & 0.00 & 0.03 & 0.03 & 0.00 & 0.00 \\
\hline Common Hackberry & Celtis occidentalis $\mathrm{L}$. & 0.51 & 0.40 & 0.04 & 0.03 & 2.23 & 2.21 \\
\hline Common Mugwort & Artemisia vulgaris $\mathrm{L}$. & 0.28 & 0.15 & 0.06 & 0.06 & 0.00 & 0.00 \\
\hline Common Pigweed & Amaranthus hybridus L. & 0.02 & 0.02 & 0.00 & 0.00 & 0.00 & 0.00 \\
\hline
\end{tabular}


Appendix 6 Continued

\begin{tabular}{|c|c|c|c|c|c|c|c|}
\hline Common Ragweed & Ambrosia artemisiifolia $\mathrm{L}$. & 0.05 & 0.03 & 0.00 & 0.00 & 0.00 & 0.00 \\
\hline Common Rush & Juncus effusus L. & 0.11 & 0.11 & 0.00 & 0.00 & 0.00 & 0.00 \\
\hline Common Thistle & Cirsium vulgare (Savi) Tenore & 0.02 & 0.02 & 0.00 & 0.00 & 0.00 & 0.00 \\
\hline Crested Sedge & Carex cristatella Britton & 0.05 & 0.05 & 0.00 & 0.00 & 0.00 & 0.00 \\
\hline Cutleaf Blackberry & Rubus laciniatus Willd. & 0.00 & 0.00 & 0.03 & 0.03 & 0.00 & 0.00 \\
\hline Daisy Fleabane & Erigeron strigosus Muhl. ex Willd. & 0.02 & 0.02 & 0.00 & 0.00 & 0.00 & 0.00 \\
\hline Deertongue Grass & Dichanthelium clandestinum (L.) Gould & 0.23 & 0.20 & 0.00 & 0.00 & 0.04 & 0.04 \\
\hline Eastern Black Nightshade & Solanum americanum Mill. & 0.02 & 0.02 & 0.00 & 0.00 & 0.00 & 0.00 \\
\hline Eastern Woodland Sedge & Carex blanda Dewey & 0.00 & 0.00 & 0.00 & 0.00 & 0.04 & 0.04 \\
\hline English Plantain & Plantago lanceolata L. & 0.39 & 0.31 & 0.00 & 0.00 & 0.00 & 0.00 \\
\hline False Nettle & Boehmeria cylindrica (L.) Sw. & 1.88 & 1.43 & 0.58 & 0.58 & 0.25 & 0.21 \\
\hline Fowl Mannagrass & Glyceria striata (Lam.) Hitchc. & 0.02 & 0.02 & 0.00 & 0.00 & 0.00 & 0.00 \\
\hline Foxtail Sedge & Carex vulpinoidea Michx. & 0.03 & 0.03 & 0.00 & 0.00 & 0.00 & 0.00 \\
\hline Frank's Sedge & Carex frankii Kunth & 0.11 & 0.11 & 0.00 & 0.00 & 0.00 & 0.00 \\
\hline Gall-of-the-Earth & Prenanthes serpentaria Pursh & 0.02 & 0.02 & 0.00 & 0.00 & 0.00 & 0.00 \\
\hline Garlic Mustard & $\begin{array}{l}\text { Alliaria petiolata (M. Bieb.) Cavara \& } \\
\text { Grande }\end{array}$ & 2.67 & 0.90 & 3.69 & 1.60 & 3.43 & 1.24 \\
\hline Giant Chickweed & Myosoton aquaticum L. Moench & 0.00 & 0.00 & 0.00 & 0.00 & 0.04 & 0.04 \\
\hline Giant Foxtail Grass & Setaria faberi Herm. & 0.02 & 0.02 & 0.00 & 0.00 & 0.00 & 0.00 \\
\hline Gray's Sedge & Carex grayi Carey & 0.00 & 0.00 & 0.03 & 0.03 & 0.00 & 0.00 \\
\hline Great Chickweed & Stellaria pubera Michx. & 0.03 & 0.03 & 0.00 & 0.00 & 0.00 & 0.00 \\
\hline Ground-Ivy & Glechoma hederacea L. & 5.84 & 2.42 & 14.64 & 7.51 & 40.57 & 11.70 \\
\hline Groundnut & Apios americana Medik & 0.02 & 0.02 & 0.00 & 0.00 & 0.00 & 0.00 \\
\hline Hairy Bittercress & Cardamine hirsuta L. & 0.00 & 0.00 & 0.03 & 0.03 & 0.00 & 0.00 \\
\hline
\end{tabular}




\begin{tabular}{|c|c|c|c|c|c|c|c|}
\hline \multicolumn{8}{|l|}{ Appendix 6 Continued } \\
\hline Hairy Chess & Bromus commutatus L. & 0.47 & 0.47 & 0.00 & 0.00 & 0.00 & 0.00 \\
\hline Hedge Bindweed & Calystegia sepium (L.) R. Br. & 0.11 & 0.11 & 0.06 & 0.04 & 0.00 & 0.00 \\
\hline Hog-Peanut & Amphicarpaea bracteata (L.) Fernald & 0.00 & 0.00 & 0.00 & 0.00 & 0.14 & 0.14 \\
\hline Honeyvine & Cynanchum laeve (Michx.) Pers. & 0.09 & 0.09 & 0.00 & 0.00 & 0.00 & 0.00 \\
\hline Horse-Nettle & Solanum carolinense L. & 0.02 & 0.02 & 0.00 & 0.00 & 0.04 & 0.04 \\
\hline Intermediate Enchanter's Nightshade & Circaea lutetiana $\mathrm{L}$. & 0.09 & 0.09 & 0.00 & 0.00 & 0.00 & 0.00 \\
\hline Italian Perennial Rye Grass & Lolium perenne L. & 2.19 & 1.01 & 0.00 & 0.00 & 0.00 & 0.00 \\
\hline Japanese Honeysuckle & Lonicera japonica Thonb. & 1.53 & 1.04 & 11.50 & 7.22 & 0.36 & 0.24 \\
\hline Japanese Hop & Humulus japonicus Siebold \& Zucc. & 1.41 & 0.71 & 0.89 & 0.69 & 0.00 & 0.00 \\
\hline Japanese Knotweed & Polygonum cuspidatum Siebold \& Zucc. & 1.55 & 1.02 & 4.36 & 4.33 & 2.96 & 2.96 \\
\hline Japanese Millet & $\begin{array}{l}\text { Echinochloa crus-galli var frumentacea } \\
\text { P. Beauv. }\end{array}$ & 3.08 & 2.11 & 0.00 & 0.00 & 0.00 & 0.00 \\
\hline Japanese Stilt Grass & Microstegium vimineum (Trin.) A. Camus & 1.30 & 0.63 & 0.28 & 0.19 & 1.71 & 1.67 \\
\hline Jewelweed & Impatiens capensis Meerb. & 0.00 & 0.00 & 0.72 & 0.45 & 0.00 & 0.00 \\
\hline Johnson Grass & Sorghum halepense Pers. & 1.27 & 1.01 & 0.00 & 0.00 & 0.00 & 0.00 \\
\hline Jointed Grass & Arthraxon hispidus (Thunb.) Makino & 0.48 & 0.48 & 0.00 & 0.00 & 0.00 & 0.00 \\
\hline Kentucky 31 Fescue & Lolium arundinaceum (Scop.) Holub & 5.36 & 3.21 & 3.19 & 3.16 & 0.00 & 0.00 \\
\hline Kentucky Bluegrass & Poa pratensis $\mathrm{L}$. & 0.45 & 0.31 & 15.92 & 10.32 & 3.04 & 2.09 \\
\hline Kill Cow & Eleocharis tenuis Kunth & 0.02 & 0.02 & 0.00 & 0.00 & 0.00 & 0.00 \\
\hline Lady's Thumb & Polygonum persicaria $\mathrm{L}$. & 1.34 & 0.57 & 2.72 & 1.39 & 3.00 & 1.54 \\
\hline Lamb's Quarters & Chenopodium album L. & 0.02 & 0.02 & 0.03 & 0.03 & 0.00 & 0.00 \\
\hline Lanceleaf Frog-Fruit & Phyla lanceolata (Michx.) Greene & 0.02 & 0.02 & 0.00 & 0.00 & 0.00 & 0.00 \\
\hline Large-flowered Bellwort & Uvularia grandiflora Sm. & 0.19 & 0.19 & 0.00 & 0.00 & 0.00 & 0.00 \\
\hline Large-leaved Pondweed & Potamogeton amplifolius Tuck. & 0.00 & 0.00 & 0.17 & 0.17 & 0.00 & 0.00 \\
\hline
\end{tabular}


Appendix 6 Continued

\begin{tabular}{|c|c|c|c|c|c|c|c|}
\hline Late Goldenrod & Solidago gigantean Aiton & 0.02 & 0.02 & 0.08 & 0.06 & 0.00 & 0.00 \\
\hline Late Meadowrue & Thalictrum pubescens Pursh & 0.00 & 0.00 & 0.03 & 0.03 & 0.00 & 0.00 \\
\hline Late-flowering Thoroughwort & Eupatorium serotinum Michx. & 0.02 & 0.02 & 0.17 & 0.17 & 0.00 & 0.00 \\
\hline May-Apple & Podophyllum peltatum $\mathrm{L}$. & 0.19 & 0.19 & 0.00 & 0.00 & 0.00 & 0.00 \\
\hline Mile-A-Minute Weed & Polygonum perfoliata (L.) H. Gross & 1.34 & 0.57 & 2.72 & 1.39 & 3.00 & 1.54 \\
\hline Moneywort & Lysimachia nummularia $\mathrm{L}$. & 0.02 & 0.02 & 0.00 & 0.00 & 0.00 & 0.00 \\
\hline Morrow's Honeysuckle & Lonicera morrowii A. Gray & 0.00 & 0.00 & 0.03 & 0.03 & 0.00 & 0.00 \\
\hline Multiflora Rose & Rosa multiflora Thunb. & 0.02 & 0.02 & 0.61 & 0.61 & 0.89 & 0.53 \\
\hline Nodding Fescue & Festuca subverticillata (Pers.)Alexee & 0.00 & 0.00 & 0.00 & 0.00 & 3.25 & 2.24 \\
\hline Northern Catalpa & $\begin{array}{l}\text { Catalpa speciosa (Warder) Warder ex } \\
\text { Engelm }\end{array}$ & 2.85 & 2.85 & 0.00 & 0.00 & 0.00 & 0.00 \\
\hline Norway Maple & Acer platanoides $\mathrm{L}$. & 0.08 & 0.08 & 0.00 & 0.00 & 0.00 & 0.00 \\
\hline Orchard Grass & Dactylis glomerata L. & 0.64 & 0.43 & 0.00 & 0.00 & 0.21 & 0.21 \\
\hline Panic Grass & $\begin{array}{l}\text { Dichanthelium acuminatum (Sw.) Gould } \\
\text { \& C.S. Clark }\end{array}$ & 0.09 & 0.09 & 0.00 & 0.00 & 1.11 & 1.11 \\
\hline Pawpaw & Asimina triloba (L.) Dunal & 0.06 & 0.04 & 7.18 & 7.06 & 0.96 & 0.42 \\
\hline Pear & Pyrus angustifolia Aiton & 0.00 & 0.00 & 0.08 & 0.08 & 0.00 & 0.00 \\
\hline Pennsylvania Blackberry & Rubus pensilvanicus Poir. & 0.00 & 0.00 & 0.00 & 0.00 & 0.46 & 0.30 \\
\hline Pilewort & Erechtites hieraciifolia (L.) Raf. ex DC & 0.02 & 0.02 & 0.00 & 0.00 & 0.00 & 0.00 \\
\hline Poison Ivy & Toxicodendron radicans (L.) Kuntze & 0.27 & 0.23 & 3.17 & 2.05 & 1.18 & 0.57 \\
\hline Poison Oak & Toxicodendron pubescens Mill. & 0.03 & 0.03 & 0.00 & 0.00 & 0.00 & 0.00 \\
\hline Pokeweed & Phytolacca americana $\mathrm{L}$. & 0.00 & 0.00 & 0.00 & 0.00 & 0.04 & 0.04 \\
\hline Prickly Lettuce & Lactuca serriola L. & 0.00 & 0.00 & 0.03 & 0.03 & 0.00 & 0.00 \\
\hline Privet & Ligustrum vulgare L. & 0.00 & 0.00 & 0.42 & 0.42 & 0.00 & 0.00 \\
\hline Prostrate Knotweed & Polygonum aviculare L. & 0.00 & 0.00 & 0.03 & 0.03 & 0.00 & 0.00 \\
\hline
\end{tabular}




\begin{tabular}{|c|c|c|c|c|c|c|c|}
\hline \multicolumn{8}{|c|}{ Appendix 6 Continued } \\
\hline Quaking Aspen & Populus tremuloides Michx. & 0.00 & 0.00 & 5.00 & 5.00 & 0.00 & 0.00 \\
\hline Queen Ann's Lace & Daucus carota L. & 0.02 & 0.02 & 0.03 & 0.03 & 0.00 & 0.00 \\
\hline Rabbitfoot Clover & Trifolium arvense $\mathrm{L}$. & 0.05 & 0.03 & 0.00 & 0.00 & 0.00 & 0.00 \\
\hline Red Maple & Acer rubrum $\mathrm{L}$. & 0.04 & 0.03 & 2.36 & 2.36 & 0.00 & 0.00 \\
\hline Red Mulberry & Morus rubra L. & 0.00 & 0.00 & 0.33 & 0.33 & 0.00 & 0.00 \\
\hline Red Oak & Quercus rubra L. & 1.12 & 0.74 & 0.00 & 0.00 & 0.00 & 0.00 \\
\hline Redtop & Agrostis alba Roth & 1.19 & 0.75 & 0.03 & 0.03 & 0.00 & 0.00 \\
\hline Reed Canary Grass & Phalaris arundinacea $\mathrm{L}$. & 10.88 & 6.07 & 7.83 & 3.49 & 1.79 & 1.25 \\
\hline Rice Cutgrass & Leersia oryzoides (L.) Sw. & 0.02 & 0.02 & 0.00 & 0.00 & 0.04 & 0.04 \\
\hline River-bank Grape & Vitis riparia Michx. & 0.02 & 0.02 & 0.00 & 0.00 & 0.00 & 0.00 \\
\hline Russian Olive & Elaeagnus angustifolia $\mathrm{L}$. & 0.00 & 0.00 & 0.08 & 0.08 & 0.00 & 0.00 \\
\hline Sachaline & $\begin{array}{l}\text { Polygonum sachalinense F. Schmidt ex } \\
\text { Maxin }\end{array}$ & 0.00 & 0.00 & 0.42 & 0.42 & 0.00 & 0.00 \\
\hline Sassafras & Sassafras albidum (Nutt.) Nees & 0.40 & 0.40 & 0.00 & 0.00 & 0.00 & 0.00 \\
\hline Sericea & Lespedeza cuneata Lindl. & 0.86 & 0.50 & 0.00 & 0.00 & 0.00 & 0.00 \\
\hline Shellbark Hickory & Carya laciniosa (Michx. f.) G. Don & 0.00 & 0.00 & 0.00 & 0.00 & 0.58 & 0.58 \\
\hline Silver Maple & Acer saccharinum $\mathrm{L}$. & 11.16 & 5.97 & 36.99 & 22.76 & 25.59 & 6.43 \\
\hline Smooth Bromegrass & Bromus inermis Leyss. & 0.00 & 0.00 & 1.00 & 0.67 & 0.00 & 0.00 \\
\hline Smooth Hedge-Nettle & Stachys tenuifolia Willd. & 0.09 & 0.09 & 0.00 & 0.00 & 0.00 & 0.00 \\
\hline Speedwell & Veronica sp. L. & 0.02 & 0.02 & 0.00 & 0.00 & 0.00 & 0.00 \\
\hline Spicebush & Lindera benzoin L. Blume & 1.28 & 1.02 & 0.00 & 0.00 & 7.96 & 2.69 \\
\hline Spiny cocklebur & Xanthium strumarium L. & 0.00 & 0.00 & 0.00 & 0.00 & 0.04 & 0.04 \\
\hline Spiny Sow Thistle & Sonchus asper (L.) Hill & 0.02 & 0.02 & 0.00 & 0.00 & 0.00 & 0.00 \\
\hline Spreading Dogbane & Apocynum androsaemifolium $\mathrm{L}$. & 0.00 & 0.00 & 0.00 & 0.00 & 0.21 & 0.21 \\
\hline
\end{tabular}


Appendix 6 Continued

\begin{tabular}{|c|c|c|c|c|c|c|c|}
\hline Staghorn Sumac & Rhus typhina L. & 0.00 & 0.00 & 0.01 & 0.01 & 0.00 & 0.00 \\
\hline Stalk-Grain Sedge & Carex stipata Muhl ex. Willd & 0.09 & 0.09 & 0.00 & 0.00 & 0.00 & 0.00 \\
\hline Sugar Maple & Acer saccharum Marsh. & 0.87 & 0.58 & 0.00 & 0.00 & 0.00 & 0.00 \\
\hline Summer Grape & Vitis aestivalis Michx. & 0.30 & 0.26 & 0.09 & 0.09 & 0.19 & 0.05 \\
\hline Swamp Dewberry & Rubus hispidus L. & 0.00 & 0.00 & 0.03 & 0.03 & 0.00 & 0.00 \\
\hline Tall Coneflower & Rudbeckia laciniata $\mathrm{L}$. & 0.00 & 0.00 & 0.83 & 0.83 & 0.32 & 0.21 \\
\hline Tall Thistle & Cirsium altissimum (L.) Hill & 0.00 & 0.00 & 1.75 & 1.75 & 0.00 & 0.00 \\
\hline Three-Square & Schoenplectus pungens (Vahl) Palla & 0.00 & 0.00 & 0.86 & 0.86 & 0.00 & 0.00 \\
\hline Timothy & Phleum pratense $\mathrm{L}$. & 0.47 & 0.37 & 0.00 & 0.00 & 0.00 & 0.00 \\
\hline Touch-Me-Not & Impatiens sp. L. & 0.23 & 0.15 & 0.06 & 0.06 & 0.93 & 0.89 \\
\hline Tree of Heaven & Ailanthus altissima (Mill.) Swingle & 0.17 & 0.17 & 0.01 & 0.01 & 0.10 & 0.07 \\
\hline Valdivia Duckweed & Lemna valdiviana Phil. & 0.00 & 0.00 & 0.06 & 0.06 & 0.00 & 0.00 \\
\hline Violet & Viola sp. L. & 0.33 & 0.20 & 0.08 & 0.06 & 4.07 & 1.17 \\
\hline Virginia Creeper & Parthenocissus quinquefolia (L.) Planch & 0.25 & 0.15 & 0.81 & 0.55 & 0.86 & 0.33 \\
\hline Virginia Knotweed & Polygonum virginianum $\mathrm{L}$. & 0.09 & 0.09 & 0.03 & 0.03 & 0.93 & 0.85 \\
\hline Virginia Strawberry & Fragaria virginiana Duchesne & 0.00 & 0.00 & 0.00 & 0.00 & 0.04 & 0.04 \\
\hline White Ash & Fraxinus americana L. & 0.53 & 0.53 & 0.00 & 0.00 & 0.00 & 0.00 \\
\hline White Avens & Geum canadense Jacq. & 0.00 & 0.00 & 0.06 & 0.06 & 0.00 & 0.00 \\
\hline White Clover & Trifolium repens $\mathrm{L}$. & 0.38 & 0.25 & 0.00 & 0.00 & 0.00 & 0.00 \\
\hline White Grass & Leersia virginica Willd. & 0.91 & 0.58 & 0.11 & 0.07 & 2.64 & 1.44 \\
\hline White Mulberry & Morus alba L. & 0.00 & 0.00 & 0.05 & 0.05 & 0.00 & 0.00 \\
\hline White Snakeroot & Ageratina altissima (L.) King \& H. Rob. & 0.73 & 0.41 & 1.33 & 1.21 & 1.29 & 0.81 \\
\hline White Vervain & Verbena urticifolia L. & 0.09 & 0.09 & 0.00 & 0.00 & 0.00 & 0.00 \\
\hline White Wood Aster & Eurybia divaricata (L.) G.L. Nesom & 0.97 & 0.74 & 0.00 & 0.00 & 0.00 & 0.00 \\
\hline
\end{tabular}




\begin{tabular}{|c|c|c|c|c|c|c|c|}
\hline Wild Rye & Elymus riparius Wiegand & 0.00 & 0.00 & 0.06 & 0.06 & 0.00 & 0.00 \\
\hline Wild Stinging Nettle & Urtica dioica $\mathrm{L}$. & 4.91 & 2.66 & 1.19 & 0.88 & 0.04 & 0.04 \\
\hline Wild Stonecrop & Sedum ternatum Michx. & 0.02 & 0.02 & 0.00 & 0.00 & 0.00 & 0.00 \\
\hline Wing-stem & $\begin{array}{l}\text { Verbesina alternifolia (L.) Britton ex } \\
\text { Kearney }\end{array}$ & 6.06 & 2.16 & 16.31 & 5.16 & 15.57 & 4.32 \\
\hline Winter Creeper & Euonymus fortunei (Turcz.) Hand.-Maz. & 0.03 & 0.03 & 0.00 & 0.00 & 0.00 & 0.00 \\
\hline Winter Grape & Vitis vulpina $\mathrm{L}$. & 0.11 & 0.11 & 0.47 & 0.41 & 0.00 & 0.00 \\
\hline Wiregrass & Juncus tenuis Willd. & 0.02 & 0.02 & 0.17 & 0.17 & 0.00 & 0.00 \\
\hline Wirestem Muhly & Muhlenbergia frondosa (Poir.) Fernald & 0.02 & 0.02 & 0.00 & 0.00 & 0.00 & 0.00 \\
\hline Wood Nettle & Laportea canadensis (L.) Weddell & 0.00 & 0.00 & 1.17 & 1.17 & 1.00 & 1.00 \\
\hline Yellow Buckeye & Aesculus flava Aiton & 0.30 & 0.22 & 0.03 & 0.02 & 0.10 & 0.09 \\
\hline Yellow Wood Sorrel & Oxalis stricta $\mathrm{L}$. & 0.31 & 0.13 & 0.00 & 0.00 & 0.00 & 0.00 \\
\hline
\end{tabular}


Appendix 7: List of all non-native and exotic plant species to the Ohio River islands study area (Blennerhassett, Buckley, and Muskingum islands, West Virginia, USA) and their means (\% cover for herbs and shrubs and basal area $\left[\mathrm{m}^{2} / \mathrm{ha}\right]$ for trees) and standard errors (SE) that were sampled during the July 2008 field season.

\begin{tabular}{|c|c|c|c|c|c|c|c|}
\hline \multirow{2}{*}{ Common Name } & \multirow{2}{*}{ Scientific Name } & \multicolumn{2}{|c|}{ Blennerhassett } & \multicolumn{2}{|c|}{ Buckley } & \multicolumn{2}{|c|}{ Muskingum } \\
\hline & & $\bar{x}$ & SE & $\bar{x}$ & SE & $\bar{x}$ & SE \\
\hline Asiatic Water Pepper & Polygonum cespitosum Blume & 0.00 & 0.00 & 0.03 & 0.03 & 0.00 & 0.00 \\
\hline Autumn Olive & Elaeagnus umbellate Thunb. & 0.00 & 0.00 & 0.03 & 0.03 & 0.00 & 0.00 \\
\hline Bird's Foot Trefoil & Lotus corniculatus L. & 2.66 & 1.60 & 0.00 & 0.00 & 0.00 & 0.00 \\
\hline Bittercress & Cardamine impatiens L. & 0.02 & 0.02 & 0.03 & 0.03 & 0.00 & 0.00 \\
\hline Bittersweet & Solanum dulcamara $\mathrm{L}$. & 0.02 & 0.02 & 0.00 & 0.00 & 0.00 & 0.00 \\
\hline Black Medic & Medicago lupulina L. & 0.02 & 0.02 & 0.00 & 0.00 & 0.00 & 0.00 \\
\hline Broadleaf Dock & Rumex obtusifolius L. & 0.03 & 0.03 & 0.33 & 0.21 & 0.00 & 0.00 \\
\hline Canada Thistle & Cirsium arvense (L.) Scop. & 5.98 & 2.75 & 1.25 & 0.73 & 0.00 & 0.00 \\
\hline Common Burdock & Arctium minus (Hill) Bernh. & 0.00 & 0.00 & 2.78 & 2.00 & 0.00 & 0.00 \\
\hline Common Dandelion & Taraxacum officinale Zinn & 0.00 & 0.00 & 0.03 & 0.03 & 0.00 & 0.00 \\
\hline Common Mugwort & Artemisia vulgaris $\mathrm{L}$. & 0.28 & 0.15 & 0.06 & 0.06 & 0.00 & 0.00 \\
\hline Common Thistle & Cirsium vulgare (Savi) Tenore & 0.02 & 0.02 & 0.00 & 0.00 & 0.00 & 0.00 \\
\hline English Plantain & Plantago lanceolata $\mathrm{L}$. & 0.39 & 0.31 & 0.00 & 0.00 & 0.00 & 0.00 \\
\hline Garlic Mustard & $\begin{array}{l}\text { Alliaria petiolata (M. Bieb.) Cavara } \\
\& \text { Grande }\end{array}$ & 2.67 & 0.90 & 3.69 & 1.60 & 3.43 & 1.24 \\
\hline Giant Chickweed & Myosoton aquaticum L. Moench & 0.00 & 0.00 & 0.00 & 0.00 & 0.04 & 0.04 \\
\hline Giant Foxtail Grass & Setaria faberi Herm. & 0.02 & 0.02 & 0.00 & 0.00 & 0.00 & 0.00 \\
\hline Ground-Ivy & Glechoma hederacea L. & 5.84 & 2.42 & 14.64 & 7.51 & 40.57 & 11.70 \\
\hline Hairy Chess & Bromus commutatus L. & 0.47 & 0.47 & 0.00 & 0.00 & 0.00 & 0.00 \\
\hline Italian Perennial Rye Grass & Lolium perenne L. & 2.19 & 1.01 & 0.00 & 0.00 & 0.00 & 0.00 \\
\hline
\end{tabular}




\begin{tabular}{|c|c|c|c|c|c|c|c|}
\hline Japanese Honeysuckle & Lonicera japonica (Thonb.) & 1.53 & 1.04 & 11.50 & 7.22 & 0.36 & 0.24 \\
\hline Japanese Hop & Humulus japonicus Siebold \& Zucc. & 1.41 & 0.71 & 0.89 & 0.69 & 0.00 & 0.00 \\
\hline Japanese Knotweed & $\begin{array}{l}\text { Polygonum cuspidatum Siebold \& } \\
\text { Zucc. }\end{array}$ & 1.55 & 1.02 & 4.36 & 4.33 & 2.96 & 2.96 \\
\hline Japanese Millet & $\begin{array}{l}\text { Echinocchloa crus-galli var } \\
\text { frumentacea P. Beauv. }\end{array}$ & 3.08 & 2.11 & 0.00 & 0.00 & 0.00 & 0.00 \\
\hline Japanese Stilt Grass & $\begin{array}{l}\text { Microstegium vimineum (Trin.) A. } \\
\text { Camus }\end{array}$ & 1.30 & 0.63 & 0.28 & 0.19 & 1.71 & 1.67 \\
\hline Johnson Grass & Sorghum halepense Pers. & 1.27 & 1.01 & 0.00 & 0.00 & 0.00 & 0.00 \\
\hline Jointed Grass & Arthraxon hispidus (Thunb.) Makino & 0.48 & 0.48 & 0.00 & 0.00 & 0.00 & 0.00 \\
\hline Kentucky 31 Fescue & Lolium arundinaceum (Scop.) Holub & 5.36 & 3.21 & 3.19 & 3.16 & 0.00 & 0.00 \\
\hline Kentucky Bluegrass & Poa pratensis $\mathrm{L}$. & 0.45 & 0.31 & 15.92 & 10.32 & 3.04 & 2.09 \\
\hline Lady's Thumb & Polygonum persicaria $\mathrm{L}$. & 1.34 & 0.57 & 2.72 & 1.39 & 3.00 & 1.54 \\
\hline Lamb's Quarters & Chenopodium album $\mathrm{L}$. & 0.02 & 0.02 & 0.03 & 0.03 & 0.00 & 0.00 \\
\hline Mile-A-Minute Weed & Polygonum perfoliata (L.) H. Gross & 1.34 & 0.57 & 2.72 & 1.39 & 3.00 & 1.54 \\
\hline Moneywort & Lysimachia nummularia $\mathrm{L}$. & 0.02 & 0.02 & 0.00 & 0.00 & 0.00 & 0.00 \\
\hline Morrow's Honeysuckle & Lonicera morrowii A. Gray & 0.00 & 0.00 & 0.03 & 0.03 & 0.00 & 0.00 \\
\hline Multiflora Rose & Rosa multiflora Thonb. & 0.02 & 0.02 & 0.61 & 0.61 & 0.89 & 0.53 \\
\hline Norway Maple & Acer platanoides $\mathrm{L}$. & 0.08 & 0.08 & 0.00 & 0.00 & 0.00 & 0.00 \\
\hline Orchard Grass & Dactylis glomerata L. & 0.64 & 0.43 & 0.00 & 0.00 & 0.21 & 0.21 \\
\hline Prickly Lettuce & Lactuca serriola L. & 0.00 & 0.00 & 0.03 & 0.03 & 0.00 & 0.00 \\
\hline Privet & Ligustrum vulgare L. & 0.00 & 0.00 & 0.42 & 0.42 & 0.00 & 0.00 \\
\hline Prostrate Knotweed & Polygonum aviculare L. & 0.00 & 0.00 & 0.03 & 0.03 & 0.00 & 0.00 \\
\hline Queen Ann's Lace & Daucus carota L. & 0.02 & 0.02 & 0.03 & 0.03 & 0.00 & 0.00 \\
\hline Rabbitfoot Clover & Trifolium arvense $\mathrm{L}$. & 0.05 & 0.03 & 0.00 & 0.00 & 0.00 & 0.00 \\
\hline
\end{tabular}




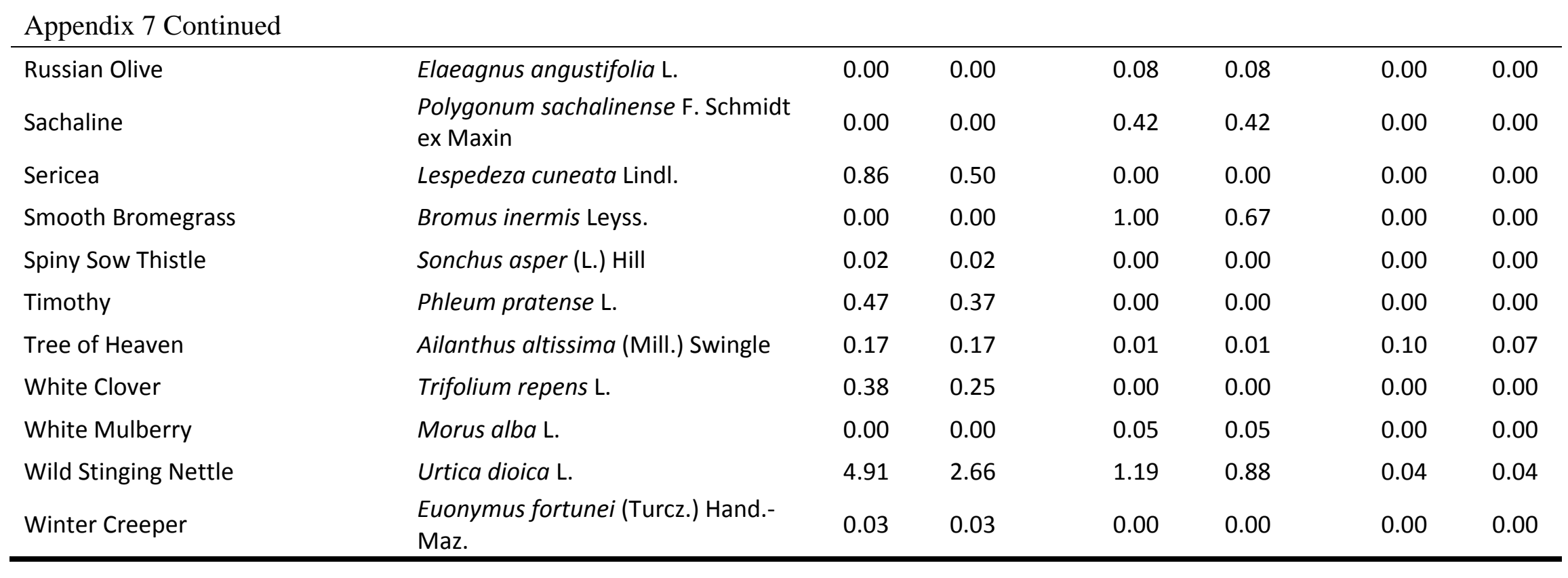


Appendix 8: Summary of simple effects analysis for six soil variables (ppm of soluble sulfur, phosphorus, bray II phosphorus, potassium, sodium, and zinc) that had a significant site by distance interaction for Blennerhassett, Buckley, and Muskingum islands, West Virginia, USA and at 0,100, and $300 \mathrm{~m}$ from the bridge (bolded values indicate significant contrasts of simple effects at $\alpha=$ 0.05 ) with the estimate, standard error (SE), degrees of freedom (df), t-value, and P-value $(P)$.

\begin{tabular}{|c|c|c|c|c|c|}
\hline Soil Variable & Estimate & SE & $\mathrm{df}$ & t value & $P$ \\
\hline \multicolumn{6}{|l|}{ Soluble Sulfur } \\
\hline Blennerhassett $0 \mathrm{~m}$ vs. Blennerhassett $100 \mathrm{~m}$ & 1.17 & 0.21 & 26.0 & 5.54 & $<0.001$ \\
\hline Blennerhassett $0 \mathrm{~m}$ vs. Blennerhassett $300 \mathrm{~m}$ & 1.04 & 0.22 & 26.0 & 4.80 & $<0.001$ \\
\hline Blennerhassett $100 \mathrm{~m}$ vs. Blennerhassett $300 \mathrm{~m}$ & -0.13 & 0.17 & 26.0 & -0.78 & 0.445 \\
\hline Buckley $0 \mathrm{~m}$ vs. Buckley $100 \mathrm{~m}$ & 1.46 & 0.22 & 26.0 & 6.53 & $<0.001$ \\
\hline Buckley $0 \mathrm{~m}$ vs. Buckley $300 \mathrm{~m}$ & 1.23 & 0.23 & 26.0 & 5.26 & $<0.001$ \\
\hline Buckley 100 m vs. Buckley 300 m & -0.23 & 0.21 & 26.0 & -1.12 & 0.273 \\
\hline Muskingum $0 \mathrm{~m}$ vs. Muskingum $100 \mathrm{~m}$ & 0.05 & 0.35 & 26.0 & 0.12 & 0.905 \\
\hline Muskingum $0 \mathrm{~m}$ vs. Muskingum $300 \mathrm{~m}$ & 0.12 & 0.35 & 26.0 & 0.34 & 0.740 \\
\hline Muskingum 100 m vs. Muskingum 300 m & 0.08 & 0.25 & 26.0 & 0.30 & 0.764 \\
\hline Blennerhassett $0 \mathrm{~m}$ vs. Buckley $0 \mathrm{~m}$ & -0.22 & 0.25 & 26.0 & -0.87 & 0.391 \\
\hline Blennerhassett $0 \mathrm{~m}$ vs. Muskingum $0 \mathrm{~m}$ & 0.69 & 0.35 & 26.0 & 1.94 & 0.063 \\
\hline Buckley $0 \mathrm{~m}$ vs. Muskingum $0 \mathrm{~m}$ & 0.91 & 0.35 & 26.0 & 2.56 & 0.017 \\
\hline Blennerhassett $100 \mathrm{~m}$ vs. Buckley $100 \mathrm{~m}$ & 0.07 & 0.18 & 26.0 & 0.40 & 0.696 \\
\hline Blennerhassett $100 \mathrm{~m}$ vs. Muskingum $100 \mathrm{~m}$ & -0.44 & 0.2 & 26.0 & -2.09 & 0.047 \\
\hline Buckley 100 m vs. Muskingum $100 \mathrm{~m}$ & -0.51 & 0.22 & 26.0 & -2.29 & 0.031 \\
\hline Blennerhassett 300 m vs. Buckley 300 m & -0.03 & 0.20 & 26.0 & -0.14 & 0.892 \\
\hline Blennerhassett 300 m vs. Muskingum $300 \mathrm{~m}$ & -0.23 & 0.22 & 26.0 & -1.07 & 0.293 \\
\hline Buckley 300 m vs. Muskingum 300 m & -0.21 & 0.23 & 26.0 & -0.88 & 0.388 \\
\hline
\end{tabular}


Appendix 8 Continued

Phosphorus

Blennerhassett $0 \mathrm{~m}$ vs. Blennerhassett $100 \mathrm{~m}$

1.82

Blennerhassett $0 \mathrm{~m}$ vs. Blennerhassett $300 \mathrm{~m}$

1.74

Blennerhassett $100 \mathrm{~m}$ vs. Blennerhassett $300 \mathrm{~m}$

$-0.08$

Buckley $0 \mathrm{~m}$ vs. Buckley $100 \mathrm{~m}$

0.46

0.35

$-0.10$

Buckley 100 m vs. Buckley 300 m

Muskingum $0 \mathrm{~m}$ vs. Muskingum $100 \mathrm{~m}$

Muskingum $0 \mathrm{~m}$ vs. Muskingum $300 \mathrm{~m}$

0.75

0.82

Muskingum 100 m vs. Muskingum $300 \mathrm{~m}$

0.07

1.35

Blennerhassett $0 \mathrm{~m}$ vs. Buckley $0 \mathrm{~m}$

1.35

Blennerhassett $0 \mathrm{~m}$ vs. Muskingum $0 \mathrm{~m}$

1.29

Buckley $0 \mathrm{~m}$ vs. Muskingum $0 \mathrm{~m}$

Blennerhassett $100 \mathrm{~m}$ vs. Buckley $100 \mathrm{~m}$

$-0.06$

$-0.01$

Blennerhassett 100 m vs. Muskingum 100 m

0.21

0.22

$-0.03$

0.37

0.40

0.26

26.0

6.94

$<0.001$

Buckley 100 m vs. Muskingum $100 \mathrm{~m}$

0.27

26.0

6.47

$<0.001$

Blennerhassett $300 \mathrm{~m}$ vs. Buckley $300 \mathrm{~m}$

Blennerhassett $300 \mathrm{~m}$ vs. Muskingum $300 \mathrm{~m}$

Buckley 300 m vs. Muskingum 300 m

Bray II Phosphorus

Blennerhassett $0 \mathrm{~m}$ vs. Blennerhassett $100 \mathrm{~m}$

Blennerhassett $0 \mathrm{~m}$ vs. Blennerhassett $300 \mathrm{~m}$

Blennerhassett $100 \mathrm{~m}$ vs. Blennerhassett $300 \mathrm{~m}$

Buckley $0 \mathrm{~m}$ vs. Buckley $100 \mathrm{~m}$

183.73

177.33

$-1.71$

65.40

$\begin{array}{llll}0.21 & 26.0 & -0.39 & 0.703\end{array}$

$\begin{array}{llll}0.28 & 26.0 & 1.66 & 0.109\end{array}$

$\begin{array}{llll}0.29 & 26.0 & 1.22 & 0.232\end{array}$

$\begin{array}{llll}0.25 & 26.0 & -0.41 & 0.684\end{array}$

$\begin{array}{llll}0.44 & 26.0 & 1.70 & 0.101\end{array}$

$\begin{array}{llll}0.44 & 26.0 & 1.87 & 0.073\end{array}$

$\begin{array}{llll}0.31 & 26.0 & 0.23 & 0.819\end{array}$

$\begin{array}{llll}0.31 & 26.0 & 4.36 & <0.001\end{array}$

$\begin{array}{llll}0.44 & 26.0 & 2.93 & 0.007\end{array}$

$\begin{array}{llll}0.44 & 26.0 & -0.15 & 0.884\end{array}$

$\begin{array}{llll}0.22 & 26.0 & -0.04 & 0.970\end{array}$

$\begin{array}{llll}0.26 & 26.0 & 0.82 & 0.422\end{array}$

$\begin{array}{llll}0.28 & 26.0 & 0.80 & 0.430\end{array}$

$\begin{array}{llll}0.24 & 26.0 & -0.13 & 0.897\end{array}$

$\begin{array}{llll}0.27 & 26.0 & 1.37 & 0.184\end{array}$

$\begin{array}{llll}0.29 & 26.0 & 1.37 & 0.181\end{array}$

\begin{tabular}{rrrr}
36.17 & 20.8 & 5.08 & $<0.001$ \\
37.27 & 13.0 & 4.76 & $<0.001$ \\
29.33 & 13.0 & -0.06 & 0.954 \\
31.93 & 9.0 & 2.05 & 0.071 \\
\hline
\end{tabular}


Appendix 8 Continued

Buckley $0 \mathrm{~m}$ vs. Buckley $300 \mathrm{~m}$

52.50

$-12.90$

33.40

9.0

1.57

0.150

Buckley 100 m vs. Buckley $300 \mathrm{~m}$

$-6.33$

Muskingum $0 \mathrm{~m}$ vs. Muskingum $100 \mathrm{~m}$

Muskingum $0 \mathrm{~m}$ vs. Muskingum $300 \mathrm{~m}$

Muskingum $100 \mathrm{~m}$ vs. Muskingum $300 \mathrm{~m}$

1.67

8.00

Blennerhassett $0 \mathrm{~m}$ vs. Buckley $\mathbf{0} \mathrm{m}$

118.33

Blennerhassett $0 \mathrm{~m}$ vs. Muskingum $0 \mathrm{~m}$

\section{Buckley $\mathbf{0} \mathrm{m}$ vs. Muskingum $\mathbf{0} \mathrm{m}$}

Blennerhassett $100 \mathrm{~m}$ vs. Buckley $100 \mathrm{~m}$

Blennerhassett $100 \mathrm{~m}$ vs. Muskingum $100 \mathrm{~m}$

Buckley $100 \mathrm{~m}$ vs. Muskingum $100 \mathrm{~m}$

Blennerhassett $300 \mathrm{~m}$ vs. Buckley $300 \mathrm{~m}$

Blennerhassett $300 \mathrm{~m}$ vs. Muskingum $300 \mathrm{~m}$

Buckley 300 m vs. Muskingum 300 m

\section{Potassium}

Blennerhassett $0 \mathrm{~m}$ vs. Blennerhassett $100 \mathrm{~m}$

Blennerhassett $0 \mathrm{~m}$ vs. Blennerhassett $300 \mathrm{~m}$

Blennerhassett $100 \mathrm{~m}$ vs. Blennerhassett $300 \mathrm{~m}$

Buckley $0 \mathrm{~m}$ vs. Buckley $100 \mathrm{~m}$

Buckley $0 \mathrm{~m}$ vs. Buckley $300 \mathrm{~m}$

Buckley 100 m vs. Buckley 300 m

Muskingum $0 \mathrm{~m}$ vs. Muskingum $100 \mathrm{~m}$

Muskingum $0 \mathrm{~m}$ vs. Muskingum $300 \mathrm{~m}$

Muskingum $100 \mathrm{~m}$ vs. Muskingum $300 \mathrm{~m}$

195.33

77.00

4.69

9.95

5.27

$-6.50$

19.67

26.17

0.81

0.62

$-0.19$

0.25

0.20

$-0.09$

$-0.60$

$-0.61$

$-0.01$

29.33

$$
5.75
$$

5.75

4.07

39.54

30.84

25.73

27.92

20.13

19.77

30.68

21.71

22.05

0.22

0.23

0.18

0.23

0.24

0.19

0.37

0.37

0.26

$9.0 \quad-0.44$

0.671

$4.0 \quad-1.10$

0.333

$\begin{array}{ll}4.0 & 0.29\end{array}$

0.787

$4.0 \quad 1.97$

0.121

$22.0 \quad 2.99$

0.007

$13.7 \quad 6.33$

$<0.001$

$9.7 \quad 2.99$

0.014

$21.4 \quad 0.17$

0.868

$13.5 \quad 0.49$

0.629

$9.4 \quad 0.27$

0.796

$21.1-0.21$

0.834

$13.5 \quad 0.91$

0.381

9.3

1.19

0.265

\section{0}

3.66

0.001

26.0

2.74

0.011

$26.0 \quad-1.06$

0.230

$26.0 \quad 1.09$

0.285

$26.0 \quad 0.82$

0.422

$26.0-0.46$

0.649

$26.0-1.62$

0.118

$26.0-1.65$

0.112 
Appendix 8 Continued

Blennerhassett $0 \mathrm{~m}$ vs. Buckley $0 \mathrm{~m}$

$\begin{array}{rrrrr}0.45 & 0.26 & 26.0 & 1.73 & 0.095 \\ \mathbf{1 . 4 2} & \mathbf{0 . 3 7} & \mathbf{2 6 . 0} & \mathbf{3 . 8 5} & \mathbf{0 . 0 0 1} \\ \mathbf{0 . 9 7} & \mathbf{0 . 3 7} & \mathbf{2 6 . 0} & \mathbf{2 . 6 3} & \mathbf{0 . 0 1 4} \\ -0.10 & 0.19 & 26.0 & -0.53 & 0.601 \\ 0.02 & 0.22 & 26.0 & 0.08 & 0.935 \\ 0.12 & 0.23 & 26.0 & 0.50 & 0.620 \\ 0.03 & 0.51 & 26.0 & 0.16 & 0.872 \\ 0.20 & 0.23 & 26.0 & 0.87 & 0.395 \\ 0.17 & 0.24 & 26.0 & 0.66 & 0.513\end{array}$

Sodium

Blennerhassett $0 \mathrm{~m}$ vs. Blennerhassett $100 \mathrm{~m}$

0.90

Blennerhassett $0 \mathrm{~m}$ vs. Blennerhassett $300 \mathrm{~m}$

0.90

0.28

26.0

3.17

0.004

Blennerhassett $100 \mathrm{~m}$ vs. Blennerhassett $300 \mathrm{~m}$

0.05

0.29

26.0

3.27

0.003

Buckley $0 \mathrm{~m}$ vs. Buckley $100 \mathrm{~m}$

3.64

0.23

26.0

0.23

0.817

Buckley $0 \mathrm{~m}$ vs. Buckley $\mathbf{3 0 0} \mathrm{m}$

3.80

0.30

26.0

12.13

$<0.001$

Buckley 100 m vs. Buckley 300 m

Muskingum $0 \mathrm{~m}$ vs. Muskingum $100 \mathrm{~m}$

0.15

0.31

26.0

12.09

$<0.001$

$-0.41$

0.28

26.0

0.56

0.580

Muskingum $0 \mathrm{~m}$ vs. Muskingum $300 \mathrm{~m}$

$-0.48$

0.48

26.0

$-0.86$

0.399

Muskingum $100 \mathrm{~m}$ vs. Muskingum $300 \mathrm{~m}$

$-0.08$

0.38

26.0

1.02

0.318

Blennerhassett $0 \mathrm{~m}$ vs. Blennerhassett $0 \mathrm{~m}$

0.34

26.0

0.822

Blennerhassett $0 \mathrm{~m}$ vs. Muskingum $0 \mathrm{~m}$

1.22

Buckley $0 \mathrm{~m}$ vs. Muskingum $0 \mathrm{~m}$

Blennerhassett $100 \mathrm{~m}$ vs. Buckley $100 \mathrm{~m}$

4.08

0.34

26.0

$-0.23$

$<0.001$

Blennerhassett $100 \mathrm{~m}$ vs. Muskingum $100 \mathrm{~m}$

$-0.10$

0.48

26.0

$-8.49$

0.016

0.48

26.0

2.58

$<0.001$

$-0.08$

0.24

26.0

8.58

0.667

0.29

26.0

0.774 
Appendix 8 Continued

Buckley $100 \mathrm{~m}$ vs. Muskingum $100 \mathrm{~m}$

0.02

$-0.01$

0.30

$-0.01$

Blennerhassett $300 \mathrm{~m}$ vs. Muskingum $300 \mathrm{~m}$

$-0.21$

$-0.21$

0.27

26.0

0.07

0.27

26.0

$-0.01$

0.941

Buckley 300 m vs. Muskingum 300 m

0.29

26.0

$-0.73$

0.989

$\underline{\text { Zinc }}$

Blennerhassett $0 \mathrm{~m}$ vs. Blennerhassett $100 \mathrm{~m}$

\begin{tabular}{rrrrr}
-12.13 & 6.34 & 26.0 & -1.91 & 0.067 \\
-12.83 & 6.49 & 26.0 & -1.98 & 0.059 \\
-0.70 & 5.11 & 26.0 & -0.14 & 0.892 \\
$\mathbf{2 9 . 4 7}$ & 6.70 & 26.0 & 4.39 & $<0.001$ \\
$\mathbf{2 5 . 0 7}$ & $\mathbf{7 . 0 1}$ & 26.0 & $\mathbf{3 . 5 8}$ & $<0.001$ \\
-4.40 & 6.16 & 26.0 & -0.71 & 0.482 \\
-6.48 & 10.60 & 26.0 & -0.61 & 0.547 \\
-7.25 & 10.60 & 26.0 & -0.68 & 0.500 \\
-0.78 & 7.50 & 26.0 & -0.10 & 0.918 \\
-42.54 & 7.50 & 26.0 & -5.67 & $<0.001$ \\
-6.72 & 10.60 & 26.0 & -0.63 & 0.532 \\
35.81 & 10.60 & 26.0 & 3.38 & 0.002 \\
-0.94 & 5.38 & 26.0 & -0.18 & 0.862 \\
-1.08 & 6.34 & 26.0 & -0.17 & 0.867 \\
-0.13 & 6.70 & 26.0 & -0.02 & 0.985 \\
-4.64 & 5.93 & 26.0 & -0.78 & 0.441 \\
-1.15 & 6.49 & 26.0 & -0.18 & 0.861 \\
3.49 & 7.01 & 26.0 & 0.50 & 0.623 \\
\hline
\end{tabular}


Appendix 9: Cumulative list of waterbirds (individuals/39.25 ha plot) with their means and standard errors (SE) for Blennerhassett, Buckley, and Muskingum islands, West Virginia, USA for the 2007-2009 field seasons.

\begin{tabular}{|c|c|c|c|c|c|c|c|}
\hline \multirow{2}{*}{ Common Name } & \multirow{2}{*}{ Scientific Name } & \multicolumn{2}{|c|}{ Blennerhassett } & \multicolumn{2}{|c|}{ Buckley } & \multicolumn{2}{|c|}{ Muskingum } \\
\hline & & $\bar{x}$ & SE & $\bar{x}$ & SE & $\bar{x}$ & SE \\
\hline American Black Duck & Anas rubripes Brewster & 0.00 & 0.00 & 0.00 & 0.00 & 0.05 & 0.05 \\
\hline American Coot & Fulica americana Gmelin & 0.14 & 0.14 & 0.00 & 0.00 & 0.14 & 0.14 \\
\hline Belted Kingfisher & Megaceryle alcyon Linnaeus & 0.18 & 0.08 & 0.05 & 0.05 & 0.27 & 0.12 \\
\hline Bonaparte's Gull & Chroicocephalus philadelphia Ord & 0.00 & 0.00 & 0.00 & 0.00 & 0.05 & 0.05 \\
\hline Bufflehead & Bucephala albeola Linnaeus & 0.00 & 0.00 & 0.00 & 0.00 & 0.59 & 0.44 \\
\hline Canada Goose & Branta canadensis Linnaeus & 28.59 & 8.12 & 6.86 & 2.46 & 10.32 & 2.52 \\
\hline Common Loon & Gavia immer Brunnich & 0.00 & 0.00 & 0.00 & 0.00 & 0.18 & 0.13 \\
\hline Double-crested Cormorant & Phalacrocorax auritus Lesson & 0.09 & 0.09 & 0.00 & 0.00 & 1.18 & 1.00 \\
\hline Great Blue Heron & Ardea herodias Linnaeus & 0.32 & 0.12 & 0.09 & 0.06 & 1.23 & 0.39 \\
\hline Hooded Merganser & Lophodytes cucullatus Linnaeus & 0.23 & 0.23 & 0.00 & 0.00 & 0.41 & 0.33 \\
\hline Horned Grebe & Podiceps auritus Linnaeus & 0.00 & 0.00 & 0.00 & 0.00 & 1.18 & 1.18 \\
\hline Killdeer & Charadrius vociferus Linnaeus & 0.05 & 0.05 & 0.00 & 0.00 & 0.23 & 0.16 \\
\hline Lesser Scaup & Aythya affinis Eyton & 0.64 & 0.64 & 0.00 & 0.00 & 0.05 & 0.05 \\
\hline Mallard & Anas platyrhynchos Linnaeus & 2.50 & 0.81 & 0.64 & 0.29 & 2.50 & 0.57 \\
\hline Osprey & Pandion haliaetus Savigny & 0.00 & 0.00 & 0.05 & 0.05 & 0.00 & 0.00 \\
\hline Pied-billed Grebe & Podilymbus podiceps Linnaeus & 0.14 & 0.10 & 0.05 & 0.05 & 0.14 & 0.07 \\
\hline Ring-billed Gull & Larus delawarensis Ord & 0.00 & 0.00 & 0.18 & 0.18 & 0.00 & 0.00 \\
\hline Spotted Sandpiper & Actitis macularia Linnaeus & 0.00 & 0.00 & 0.00 & 0.00 & 0.45 & 0.22 \\
\hline Wood Duck & Aix sponsa Linnaeus & 0.91 & 0.35 & 0.91 & 0.55 & 0.64 & 0.30 \\
\hline
\end{tabular}


Appendix 10: List of additional waterbirds and the number detected within the study area but not during survey hours for Blennerhassett, Buckley, and Muskingum islands, West Virginia, USA during the 2007-2009 field seasons.

\begin{tabular}{|c|c|c|c|c|}
\hline Common Name & Scientific Name & Blennerhassett & Buckley & Muskingum \\
\hline American White Pelican & Pelecanus erythrorhynchos Gmelin & 0 & 1 & 0 \\
\hline American Wigeon & Anas americana Gmelin & 0 & 3 & 0 \\
\hline Black-crowned Night Heron & Nycticorax nycticorax Linnaeus & 1 & 0 & 0 \\
\hline Canvasback & Aythya valisineria Wilson & 0 & 1 & 0 \\
\hline Common Goldeneye & Bucephala ciangula Linnaeus & 0 & 2 & 3 \\
\hline Common Tern & Sterna hirundo Linnaeus & 1 & 0 & 0 \\
\hline Glossy Ibis & Plegadis falcinellus Linnaeus & 0 & 1 & 0 \\
\hline Great Egret & Ardea alba Linnaeus & 2 & 0 & 0 \\
\hline Greater Yellowlegs & Tringa melanoleuca Gmelin & 0 & 1 & 0 \\
\hline Green Heron & Butorides virescens Linnaeus & 4 & 0 & 0 \\
\hline Herring Gull & Larus argentatus Pontoppidan & 1 & 4 & 6 \\
\hline Red-breasted Merganser & Mergus serrator Linnaeus & 2 & 0 & 0 \\
\hline Ring-necked Duck & Aythya collaris Donovan & 2 & 0 & 0 \\
\hline Tundra Swan & Cygnus columbianus Ord & 1 & 0 & 0 \\
\hline Wilson's Snipe & Gallinago delicata Ord & 0 & 0 & 1 \\
\hline
\end{tabular}


Appendix 11: Cumulative list of songbirds (individuals/ha) with their means and standard errors (SE) for Blennerhassett, Buckley, and Muskingum islands, West Virginia, USA for the 2008-2009 field seasons (46 species (bolded) for sites and 44 species (represented by asterisk) for distance occurred 3 or more times and were used in the PERMANOVA and multi response permutations procedures analyses).

\begin{tabular}{|c|c|c|c|c|c|c|c|}
\hline \multirow{2}{*}{ Common Name } & \multirow{2}{*}{ Scientific Name } & \multicolumn{2}{|c|}{ Blennerhassett } & \multicolumn{2}{|c|}{ Buckley } & \multicolumn{2}{|c|}{ Muskingum } \\
\hline & & $\bar{x}$ & SE & $\bar{x}$ & SE & $\bar{x}$ & SE \\
\hline Acadian Flycatcher* & Empidonax virescens Vieillot & 0.16 & 0.06 & 0.29 & 0.07 & 0.29 & 0.11 \\
\hline American Goldfinch* & Spinus tristis Linnaeus & 0.38 & 0.08 & 0.60 & 0.12 & 0.42 & 0.16 \\
\hline American Redstart* & Setophaga ruticilla Linnaeus & 0.02 & 0.02 & 0.08 & 0.04 & 0.29 & 0.13 \\
\hline American Robin* & Turdus migratorius Linnaeus & 0.82 & 0.14 & 0.94 & 0.16 & 0.67 & 0.20 \\
\hline Baltimore Oriole* & Icterus galbula Linnaeus & 0.04 & 0.03 & 0.04 & 0.03 & 0.00 & 0.00 \\
\hline Black-and-white Warbler & Mniotilta varia Linnaeus & 0.00 & 0.00 & 0.02 & 0.02 & 0.04 & 0.04 \\
\hline Blue Jay* & Cyanocitta cristata Linnaeus & 0.20 & 0.07 & 0.08 & 0.04 & 0.33 & 0.10 \\
\hline Blue-gray Gnatcatcher* & Polioptila caerulea Linnaeus & 0.20 & 0.06 & 0.21 & 0.07 & 0.42 & 0.13 \\
\hline Blue-winged Warbler & Vermivora pinus Linnaeus & 0.04 & 0.03 & 0.00 & 0.00 & 0.00 & 0.00 \\
\hline Brown Thrasher* & Toxostoma rufum Linnaeus & 0.04 & 0.03 & 0.02 & 0.02 & 0.00 & 0.00 \\
\hline Brown-headed Cowbird* & Molothrus ater Boddaert & 0.11 & 0.04 & 0.42 & 0.16 & 0.17 & 0.08 \\
\hline Carolina Chickadee* & Poecile carolinensis Audubon & 0.33 & 0.10 & 0.21 & 0.07 & 1.13 & 0.28 \\
\hline Carolina Wren* & Thryothorus ludovicianus Latham & 0.84 & 0.13 & 0.73 & 0.15 & 1.33 & 0.14 \\
\hline Cedar Waxwing* & Bombycilla cedrorum Vieillot & 0.18 & 0.06 & 0.25 & 0.09 & 0.13 & 0.09 \\
\hline Cliff Swallow* & Petrochelidon pyrrhonota Vieillot & 0.00 & 0.00 & 0.77 & 0.31 & 0.00 & 0.00 \\
\hline Common Grackle* & Quiscalus quiscula Linnaeus & 0.22 & 0.07 & 0.08 & 0.04 & 0.04 & 0.04 \\
\hline Common Yellowthroat* & Geothlypis trichas Linnaeus & 0.58 & 0.10 & 0.23 & 0.07 & 0.33 & 0.13 \\
\hline Downy Woodpecker* & Picoides pubescens Linnaeus & 0.18 & 0.06 & 0.19 & 0.07 & 0.67 & 0.16 \\
\hline Eastern Bluebird* & Sialia sialis Linnaeus & 0.15 & 0.08 & 0.02 & 0.02 & 0.08 & 0.06 \\
\hline
\end{tabular}


Appendix 11 Continued

\begin{tabular}{|c|c|c|c|c|c|c|c|}
\hline Eastern Kingbird & Tyrannus tyrannus Linnaeus & 0.13 & 0.08 & 0.00 & 0.00 & 0.00 & 0.00 \\
\hline Eastern Meadowlark & Sturnella magna Linnaeus & 0.00 & 0.00 & 0.00 & 0.00 & 0.08 & 0.08 \\
\hline Eastern Phoebe* & Sayornis phoebe Latham & 0.22 & 0.06 & 0.04 & 0.03 & 0.13 & 0.09 \\
\hline Eastern Towhee* & Pipilo erythrophthalmus Linnaeus & 0.04 & 0.03 & 0.19 & 0.08 & 1.08 & 0.18 \\
\hline Eastern Wood-Pewee* & Contopus virens Linnaeus & 0.04 & 0.03 & 0.06 & 0.04 & 0.25 & 0.11 \\
\hline European Starling* & Sturnus vulgaris Linnaeus & 0.25 & 0.14 & 1.15 & 0.49 & 0.04 & 0.04 \\
\hline Field Sparrow & Spizella pusilla Wilson & 0.00 & 0.00 & 0.02 & 0.02 & 0.08 & 0.06 \\
\hline Gray Catbird* & Dumetella carolinensis Linnaeus & 0.78 & 0.11 & 1.38 & 0.17 & 1.50 & 0.21 \\
\hline Hairy Woodpecker* & Picoides villosus Linnaeus & 0.02 & 0.02 & 0.13 & 0.06 & 0.04 & 0.04 \\
\hline House Finch* & Carpodacus mexicanus Muller & 0.00 & 0.00 & 0.21 & 0.08 & 0.00 & 0.00 \\
\hline House Sparrow & Passer domesticus Linnaeus & 0.00 & 0.00 & 0.02 & 0.02 & 0.00 & 0.00 \\
\hline House Wren* & Troglodytes aedon Vieillot & 0.82 & 0.15 & 0.31 & 0.09 & 0.29 & 0.13 \\
\hline Indigo Bunting* & Passerina cyanea Linnaeus & 0.55 & 0.10 & 0.60 & 0.10 & 0.96 & 0.15 \\
\hline Kentucky Warbler & Oporornis formosus Wilson & 0.02 & 0.02 & 0.00 & 0.00 & 0.00 & 0.00 \\
\hline Mourning Dove* & Zenaida macroura Linnaeus & 0.15 & 0.05 & 1.25 & 0.85 & 0.08 & 0.06 \\
\hline Northern Cardinal* & Cardinalis cardinalis Linnaeus & 0.62 & 0.10 & 0.90 & 0.16 & 1.21 & 0.19 \\
\hline Northern Flicker* & Colaptes auratus Linnaeus & 0.13 & 0.06 & 0.23 & 0.06 & 0.29 & 0.09 \\
\hline Northern Mockingbird* & Mimus polyglottos Linnaeus & 0.05 & 0.03 & 0.06 & 0.04 & 0.00 & 0.00 \\
\hline Northern Parula & Parula americana Linnaeus & 0.00 & 0.00 & 0.02 & 0.02 & 0.00 & 0.00 \\
\hline Northern Rough-winged Swallow* & Stelgidopteryx serripennis Audubon & 0.05 & 0.04 & 0.06 & 0.05 & 0.04 & 0.04 \\
\hline Orchard Oriole* & Icterus spurius Linnaeus & 0.25 & 0.07 & 0.06 & 0.05 & 0.08 & 0.06 \\
\hline Pileated Woodpecker & Dryocopus pileatus Linnaeus & 0.00 & 0.00 & 0.04 & 0.03 & 0.00 & 0.00 \\
\hline Prothonotary Warbler* & Protonotaria citrea Boddaert & 0.11 & 0.05 & 0.00 & 0.00 & 0.04 & 0.04 \\
\hline Red-bellied Woodpecker* & Melanerpes carolinus Linnaeus & 0.13 & 0.05 & 0.13 & 0.05 & 0.46 & 0.13 \\
\hline
\end{tabular}


Appendix 11 Continued

\begin{tabular}{|c|c|c|c|c|c|c|c|}
\hline Red-eyed Vireo* & Vireo olivaceus Linnaeus & 0.16 & 0.06 & 0.54 & 0.09 & 0.79 & 0.13 \\
\hline Red-winged Blackbird* & Agelaius phoeniceus Linnaeus & 1.35 & 0.31 & 0.15 & 0.05 & 0.21 & 0.10 \\
\hline Rock Pigeon* & Columba livia Gmelin & 0.29 & 0.12 & 0.90 & 0.29 & 0.00 & 0.00 \\
\hline Ruby-throated Hummingbird & Archilochus colubris Linnaeus & 0.00 & 0.00 & 0.02 & 0.02 & 0.00 & 0.00 \\
\hline Scarlet Tanager & Piranga olivacea Gmelin & 0.02 & 0.02 & 0.02 & 0.02 & 0.04 & 0.04 \\
\hline Song Sparrow* & Melospiza melodia Wilson & 2.91 & 0.21 & 1.79 & 0.20 & 1.83 & 0.26 \\
\hline Tufted Titmouse* & Baeolophus bicolor Linnaeus & 0.20 & 0.05 & 0.29 & 0.07 & 1.13 & 0.23 \\
\hline Warbling Vireo & Vireo gilvus Vieillot & 0.00 & 0.00 & 0.02 & 0.02 & 0.04 & 0.04 \\
\hline White-breasted Nuthatch* & Sitta carolinensis Latham & 0.05 & 0.03 & 0.06 & 0.04 & 0.38 & 0.12 \\
\hline White-eyed Vireo* & Vireo griseus Boddaert & 0.09 & 0.05 & 0.04 & 0.03 & 0.04 & 0.04 \\
\hline Willow Flycatcher* & Empidonax traillii Audubon & 0.24 & 0.08 & 0.17 & 0.07 & 0.00 & 0.00 \\
\hline Wood Thrush* & Hylocichla mustelina Gmelin & 0.18 & 0.06 & 0.04 & 0.03 & 0.50 & 0.15 \\
\hline Yellow Warbler* & Dendroica petechia Linnaeus & 0.25 & 0.07 & 0.65 & 0.13 & 0.17 & 0.08 \\
\hline Yellow-billed Cuckoo & Coccyzus americanus Linnaeus & 0.02 & 0.02 & 0.00 & 0.00 & 0.00 & 0.00 \\
\hline Yellow-breasted Chat & Icteria virens Linnaeus & 0.00 & 0.00 & 0.08 & 0.04 & 0.00 & 0.00 \\
\hline Yellow-throated Vireo & Vireo flavifrons Vieillot & 0.02 & 0.02 & 0.00 & 0.00 & 0.00 & 0.00 \\
\hline Yellow-throated Warbler & Dendroica dominica Linnaeus & 0.00 & 0.00 & 0.02 & 0.02 & 0.00 & 0.00 \\
\hline
\end{tabular}


Appendix 12: Summary of simple effects analysis for four songbird variables (all songbirds, Carolina Chickadee, House Wren, and Rock Pigeon) that had a significant site by distance interaction for Blennerhassett, Buckley, and Muskingum islands, West Virginia, USA and at 0,100 , and $300 \mathrm{~m}$ from the bridge (bolded values indicate significant contrasts of simple effects at $\alpha=0.05$ ) with the estimate, standard error (SE), degrees of freedom (df), t-value, and P-value $(P)$.

\begin{tabular}{|c|c|c|c|c|c|}
\hline Soil Variable & Estimate & SE & $\mathrm{df}$ & $\mathrm{t}$ value & $P$ \\
\hline \multicolumn{6}{|l|}{ All Songbirds } \\
\hline Blennerhassett $0 \mathrm{~m}$ vs. Blennerhassett $100 \mathrm{~m}$ & -4.54 & 2.15 & 57.9 & -2.11 & 0.039 \\
\hline Blennerhassett $0 \mathrm{~m}$ vs. Blennerhassett $300 \mathrm{~m}$ & -4.44 & 2.15 & $\mathbf{5 7 . 0}$ & -2.06 & 0.045 \\
\hline Blennerhassett $100 \mathrm{~m}$ vs. Blennerhassett $300 \mathrm{~m}$ & 0.10 & 1.76 & 57.9 & 0.05 & 0.957 \\
\hline Buckley $0 \mathrm{~m}$ vs. Buckley $100 \mathrm{~m}$ & 5.00 & 2.17 & 53.7 & 2.31 & 0.025 \\
\hline Buckley 0 m vs. Buckley 300 m & 2.50 & 2.26 & 53.7 & 1.10 & 0.275 \\
\hline Buckley 100 m vs. Buckley 300 m & -2.50 & 1.99 & 53.7 & -1.26 & 0.214 \\
\hline Muskingum $0 \mathrm{~m}$ vs. Muskingum $100 \mathrm{~m}$ & 3.32 & 3.51 & 53.7 & 0.95 & 0.348 \\
\hline Muskingum $0 \mathrm{~m}$ vs. Muskingum $300 \mathrm{~m}$ & 2.62 & 3.51 & 53.7 & 0.75 & 0.458 \\
\hline Muskingum 100 m vs. Muskingum 300 m & -.70 & 2.65 & 53.7 & -0.26 & 0.793 \\
\hline Blennerhassett $0 \mathrm{~m}$ vs. Buckley $0 \mathrm{~m}$ & -9.02 & 2.45 & 55.8 & -3.67 & 0.001 \\
\hline Blennerhassett $0 \mathrm{~m}$ vs. Muskingum $0 \mathrm{~m}$ & -9.27 & 3.45 & 54.7 & -2.69 & 0.010 \\
\hline Buckley $0 \mathrm{~m}$ vs. Muskingum $0 \mathrm{~m}$ & -0.25 & 3.42 & 53.7 & -0.07 & 0.942 \\
\hline Blennerhassett $100 \mathrm{~m}$ vs. Buckley $100 \mathrm{~m}$ & 0.52 & 1.82 & 55.7 & 0.29 & 0.775 \\
\hline Blennerhassett $100 \mathrm{~m}$ vs. Muskingum $100 \mathrm{~m}$ & -1.40 & 2.25 & 54.9 & -0.62 & 0.535 \\
\hline Buckley 100 m vs. Muskingum 100 m & -1.93 & 2.29 & 53.7 & -0.84 & 0.405 \\
\hline Blennerhassett $300 \mathrm{~m}$ vs. Buckley $300 \mathrm{~m}$ & -2.07 & 1.94 & 55.4 & -1.07 & 0.289 \\
\hline Blennerhassett 300 m vs. Muskingum 300 m & -2.20 & 2.25 & 54.9 & -0.98 & 0.333 \\
\hline Buckley 300 m vs. Muskingum 300 m & -0.13 & 2.39 & 53.7 & -0.05 & 0.957 \\
\hline
\end{tabular}


Appendix 12 Continued

\section{Carolina Chickadee}

Blennerhassett $0 \mathrm{~m}$ vs. Blennerhassett $100 \mathrm{~m}$

\begin{tabular}{rrrrr}
-0.36 & 0.29 & 59.6 & -1.26 & 0.211 \\
-0.23 & 0.29 & 59.6 & -0.78 & 0.438 \\
0.14 & 0.24 & 59.6 & 0.59 & 0.556 \\
0.00 & 0.29 & 54.5 & 0.00 & 1.000 \\
0.13 & 0.30 & 54.5 & 0.42 & 0.678 \\
0.13 & 0.26 & 54.5 & 0.48 & 0.636 \\
1.74 & $\mathbf{0 . 4 6}$ & $\mathbf{5 4 . 5}$ & $\mathbf{3 . 7 5}$ & $<\mathbf{0 . 0 0 1}$ \\
$\mathbf{1 . 6 4}$ & $\mathbf{0 . 4 6}$ & $\mathbf{5 4 . 5}$ & $\mathbf{3 . 5 3}$ & $\mathbf{0 . 0 0 1}$ \\
-0.10 & 0.35 & 54.5 & -0.29 & 0.777 \\
-0.18 & 0.33 & 57.1 & -0.54 & 0.590 \\
$-\mathbf{2 . 4 3}$ & $\mathbf{0 . 4 6}$ & $\mathbf{5 5 . 9}$ & -5.31 & $<0.001$ \\
$\mathbf{- 2 . 2 5}$ & $\mathbf{0 . 4 5}$ & $\mathbf{5 4 . 5}$ & $-\mathbf{4 . 9 7}$ & $<\mathbf{0 . 0 0 1}$ \\
0.19 & 0.24 & 57.0 & 0.78 & 0.441 \\
-0.32 & 0.30 & 56.0 & -1.08 & 0.284 \\
-0.51 & 0.30 & 54.5 & -1.68 & 0.098 \\
0.17 & 0.26 & 56.7 & 0.67 & 0.504 \\
-0.56 & 0.30 & 56.0 & -1.88 & 0.065 \\
-0.74 & $\mathbf{0 . 3 2}$ & $\mathbf{5 4 . 5}$ & $\mathbf{- 2 . 3 3}$ & $\mathbf{0 . 0 2 4}$ \\
& & & & \\
0.72 & 0.38 & 55.0 & 1.89 & 0.064 \\
$\mathbf{1 . 1 5}$ & $\mathbf{0 . 3 8}$ & $\mathbf{5 5 . 0}$ & $\mathbf{3 . 0 2}$ & $\mathbf{0 . 0 0 4}$ \\
0.43 & 0.31 & 55.0 & 1.39 & 0.172 \\
-0.45 & 0.39 & 51.7 & -1.16 & 0.250 \\
\hline & & & &
\end{tabular}


Appendix 12 Continued

Buckley 0 m vs. Buckley 300 m

$-0.38$

0.08

0.41

51.7

$-0.93$

0.08

Muskingum $0 \mathrm{~m}$ vs. Muskingum $100 \mathrm{~m}$

0.26

Muskingum $0 \mathrm{~m}$ vs. Muskingum $300 \mathrm{~m}$

Muskingum $100 \mathrm{~m}$ vs. Muskingum $300 \mathrm{~m}$

$-0.34$

$-0.60$

Blennerhassett $0 \mathrm{~m}$ vs. Buckley $\mathbf{0} \mathrm{m}$

1.57

Blennerhassett $0 \mathrm{~m}$ vs. Muskingum $0 \mathrm{~m}$

1.32

Buckley $0 \mathrm{~m}$ vs. Muskingum $0 \mathrm{~m}$

Blennerhassett $100 \mathrm{~m}$ vs. Buckley $100 \mathrm{~m}$

$-0.25$

0.39

Blennerhassett $100 \mathrm{~m}$ vs. Muskingum $100 \mathrm{~m}$

Buckley $100 \mathrm{~m}$ vs. Muskingum $100 \mathrm{~m}$

0.85

0.46

Blennerhassett $300 \mathrm{~m}$ vs. Buckley $300 \mathrm{~m}$

Blennerhassett $300 \mathrm{~m}$ vs. Muskingum $300 \mathrm{~m}$

Buckley 300 m vs. Muskingum 300 m

0.04

$-0.18$

$-0.22$

0.36

51.7

$-0.93$

0.359

0.63

51.8

0.21

0.834

0.63

51.8

0.41

0.683

$\begin{array}{llll}0.47 & 51.9 & -1.26 & 0.218\end{array}$

Rock Pigeon

Blennerhassett $0 \mathrm{~m}$ vs. Blennerhassett $100 \mathrm{~m}$

Blennerhassett $0 \mathrm{~m}$ vs. Blennerhassett $300 \mathrm{~m}$

Blennerhassett $100 \mathrm{~m}$ vs. Blennerhassett $300 \mathrm{~m}$

Buckley $0 \mathrm{~m}$ vs. Buckley $100 \mathrm{~m}$

Buckley $0 \mathrm{~m}$ vs. Buckley $300 \mathrm{~m}$

Buckley $100 \mathrm{~m}$ vs. Buckley $300 \mathrm{~m}$

Muskingum $0 \mathrm{~m}$ vs. Muskingum $100 \mathrm{~m}$

Muskingum $0 \mathrm{~m}$ vs. Muskingum $300 \mathrm{~m}$

Muskingum $100 \mathrm{~m}$ vs. Muskingum $300 \mathrm{~m}$

\begin{tabular}{rrrrr}
$\mathbf{1 . 4 4}$ & $\mathbf{0 . 3 7}$ & $\mathbf{5 9 . 0}$ & $\mathbf{3 . 8 6}$ & $<\mathbf{0 . 0 0 1}$ \\
$\mathbf{1 . 4 4}$ & $\mathbf{0 . 3 7}$ & $\mathbf{5 9 . 0}$ & $\mathbf{3 . 8 6}$ & $<\mathbf{0 . 0 0 1}$ \\
0.00 & 0.30 & 59.0 & 0.00 & 1.000 \\
$\mathbf{3 . 5 8}$ & $\mathbf{0 . 3 7}$ & $\mathbf{5 4 . 0}$ & $\mathbf{9 . 6 9}$ & $<\mathbf{0 . 0 0 1}$ \\
$\mathbf{3 . 5 8}$ & $\mathbf{0 . 3 9}$ & $\mathbf{5 4 . 0}$ & $\mathbf{9 . 2 7}$ & $<\mathbf{0 . 0 0 1}$ \\
0.00 & 0.34 & 54.0 & -0.00 & 1.000 \\
0.00 & 0.60 & 54.0 & 0.01 & 0.995 \\
0.00 & 0.60 & 54.0 & 0.01 & 0.995 \\
0.00 & 0.45 & 54.0 & 0.00 & 1.000 \\
\hline
\end{tabular}


Appendix 12 Continued

Blennerhassett $0 \mathrm{~m}$ vs. Buckley $0 \mathrm{~m}$

\begin{tabular}{rrrrr}
$\mathbf{- 2 . 1 5}$ & $\mathbf{0 . 4 2}$ & $\mathbf{5 6 . 6}$ & $\mathbf{- 5 . 1 0}$ & $<\mathbf{0 . 0 0 1}$ \\
$\mathbf{1 . 4 3}$ & $\mathbf{0 . 5 9}$ & $\mathbf{5 5 . 3}$ & $\mathbf{2 . 4 3}$ & $\mathbf{0 . 0 1 8}$ \\
$\mathbf{3 . 5 8}$ & $\mathbf{0 . 5 8}$ & $\mathbf{5 4 . 0}$ & $\mathbf{6 . 1 3}$ & $<\mathbf{0 . 0 0 1}$ \\
0.00 & 0.31 & 56.4 & -0.00 & 0.996 \\
0.00 & 0.39 & 55.4 & 0.01 & 0.996 \\
0.00 & 0.39 & 54.0 & 0.01 & 0.993 \\
-0.00 & 0.33 & 56.1 & -0.00 & 0.997 \\
0.00 & 0.39 & 55.4 & 0.01 & 0.996 \\
0.00 & 0.41 & 54.0 & 0.01 & 0.993 \\
\hline
\end{tabular}


Appendix 13: Summary of total turtle individuals (TI) and total captures (TC) for Blennerhassett, Buckley, Muskingum, and Grape islands, West Virginia, USA for the 2008 and 2009 field seasons.

\begin{tabular}{|c|c|c|c|c|c|c|c|c|c|}
\hline \multirow{2}{*}{ Common Name } & \multirow{2}{*}{ Scientific Name } & \multicolumn{2}{|c|}{ Blennerhassett } & \multicolumn{2}{|c|}{ Buckley } & \multicolumn{2}{|c|}{ Muskingum } & \multicolumn{2}{|c|}{ Grape } \\
\hline & & TI & TC & $\mathrm{TI}$ & TC & TI & TC & TI & $\mathrm{TC}$ \\
\hline Eastern Spiny Softshell & Apalone spinifera spinifera Lesueur & 18 & 18 & 10 & 10 & 10 & 10 & 8 & 8 \\
\hline Common Snapping Turtle & Chelydra serpentina Linnaeus & 13 & 15 & 1 & 2 & 5 & 5 & 12 & 17 \\
\hline Northern Map Turtle & Graptemys geographica Le Suer & 5 & 5 & 1 & 1 & 0 & 0 & 0 & 0 \\
\hline Midland Painted Turtle & Chrysemys picta marginata Agassiz & 4 & 4 & 0 & 0 & 0 & 0 & 0 & 0 \\
\hline Stinkpot & Sternotherus odoratus Latrielle & 0 & 0 & 1 & 1 & 0 & 0 & 0 & 0 \\
\hline Total & & 40 & 42 & 13 & 14 & 15 & 15 & 20 & 25 \\
\hline
\end{tabular}


Appendix 14: Summary of total small mammal individuals (TI) and total captures (TC) for Blennerhassett, Buckley, and Muskingum islands, West Virginia, USA for the 2008 and 2009 field seasons.

\begin{tabular}{|c|c|c|c|c|c|c|c|}
\hline \multirow{2}{*}{ Common Name } & \multirow{2}{*}{ Scientific Name } & \multicolumn{2}{|c|}{ Blennerhassett } & \multicolumn{2}{|c|}{ Buckley } & \multicolumn{2}{|c|}{ Muskingum } \\
\hline & & TI & TC & $\mathrm{TI}$ & TC & TI & TC \\
\hline Deer mouse & Peromyscus maniculatus Wagner & 162 & 327 & 31 & 45 & 55 & 76 \\
\hline White-footed mouse & Peromyscus leucopus Rafinesque & 188 & 323 & 18 & 26 & 37 & 67 \\
\hline Meadow vole & Microtus pennsy/vanicus Ord & 97 & 102 & 89 & 95 & 0 & 0 \\
\hline House mouse & Mus musculus Linnaeus & 0 & 0 & 16 & 22 & 0 & 0 \\
\hline Northern short-tailed shrew & Blarina brevicauda Say & 3 & 3 & 6 & 6 & 5 & 5 \\
\hline Eastern chipmunk & Tamias striatus Linnaeus & 3 & 3 & 18 & 18 & 2 & 2 \\
\hline Norway rat & Rattus norvegicus Berkenhout & 1 & 2 & 0 & 0 & 0 & 0 \\
\hline Southern flying squirrel & Glaucomys volans Linnaeus & 1 & 1 & 0 & 0 & 0 & 0 \\
\hline Red squirrel & Tamiasciurus hudsonicus Erxleben & 0 & 0 & 1 & 1 & 0 & 0 \\
\hline Totals & & 455 & 761 & 179 & 213 & 99 & 150 \\
\hline
\end{tabular}


Appendix 15: Summary of simple effects analysis for three small mammal variables (Peromyscus spp., species richness, Shannon Diversity Index) that had a significant site by distance interaction for Blennerhassett, Buckley, and Muskingum islands, West Virginia, USA and at 0,100 , and $300 \mathrm{~m}$ from the bridge (bolded values indicate significant contrasts of simple effects at $\alpha=0.05$ ) with the estimate, standard error (SE), degrees of freedom (df), t-value, and P-value $(P)$.

\begin{tabular}{|c|c|c|c|c|c|}
\hline Soil Variable & Estimate & SE & $\mathrm{df}$ & $\mathrm{t}$ value & $P$ \\
\hline \multicolumn{6}{|l|}{ Peromyscus spp. } \\
\hline Blennerhassett $0 \mathrm{~m}$ vs. Blennerhassett $100 \mathrm{~m}$ & -6.11 & 1.67 & 50.4 & -3.66 & 0.001 \\
\hline Blennerhassett $0 \mathrm{~m}$ vs. Blennerhassett $300 \mathrm{~m}$ & -5.50 & 1.67 & 50.4 & -3.30 & 0.002 \\
\hline Blennerhassett $100 \mathrm{~m}$ vs. Blennerhassett $300 \mathrm{~m}$ & 0.61 & 1.36 & 50.4 & 0.45 & 0.657 \\
\hline Buckley $0 \mathrm{~m}$ vs. Buckley $100 \mathrm{~m}$ & 1.01 & 1.66 & 45.8 & 0.61 & 0.546 \\
\hline Buckley 0 m vs. Buckley 300 m & 0.98 & 1.74 & 45.8 & 0.56 & 0.577 \\
\hline Buckley 100 m vs. Buckley 300 m & -0.03 & 1.53 & 45.8 & -0.02 & 0.983 \\
\hline Muskingum $0 \mathrm{~m}$ vs. Muskingum $100 \mathrm{~m}$ & 1.16 & 2.65 & 47.0 & 0.44 & 0.666 \\
\hline Muskingum $0 \mathrm{~m}$ vs. Muskingum $300 \mathrm{~m}$ & 0.96 & 2.65 & 46.0 & 0.36 & 0.719 \\
\hline Muskingum 100 m vs. Muskingum 300 m & -0.19 & 1.92 & 50.4 & -0.10 & 0.921 \\
\hline Blennerhassett $0 \mathrm{~m}$ vs. Buckley $0 \mathrm{~m}$ & -1.10 & 1.89 & 48.1 & -0.58 & 0.565 \\
\hline Blennerhassett $0 \mathrm{~m}$ vs. Muskingum $0 \mathrm{~m}$ & -3.45 & 2.65 & 47.0 & -1.30 & 0.200 \\
\hline Buckley $0 \mathrm{~m}$ vs. Muskingum $0 \mathrm{~m}$ & -2.35 & 2.63 & 45.8 & -0.89 & 0.376 \\
\hline Blennerhassett $100 \mathrm{~m}$ vs. Buckley $100 \mathrm{~m}$ & 6.02 & 1.40 & 47.9 & 4.30 & $<0.001$ \\
\hline Blennerhassett $100 \mathrm{~m}$ vs. Muskingum $100 \mathrm{~m}$ & 3.81 & 1.67 & 50.4 & 2.29 & 0.027 \\
\hline Buckley 100 m vs. Muskingum 100 m & -2.21 & 1.70 & 48.7 & -1.30 & 0.199 \\
\hline Blennerhassett $300 \mathrm{~m}$ vs. Buckley $300 \mathrm{~m}$ & 5.38 & 1.49 & 47.7 & 3.61 & 0.001 \\
\hline Blennerhassett 300 m vs. Muskingum 300 m & 3.01 & 1.67 & 50.4 & 1.81 & 0.077 \\
\hline Buckley 300 m vs. Muskingum 300 m & -2.37 & 1.78 & 48.5 & -1.34 & 0.188 \\
\hline
\end{tabular}


Appendix 15 Continued

Species Richness

Blennerhassett $0 \mathrm{~m}$ vs. Blennerhassett $100 \mathrm{~m}$

\begin{tabular}{rrrrr}
$-\mathbf{- 1 . 2 2}$ & $\mathbf{0 . 2 8}$ & $\mathbf{7 4 . 5}$ & $-\mathbf{4 . 3 3}$ & $<\mathbf{0 . 0 0 1}$ \\
$-\mathbf{1 . 1 8}$ & $\mathbf{0 . 2 8}$ & $\mathbf{7 4 . 5}$ & -4.18 & $<0.001$ \\
0.04 & 0.23 & 74.5 & 0.18 & 0.855 \\
0.41 & 0.27 & 66.0 & 1.52 & 0.134 \\
$\mathbf{0 . 6 1}$ & $\mathbf{0 . 2 8}$ & $\mathbf{6 6 . 0}$ & $\mathbf{2 . 1 8}$ & $\mathbf{0 . 0 3 3}$ \\
0.20 & 0.25 & 66.0 & 0.82 & 0.413 \\
-0.09 & 0.44 & 68.3 & -0.23 & 0.819 \\
-0.14 & 0.44 & 68.3 & -0.32 & 0.750 \\
-0.04 & 0.33 & 74.5 & -0.12 & 0.904 \\
$-\mathbf{0 . 8 4}$ & $\mathbf{0 . 3 1}$ & $\mathbf{7 0 . 5}$ & $-\mathbf{2 . 6 8}$ & $\mathbf{0 . 0 0 9}$ \\
-0.57 & 0.44 & 68.3 & -1.30 & 0.197 \\
0.27 & 0.43 & 66.0 & 0.64 & 0.523 \\
$\mathbf{0 . 7 9}$ & $\mathbf{0 . 2 3}$ & $\mathbf{7 0 . 1}$ & $\mathbf{3 . 4 1}$ & $\mathbf{0 . 0 0 1}$ \\
0.55 & 0.28 & 74.5 & 1.97 & 0.053 \\
-0.24 & 0.28 & 71.5 & -0.83 & 0.408 \\
$\mathbf{0 . 9 5}$ & $\mathbf{0 . 2 5}$ & $\mathbf{6 9 . 6}$ & $\mathbf{3 . 8 7}$ & $<\mathbf{0 . 0 0 1}$ \\
0.47 & 0.28 & 74.5 & 1.68 & 0.098 \\
-0.48 & 0.30 & 71.1 & -1.62 & 0.109 \\
& & & & \\
$\mathbf{- 0 . 3 3}$ & $\mathbf{0 . 1 1}$ & $\mathbf{7 2 . 4}$ & $\mathbf{- 2 . 9 9}$ & $\mathbf{0 . 0 0 4}$ \\
$\mathbf{- 0 . 3 7}$ & $\mathbf{0 . 1 1}$ & $\mathbf{7 2 . 4}$ & $\mathbf{- 3 . 3 4}$ & $\mathbf{0 . 0 0 1}$ \\
-0.04 & 0.09 & 72.4 & -0.42 & 0.674 \\
0.17 & 0.11 & 0.64 & 1.61 & 0.113 \\
\hline & & & &
\end{tabular}




\begin{tabular}{|c|c|c|c|c|c|}
\hline Buckley $0 \mathrm{~m}$ vs. Buckley $300 \mathrm{~m}$ & 0.23 & 0.11 & 64.0 & 2.08 & 0.042 \\
\hline Buckley 100 m vs. Buckley 300 m & 0.06 & 0.10 & 64.0 & 0.61 & 0.543 \\
\hline Muskingum $0 \mathrm{~m}$ vs. Muskingum $100 \mathrm{~m}$ & -0.02 & 0.17 & 66.2 & -0.10 & 0.918 \\
\hline Muskingum $0 \mathrm{~m}$ vs. Muskingum $300 \mathrm{~m}$ & -0.05 & 0.17 & 66.2 & -0.30 & 0.762 \\
\hline Muskingum 100 m vs. Muskingum 300 m & -0.03 & 0.13 & 72.4 & -0.27 & 0.791 \\
\hline Blennerhassett $0 \mathrm{~m}$ vs. Buckley $0 \mathrm{~m}$ & -0.29 & 0.12 & 68.4 & -2.32 & 0.023 \\
\hline Blennerhassett $0 \mathrm{~m}$ vs. Muskingum $0 \mathrm{~m}$ & -0.13 & 0.17 & 66.2 & -0.75 & 0.455 \\
\hline Buckley $0 \mathrm{~m}$ vs. Muskingum $0 \mathrm{~m}$ & 0.16 & 0.17 & 64.0 & 0.95 & 0.348 \\
\hline Blennerhassett 100 m vs. Buckley 100 m & 0.22 & 0.09 & 68.0 & 2.37 & 0.021 \\
\hline Blennerhassett 100 m vs. Muskingum 100 m & 0.19 & 0.11 & 72.4 & 1.68 & 0.098 \\
\hline Buckley 100 m vs. Muskingum 100 m & -0.03 & 0.11 & 69.4 & -0.27 & 0.790 \\
\hline Blennerhassett 300 m vs. Buckley 300 m & 0.31 & 0.10 & 67.5 & 3.25 & 0.002 \\
\hline Blennerhassett 300 m vs. Muskingum 300 m & 0.19 & 0.11 & 72.4 & 1.72 & 0.091 \\
\hline Buckley 300 m vs. Muskingum 300 m & -0.12 & 0.12 & 69.0 & -1.06 & 0.292 \\
\hline
\end{tabular}


Appendix 16: Summary of $G$-tests for Raccoon presence and absence for site and distance with $G$ as the $G$-statistic, Williams as the William's correction factor, $G_{\text {adj }}$ as the adjusted $G$-statistic with the William's correction factor, df as the degrees of freedom, and $P$ as the P-value $(\alpha=0.05)$ for Blennerhassett, Buckley, and Muskingum islands, West Virginia, USA for the 2008 and 2009 field seasons.

\begin{tabular}{|c|c|c|c|c|c|}
\hline Stratum & G & Williams & Gadj & df & $P$ \\
\hline Site & 7.49 & 1.01 & 7.39 & 2.00 & 0.025 \\
\hline Blennerhassett Island vs. Buckley Island & 6.50 & 1.33 & 4.88 & 1.00 & 0.027 \\
\hline Blennerhassett Island vs. Muskingum Island & 6.79 & 1.33 & 5.09 & 1.00 & 0.024 \\
\hline Buckley Island vs. Muskingum Island & 0.01 & 1.33 & 0.01 & 1.00 & 0.929 \\
\hline Distance & 7.11 & 1.02 & 7.00 & 2.00 & 0.030 \\
\hline $0 \mathrm{~m}$ vs. $100 \mathrm{~m}$ & 4.48 & 1.30 & 3.46 & 1.00 & 0.063 \\
\hline $0 \mathrm{~m}$ vs. $300 \mathrm{~m}$ & 6.68 & 1.31 & 5.11 & 1.00 & 0.024 \\
\hline $100 \mathrm{~m}$ vs. $300 \mathrm{~m}$ & 0.36 & 1.33 & 0.27 & 1.00 & 0.601 \\
\hline
\end{tabular}


Appendix 17: Summary of $G$-tests for Red Fox presence and absence for site with $G$ as the $G$-statistic, Williams as the William's correction factor, $G_{\text {adj }}$ as the adjusted $G$-statistic with the William's correction factor, df as the degrees of freedom, and $P$ as the Pvalue $(\alpha=0.05)$ for Blennerhassett, Buckley, and Muskingum islands, West Virginia, USA for the 2008 and 2009 field seasons.

\begin{tabular}{|c|c|c|c|c|c|}
\hline Stratum & G & Williams & Gadj & df & $P$ \\
\hline Site & 13.90 & 1.05 & 13.14 & 2 & 0.001 \\
\hline Blennerhassett Island vs. Buckley Island & 7.77 & 1.33 & 5.83 & 1 & 0.016 \\
\hline Blennerhassett Island vs. Muskingum Island & 9.77 & 1.29 & 7.58 & 1 & 0.006 \\
\hline Buckley Island vs. Muskingum Island & 1.64 & 1.29 & 1.28 & 1 & 0.259 \\
\hline
\end{tabular}


Appendix 18: List of all plant species sampled and their means (\% cover for herbs and shrubs and importance values for trees) and standard errors (SE) for Blennerhassett and Buckley islands, West Virginia, USA during Phases II (Pre: 1998-2000) and III (Post: 2007-2009).

\begin{tabular}{|c|c|c|c|c|c|c|c|c|c|}
\hline \multirow{3}{*}{ Common Name } & \multirow{3}{*}{ Scientific Name } & \multicolumn{4}{|c|}{ Blennerhassett Island } & \multicolumn{4}{|c|}{ Buckley Island } \\
\hline & & \multicolumn{2}{|c|}{ Pre } & \multicolumn{2}{|c|}{ Post } & \multicolumn{2}{|c|}{ Pre } & \multicolumn{2}{|c|}{ Post } \\
\hline & & $\bar{x}$ & SE & $\bar{x}$ & SE & $\bar{x}$ & SE & $\bar{x}$ & SE \\
\hline Agrimony & Agrimonia sp. L. & 0.00 & 0.00 & 0.00 & 0.00 & 0.05 & 0.05 & 0.00 & 0.00 \\
\hline American Elm & Ulmus americana $\mathrm{L}$. & 0.00 & 0.00 & 1.26 & 0.96 & 0.00 & 0.00 & 0.00 & 0.00 \\
\hline American Germander & Teuchrium canadense L. & 0.00 & 0.00 & 0.04 & 0.04 & 0.00 & 0.00 & 0.00 & 0.00 \\
\hline American Sycamore & Platanus occidentalis L. & 0.80 & 0.80 & 0.00 & 0.00 & 7.97 & 7.97 & 0.00 & 0.00 \\
\hline Arrowleaf Tearthumb & Polygonum sagittatum L. & 0.00 & 0.00 & 0.00 & 0.00 & 0.00 & 0.00 & 0.13 & 0.09 \\
\hline Aster & Aster sp. L. & 0.00 & 0.00 & 0.29 & 0.25 & 0.00 & 0.00 & 0.00 & 0.00 \\
\hline Barnyard Grass & Echinochloa crusgalli (L.) P. Beauv & 0.00 & 0.00 & 0.00 & 0.00 & 0.80 & 0.80 & 0.04 & 0.04 \\
\hline Beggar-Ticks & Bidens sp. L. & 0.00 & 0.00 & 0.25 & 0.25 & 0.03 & 0.03 & 0.00 & 0.00 \\
\hline Birdsfoot Trefoil & Lotus corniculatus L. & 0.00 & 0.00 & 0.25 & 0.25 & 0.00 & 0.00 & 0.00 & 0.00 \\
\hline Black Cherry & Prunus serotina Ehrh. & 0.00 & 0.00 & 0.00 & 0.00 & 0.64 & 0.55 & 0.00 & 0.00 \\
\hline Black Locust & Robinia pseudoacacia L. & 3.07 & 3.07 & 0.33 & 0.33 & 1.14 & 1.14 & 0.00 & 0.00 \\
\hline Black Medic & Medicago lupulina L. & 0.00 & 0.00 & 0.04 & 0.04 & 0.00 & 0.00 & 0.00 & 0.00 \\
\hline Black Walnut & Juglans nigra L. & 0.00 & 0.00 & 0.00 & 0.00 & 0.00 & 0.00 & 0.51 & 0.33 \\
\hline Blue Vervain & Verbena hastata L. & 0.00 & 0.00 & 0.04 & 0.04 & 0.00 & 0.00 & 0.00 & 0.00 \\
\hline Box Elder & Acer negundo L. & 32.72 & 24.04 & 34.32 & 17.32 & 1.06 & 1.06 & 7.99 & 7.99 \\
\hline Broadleaf Dock & Rumex obtusifolius L. & 0.00 & 0.00 & 0.08 & 0.08 & 0.00 & 0.00 & 0.79 & 0.61 \\
\hline Broad-leaved Cattail & Typha latifolia L. & 0.00 & 0.00 & 0.00 & 0.00 & 0.30 & 0.30 & 0.00 & 0.00 \\
\hline Canada Goldenrod & Solidago canadensis L. & 0.00 & 0.00 & 0.00 & 0.00 & 1.35 & 1.35 & 0.33 & 0.33 \\
\hline
\end{tabular}




\begin{tabular}{|c|c|c|c|c|c|c|c|c|c|}
\hline Canada Thistle & Cirsium arvense (L.) Scop. & 0.00 & 0.00 & 0.00 & 0.00 & 0.00 & 0.00 & 1.63 & 1.07 \\
\hline Canada Wild Rye & Elymus canadensis L. & 0.00 & 0.00 & 0.08 & 0.08 & 0.00 & 0.00 & 0.04 & 0.04 \\
\hline Canadian Horseweed & Conyza canadensis L. & 0.00 & 0.00 & 0.04 & 0.04 & 0.00 & 0.00 & 0.00 & 0.00 \\
\hline Chinquapin Oak & Quercus muehlenbergii Engelm. & 1.16 & 1.16 & 0.00 & 0.00 & 0.00 & 0.00 & 0.00 & 0.00 \\
\hline Clearweed & Pilea pumila L. & 0.00 & 0.00 & 0.04 & 0.04 & 0.00 & 0.00 & 0.04 & 0.04 \\
\hline Common Blue Violet & Viola sororia Willd. & 0.00 & 0.00 & 0.00 & 0.00 & 0.05 & 0.05 & 0.00 & 0.00 \\
\hline Common Burdock & Arctum minus (Hill) Bernh. & 0.00 & 0.00 & 0.00 & 0.00 & 0.28 & 0.22 & 3.00 & 3.00 \\
\hline Common Hackberry & Celtis occidentalis $\mathrm{L}$. & 0.20 & 0.20 & 0.17 & 0.17 & 0.00 & 0.00 & 0.33 & 0.33 \\
\hline Common Mugwort & Artemisia vulgaris $\mathrm{L}$. & 0.00 & 0.00 & 0.25 & 0.25 & 0.00 & 0.00 & 1.00 & 0.90 \\
\hline Common Rush & Juncus effusus L. & 0.00 & 0.00 & 8.58 & 5.51 & 0.00 & 0.00 & 0.00 & 0.00 \\
\hline Cutleaf Blackberry & Rubus laciniatus Willd. & 0.00 & 0.00 & 0.00 & 0.00 & 0.00 & 0.00 & 0.03 & 0.03 \\
\hline Deertounge Grass & Dichanthelium clandestinum (L.) Gould & 0.00 & 0.00 & 0.00 & 0.00 & 0.30 & 0.30 & 0.00 & 0.00 \\
\hline Dotted Smartweed & Polygonum punctatium Elliot & 0.00 & 0.00 & 0.00 & 0.00 & 0.65 & 0.65 & 0.00 & 0.00 \\
\hline Eastern Black Nightshade & Solanum americanum Mill. & 0.00 & 0.00 & 0.08 & 0.08 & 0.00 & 0.00 & 0.00 & 0.00 \\
\hline Eastern Cottonwood & Populus deltoides Bartram ex Marsh. & 7.08 & 7.08 & 0.00 & 0.00 & 0.26 & 0.26 & 0.00 & 0.00 \\
\hline English Plantain & Plantago lanceolata $\mathrm{L}$. & 0.00 & 0.00 & 0.79 & 0.79 & 0.00 & 0.00 & 0.00 & 0.00 \\
\hline False Nettle & Boehmeria cylindrica (L.) Sw. & 6.33 & 4.59 & 0.00 & 0.00 & 0.15 & 0.10 & 0.88 & 0.88 \\
\hline Fowl Mannagrass & Glyceria striata (Lam.) Hitchc. & 0.00 & 0.00 & 0.00 & 0.00 & 0.00 & 0.00 & 0.25 & 0.25 \\
\hline Frank's Sedge & Carex frankii Kunth & 0.00 & 0.00 & 0.00 & 0.00 & 0.00 & 0.00 & 0.63 & 0.63 \\
\hline Garlic Mustard & Alliaria petiolata (M. Bieb.) Cavara \& Grande & 0.00 & 0.00 & 2.38 & 1.35 & 0.00 & 0.00 & 3.58 & 1.82 \\
\hline Giant Chickweed & Stellaria pubera L. Moench & 0.00 & 0.00 & 0.29 & 0.29 & 0.00 & 0.00 & 0.00 & 0.00 \\
\hline Giant Foxtail Grass & Setaria faberi Herm. & 0.00 & 0.00 & 0.04 & 0.04 & 0.00 & 0.00 & 0.00 & 0.00 \\
\hline Golden Ragwort & Packera aurea (L.) & 0.00 & 0.00 & 0.00 & 0.00 & 3.45 & 3.03 & 0.00 & 0.00 \\
\hline Great Ragweed & Ambrosia trifida L. & 0.00 & 0.00 & 0.00 & 0.00 & 0.75 & 0.75 & 0.00 & 0.00 \\
\hline
\end{tabular}




\begin{tabular}{|c|c|c|c|c|c|c|c|c|c|}
\hline \multicolumn{10}{|l|}{ Appendix 18 Continued } \\
\hline Ground-Ivy & Glechoma hederacea L. & 1.08 & 0.55 & 0.63 & 0.63 & 22.45 & 13.05 & 15.25 & 10.18 \\
\hline Hairy Bittercress & Cardamine hirsuta $\mathrm{L}$. & 0.00 & 0.00 & 0.00 & 0.00 & 0.00 & 0.00 & 0.04 & 0.04 \\
\hline Hedge Bindweed & Calystegia sepium (L.) R. Br. & 0.00 & 0.00 & 0.00 & 0.00 & 0.00 & 0.00 & 0.08 & 0.05 \\
\hline Honeyvine & Cynanchum laeve (Michx.) Pers. & 0.00 & 0.00 & 0.67 & 0.62 & 0.00 & 0.00 & 0.25 & 0.25 \\
\hline Horse-Nettle & Solanum carolinense L. & 0.00 & 0.00 & 0.04 & 0.04 & 0.00 & 0.00 & 0.00 & 0.00 \\
\hline Italian Perennial Rye Grass & Lolium perenne L. & 0.00 & 0.00 & 0.38 & 0.38 & 0.00 & 0.00 & 0.00 & 0.00 \\
\hline Japanese Honeysuckle & Lonicera japonica Thonb. & 0.00 & 0.00 & 0.00 & 0.00 & 0.00 & 0.00 & 0.88 & 0.83 \\
\hline Japanese Hop & Humulus japonicus Siebold \& Zucc. & 7.08 & 4.19 & 1.96 & 1.45 & 1.14 & 1.14 & 0.29 & 0.25 \\
\hline Japanese Knotweed & Polygonum cuspidatum Siebold \& Zucc. & 0.50 & 0.50 & 1.54 & 1.06 & 4.80 & 3.27 & 6.54 & 6.49 \\
\hline Japanese Millet & Echinochloa crus-galli var frumentacea P. Beauv. & 0.00 & 0.00 & 5.00 & 5.00 & 0.00 & 0.00 & 0.00 & 0.00 \\
\hline Japanese Stilt Grass & Microstegium vimineum (Trin.) A. Camus & 0.00 & 0.00 & 1.92 & 1.64 & 0.08 & 0.08 & 0.25 & 0.25 \\
\hline Jewelweed & Impatiens capensis Meerb. & 0.00 & 0.00 & 0.00 & 0.00 & 0.00 & 0.00 & 0.83 & 0.65 \\
\hline Johnson Grass & Sorghum halepense Pers. & 0.00 & 0.00 & 0.04 & 0.04 & 0.00 & 0.00 & 0.00 & 0.00 \\
\hline Kentucky 31 Fescue & Lolium arundinaceum (Scop.) Holub & 0.00 & 0.00 & 0.00 & 0.00 & 0.00 & 0.00 & 4.79 & 4.74 \\
\hline Kentucky Bluegrass & Poa pratensis $\mathrm{L}$. & 0.58 & 0.58 & 0.08 & 0.05 & 0.95 & 0.61 & 0.96 & 0.62 \\
\hline Knotweed & Polygonum sp. L. & 0.00 & 0.00 & 0.00 & 0.00 & 1.30 & 1.30 & 0.04 & 0.04 \\
\hline Lady's Thumb & Polygonum persicaria $\mathrm{L}$. & 0.00 & 0.00 & 0.83 & 0.74 & 0.05 & 0.05 & 1.92 & 1.67 \\
\hline Lamb's Quarters & Chenopodium album $\mathrm{L}$. & 0.00 & 0.00 & 0.00 & 0.00 & 0.00 & 0.00 & 0.04 & 0.04 \\
\hline Large-leaved Pondweed & Potamogeton amplifolius Tuck. & 0.00 & 0.00 & 0.00 & 0.00 & 0.00 & 0.00 & 0.25 & 0.25 \\
\hline Late Meadowrue & Thalictrum pubescens Pursh & 0.00 & 0.00 & 0.04 & 0.04 & 0.00 & 0.00 & 0.04 & 0.04 \\
\hline May-Apple & Podophyllum peltatum L. & 0.00 & 0.00 & 0.54 & 0.38 & 0.00 & 0.00 & 0.00 & 0.00 \\
\hline Mile-A-Minute Weed & Polygonum perfoliata (L.) H. Gross & 1.25 & 1.25 & 0.83 & 0.74 & 0.00 & 0.00 & 1.92 & 1.67 \\
\hline Northern Red Oak & Quercus rubra L. & 0.00 & 0.00 & 0.36 & 0.36 & 0.00 & 0.00 & 0.00 & 0.00 \\
\hline Norway Maple & Acer platanoides L. & 0.00 & 0.00 & 1.15 & 1.15 & 0.00 & 0.00 & 0.00 & 0.00 \\
\hline
\end{tabular}




\begin{tabular}{|c|c|c|c|c|c|c|c|c|c|}
\hline \multicolumn{10}{|c|}{ Appendix 18 Continued } \\
\hline Ohio Buckeye & Aesculus glabra Willd. & 29.58 & 24.18 & 0.00 & 0.00 & 0.00 & 0.00 & 0.00 & 0.00 \\
\hline Orchard Grass & Dactylis glomerata L. & 0.00 & 0.00 & 0.25 & 0.25 & 0.00 & 0.00 & 0.00 & 0.00 \\
\hline Pasture Thistle & Cirsium pumilum Spreng. & 2.58 & 1.88 & 0.00 & 0.00 & 0.40 & 0.40 & 0.00 & 0.00 \\
\hline Pawpaw & Asimina triloba (L.) Dunal & 1.76 & 1.76 & 2.03 & 2.03 & 0.48 & 0.48 & 15.21 & 10.11 \\
\hline Pear & Pyrus angustifolia Aiton & 0.00 & 0.00 & 0.00 & 0.00 & 0.00 & 0.00 & 0.26 & 0.26 \\
\hline Poison Ivy & Toxicodendron radicans (L.) Kuntze & 0.00 & 0.00 & 0.00 & 0.00 & 0.00 & 0.00 & 4.71 & 2.93 \\
\hline Prickly Lettuce & Lactuca serriola L. & 0.00 & 0.00 & 0.54 & 0.54 & 0.00 & 0.00 & 1.08 & 1.03 \\
\hline Privet & Ligustrum vulgare L. & 0.00 & 0.00 & 0.00 & 0.00 & 0.00 & 0.00 & 0.54 & 0.54 \\
\hline Quaking Aspen & Populus tremuloides Michx. & 0.00 & 0.00 & 0.00 & 0.00 & 0.00 & 0.00 & 3.85 & 3.85 \\
\hline Queen Ann's Lace & Daucus carota $\mathrm{L}$. & 0.00 & 0.00 & 0.08 & 0.05 & 0.05 & 0.05 & 0.00 & 0.00 \\
\hline Rabbitfoot Clover & Trifolium arvense L. & 0.00 & 0.00 & 0.08 & 0.08 & 0.00 & 0.00 & 0.00 & 0.00 \\
\hline Red Fescue & Festuca rubra L. & 0.00 & 0.00 & 0.00 & 0.00 & 3.85 & 3.49 & 0.00 & 0.00 \\
\hline Red Maple & Acer rubrum $\mathrm{L}$. & 10.49 & 10.49 & 0.42 & 0.42 & 0.00 & 0.00 & 2.30 & 2.30 \\
\hline Red Mulberry & Morus rubra L. & 0.00 & 0.00 & 0.00 & 0.00 & 0.00 & 0.00 & 0.41 & 0.41 \\
\hline Redtop & Agrostis alba Roth & 0.00 & 0.00 & 0.04 & 0.04 & 0.00 & 0.00 & 0.04 & 0.04 \\
\hline Reed Canary Grass & Phalaris arundinacea $\mathrm{L}$. & 58.58 & 1.79 & 23.17 & 14.76 & 14.00 & 11.60 & 10.50 & 4.87 \\
\hline River-bank Grape & Vitis riparia Michx. & 0.00 & 0.00 & 0.70 & 0.70 & 0.00 & 0.00 & 0.00 & 0.00 \\
\hline Russian Autumn Olive & Elaeagnus angustifolia $\mathrm{L}$. & 0.00 & 0.00 & 0.00 & 0.00 & 0.00 & 0.00 & 0.26 & 0.26 \\
\hline Sericea & Lespedeza cuneata Lindl. & 0.00 & 0.00 & 0.04 & 0.04 & 0.00 & 0.00 & 0.00 & 0.00 \\
\hline Silver Maple & Acer saccharinum $\mathrm{L}$. & 6.23 & 6.23 & 18.72 & 12.38 & 68.26 & 19.52 & 17.34 & 11.28 \\
\hline Silver Plumegrass & Saccharum alopecuroides (L.) Nutt. & 0.00 & 0.00 & 0.00 & 0.00 & 0.75 & 0.75 & 0.00 & 0.00 \\
\hline Slippery Elm & Ulmus rubra Muhl. & 2.67 & 1.11 & 0.00 & 0.00 & 0.00 & 0.00 & 0.00 & 0.00 \\
\hline Smooth Bromegrass & Bromus inermis Leyss. & 0.00 & 0.00 & 0.25 & 0.25 & 0.00 & 0.00 & 0.88 & 0.88 \\
\hline Softstem Bullrush & Schoenoplectus tabernaemontani (C.C. Gmel.) Palla & 0.00 & 0.00 & 0.00 & 0.00 & 0.75 & 0.75 & 0.00 & 0.00 \\
\hline
\end{tabular}




\begin{tabular}{|c|c|c|c|c|c|c|c|c|c|}
\hline Speedwell & Veronica sp. L. & 0.00 & 0.00 & 0.04 & 0.04 & 0.00 & 0.00 & 0.00 & 0.00 \\
\hline Staghorn Sumac & Rhus typhina L. & 0.00 & 0.00 & 16.67 & 16.67 & 0.00 & 0.00 & 0.00 & 0.00 \\
\hline Stalk-grain Sedge & Carex stipata Muhl ex Willd & 0.00 & 0.00 & 0.25 & 0.25 & 0.00 & 0.00 & 0.00 & 0.00 \\
\hline Sugar Maple & Acer saccharum Marsh. & 3.00 & 3.00 & 0.00 & 0.00 & 0.00 & 0.00 & 0.00 & 0.00 \\
\hline Summer Grape & Vitis aestivalis Michx. & 0.00 & 0.00 & 4.60 & 4.60 & 0.00 & 0.00 & 0.78 & 0.78 \\
\hline Tall Coneflower & Rudbeckia laciniata $\mathrm{L}$. & 0.00 & 0.00 & 0.42 & 0.42 & 0.65 & 0.65 & 0.63 & 0.63 \\
\hline Tall Thistle & Cirsium altissimum (L.) Hill & 0.00 & 0.00 & 0.04 & 0.04 & 0.00 & 0.00 & 0.04 & 0.04 \\
\hline Three-Square & Schoenplectus pungens (Vahl) Palla & 0.00 & 0.00 & 0.25 & 0.25 & 0.00 & 0.00 & 1.29 & 1.29 \\
\hline Touch-Me-Not & Impatiens sp. L. & 0.00 & 0.00 & 0.04 & 0.04 & 0.00 & 0.00 & 0.00 & 0.00 \\
\hline Tree of Heaven & Ailanthus altissima (Mill.) Swingle & 0.00 & 0.00 & 0.00 & 0.00 & 0.18 & 0.18 & 0.00 & 0.00 \\
\hline Valdivia Duckweed & Lemna valdiviana Phil. & 0.00 & 0.00 & 0.00 & 0.00 & 0.00 & 0.00 & 0.08 & 0.08 \\
\hline Violet & Viola sp. L. & 0.00 & 0.00 & 0.00 & 0.00 & 0.00 & 0.00 & 0.08 & 0.08 \\
\hline Virginia Knotweed & Polygonum virginianum $\mathrm{L}$. & 0.00 & 0.00 & 0.00 & 0.00 & 0.05 & 0.05 & 0.04 & 0.04 \\
\hline White Ash & Fraxinus americana $\mathrm{L}$. & 1.27 & 1.27 & 0.00 & 0.00 & 0.00 & 0.00 & 0.00 & 0.00 \\
\hline White Avens & Geum canadense Jacq. & 0.00 & 0.00 & 0.00 & 0.00 & 0.00 & 0.00 & 0.08 & 0.08 \\
\hline White Clover & Trifolium repens $\mathrm{L}$. & 0.00 & 0.00 & 0.04 & 0.04 & 0.00 & 0.00 & 0.04 & 0.04 \\
\hline White Grass & Leersia virginica Willd. & 0.00 & 0.00 & 0.67 & 0.67 & 0.00 & 0.00 & 0.08 & 0.08 \\
\hline White Snakeroot & Ageratina altissima (L.) King \& H. Rob. & 0.00 & 0.00 & 1.46 & 0.95 & 1.88 & 0.98 & 0.17 & 0.12 \\
\hline Wild Rye & Elymus riparius Wiegand & 0.08 & 0.08 & 2.96 & 2.96 & 0.00 & 0.00 & 0.00 & 0.00 \\
\hline Wild Stinging Nettle & Utrica dioica $\mathrm{L}$. & 3.83 & 3.11 & 9.46 & 6.03 & 0.23 & 0.23 & 0.00 & 0.00 \\
\hline Wild Teasel & Dispacus fullonum L. & 0.00 & 0.00 & 0.00 & 0.00 & 2.05 & 2.05 & 0.00 & 0.00 \\
\hline Wing-stem & Verbesina alternifolia (L.) Britton ex Kearney & 12.67 & 3.18 & 4.92 & 3.11 & 5.48 & 3.15 & 10.54 & 5.29 \\
\hline Winter Creeper & Euonymus fortunei (Turcz.) Hand.-Maz. & 0.00 & 0.00 & 0.33 & 0.33 & 0.00 & 0.00 & 0.00 & 0.00 \\
\hline Winter Grape & Vitis vulpina $\mathrm{L}$. & 0.00 & 0.00 & 0.08 & 0.08 & 0.00 & 0.00 & 0.08 & 0.05 \\
\hline
\end{tabular}


Appendix 18 Continued

Wirestem Muhly Muhlenbergia frondosa (Poir.) Fernald

\begin{tabular}{llllllll}
0.00 & 0.00 & 2.25 & 2.20 & 0.00 & 0.00 & 0.00 & 0.00 \\
0.00 & 0.00 & 1.33 & 1.33 & 0.00 & 0.00 & 0.00 & 0.00 \\
0.00 & 0.00 & 2.63 & 2.63 & 0.00 & 0.00 & 0.23 & 0.16 \\
0.00 & 0.00 & 0.54 & 0.34 & 0.00 & 0.00 & 0.00 & 0.00 \\
\hline
\end{tabular}


Appendix 19: Cumulative waterbirds and their means (individuals/39.25 ha plot) and standard errors (SE) observed during waterbird observations at Blennerhassett and Buckley islands, West Virginia, USA during Phases I (Pre: 1985-1987) and II (Post: 2007-2009). SE could not be calculated for pre-construction at Blennerhassett.

\begin{tabular}{|c|c|c|c|c|c|c|c|}
\hline \multirow{3}{*}{ Common Name } & \multirow{3}{*}{ Scientific Name } & \multicolumn{3}{|c|}{ Blennerhassett } & \multicolumn{3}{|c|}{ Buckley } \\
\hline & & \multirow{2}{*}{$\frac{\text { Pre }}{\bar{x}}$} & \multicolumn{2}{|c|}{ Post } & \multirow{2}{*}{$\frac{\text { Pre }}{\bar{x}}$} & \multicolumn{2}{|c|}{ Post } \\
\hline & & & $\bar{x}$ & SE & & $\bar{x}$ & SE \\
\hline American Black Duck & Anas rubripes Brewster & 0.04 & 0.00 & 0.00 & 0.00 & 0.00 & 0.00 \\
\hline Belted Kingfisher & Megaceryle alcyon Linnaeus & 0.39 & 0.14 & 0.14 & 0.22 & 0.00 & 0.00 \\
\hline Blue-winged Teal & Anas discors Linnaeus & 0.22 & 0.00 & 0.00 & 0.00 & 0.00 & 0.00 \\
\hline Canada Goose & Branta canadensis Linnaeus & 0.35 & 23.00 & 7.67 & 0.72 & 14.86 & 6.10 \\
\hline Common Merganser & Mergus merganser Linnaeus & 0.17 & 0.00 & 0.00 & 0.00 & 0.00 & 0.00 \\
\hline Great Blue Heron & Ardea herodias Linnaeus & 0.48 & 0.14 & 0.14 & 0.00 & 0.00 & 0.00 \\
\hline Great Egret & Ardea alba Linnaeus & 0.04 & 0.00 & 0.00 & 0.00 & 0.00 & 0.00 \\
\hline Green Heron & Butorides virescens Linnaeus & 0.00 & 0.00 & 0.00 & 0.33 & 0.00 & 0.00 \\
\hline Hooded Merganser & Lophodytes cucullatus Linnaeus & 0.00 & 0.71 & 0.71 & 0.00 & 0.00 & 0.00 \\
\hline Lesser Scaup & Aythya affinis Eyton & 0.70 & 0.00 & 0.00 & 0.00 & 0.00 & 0.00 \\
\hline Mallard & Anas platyrhynchos Linnaeus & 0.22 & 2.14 & 1.26 & 0.00 & 0.86 & 0.46 \\
\hline Osprey & Pandion haliaetus Savigny & 0.04 & 0.00 & 0.00 & 0.00 & 0.00 & 0.00 \\
\hline Pied-billed Grebe & Podilymbus podiceps Linnaeus & 0.00 & 0.29 & 0.29 & 0.00 & 0.00 & 0.00 \\
\hline Ring-billed Gull & Larus delawarensis Ord & 0.09 & 0.00 & 0.00 & 0.22 & 0.00 & 0.00 \\
\hline Snowy Egret & Egretta thula Molina & 0.04 & 0.00 & 0.00 & 0.00 & 0.00 & 0.00 \\
\hline Wood Duck & Aix sponsa Linnaeus & 0.87 & 0.71 & 0.47 & 0.06 & 1.85 & 4.49 \\
\hline
\end{tabular}


Appendix 20: Cumulative list of songbirds with their means (individuals/ha) and standard errors (SE) for Blennerhassett Island, West Virginia, USA during Phases I (1985-1987), II (1998-2000), and III (2007-2009).

\begin{tabular}{|c|c|c|c|c|c|c|c|}
\hline \multirow{2}{*}{ Common Name } & \multirow{2}{*}{ Scientific Name } & \multicolumn{2}{|c|}{ Phase I } & \multicolumn{2}{|c|}{ Phase II } & \multicolumn{2}{|c|}{ Phase III } \\
\hline & & $\bar{x}$ & SE & $\bar{x}$ & SE & $\bar{x}$ & SE \\
\hline Acadian Flycatcher & Empidonax virescens Vieillot & 0.00 & 0.00 & 0.03 & 0.03 & 0.21 & 0.21 \\
\hline American Goldfinch & Spinus tristis Linnaeus & 1.10 & 0.30 & 0.70 & 0.41 & 0.54 & 0.21 \\
\hline American Redstart & Setophaga ruticilla Linnaeus & 0.00 & 0.00 & 0.00 & 0.00 & 0.04 & 0.04 \\
\hline American Robin & Turdus migratorius Linnaeus & 0.20 & 0.13 & 0.22 & 0.16 & 0.71 & 0.12 \\
\hline American Tree Sparrow & Spizella arborea Wilson & 0.10 & 0.07 & 0.00 & 0.00 & 0.00 & 0.00 \\
\hline Baltimore Oriole & Icterus galbula Linnaeus & 0.00 & 0.00 & 0.03 & 0.03 & 0.04 & 0.04 \\
\hline Bank Swallow & Riparia riparia Linnaeus & 0.03 & 0.03 & 0.00 & 0.00 & 0.00 & 0.00 \\
\hline Barn Swallow & Hirundo rustica Linnaeus & 0.07 & 0.04 & 0.00 & 0.00 & 0.00 & 0.00 \\
\hline Black-billed Cuckoo & Coccyzus erythropthalmus Wilson & 0.00 & 0.00 & 0.03 & 0.03 & 0.00 & 0.00 \\
\hline Blue Jay & Cyanocitta cristata Linnaeus & 0.07 & 0.04 & 0.08 & 0.08 & 0.17 & 0.08 \\
\hline Blue-gray Gnatcatcher & Polioptila caerulea Linnaeus & 0.00 & 0.00 & 0.00 & 0.00 & 0.08 & 0.05 \\
\hline Blue-winged Warbler & Vermivora pinus Linnaeus & 0.00 & 0.00 & 0.00 & 0.00 & 0.08 & 0.08 \\
\hline Brown-headed Cowbird & Molothrus ater Boddaert & 0.03 & 0.03 & 0.17 & 0.11 & 0.13 & 0.09 \\
\hline Carolina Chickadee & Poecile carolinensis Audubon & 0.53 & 0.53 & 0.56 & 0.22 & 0.17 & 0.08 \\
\hline Carolina Wren & Thryothorus ludovicianus Latham & 0.40 & 0.09 & 0.53 & 0.10 & 1.04 & 0.12 \\
\hline Cedar Waxwing & Bombycilla cedrorum Vieillot & 0.00 & 0.00 & 0.28 & 0.10 & 0.33 & 0.20 \\
\hline Chimney Swift & Chaetura pelagica Linnaeus & 0.03 & 0.03 & 0.08 & 0.06 & 0.00 & 0.00 \\
\hline Chipping Sparrow & Spizella passerina Bechstein & 0.03 & 0.03 & 0.00 & 0.00 & 0.00 & 0.00 \\
\hline Common Grackle & Quiscalus quiscula Linnaeus & 0.23 & 0.12 & 0.17 & 0.06 & 0.21 & 0.08 \\
\hline Common Yellowthroat & Geothlypis trichas Linnaeus & 0.27 & 0.12 & 0.64 & 0.37 & 0.33 & 0.20 \\
\hline
\end{tabular}




\begin{tabular}{|c|c|c|c|c|c|c|c|}
\hline \multicolumn{8}{|l|}{ Appendix 20 Continued } \\
\hline Downy Woodpecker & Picoides pubescens Linnaeus & 0.40 & 0.19 & 0.34 & 0.15 & 0.21 & 0.10 \\
\hline Eastern Bluebird & Sialia sialis Linnaeus & 0.00 & 0.00 & 0.28 & 0.22 & 0.08 & 0.08 \\
\hline Eastern Kingbird & Tyrannus tyrannus Linnaeus & 0.00 & 0.00 & 0.00 & 0.00 & 0.17 & 0.17 \\
\hline Eastern Phoebe & Sayornis phoebe Latham & 0.00 & 0.00 & 0.00 & 0.00 & 0.25 & 0.06 \\
\hline Eastern Towhee & Pipilo erythrophthalmus Linnaeus & 0.17 & 0.10 & 0.00 & 0.00 & 0.00 & 0.00 \\
\hline European Starling & Sturnus vulgaris Linnaeus & 0.00 & 0.00 & 0.03 & 0.03 & 0.04 & 0.04 \\
\hline Gray Catbird & Dumetella carolinensis Linnaeus & 0.53 & 0.19 & 0.22 & 0.16 & 0.79 & 0.10 \\
\hline Hairy Woodpecker & Picoides villosus Linnaeus & 0.20 & 0.14 & 0.00 & 0.00 & 0.04 & 0.04 \\
\hline House Wren & Troglodytes aedon Vieillot & 0.23 & 0.11 & 0.61 & 0.29 & 0.79 & 0.41 \\
\hline Indigo Bunting & Passerina cyanea Linnaeus & 0.33 & 0.08 & 0.31 & 0.12 & 0.75 & 0.17 \\
\hline Kentucky Warbler & Oporornis formosus Wilson & 0.07 & 0.04 & 0.00 & 0.00 & 0.04 & 0.04 \\
\hline Mourning Dove & Zenaida macroura Linnaeus & 0.00 & 0.00 & 0.00 & 0.00 & 0.04 & 0.04 \\
\hline Northern Cardinal & Cardinalis cardinalis Linnaeus & 1.27 & 0.36 & 1.14 & 0.30 & 0.79 & 0.22 \\
\hline Northern Flicker & Colaptes auratus Linnaeus & 0.20 & 0.10 & 0.00 & 0.00 & 0.17 & 0.11 \\
\hline Northern Mockingbird & Mimus polyglottos Linnaeus & 0.00 & 0.00 & 0.00 & 0.00 & 0.04 & 0.04 \\
\hline Northern Parula & Parula americana Linnaeus & 0.03 & 0.03 & 0.00 & 0.00 & 0.00 & 0.00 \\
\hline Northern Rough-winged Swallow & Stelgidopteryx serripennis Audubon & 0.00 & 0.00 & 0.08 & 0.06 & 0.13 & 0.09 \\
\hline Orchard Oriole & Icterus spurius Linnaeus & 0.00 & 0.00 & 0.03 & 0.03 & 0.25 & 0.17 \\
\hline Pileated Woodpecker & Dryocopus pileatus Linnaeus & 0.03 & 0.03 & 0.03 & 0.03 & 0.00 & 0.00 \\
\hline Prothonotary Warbler & Protonotaria citrea Boddaert & 0.00 & 0.00 & 0.14 & 0.11 & 0.08 & 0.05 \\
\hline Purple Martin & Progne subis Linnaeus & 0.00 & 0.00 & 0.17 & 0.11 & 0.00 & 0.00 \\
\hline Red-bellied Woodpecker & Melanerpes carolinus Linnaeus & 0.00 & 0.00 & 0.00 & 0.00 & 0.17 & 0.12 \\
\hline Red-eyed Vireo & Vireo olivaceus Linnaeus & 0.23 & 0.10 & 0.28 & 0.18 & 0.21 & 0.08 \\
\hline Red-winged Blackbird & Agelaius phoeniceus Linnaeus & 0.03 & 0.03 & 0.25 & 0.22 & 0.92 & 0.72 \\
\hline
\end{tabular}




\begin{tabular}{|c|c|c|c|c|c|c|c|}
\hline \multicolumn{8}{|l|}{ Appendix 20 Continued } \\
\hline Rock Pigeon & Columba livia Gmelin & 0.00 & 0.00 & 0.00 & 0.00 & 0.29 & 0.29 \\
\hline Rose-breasted Grosbeak & Pheucticus ludovicianus Linnaeus & 0.00 & 0.00 & 0.03 & 0.03 & 0.00 & 0.00 \\
\hline Song Sparrow & Melospiza melodia Wilson & 0.50 & 0.15 & 1.06 & 0.53 & 3.00 & 0.37 \\
\hline Tree Swallow & Tachycineta bicolor Vieillot & 0.03 & 0.03 & 0.00 & 0.00 & 0.00 & 0.00 \\
\hline Tufted Titmouse & Baeolophus bicolor Linnaeus & 0.57 & 0.24 & 0.33 & 0.16 & 0.17 & 0.08 \\
\hline White-eyed Vireo & Vireo griseus Boddaert & 0.23 & 0.08 & 0.28 & 0.13 & 0.04 & 0.04 \\
\hline Willow Flycatcher & Empidonax traillii Audubon & 0.00 & 0.00 & 0.06 & 0.04 & 0.04 & 0.04 \\
\hline Wood Thrush & Hylocichla mustelina Gmelin & 0.03 & 0.03 & 0.19 & 0.14 & 0.13 & 0.09 \\
\hline Yellow Warbler & Dendroica petechia Linnaeus & 0.17 & 0.13 & 0.47 & 0.44 & 0.33 & 0.11 \\
\hline Yellow-billed Cuckoo & Coccyzus americanus Linnaeus & 0.07 & 0.07 & 0.06 & 0.04 & 0.04 & 0.04 \\
\hline Yellow-breasted Chat & Icteria virens Linnaeus & 0.30 & 0.13 & 0.11 & 0.11 & 0.00 & 0.00 \\
\hline
\end{tabular}


Appendix 21: Cumulative list of songbirds with their means (individuals/ha) and standard errors (SE) for Buckley Island, West Virginia, USA during Phases I (1985-1987), II (1998-2000), and III (2007-2009).

\begin{tabular}{|c|c|c|c|c|c|c|c|}
\hline \multirow{2}{*}{ Common Name } & \multirow{2}{*}{ Scientific Name } & \multicolumn{2}{|c|}{ Phase I } & \multicolumn{2}{|c|}{ Phase II } & \multicolumn{2}{|c|}{ Phase III } \\
\hline & & $\bar{x}$ & SE & $\bar{x}$ & SE & $\bar{x}$ & SE \\
\hline Acadian Flycatcher & Empidonax virescens Vieillot & 0.00 & 0.00 & 0.00 & 0.00 & 0.34 & 0.16 \\
\hline American Goldfinch & Spinus tristis Linnaeus & 0.26 & 0.06 & 0.67 & 0.13 & 0.56 & 0.12 \\
\hline American Redstart & Setophaga ruticilla Linnaeus & 0.00 & 0.00 & 0.02 & 0.02 & 0.03 & 0.03 \\
\hline American Robin & Turdus migratorius Linnaeus & 0.61 & 0.17 & 0.48 & 0.22 & 1.09 & 0.25 \\
\hline American Tree Sparrow & Spizella arborea Wilson & 0.13 & 0.05 & 0.00 & 0.00 & 0.00 & 0.00 \\
\hline Baltimore Oriole & Icterus galbula Linnaeus & 0.03 & 0.02 & 0.08 & 0.08 & 0.00 & 0.00 \\
\hline Barn Swallow & Hirundo rustica Linnaeus & 0.01 & 0.01 & 0.00 & 0.00 & 0.00 & 0.00 \\
\hline Blue Jay & Cyanocitta cristata Linnaeus & 0.07 & 0.04 & 0.04 & 0.03 & 0.09 & 0.05 \\
\hline Blue-gray Gnatcatcher & Polioptila caerulea Linnaeus & 0.00 & 0.00 & 0.00 & 0.00 & 0.16 & 0.08 \\
\hline Brown Thrasher & Toxostoma rufum Linnaeus & 0.05 & 0.03 & 0.00 & 0.00 & 0.03 & 0.03 \\
\hline Brown-headed Cowbird & Molothrus ater Boddaert & 0.03 & 0.02 & 0.40 & 0.10 & 0.25 & 0.22 \\
\hline Carolina Chickadee & Poecile carolinensis Audubon & 0.33 & 0.08 & 0.19 & 0.08 & 0.22 & 0.07 \\
\hline Carolina Wren & Thryothorus ludovicianus Latham & 0.12 & 0.10 & 0.40 & 0.15 & 0.66 & 0.32 \\
\hline Cedar Waxwing & Bombycilla cedrorum Vieillot & 0.15 & 0.10 & 0.38 & 0.12 & 0.19 & 0.09 \\
\hline Cerulean Warbler & Dendroica cerulea Wilson & 0.00 & 0.00 & 0.08 & 0.08 & 0.00 & 0.00 \\
\hline Chimney Swift & Chaetura pelagica Linnaeus & 0.01 & 0.01 & 0.08 & 0.05 & 0.00 & 0.00 \\
\hline Cliff Swallow & Petrochelidon pyrrhonota Vieillot & 0.02 & 0.01 & 0.06 & 0.06 & 1.16 & 0.70 \\
\hline Common Grackle & Quiscalus quiscula Linnaeus & 0.35 & 0.11 & 0.17 & 0.08 & 0.06 & 0.04 \\
\hline Common Yellowthroat & Geothlypis trichas Linnaeus & 0.23 & 0.08 & 0.29 & 0.13 & 0.19 & 0.09 \\
\hline Downy Woodpecker & Picoides pubescens Linnaeus & 0.00 & 0.00 & 0.42 & 0.18 & 0.13 & 0.07 \\
\hline
\end{tabular}


Appendix 21 Continued

\begin{tabular}{|c|c|c|c|c|c|c|c|}
\hline Eastern Kingbird & Tyrannus tyrannus Linnaeus & 0.06 & 0.04 & 0.00 & 0.00 & 0.00 & 0.00 \\
\hline Eastern Meadowlark & Sturnella magna Linnaeus & 0.00 & 0.00 & 0.02 & 0.20 & 0.00 & 0.00 \\
\hline Eastern Towhee & Pipilo erythrophthalmus Linnaeus & 0.00 & 0.00 & 0.04 & 0.03 & 0.13 & 0.07 \\
\hline Eastern Wood-Pewee & Contopus virens Linnaeus & 0.02 & 0.01 & 0.00 & 0.00 & 0.06 & 0.04 \\
\hline European Starling & Sturnus vulgaris Linnaeus & 0.13 & 0.11 & 0.92 & 0.41 & 1.69 & 0.78 \\
\hline Field Sparrow & Spizella pusilla Wilson & 0.00 & 0.00 & 0.00 & 0.00 & 0.03 & 0.03 \\
\hline Gray Catbird & Myiarchus crinitus Linnaeus & 0.75 & 0.13 & 1.08 & 0.24 & 1.31 & 0.27 \\
\hline Great Crested Flycatcher & Dumetella carolinensis Linnaeus & 0.01 & 0.01 & 0.02 & 0.02 & 0.00 & 0.00 \\
\hline Hairy Woodpecker & Picoides villosus Linnaeus & 0.02 & 0.01 & 0.04 & 0.04 & 0.19 & 0.10 \\
\hline House Finch & Carpodacus mexicanus Muller & 0.00 & 0.00 & 0.29 & 0.25 & 0.22 & 0.10 \\
\hline House Sparrow & Passer domesticus Linnaeus & 0.03 & 0.02 & 0.00 & 0.00 & 0.03 & 0.03 \\
\hline House Wren & Troglodytes aedon Vieillot & 0.17 & 0.09 & 0.19 & 0.08 & 0.34 & 0.15 \\
\hline Indigo Bunting & Passerina cyanea Linnaeus & 0.28 & 0.05 & 0.42 & 0.20 & 0.56 & 0.10 \\
\hline Mourning Dove & Zenaida macroura Linnaeus & 0.69 & 0.34 & 0.46 & 0.22 & 1.78 & 1.26 \\
\hline Northern Cardinal & Cardinalis cardinalis Linnaeus & 0.49 & 0.06 & 0.94 & 0.16 & 0.84 & 0.18 \\
\hline Northern Flicker & Colaptes auratus Linnaeus & 0.09 & 0.04 & 0.02 & 0.02 & 0.22 & 0.07 \\
\hline Northern Mockingbird & Mimus polyglottos Linnaeus & 0.00 & 0.00 & 0.00 & 0.00 & 0.03 & 0.03 \\
\hline Northern Parula & Parula americana Linnaeus & 0.00 & 0.00 & 0.04 & 0.03 & 0.03 & 0.03 \\
\hline Northern Rough-winged Swallow & Stelgidopteryx serripennis Audubon & 0.00 & 0.00 & 0.06 & 0.04 & 0.09 & 0.07 \\
\hline Orchard Oriole & Icterus spurius Linnaeus & 0.01 & 0.01 & 0.00 & 0.00 & 0.03 & 0.03 \\
\hline Pileated Woodpecker & Dryocopus pileatus Linnaeus & 0.01 & 0.01 & 0.00 & 0.00 & 0.06 & 0.04 \\
\hline Purple Finch & Carpodacus purpureus Gmelin & 0.22 & 0.20 & 0.00 & 0.00 & 0.00 & 0.00 \\
\hline Red-bellied Woodpecker & Melanerpes carolinus Linnaeus & 0.00 & 0.00 & 0.00 & 0.00 & 0.16 & 0.07 \\
\hline Red-eyed Vireo & Vireo olivaceus Linnaeus & 0.25 & 0.08 & 0.19 & 0.10 & 0.53 & 0.10 \\
\hline
\end{tabular}




\begin{tabular}{|c|c|c|c|c|c|c|c|}
\hline Red-winged Blackbird & Agelaius phoeniceus Linnaeus & 0.13 & 0.05 & 0.04 & 0.04 & 0.16 & 0.05 \\
\hline Rock Pigeon & Columba livia Gmelin & 3.17 & 2.20 & 0.46 & 0.20 & 1.34 & 0.80 \\
\hline Rose-breasted Grosbeak & Pheucticus ludovicianus Linnaeus & 0.00 & 0.00 & 0.04 & 0.03 & 0.00 & 0.00 \\
\hline Ruby-throated Hummingbird & Archilochus colubris Linnaeus & 0.01 & 0.01 & 0.02 & 0.02 & 0.00 & 0.00 \\
\hline Song Sparrow & Melospiza melodia Wilson & 0.97 & 0.13 & 1.81 & 0.43 & 1.78 & 0.30 \\
\hline Tufted Titmouse & Baeolophus bicolor Linnaeus & 0.10 & 0.03 & 0.23 & 0.11 & 0.28 & 0.06 \\
\hline Warbling Vireo & Vireo gilvus Vieillot & 0.08 & 0.04 & 0.00 & 0.00 & 0.00 & 0.00 \\
\hline White-eyed Vireo & Vireo griseus Boddaert & 0.01 & 0.01 & 0.10 & 0.05 & 0.00 & 0.00 \\
\hline White-breasted Nuthatch & Sitta carolinensis Latham & 0.00 & 0.00 & 0.00 & 0.00 & 0.06 & 0.04 \\
\hline Willow Flycatcher & Empidonax traillii Audubon & 0.00 & 0.00 & 0.02 & 0.02 & 0.03 & 0.04 \\
\hline Wood Thrush & Hylocichla mustelina Gmelin & 0.00 & 0.00 & 0.00 & 0.00 & 0.06 & 0.04 \\
\hline Yellow Warbler & Dendroica petechia Linnaeus & 0.11 & 0.01 & 0.21 & 0.10 & 0.41 & 0.14 \\
\hline Yellow-breasted Chat & Icteria virens Linnaeus & 0.04 & 0.02 & 0.00 & 0.00 & 0.00 & 0.00 \\
\hline Yellow-throated Vireo & Vireo flavifrons Vieillot & 0.01 & 0.01 & 0.00 & 0.00 & 0.00 & 0.00 \\
\hline Yellow-throated Warbler & Dendroica dominica Linnaeus & 0.00 & 0.00 & 0.00 & 0.00 & 0.03 & 0.03 \\
\hline
\end{tabular}


Appendix 22: Summary of all songbirds along with species richness and Shannon Diversity Index used in the site by phase, distance by phase, and site, distance, phase interactions at $\alpha=0.05$ for Blennerhassett and Buckley islands, West Virginia, USA during Phases I, II, and III with $F$ as the F-statistic and $P$ as the P-value.

\begin{tabular}{|c|c|c|c|c|c|c|c|}
\hline \multirow{2}{*}{ Common Name } & \multirow{2}{*}{ Scientific Name } & \multicolumn{2}{|c|}{ Site:Phase } & \multicolumn{2}{|c|}{ Distance:Phase } & \multicolumn{2}{|c|}{ Site:Distance:Phase } \\
\hline & & $F_{2,24}$ & $P$ & $F_{4,24}$ & $P$ & $F_{4,24}$ & $P$ \\
\hline American Goldfinch & Spinus tristis Linnaeus & 2.75 & 0.084 & 0.48 & 0.748 & 0.55 & 0.703 \\
\hline American Robin & Turdus migratorius Linnaeus & 0.08 & 0.926 & 0.30 & 0.873 & 0.29 & 0.881 \\
\hline Baltimore Oriole & Icterus galbula Linnaeus & 0.59 & 0.560 & 1.57 & 0.213 & 0.30 & 0.872 \\
\hline Blue Jay & Cyanocitta cristata Linnaeus & 0.29 & 0.749 & 2.38 & 0.080 & 0.90 & 0.482 \\
\hline Brown-headed Cowbird & Molothrus ater Boddaert & 0.36 & 0.699 & 0.56 & 0.692 & 0.37 & 0.825 \\
\hline Carolina Chickadee & Poecile carolinensis Audubon & 0.53 & 0.594 & 1.18 & 0.346 & 1.84 & 0.154 \\
\hline Carolina Wren & Thryothorus Iudovicianus Latham & 0.24 & 0.790 & 1.57 & 0.213 & 0.32 & 0.865 \\
\hline Cedar Waxwing & Bombycilla cedrorum Vieillot & 0.97 & 0.392 & 0.77 & 0.555 & 1.49 & 0.236 \\
\hline Cliff Swallow & Petrochelidon pyrrhonota Vieillot & 3.91 & 0.034 & 4.52 & 0.007 & 3.20 & 0.023 \\
\hline Common Grackle & Quiscalus quiscula Linnaeus & 1.22 & 0.312 & 0.28 & 0.890 & 1.88 & 0.147 \\
\hline Common Yellowthroat & Geothlypis trichas Linnaeus & 0.37 & 0.697 & 0.25 & 0.909 & 1.00 & 0.428 \\
\hline Downy Woodpecker & Picoides pubescens Linnaeus & 1.40 & 0.266 & 0.52 & 0.723 & 0.13 & 0.970 \\
\hline Eastern Towhee & Pipilo erythrophthalmus Linnaeus & 4.37 & 0.024 & 0.65 & 0.635 & 0.55 & 0.699 \\
\hline European Starling & Sturnus vulgaris Linnaeus & 1.62 & 0.219 & 1.25 & 0.317 & 0.86 & 0.503 \\
\hline Gray Catbird & Dumetella carolinensis Linnaeus & 0.88 & 0.429 & 0.20 & 0.936 & 0.34 & 0.849 \\
\hline Hairy Woodpecker & Picoides villosus Linnaeus & 3.82 & 0.036 & 3.63 & 0.019 & 1.48 & 0.238 \\
\hline House Wren & Troglodytes aedon Vieillot & 0.48 & 0.622 & 0.28 & 0.888 & 0.44 & 0.780 \\
\hline Indigo Bunting & Passerina cyanea Linnaeus & 0.49 & 0.620 & 0.37 & 0.828 & 0.44 & 0.775 \\
\hline Mourning Dove & Zenaida macroura Linnaeus & 0.57 & 0.575 & 0.84 & 0.511 & 0.78 & 0.549 \\
\hline
\end{tabular}




\begin{tabular}{|c|c|c|c|c|c|c|c|}
\hline Northern Cardinal & Cardinalis cardinalis Linnaeus & 1.68 & 0.208 & 0.63 & 0.648 & 0.51 & 0.730 \\
\hline Northern Flicker & Colaptes auratus Linnaeus & 0.91 & 0.415 & 1.50 & 0.234 & 1.15 & 0.357 \\
\hline Northern Parula & Parula americana Linnaeus & 1.38 & 0.272 & 0.61 & 0.656 & 0.49 & 0.744 \\
\hline Orchard Oriole & Icterus spurius Linnaeus & 1.81 & 0.185 & 0.72 & 0.589 & 0.65 & 0.632 \\
\hline Pileated Woodpecker & Dryocopus pileatus Linnaeus & 1.77 & 0.191 & 0.46 & 0.762 & 1.07 & 0.392 \\
\hline Red-eyed Vireo & Vireo olivaceus Linnaeus & 1.65 & 0.215 & 0.39 & 0.814 & 0.28 & 0.890 \\
\hline Red-winged Blackbird & Agelaius phoeniceus Linnaeus & 1.33 & 0.283 & 1.16 & 0.353 & 1.04 & 0.405 \\
\hline Rock Pigeon & Columba livia Gmelin & 1.09 & 0.352 & 1.38 & 0.270 & 1.02 & 0.415 \\
\hline Song Sparrow & Melospiza melodia Wilson & 3.98 & 0.032 & 0.09 & 0.983 & 0.20 & 0.934 \\
\hline Tufted Titmouse & Baeolophus bicolor Linnaeus & 2.68 & 0.089 & 0.40 & 0.805 & 0.88 & 0.493 \\
\hline White-eyed Vireo & Vireo griseus Boddaert & 0.86 & 0.437 & 0.07 & 0.989 & 0.16 & 0.957 \\
\hline Wood Thrush & Hylocichla mustelina Gmelin & 0.91 & 0.417 & 0.82 & 0.528 & 1.28 & 0.305 \\
\hline Yellow Warbler & Dendroica petechia Linnaeus & 0.44 & 0.649 & 0.75 & 0.566 & 1.49 & 0.237 \\
\hline Yellow-billed Cuckoo & Coccyzus americanus Linnaeus & 0.09 & 0.912 & 0.42 & 0.795 & 0.50 & 0.737 \\
\hline Combined Songbirds & & 0.28 & 0.760 & 1.18 & 0.346 & 0.29 & 0.884 \\
\hline Species Richness & & 0.32 & 0.728 & 1.05 & 0.404 & 1.25 & 0.315 \\
\hline Shannon Diversity Index & & 0.09 & 0.917 & 0.64 & 0.639 & 1.25 & 0.317 \\
\hline
\end{tabular}


Appendix 23: Summary of small mammal individuals captured for Blennerhassett and Buckley islands, West Virginia, USA during Phases I (1985-1987), II (1998-2000), and III (2007-2009).

\begin{tabular}{|c|c|c|c|c|c|c|c|}
\hline \multirow{2}{*}{ Common Name } & \multirow{2}{*}{ Scientific Name } & \multicolumn{3}{|c|}{ Blennerhassett Island } & \multicolumn{3}{|c|}{ Buckley Island } \\
\hline & & Phase I & Phase II & Phase III & Phase I & Phase II & Phase III \\
\hline Deer mouse & Peromyscus maniculatus Wagner & 15 & 45 & 80 & 70 & 42 & 12 \\
\hline White-footed mouse & Peromyscus leucopus Rafinesque & 25 & 0 & 60 & 69 & 0 & 5 \\
\hline Meadow vole & Microtus pennsy/vanicus Ord & 5 & 15 & 36 & 10 & 2 & 22 \\
\hline Northern short-tailed shrew & Blarina brevicauda Say & 1 & 0 & 0 & 12 & 1 & 7 \\
\hline House mouse & Mus musculus Linnaeus & 0 & 0 & 0 & 2 & 5 & 7 \\
\hline Eastern chipmunk & Tamias striatus Linnaeus & 1 & 2 & 1 & 1 & 0 & 0 \\
\hline Meadow Jumping mouse & Zapus hudsonius Zimmermann & 0 & 0 & 0 & 4 & 0 & 0 \\
\hline Hairy-tailed mole & Parascalops breweri Bachman & 1 & 0 & 0 & 5 & 0 & 0 \\
\hline Norway rat & Rattus norvegicus Berkenhout & 1 & 0 & 0 & 0 & 0 & 0 \\
\hline Black rat & Rattus rattus Linnaeus & 0 & 0 & 0 & 0 & 1 & 0 \\
\hline
\end{tabular}


Appendix 24: Summary of all small mammals along with species richness and Shannon Diversity Index used in the site by phase, distance by phase, and site, distance, phase interactions at $\alpha=0.05$ for Blennerhassett and Buckley islands, West Virginia, USA during Phases I, II, and III with $F$ as the F-statistic and $P$ as the P-value.

\begin{tabular}{|c|c|c|c|c|c|c|c|}
\hline \multirow{2}{*}{ Common Name } & \multirow{2}{*}{ Scientific Name } & \multicolumn{2}{|c|}{ Site:Phase } & \multicolumn{2}{|c|}{ Distance:Phase } & \multicolumn{2}{|c|}{ Site:Distance:Phase } \\
\hline & & $F_{2,24}$ & $P$ & $F_{4,24}$ & $P$ & $F_{4,24}$ & $P$ \\
\hline Peromyscus spp. & Peromyscus spp. Gloger & 7.13 & 0.004 & 0.79 & 0.544 & 1.25 & 0.317 \\
\hline Meadow Vole & Microtus pennsy/vanicus Ord & 0.59 & 0.565 & 0.25 & 0.907 & 0.62 & 0.656 \\
\hline Northern Short-tailed Shrew & Blarina brevicauda Say & 1.40 & 0.266 & 0.66 & 0.629 & 0.67 & 0.621 \\
\hline House Mouse & Mus musculus Linnaeus & 0.27 & 0.764 & 0.25 & 0.906 & 0.19 & 0.944 \\
\hline Eastern Chipmunk & Tamias striatus Linnaeus & 0.47 & 0.632 & 1.45 & 0.248 & 1.31 & 0.295 \\
\hline Combined Small Mammals & & 5.33 & 0.012 & 0.58 & 0.683 & 1.17 & 0.350 \\
\hline Species Richness & & 0.72 & 0.498 & 0.26 & 0.903 & 0.09 & 0.985 \\
\hline Shannon Diversity Index & & 0.48 & 0.626 & 0.45 & 0.768 & 0.06 & 0.993 \\
\hline
\end{tabular}


Appendix 25: Cumulative list of songbirds (individuals/ha) and small mammals (captures/100 trap nights) sampled at 0, 100, and 300 $\mathrm{m}$ from the bridge at Blennerhassett Island, WV, USA during the 2008 and 2009 field seasons separated by island and mainland transects.

\begin{tabular}{|c|c|c|c|c|c|c|c|}
\hline \multirow{2}{*}{ Common Name } & \multirow{2}{*}{ Scientific Name } & \multicolumn{2}{|c|}{$0 \mathrm{~m}$} & \multicolumn{2}{|c|}{$100 \mathrm{~m}$} & \multicolumn{2}{|c|}{$300 \mathrm{~m}$} \\
\hline & & $\bar{x}$ & SE & $\bar{x}$ & SE & $\bar{x}$ & SE \\
\hline \multicolumn{8}{|l|}{ Island } \\
\hline \multicolumn{8}{|l|}{$\underline{\text { Songbirds }}$} \\
\hline Acadian Flycatcher & Empidonax virescens Vieillot & 0.14 & 0.14 & 0.00 & 0.00 & 0.14 & 0.10 \\
\hline American Goldfinch & Spinus tristis Linnaeus & 0.29 & 0.18 & 0.71 & 0.24 & 0.21 & 0.11 \\
\hline American Redstart & Setophaga ruticilla Linnaeus & 0.00 & 0.00 & 0.07 & 0.07 & 0.00 & 0.00 \\
\hline American Robin & Turdus migratorius Linnaeus & 0.57 & 0.30 & 0.50 & 0.14 & 0.57 & 0.17 \\
\hline Baltimore Oriole & Icterus galbula Linnaeus & 0.00 & 0.00 & 0.00 & 0.00 & 0.00 & 0.00 \\
\hline Blue Jay & Cyanocitta cristata Linnaeus & 0.14 & 0.14 & 0.07 & 0.07 & 0.29 & 0.19 \\
\hline Blue-gray Gnatcatcher & Polioptila caerulea Linnaeus & 0.00 & 0.00 & 0.21 & 0.15 & 0.29 & 0.13 \\
\hline Blue-winged Warbler & Vermivora pinus Linnaeus & 0.00 & 0.00 & 0.14 & 0.10 & 0.00 & 0.00 \\
\hline Brown Thrasher & Toxostoma rufum Linnaeus & 0.00 & 0.00 & 0.00 & 0.00 & 0.07 & 0.07 \\
\hline Brown-headed Cowbird & Molothrus ater Boddaert & 0.14 & 0.14 & 0.00 & 0.00 & 0.00 & 0.00 \\
\hline Carolina Chickadee & Poecile carolinensis Audubon & 0.00 & 0.00 & 0.50 & 0.29 & 0.21 & 0.11 \\
\hline Carolina Wren & Thryothorus ludovicianus Latham & 0.29 & 0.29 & 0.71 & 0.19 & 0.71 & 0.24 \\
\hline Cedar Waxwing & Bombycilla cedrorum Vieillot & 0.14 & 0.14 & 0.14 & 0.10 & 0.43 & 0.20 \\
\hline Common Grackle & Quiscalus quiscula Linnaeus & 0.29 & 0.18 & 0.14 & 0.10 & 0.29 & 0.19 \\
\hline Common Yellowthroat & Geothlypis trichas Linnaeus & 0.14 & 0.14 & 0.79 & 0.19 & 1.29 & 0.16 \\
\hline Downy Woodpecker & Picoides pubescens Linnaeus & 0.14 & 0.14 & 0.21 & 0.15 & 0.14 & 0.10 \\
\hline Eastern Bluebird & Sialia sialis Linnaeus & 0.43 & 0.30 & 0.07 & 0.07 & 0.00 & 0.00 \\
\hline
\end{tabular}




\begin{tabular}{|c|c|c|c|c|c|c|c|}
\hline \multicolumn{8}{|l|}{ Appendix 25 Continued } \\
\hline Eastern Kingbird & Tyrannus tyrannus Linnaeus & 0.00 & 0.00 & 0.00 & 0.00 & 0.29 & 0.29 \\
\hline Eastern Phoebe & Sayornis phoebe Latham & 0.14 & 0.14 & 0.07 & 0.07 & 0.14 & 0.10 \\
\hline Eastern Towhee & Pipilo erythrophthalmus Linnaeus & 0.00 & 0.00 & 0.00 & 0.00 & 0.07 & 0.07 \\
\hline Eastern Wood-Pewee & Contopus virens Linnaeus & 0.00 & 0.00 & 0.00 & 0.00 & 0.07 & 0.07 \\
\hline European Starling & Sturnus vulgaris Linnaeus & 0.00 & 0.00 & 0.14 & 0.10 & 0.07 & 0.07 \\
\hline Gray Catbird & Dumetella carolinensis Linnaeus & 0.29 & 0.18 & 0.79 & 0.26 & 0.71 & 0.22 \\
\hline Hairy Woodpecker & Picoides villosus Linnaeus & 0.00 & 0.00 & 0.00 & 0.00 & 0.00 & 0.00 \\
\hline House Wren & Troglodytes aedon Vieillot & 2.43 & 0.37 & 1.29 & 0.32 & 0.57 & 0.20 \\
\hline Indigo Bunting & Passerina cyanea Linnaeus & 0.29 & 0.18 & 0.79 & 0.19 & 0.21 & 0.11 \\
\hline Kentucky Warbler & Oporornis formosus Wilson & 0.00 & 0.00 & 0.00 & 0.00 & 0.00 & 0.00 \\
\hline Mourning Dove & Zenaida macroura Linnaeus & 0.43 & 0.30 & 0.00 & 0.00 & 0.00 & 0.00 \\
\hline Northern Cardinal & Cardinalis cardinalis Linnaeus & 0.43 & 0.30 & 0.43 & 0.14 & 0.29 & 0.13 \\
\hline Northern Flicker & Colaptes auratus Linnaeus & 0.00 & 0.00 & 0.29 & 0.16 & 0.07 & 0.07 \\
\hline Northern Mockingbird & Mimus polyglottos Linnaeus & 0.00 & 0.00 & 0.00 & 0.00 & 0.00 & 0.00 \\
\hline Northern Rough-winged Swallow & Stelgidopteryx serripennis Audubon & 0.00 & 0.00 & 0.00 & 0.00 & 0.14 & 0.14 \\
\hline Orchard Oriole & Icterus spurius Linnaeus & 0.00 & 0.00 & 0.57 & 0.20 & 0.36 & 0.17 \\
\hline Prothonotary Warbler & Protonotaria citrea Boddaert & 0.14 & 0.14 & 0.21 & 0.11 & 0.14 & 0.14 \\
\hline Red-bellied Woodpecker & Melanerpes carolinus Linnaeus & 0.00 & 0.00 & 0.00 & 0.00 & 0.14 & 0.10 \\
\hline Red-eyed Vireo & Vireo olivaceus Linnaeus & 0.29 & 0.29 & 0.14 & 0.10 & 0.21 & 0.15 \\
\hline Red-winged Blackbird & Agelaius phoeniceus Linnaeus & 0.43 & 0.20 & 1.79 & 0.81 & 3.21 & 0.61 \\
\hline Rock Pigeon & Columba livia Gmelin & 1.43 & 0.75 & 0.00 & 0.00 & 0.00 & 0.00 \\
\hline Scarlet Tanager & Piranga olivacea Gmelin & 0.00 & 0.00 & 0.00 & 0.00 & 0.00 & 0.00 \\
\hline Song Sparrow & Melospiza melodia Wilson & 3.00 & 0.62 & 3.14 & 0.43 & 3.43 & 0.34 \\
\hline Tufted Titmouse & Baeolophus bicolor Linnaeus & 0.00 & 0.00 & 0.14 & 0.10 & 0.21 & 0.11 \\
\hline
\end{tabular}




\begin{tabular}{|c|c|c|c|c|c|c|c|}
\hline \multicolumn{8}{|l|}{ Appendix 25 Continued } \\
\hline White-breasted Nuthatch & Sitta carolinensis Latham & 0.00 & 0.00 & 0.14 & 0.10 & 0.07 & 0.07 \\
\hline White-eyed Vireo & Vireo griseus Boddaert & 0.00 & 0.00 & 0.14 & 0.14 & 0.07 & 0.07 \\
\hline Willow Flycatcher & Empidonax traillii Audubon & 0.00 & 0.00 & 0.36 & 0.17 & 0.57 & 0.23 \\
\hline Wood Thrush & Hylocichla mustelina Gmelin & 0.00 & 0.00 & 0.00 & 0.00 & 0.00 & 0.00 \\
\hline Yellow Warbler & Dendroica petechia Linnaeus & 0.29 & 0.18 & 0.50 & 0.20 & 0.21 & 0.11 \\
\hline Yellow-billed Cuckoo & Coccyzus americanus Linnaeus & 0.00 & 0.00 & 0.00 & 0.00 & 0.07 & 0.07 \\
\hline Yellow-throated Vireo & Vireo flavifrons Vieillot & 0.00 & 0.00 & 0.07 & 0.07 & 0.00 & 0.00 \\
\hline Total Songbirds Combined & & 12.29 & 1.17 & 15.29 & 0.92 & 16.00 & 1.21 \\
\hline \multicolumn{8}{|l|}{$\underline{\text { Small Mammals }}$} \\
\hline Deer Mouse & Peromyscus maniculatus Wagner & 0.25 & 0.17 & 4.03 & 1.37 & 3.87 & 1.34 \\
\hline Eastern Chipmunk & Tamias striatus Linnaeus & 0.00 & 0.00 & 0.00 & 0.00 & 0.00 & 0.00 \\
\hline Meadow Vole & Microtus pennsylvanicus Ord & 0.00 & 0.00 & 2.71 & 0.54 & 3.11 & 0.91 \\
\hline Northern Short-tailed Shrew & Blarina brevicauda Say & 0.00 & 0.00 & 0.14 & 0.10 & 0.07 & 0.07 \\
\hline Norway Rat & Rattus norvegicus Berkenhout & 0.00 & 0.00 & 0.00 & 0.00 & 0.00 & 0.00 \\
\hline Southern Flying Squirrel & Glaucomys volans Linnaeus & 0.00 & 0.00 & 0.00 & 0.00 & 0.00 & 0.00 \\
\hline White-footed Mouse & Peromyscus leucopus Rafinesque & 0.00 & 0.00 & 5.82 & 1.60 & 4.87 & 1.20 \\
\hline Total Small Mammals Combined & & 0.25 & 0.17 & 12.71 & 1.80 & 11.92 & 1.97 \\
\hline \multicolumn{8}{|l|}{ West Virginia Mainland } \\
\hline \multicolumn{8}{|l|}{$\underline{\text { Songbirds }}$} \\
\hline Acadian Flycatcher & Empidonax virescens Vieillot & 0.00 & 0.00 & 0.75 & 0.25 & 0.00 & 0.00 \\
\hline American Goldfinch & Spinus tristis Linnaeus & 0.00 & 0.00 & 0.38 & 0.18 & 0.38 & 0.18 \\
\hline American Redstart & Setophaga ruticilla Linnaeus & 0.00 & 0.00 & 0.00 & 0.00 & 0.00 & 0.00 \\
\hline American Robin & Turdus migratorius Linnaeus & 0.25 & 0.25 & 1.63 & 0.53 & 1.50 & 0.53 \\
\hline Baltimore Oriole & Icterus galbula Linnaeus & 0.00 & 0.00 & 0.00 & 0.00 & 0.25 & 0.16 \\
\hline
\end{tabular}




\begin{tabular}{|c|c|c|c|c|c|c|c|}
\hline \multicolumn{8}{|c|}{ Appendix 25 Continued } \\
\hline Blue Jay & Cyanocitta cristata Linnaeus & 0.00 & 0.00 & 0.13 & 0.13 & 0.50 & 0.27 \\
\hline Blue-gray Gnatcatcher & Polioptila caerulea Linnaeus & 0.00 & 0.00 & 0.25 & 0.16 & 0.25 & 0.16 \\
\hline Blue-winged Warbler & Vermivora pinus Linnaeus & 0.00 & 0.00 & 0.00 & 0.00 & 0.00 & 0.00 \\
\hline Brown Thrasher & Toxostoma rufum Linnaeus & 0.00 & 0.00 & 0.13 & 0.13 & 0.00 & 0.00 \\
\hline Brown-headed Cowbird & Molothrus ater Boddaert & 0.50 & 0.29 & 0.25 & 0.16 & 0.13 & 0.13 \\
\hline Carolina Chickadee & Poecile carolinensis Audubon & 0.25 & 0.25 & 0.38 & 0.26 & 0.50 & 0.27 \\
\hline Carolina Wren & Thryothorus Iudovicianus Latham & 1.00 & 0.71 & 1.63 & 0.42 & 0.88 & 0.30 \\
\hline Cedar Waxwing & Bombycilla cedrorum Vieillot & 0.00 & 0.00 & 0.00 & 0.00 & 0.13 & 0.13 \\
\hline Common Grackle & Quiscalus quiscula Linnaeus & 0.25 & 0.25 & 0.25 & 0.16 & 0.13 & 0.13 \\
\hline Common Yellowthroat & Geothlypis trichas Linnaeus & 0.00 & 0.00 & 0.00 & 0.00 & 0.25 & 0.16 \\
\hline Downy Woodpecker & Picoides pubescens Linnaeus & 0.00 & 0.00 & 0.25 & 0.16 & 0.25 & 0.16 \\
\hline Eastern Bluebird & Sialia sialis Linnaeus & 0.00 & 0.00 & 0.00 & 0.00 & 0.50 & 0.50 \\
\hline Eastern Kingbird & Tyrannus tyrannus Linnaeus & 0.00 & 0.00 & 0.38 & 0.26 & 0.00 & 0.00 \\
\hline Eastern Phoebe & Sayornis phoebe Latham & 0.25 & 0.25 & 0.63 & 0.18 & 0.25 & 0.16 \\
\hline Eastern Towhee & Pipilo erythrophthalmus Linnaeus & 0.00 & 0.00 & 0.13 & 0.13 & 0.00 & 0.00 \\
\hline Eastern Wood-Pewee & Contopus virens Linnaeus & 0.00 & 0.00 & 0.00 & 0.00 & 0.13 & 0.13 \\
\hline European Starling & Sturnus vulgaris Linnaeus & 0.00 & 0.00 & 0.38 & 0.38 & 1.00 & 0.87 \\
\hline Gray Catbird & Dumetella carolinensis Linnaeus & 1.00 & 0.00 & 1.13 & 0.30 & 0.88 & 0.30 \\
\hline Hairy Woodpecker & Picoides villosus Linnaeus & 0.00 & 0.00 & 0.00 & 0.00 & 0.13 & 0.13 \\
\hline House Wren & Troglodytes aedon Vieillot & 0.00 & 0.00 & 0.13 & 0.13 & 0.13 & 0.13 \\
\hline Indigo Bunting & Passerina cyanea Linnaeus & 0.75 & 0.75 & 0.63 & 0.26 & 0.75 & 0.25 \\
\hline Kentucky Warbler & Oporornis formosus Wilson & 0.00 & 0.00 & 0.13 & 0.13 & 0.00 & 0.00 \\
\hline Mourning Dove & Zenaida macroura Linnaeus & 0.00 & 0.00 & 0.38 & 0.18 & 0.25 & 0.16 \\
\hline Northern Cardinal & Cardinalis cardinalis Linnaeus & 0.50 & 0.50 & 0.88 & 0.30 & 1.50 & 0.27 \\
\hline
\end{tabular}




\begin{tabular}{|c|c|c|c|c|c|c|c|}
\hline \multicolumn{8}{|l|}{ Appendix 25 Continued } \\
\hline Northern Flicker & Colaptes auratus Linnaeus & 0.00 & 0.00 & 0.25 & 0.25 & 0.00 & 0.00 \\
\hline Northern Mockingbird & Mimus polyglottos Linnaeus & 0.25 & 0.25 & 0.13 & 0.13 & 0.13 & 0.13 \\
\hline Northern Rough-winged Swallow & Stelgidopteryx serripennis Audubon & 0.00 & 0.00 & 0.00 & 0.00 & 0.13 & 0.13 \\
\hline Orchard Oriole & Icterus spurius Linnaeus & 0.00 & 0.00 & 0.00 & 0.00 & 0.13 & 0.13 \\
\hline Prothonotary Warbler & Protonotaria citrea Boddaert & 0.00 & 0.00 & 0.00 & 0.00 & 0.00 & 0.00 \\
\hline Red-bellied Woodpecker & Melanerpes carolinus Linnaeus & 0.00 & 0.00 & 0.13 & 0.13 & 0.50 & 0.19 \\
\hline Red-eyed Vireo & Vireo olivaceus Linnaeus & 0.00 & 0.00 & 0.00 & 0.00 & 0.25 & 0.16 \\
\hline Red-winged Blackbird & Agelaius phoeniceus Linnaeus & 0.00 & 0.00 & 0.00 & 0.00 & 0.13 & 0.13 \\
\hline Rock Pigeon & Columba livia Gmelin & 1.50 & 0.29 & 0.00 & 0.00 & 0.00 & 0.00 \\
\hline Scarlet Tanager & Piranga olivacea Gmelin & 0.00 & 0.00 & 0.13 & 0.13 & 0.00 & 0.00 \\
\hline Song Sparrow & Melospiza melodia Wilson & 2.00 & 0.91 & 2.88 & 0.64 & 2.00 & 0.57 \\
\hline Tufted Titmouse & Baeolophus bicolor Linnaeus & 0.00 & 0.00 & 0.38 & 0.18 & 0.38 & 0.18 \\
\hline White-breasted Nuthatch & Sitta carolinensis Latham & 0.00 & 0.00 & 0.00 & 0.00 & 0.00 & 0.00 \\
\hline White-eyed Vireo & Vireo griseus Boddaert & 0.00 & 0.00 & 0.13 & 0.13 & 0.13 & 0.13 \\
\hline Willow Flycatcher & Empidonax traillii Audubon & 0.00 & 0.00 & 0.00 & 0.00 & 0.00 & 0.00 \\
\hline Wood Thrush & Hylocichla mustelina Gmelin & 0.00 & 0.00 & 1.00 & 0.27 & 0.25 & 0.16 \\
\hline Yellow Warbler & Dendroica petechia Linnaeus & 0.25 & 0.25 & 0.00 & 0.00 & 0.13 & 0.13 \\
\hline Yellow-billed Cuckoo & Coccyzus americanus Linnaeus & 0.00 & 0.00 & 0.00 & 0.00 & 0.00 & 0.00 \\
\hline Yellow-throated Vireo & Vireo flavifrons Vieillot & 0.00 & 0.00 & 0.00 & 0.00 & 0.00 & 0.00 \\
\hline Total Songbirds Combined & & 8.75 & 1.25 & 15.75 & 1.89 & 14.75 & 1.82 \\
\hline \multicolumn{8}{|l|}{ Small Mammals } \\
\hline Deer Mouse & Peromyscus maniculatus Wagner & 0.61 & 0.42 & 2.81 & 0.70 & 1.88 & 0.38 \\
\hline Eastern Chipmunk & Tamias striatus Linnaeus & 0.19 & 0.19 & 0.16 & 0.16 & 0.10 & 0.10 \\
\hline Meadow Vole & Microtus pennsy/vanicus Ord & 0.56 & 0.25 & 0.09 & 0.09 & 0.64 & 0.31 \\
\hline
\end{tabular}




\begin{tabular}{|c|c|c|c|c|c|c|c|}
\hline Northern Short-tailed Shrew & Blarina brevicauda Say & 0.00 & 0.00 & 0.00 & 0.00 & 0.00 & 0.00 \\
\hline Norway Rat & Rattus norvegicus Berkenhout & 0.00 & 0.00 & 0.12 & 0.12 & 0.00 & 0.00 \\
\hline Southern Flying Squirrel & Glaucomys volans Linnaeus & 0.00 & 0.00 & 0.00 & 0.00 & 0.10 & 0.10 \\
\hline White-footed Mouse & Peromyscus leucopus Rafinesque & 0.37 & 0.37 & 1.19 & 0.67 & 0.99 & 0.46 \\
\hline Total Small Mammals Combined & & 1.74 & 0.64 & 4.37 & 0.82 & 3.70 & 0.40 \\
\hline
\end{tabular}

John $\mathrm{H}$.

Hagen 